\title{
WestVirginiaUniversity
}

THE RESEARCH REPOSITORY @ WVU

Graduate Theses, Dissertations, and Problem Reports

2005

\section{Numerical analysis of seepage in earth slopes}

\author{
Kishan Kakarla \\ West Virginia University
}

Follow this and additional works at: https://researchrepository.wvu.edu/etd

\section{Recommended Citation}

Kakarla, Kishan, "Numerical analysis of seepage in earth slopes" (2005). Graduate Theses, Dissertations, and Problem Reports. 4158.

https://researchrepository.wvu.edu/etd/4158

This Thesis is protected by copyright and/or related rights. It has been brought to you by the The Research Repository @ WVU with permission from the rights-holder(s). You are free to use this Thesis in any way that is permitted by the copyright and related rights legislation that applies to your use. For other uses you must obtain permission from the rights-holder(s) directly, unless additional rights are indicated by a Creative Commons license in the record and/ or on the work itself. This Thesis has been accepted for inclusion in WVU Graduate Theses, Dissertations, and Problem Reports collection by an authorized administrator of The Research Repository @ WVU. For more information, please contact researchrepository@mail.wvu.edu. 


\title{
Numerical Analysis of Seepage in Earth Slopes
}

By

\author{
Kishan Kakarla
}

\author{
Thesis submitted to the \\ College of Engineering and Mineral Resources \\ at West Virginia University \\ in partial fulfillment of the requirements for \\ the degree of
}

\author{
Master of Science \\ in \\ Civil Engineering
}

Hema J. Siriwardane Ph.D., Chair

Udaya B. Halabe Ph.D.

Roger C. Viadero Ph.D.

Department of Civil and Environmental Engineering

\author{
Morgantown, West Virginia \\ 2005
}

Keywords: Longitudinal Trench Drains, Seepage, MODFLOW 


\section{ABSTRACT \\ Numerical Analysis of Seepage in Earth Slopes}

Kishan Kakarla

Seepage is one of the most prominent factors in causing slope stability problems. Installation of longitudinal drainage trenches along the face of the slope can be an alternative solution to reduce the seepage.

The objective of this study was to investigate the effectiveness of the longitudinal drains in reducing the seepage, by using MODFLOW, a three dimensional finite difference groundwater flow model. The influence of various parameters on the performance of longitudinal drains was investigated. These parameters include the trench spacing $(w)$, seepage depth (h), slope angle $(\theta)$, length of slope (L) and soil type $(\mathrm{K})$. Numerical analysis was performed for both laboratory and field conditions under steady state and transient conditions.

The results demonstrate that the longitudinal drainage trenches are very effective in removing the seepage from the soil. Results also show that the transient time is relatively short for the drains to become fully functional. 


\section{ACKNOWLEDGEMENTS}

The author would like to take this opportunity to thank the people who helped in the completion of this thesis. The author wishes to thank Dr. Hema Siriwardane, graduate adviser and committee chairman, for his valuable guidance, which was the corner stone for this thesis. The author also thanks Dr. Udaya Halabe and Dr. Roger Viadero for their participation in the committee.

The Financial support provided by West Virginia Department of Transportation, Division of Highways for this project through a research contract to West Virginia University is gratefully acknowledged.

The author also would like to thank family and friends for their moral support and understanding. 


\section{TABLE OF CONTENTS}

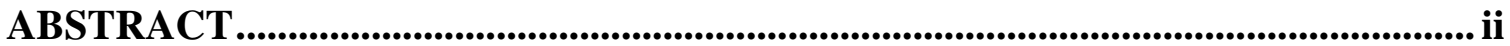

ACKNOWLEDGEMENTS ..................................................................................ii

TABLE OF CONTENTS ................................................................................................ iv

LIST OF TABLES …....................................................................................................... viii

LIST OF FIGURES ................................................................................................................. ix

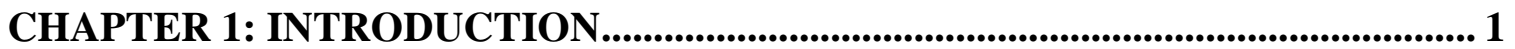

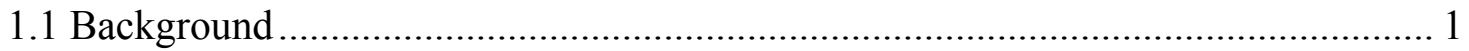

1.2 Problem statement

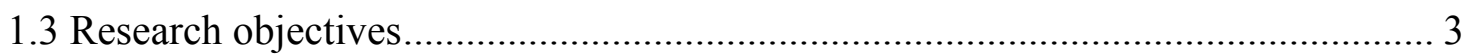

CHAPTER 2: LITERATURE REVIEW..................................................................... 4

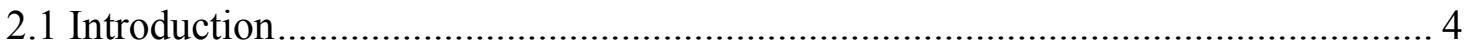

2.2 Fluid flow through porous media (seepage) ………............................................... 4

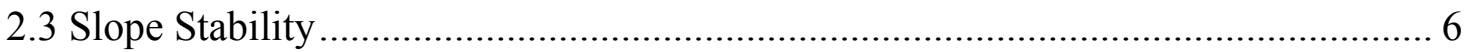

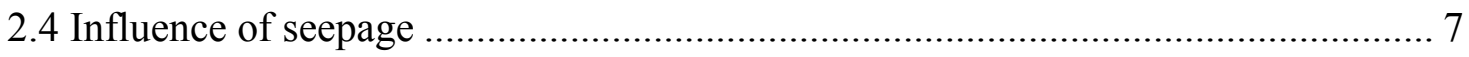

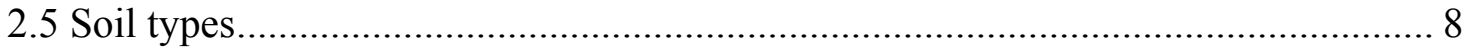

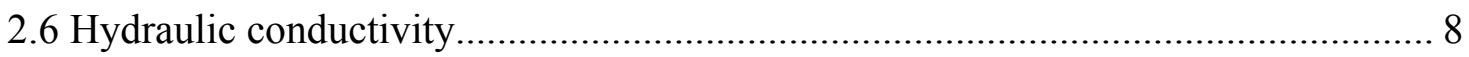

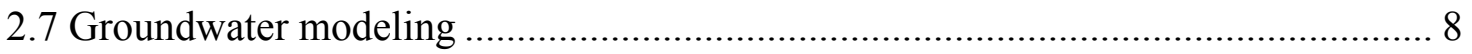

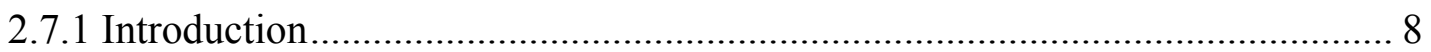

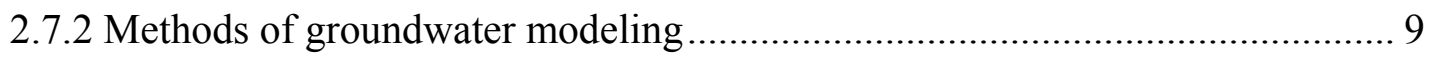

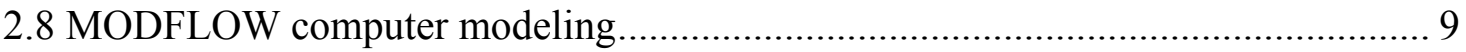

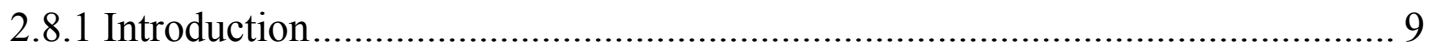

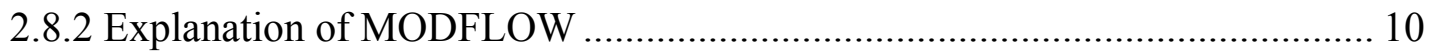




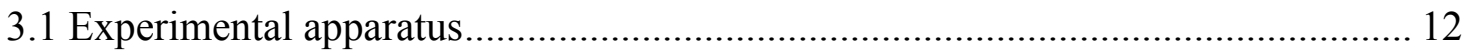

3.1.1 Boundary condition at the line of symmetry............................................... 15

3.1.2 Constant head water level (Water supply system) ......................................... 16

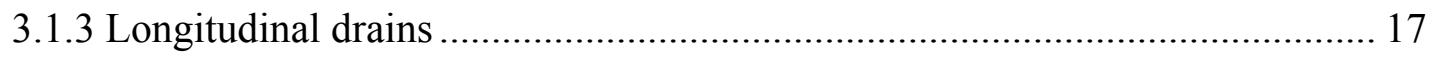

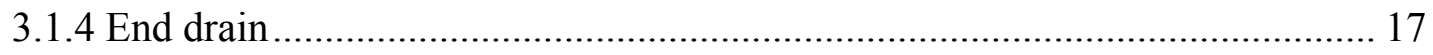

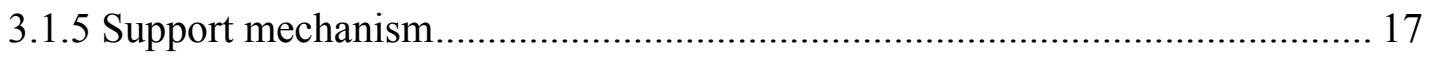

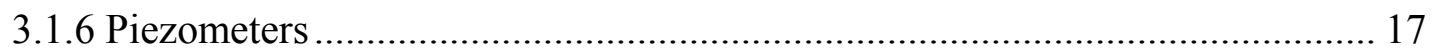

3.2 Simulation of experimental apparatus .............................................................. 18

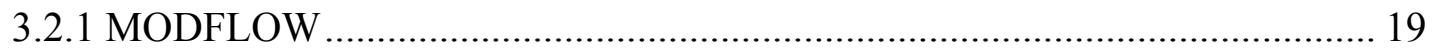

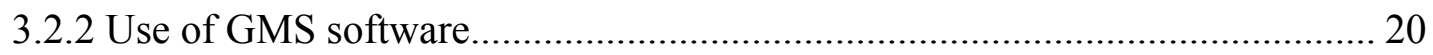

3.2.3 Creating and getting results for a steady state model using GMS .................. 21

3.2.4 Steps involved in creating an inclined model ............................................. 22

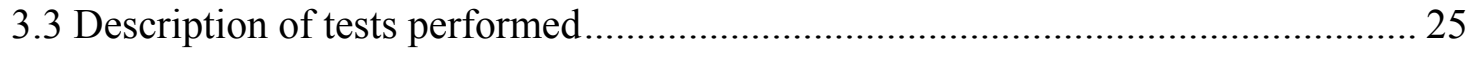

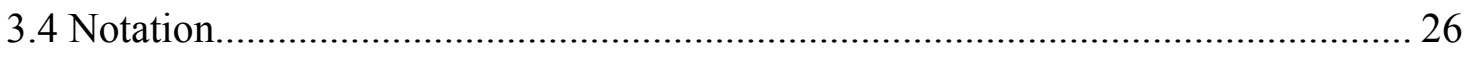

CHAPTER 4: RESULTS AND DISCUSSIONS: LAB MODEL ................................. 29

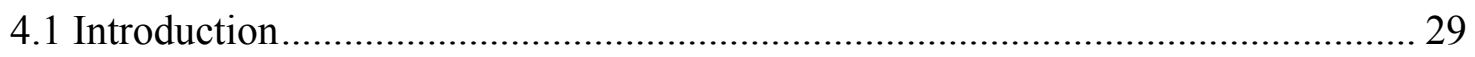

4.2 Cumulative Percentage Removal (CPR) .......................................................... 30

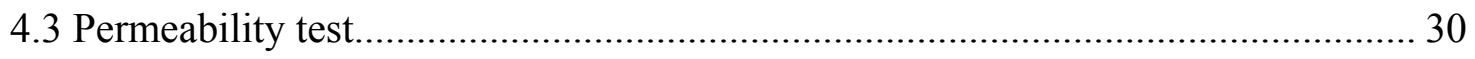

4.3.1 Experimental procudure ............................................................................. 31

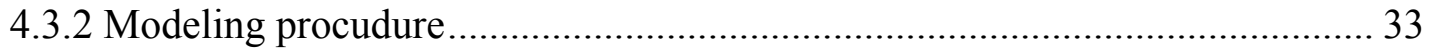

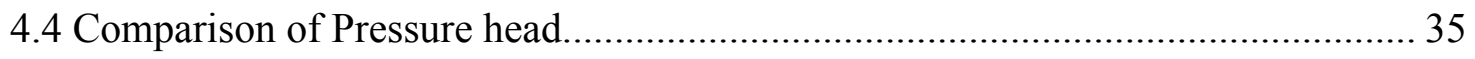

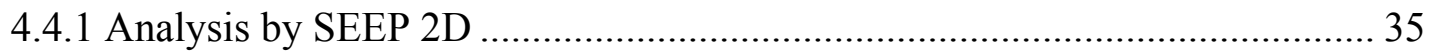




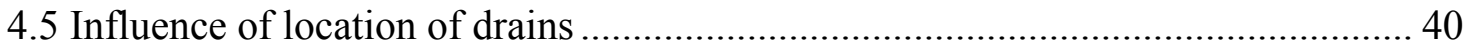

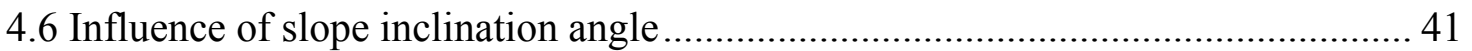

4.7 Influence of trench spacing ................................................................................. 42

CHAPTER 5: RESULTS AND DISCUSSIONS: FIELD CONDITIONS.................. 44

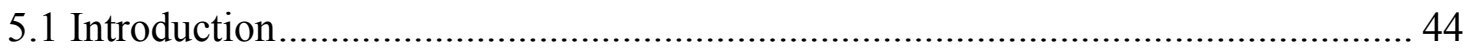

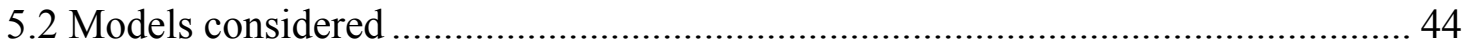

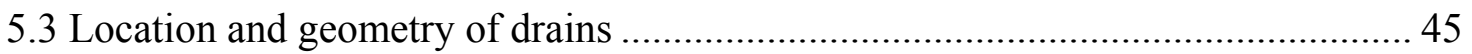

5.4 Influence of location of the drains ..................................................................... 48

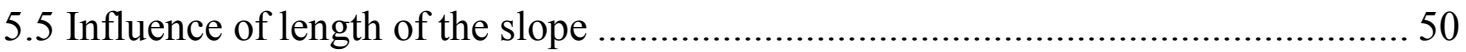

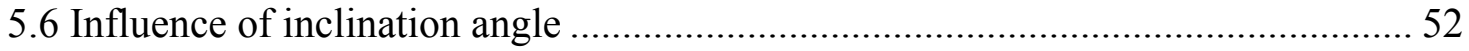

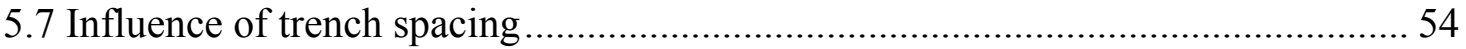

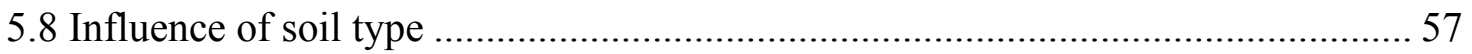

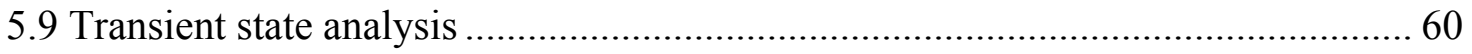

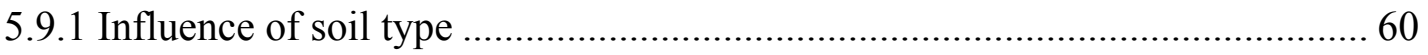

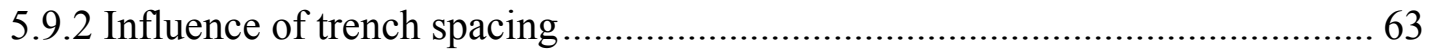

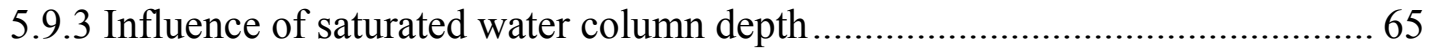

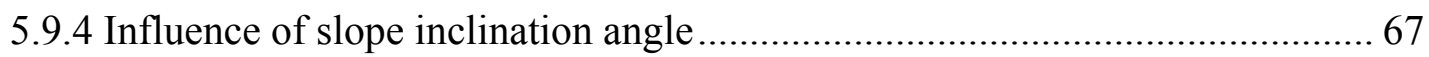

5.10 Influence of deactivating the first few drains ........................................................ 69

CHAPTER 6: CONCLUSIONS AND RECOMMENDATIONS.................................. 70

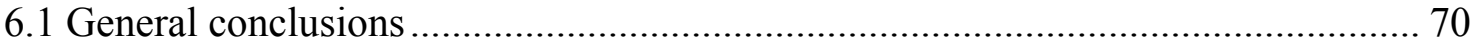

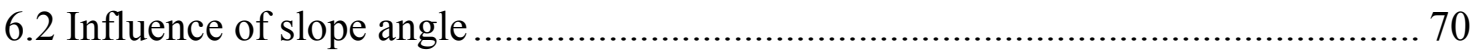

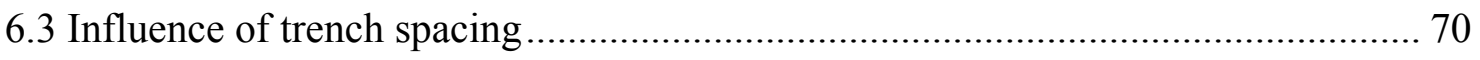

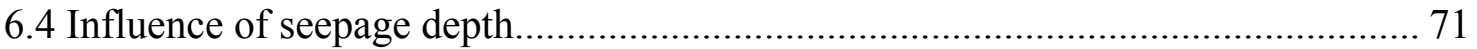


6.5 Influence of soil type

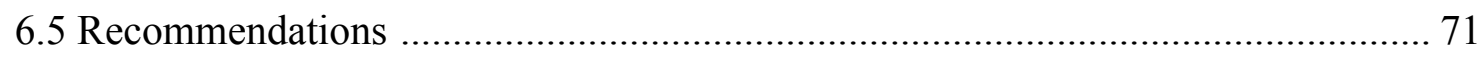

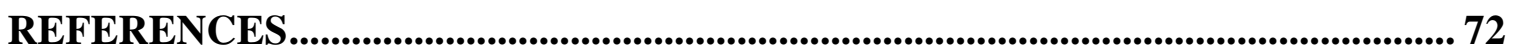

APPENDIX A: Seepage removal under laboratory conditions for Soil B .................... 74

APPENDIX B: Cumulative Percentage Removal under

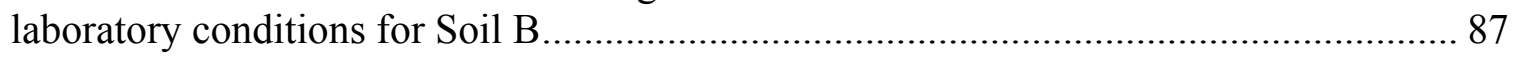

APPENDIX C: Influence of Trench spacing on seepage under

laboratory conditions for Soil B........................................................................ 100

APPENDIX D: Influence of Slope inclination angle on seepage under

laboratory conditions for Soil B

APPENDIX E: Seepage removal under field conditions for Soil B........................... 107

APPENDIX F: Influence of length of the slope on seepage under

field conditions for Soil B.....

APPENDIX G: Influence of Slope angle on seepage under

field conditions for Soil B.....

APPENDIX H: Influence of Trench spacing on seepage under

field conditions for Soil B..... 138

APPENDIX I: Derivation of governing equation. 


\section{LIST OF TABLES}

Table 3.1 A Spread sheet for $30^{\circ}$ inclination of the slope.

Table 4.1 Comparison between experimental result and numerical result for

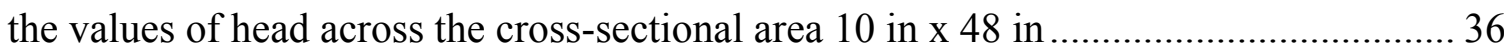

Table 4.2 Comparison between experimental result and numerical result for the values of head across the cross-sectional area 10 in $\mathrm{x} 12$ in ..................................... 38

Table 5.1 Dimensions of the models used for field conditions....................................... 45 


\section{LIST OF FIGURES}

Figure 1.1 Longitudinal drains along the slope ................................................... 2

Figure 1.2 Flow pattern before and after installing the drains ...................................... 2

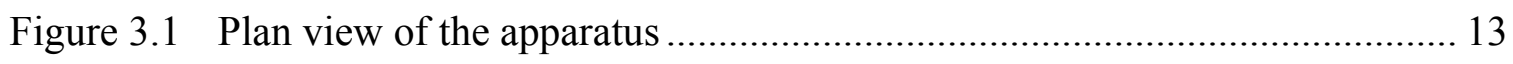

Figure 3.2 Lines of symmetry for longitudinal drains.............................................. 14

Figure 3.3 Physical Apparatus simulating the slope …………………................... 16

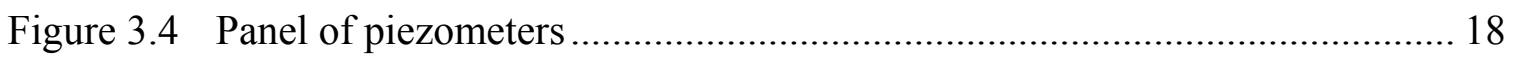

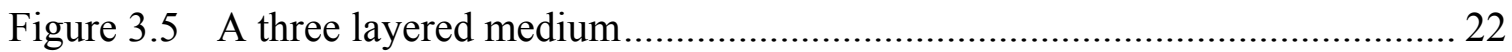

Figure 3.6 Change of co-ordinates in an inclined system ………………………..... 23

Figure 4.1 Experimental apparatus for constant head test.............................................. 31

Figure 4.2 Grid used for the permeability test.......................................................... 34

Figure 4.3 Variation of Pressure head along the Cross-section A.................................. 37

Figure 4.4 Variation of Pressure head along the Cross-section B.................................. 39

Figure 4.5 Flow net for Cross-section A ………………............................................. 39

Figure 4.6 Flow net for Cross-section B ............................................................... 40

Figure 4.7 Influence of Location of drains ................................................................. 41

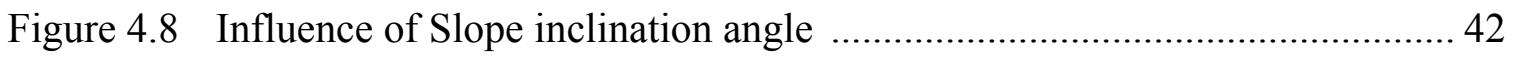

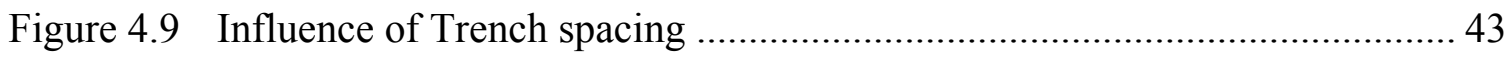

Figure 5.1 Layout of the Computer model for the slope with a length of $96 \mathrm{ft}$............ 46

Figure 5.2 Layout of the Computer model for the slope with a length of $48 \mathrm{ft}$............. 47

Figure 5.3 Influence of location of drains on seepage ……….................................... 49

Figure 5.4 Influence of Length of slope on Seepage ………….................................. 51

Figure 5.5 Influence of Inclination angle on Seepage ................................................... 53 
Figure 5.6 Influence of Trench Spacing on Seepage when slope inclination is $3: 1 \ldots \ldots . .55$

Figure 5.7 Influence of Trench Spacing on Seepage when slope inclination is $2: 1 \ldots \ldots . .56$

Figure 5.8 Influence of hydraulic conductivity on Seepage.....................................58

Figure 5.9 Influence of hydraulic conductivity on Volumetric Flow........................... 59

Figure 5.10 Influence of hydraulic conductivity on duration of transient state ............... 62

Figure 5.11 Influence of Trench width on duration of transient state........................... 64

Figure 5.12 Influence of Water level on duration of transient state ............................. 66

Figure 5.13 Influence of Inclination angle of slope on duration of transient state.......... 68

Figure 5.14 Influence of deactivating the first few drains in the steady state................ 69 


\section{CHAPTER 1}

\section{INTRODUCTION}

\subsection{Background}

Any structural engineer hopes to build his structure on a flat terrain rather than on a slope, as it solves many structural design problems. Due to the increase in population and the growth of cities, acquiring desired lands is difficult and expensive.

Construction of structures on a slope poses some problems, because slopes can become unstable due to destabilizing forces. These destabilizing forces are caused by the imbalance between the driving and resisting forces in the slope. Forces due to the seepage and loads placed on the top of the soil form the driving forces and the shear strength of the soil resists them. When the driving forces exceed the resisting forces, the slope becomes unstable and may ultimately collapse.

Seepage which results from water moving through the spaces between soil grains is found to be the most prominent factor in causing the instability to the slope. Therefore, engineers have to find a method to reduce the seepage. Conventional methods such as installing retaining walls, excavation and recompaction, deep drainage, cutoff trenches, and soil nailing are found to be expensive. Therefore, alternative methods should be employed.

\subsection{Problem Statement}

An alternative method for reducing seepage is to install longitudinal drains as shown in Figure 1.1. However, there is no information to ascertain the performance of longitudinal drains. 


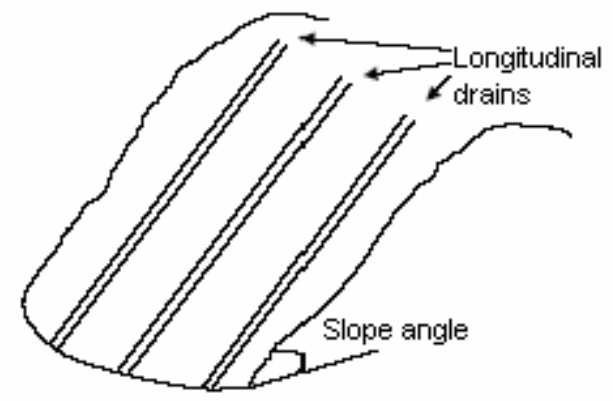

Figure 1.1: Longitudinal drains along the slope.

These drains unlike the conventional cut-off trenches are placed along the direction of the slope. The idea behind such placement is to re-direct the flow of water into these drains and there by reducing the seepage and finally saving the slope from failing due to instability. Figure 1.2 shows the flow path before installing and after installing the drains.

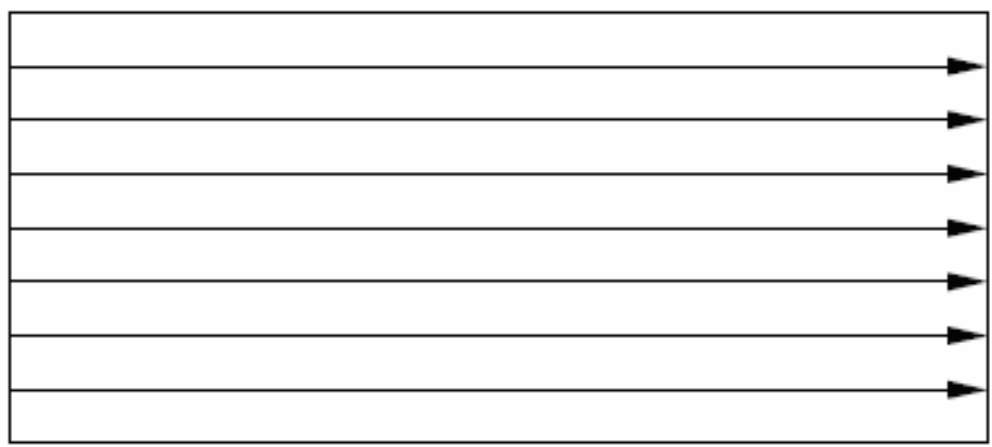

Before installing longitudinal drains

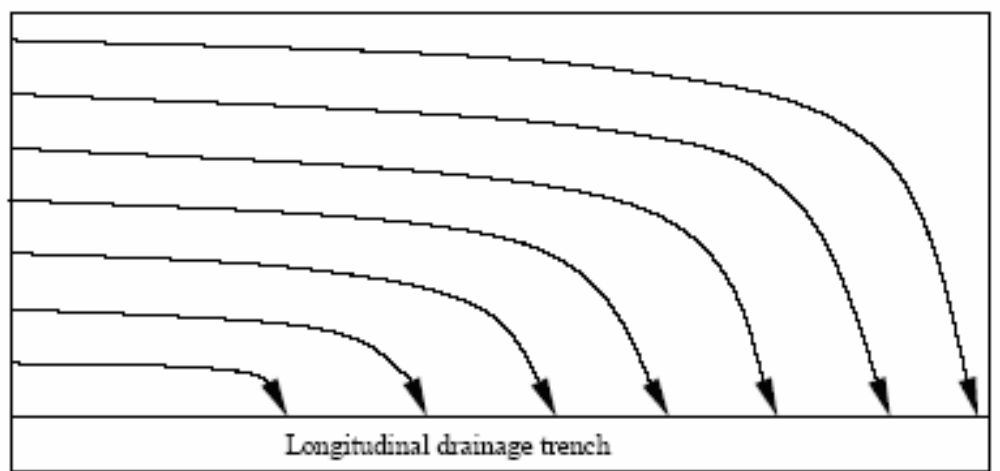

After installing longitudinal drains

Figure 1.2: Flow pattern before and after installing the drains. 
To study the effectiveness of these drains, a physical model and many computer models were created. The effectiveness of the drains was analyzed for various parameters (angle of slope, soil properties, water level and trench spacing). Numerical analysis was performed for both steady state and transient conditions. It is important to predict the transient behavior of longitudinal drains as it determines the duration of time needed for the drains to become completely functional.

Previous studies at the West Virginia University (Stuad 2000; Kiriakidis 2002) show promising results on the performance of the longitudinal drains. However the data in the previous study was limited to a physical model and only three soil types. Present research extends the previous study to the field conditions.

\subsection{Research Objectives}

Following are the objectives of this research work:

1. Review the existing literature pertaining to the usage of longitudinal drains and other forms of drainage in reducing the seepage.

2. Compare the available results from the physical model with the results from the numerical model.

3. Investigate the steady state and transient behavior of the longitudinal drains under the laboratory conditions by using numerical models. Determine the parameters that influence the performance of longitudinal drains.

4. Investigate the steady state and transient behavior of the longitudinal drains for the field conditions by using numerical models. 


\section{CHAPTER 2}

\section{LITERATURE REVIEW}

\subsection{Introduction}

The literature review was completed in order to find the existing sources of information related to longitudinal drains in slopes. In this search of literature an article by Stanic (1984) and previous studies at West Virginia University by Kiriakidis (2002) and Stuad (2000) were found. However, extensive literature was found on the modeling techniques of groundwater flow by using MODFLOW. The main aspects that were reviewed during this study are:

$>$ Fluid flow through porous media (Seepage).

Slope stability.

$>$ Soil types.

Steady State and Transient condition.

$>$ MODFLOW and modeling techniques.

\subsection{Fluid flow through porous media (Seepage)}

Soils have interconnected voids through which water can flow from points of high energy to the points of low energy. Flow through these interconnected voids is called as seepage or flow through the porous media. One of the major destabilizing forces resulting in slope instability is the flow of water through porous media. As water, or any fluid, flows through soil it exerts a force on the soil particles through friction (Cedergren, 1977). The primary law governing the flow through porous media is the Darcy's law, which is given as:

$$
v=k i
$$


Where:

$$
\begin{array}{lll}
\mathrm{v} & = & \text { Discharge velocity }(\mathrm{cm} / \mathrm{s} \text { or } \mathrm{ft} / \mathrm{s}) . \\
\mathrm{K} & = & \text { Hydraulic conductivity }(\mathrm{ft} / \mathrm{s} \text { or } \mathrm{cm} / \mathrm{s}) . \\
\mathrm{i} & = & \text { Hydraulic gradient }(\mathrm{ft} / \mathrm{ft} \text { or } \mathrm{cm} / \mathrm{cm}) .
\end{array}
$$

This form of Darcy's law states that flow rate through a porous media is equal to hydraulic gradient multiplied by the cross sectional area and a parameter, $\mathrm{K}$, called the hydraulic conductivity. The hydraulic conductivity is defined as the ratio of the difference in head across the specimen to the length of the specimen. The term head is defined in the Bernoulli's energy equation for incompressible steady flow of fluid as:

$$
\frac{v_{1}^{2}}{2 g}+\frac{p_{1}}{\rho_{w} g}+z_{1}=\frac{v_{2}^{2}}{2 g}+\frac{p_{2}}{\rho_{w} g}+z_{2}+h_{f}=\text { constant total head } \text {. }
$$

Where:

$$
\begin{array}{lll}
\mathrm{v} & = & \text { velocity }(\mathrm{cm} / \mathrm{s} \text { or } \mathrm{ft} / \mathrm{s}) \\
\mathrm{g} & = & \text { gravitational constant }\left(32.17 \mathrm{ft} / \mathrm{s}^{2} \text { or } 9.8 \mathrm{~m} / \mathrm{s}^{2}\right) \\
\mathrm{p} & = & \text { Pressure }(\mathrm{psf} \text { or } \mathrm{kPa}) \\
\rho_{\mathrm{w}} & = & \text { Density of water }\left(\mathrm{lb} / \mathrm{ft}^{3} \text { or } \mathrm{kg} / \mathrm{m}^{3}\right) \\
\mathrm{z} & = & \text { Elevation }(\mathrm{ft} \text { or } \mathrm{m}) . \\
\mathrm{h}_{\mathrm{f}} & = & \text { Head loss due to friction }(\mathrm{ft} \text { or } \mathrm{m}) .
\end{array}
$$

Since the seepage velocity, $\mathrm{v}$, is usually very small, the term $\left(\mathrm{v}^{2} / 2 \mathrm{~g}\right)$ can be neglected. The head, at any point, can now be expressed as the sum of the head due to pressure and the head due to elevation.

Hydraulic conductivity, $\mathrm{K}$, is determined experimentally and relates how well a fluid moves through the spaces in the soil matrix. The hydraulic conductivity of a soil primarily depends on grain size distribution and porosity. 


\subsection{Slope stability}

Earthen slopes can be either engineered or natural. An engineered slope can be a natural slope that has been modified, like a cut for a highway or an entirely constructed slope, like a dam. Whether the slope is engineered or natural, it follows the law of gravity and landslides are possible. The stability analysis of a slope is not an easy task Evaluation of variables such as the soil stratification and its in-place shear strength parameters may prove to be formidable task (Das, 1999).

Slope failures can be divided into two groups:

$>$ Deep seated.

Shallow.

A deep slide involves the movement of soil well below the surface of the slope, while shallow slides only involve the top layer of the soil. The stability of the constructed or natural slopes depends on the balance of resisting forces to driving forces. Resisting forces try to keep the soil mass in its place of equilibrium, while driving forces try to bring the soil down. The most prominent resisting force is the shear strength of the soil. Shear strength is a soil property that is determined experimentally and represents the maximum resistance of the material to shear deformation. Installing retaining walls and piles can provide higher resisting forces.

The sum of the resisting forces is countered by the driving forces. Unchecked driving forces cause the soil mass to move in response to gravity. The most prominent of these forces is the soil mass itself. Other forces that can lead to the instability of the slope are seepage forces. The ratio of resisting forces to driving forces is called the factor of safety. 


\subsection{Influence of Seepage}

Seepage is one of the most prominent factors in causing the slope instability after the soil mass. Slope instability in turn may cause landslides. A mass of rock, debris or earth moving as a mass down a slope is defined as a landslide (Cruden, 1991). As one of the major hazards, landslides account for significant property damage each year. There are number of factors which can trigger landslides, some of them are: sudden changes in the water table levels due to rainfall or even human drains, earthquakes, ocean waves against a cliff face, rapid increase in the shear stress or decrease in the strength of slope (Dai et al., 2001). Human activities such as deforestation or excavation of slopes for road cuts and building sites can also cause landslides.

On the verge of the failure of a slope, the driving forces equal the resisting forces. Seepage is the main driving force for the failure. A reduction of seepage force can be accomplished by redirecting the flow paths of the seepage in the slope, but most of the existing methods to reduce the seepage are expensive and are difficult to set up.

Some methods of reducing the seepage are:

$>$ Horizontal wells (for deep seated failures).

$>$ Cutoff trenches (for shallow failures).

Horizontal wells are inserted below the failing soil mass and direct the seepage force vertically down. Cut-off trenches are typically placed parallel to the top or crest of a slope and remove seepage from the slope, if the water table can be intersected before groundwater moves into the slope. If the water table cannot be intercepted before the slope begins, longitudinal trenches parallel to each other and in the direction of maximal slope inclination can be used (Stanic, 1984). With the drains installed, a majority of the seepage force is eliminated from the sum of the resisting forces thereby increasing the factor of safety. 


\subsection{Soil Types}

Different soils with similar properties may be classified into groups and sub groups according to their engineering behavior. In this research project, importance is given to the geotechnical properties of the soil such as grain size distribution, Atterberg limits, soil composition and hydraulic conductivity. The hydraulic conductivity of the sandy soils is relatively high and therefore water can be drained rapidly. Silty and clayey soils have low hydraulic conductivity and it is difficult to drain water from them. Drainage trenches are usually made up of gravel materials in view of their high hydraulic conductivity. In this study, sandy and clayey soils were used to investigate the effectiveness of longitudinal drains. The three soil samples that are used in this research are Soil A, Soil B and Soil C with hydraulic conductivities of $4 \times 10^{-1} \mathrm{in} / \mathrm{min}(1 \mathrm{~cm} / \mathrm{min}), 3 \times 10^{-2} \mathrm{in} / \mathrm{min}\left(7.6 \times 10^{-2} \mathrm{~cm} / \mathrm{min}\right)$ and $6 \times 10^{-3} \mathrm{in} / \mathrm{min}\left(1.5 \times 10^{-2} \mathrm{~cm} / \mathrm{min}\right)$, respectively.

\subsection{Hydraulic Conductivity}

The void spaces or pores between soil grains allow water to flow through them (Das, 1998). The flow rate depends upon the hydraulic conductivity. Hydraulic conductivity is a property of both the soil and the fluid that is passing through it. Hydraulic conductivity of the soil depends upon several factors: fluid viscosity, pore-size distribution, grain-size distribution, void ratio, roughness of mineral properties, and degree of soil saturation.

Two standard laboratory tests are used to determine the hydraulic conductivity of soil:

The constant head test.

The falling head test.

\subsection{Groundwater modeling}

\subsubsection{Introduction}

A mathematical model consists of a set of differential equations that are known to govern the flow of groundwater. The reliability of predictions from a groundwater model depends on how well the model approximates the field situation. Inevitably, simplifying assumptions must be made in order to construct a model because the field situation is too 
complex to be simulated exactly. Usually, the assumptions necessary to solve a mathematical model analytically are fairly restrictive, for instance, many analytical solutions require that the medium be homogenous and isotropic. To deal with more realistic situations, it is usually necessary to solve the mathematical model approximately using numerical techniques.

\subsubsection{Methods of Groundwater Modeling}

Two types of computer models can be considered for groundwater modeling:

Finite difference models.

Finite element models.

In both cases, the problem domain is superimposed with a system of nodal points. In finite element method the concept of elements is fundamental to the development of equations. This process of discretization has traditionally been performed by manually calculating each parameter value and assigning the values to the appropriate cells (Haitjema et al., 2001). In the finite difference method nodes are either located on the grid intersections or inside the grid intersections. Regardless of the representation, an equation is written in terms of each nodal point because the area surrounding a node is not directly involved in the development of finite difference equations. Aquifer properties and head are assumed to be constant within each cell.

The goal of modeling is to predict the value of the unknown variable at nodal points. However, before a predictive simulation can be made, the model should be calibrated and verified.

\subsection{MODFLOW Computer Modeling}

\subsubsection{Introduction}

MODFLOW is a three dimensional groundwater flow model, developed by USGS, based on the finite difference method (Harbaugh et al., 2000). Because of its ability to simulate a wide variety of systems and its extensive publicly available documentation, MODFLOW has become the worldwide standard groundwater flow model. MODFLOW is used to simulate systems for water supply, containment remediation and mine dewatering. 


\subsubsection{Explanation of MODFLOW}

The three-dimensional flow movement of the groundwater of constant density through porous earth material can be described by the partial differential equation (see Appendix I):

$$
\frac{\partial}{\partial x}\left(K_{x x} \frac{\partial h}{\partial x}\right)+\frac{\partial}{\partial y}\left(K_{y y} \frac{\partial h}{\partial y}\right)+\frac{\partial}{\partial z}\left(K_{z z} \frac{\partial h}{\partial z}\right)-W=S_{s} \frac{\partial h}{\partial t} \ldots \ldots . . . \mathrm{Eq} 2.3
$$

Where:

$\mathrm{K}_{\mathrm{xx}}, \mathrm{K}_{\mathrm{yy}}$ and $\mathrm{K}_{\mathrm{zz}}$ are values of hydraulic conductivity along the $\mathrm{x}, \mathrm{y}$, and $\mathrm{z}$ coordinate axes, which are assumed to be parallel to the major axes of hydraulic conductivity $\left(\mathrm{Lt}^{-1}\right)$,

$\mathrm{h}$ is the potentiometric head $(\mathrm{L})$,

$\mathrm{W}$ is the volumetric flux per unit volume and represents sources and/or sinks of water $\left(\mathrm{t}^{-1}\right)$,

$\mathrm{S}_{\mathrm{s}}$ is the specific storage of the soil $\left(\mathrm{L}^{-1}\right)$.

Derivation for the above equation is provided in Appendix I. The above equation, together with the specification of flow and initial head conditions, constitutes a mathematical representation of a ground water flow system. A solution of the equation above, in an analytical sense, is an algebraic expression giving $\mathrm{h}(\mathrm{x}, \mathrm{y}, \mathrm{z}, \mathrm{t})$. A time-varying head distribution of this nature characterizes the flow system and it measures both the energy of flow and the volume of water in storage.

Except for simple systems, analytical solutions of the above equation are rarely possible. Therefore, numerical methods must be employed to obtain approximate solutions. One such approach is the finite difference method, wherein the continuous system described by equation above is replaced by a finite set of discrete points in space and time, and the partial derivatives are replaced by terms calculated from the differences in head values at these points. The process leads to a system of simultaneous linear algebraic difference equations and their solution yields values of head at specific points of time. These values 
constitute an approximation to the time varying head distribution that would be given by an analytical solution of the partial differential equation of flow.

The finite difference analog of the above equation may be derived by applying the rules of difference calculus. However, the process is tedious and practically impossible to solve manually. Therefore, the computer program MODFLOW was introduced by USGS. Various user-friendly computer packages have been developed by using the MODFLOW program. In the current research work, GMS was used for the analysis (GMS, 2000). 


\section{CHAPTER 3}

\section{METHODOLOGY}

The objective of this research project is to study the effectiveness of the longitudinal drains. In order to achieve this objective, a series of experiments in laboratory on a physical model and a series of tests on computer models were conducted. This chapter describes the methodology used in this research work. It includes and explains the following steps:

Setting up the experimental apparatus.

Setting up the computer models.

Details of the tests performed.

Notation.

\subsection{Experimental apparatus}

During the previous study at West Virginia University by Stuad (2000) and Kiriakidis (2002), a physical model of the longitudinal drains was constructed in order to simulate the drainage patterns that occur in the soil mass between parallel longitudinal drains. The physical model can be seen in the Figure 3.1 . 


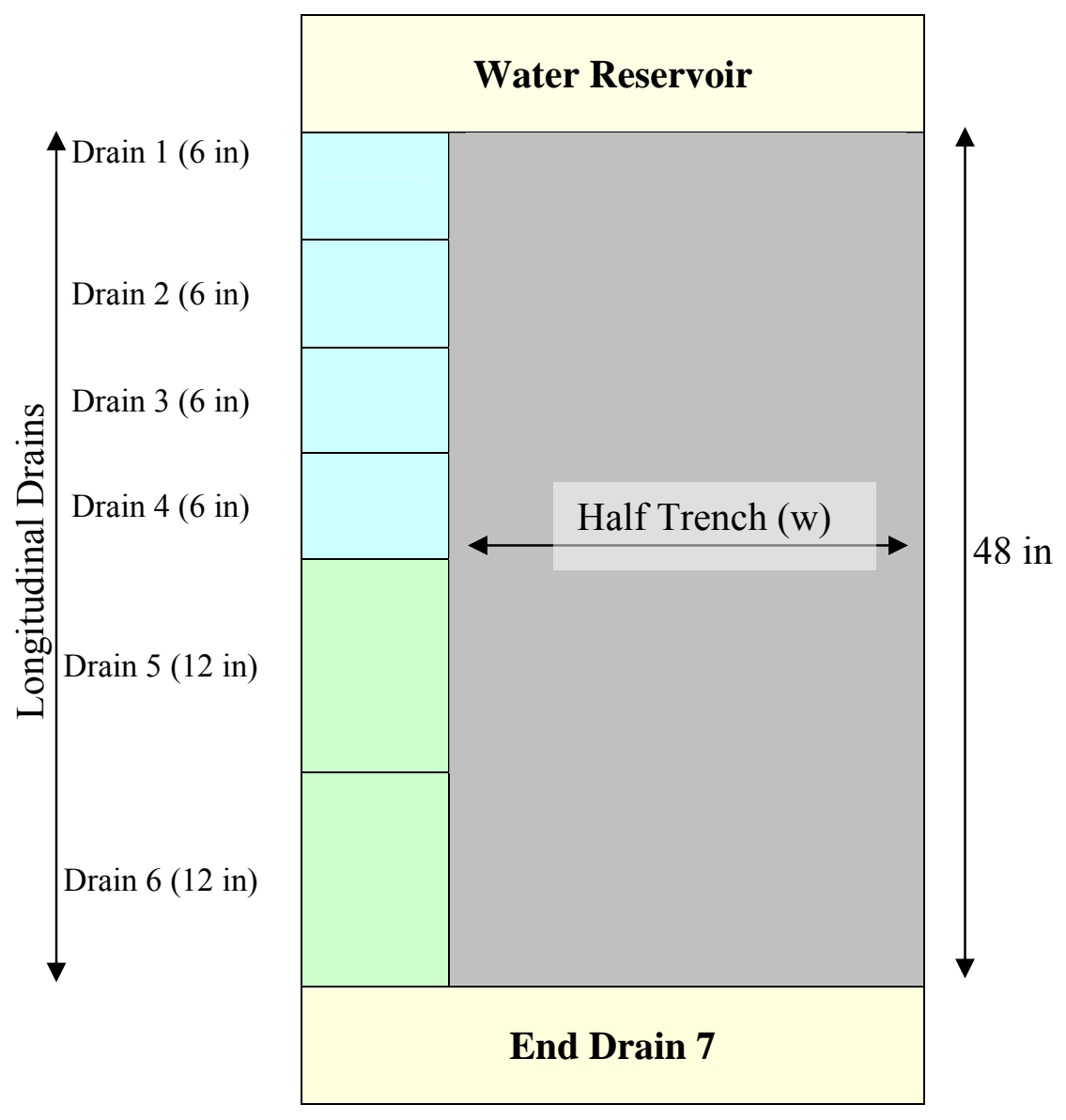

Figure 3.1: Plan view of the apparatus.

The flow between the drains is assumed to be symmetric with respect to the centerline between the two parallel drains. Because of this symmetry a no flow boundary was used to simulate the dividing line between two symmetric halves. This can be seen in the Figure 3.2. 


\section{Lines of Symmetry}

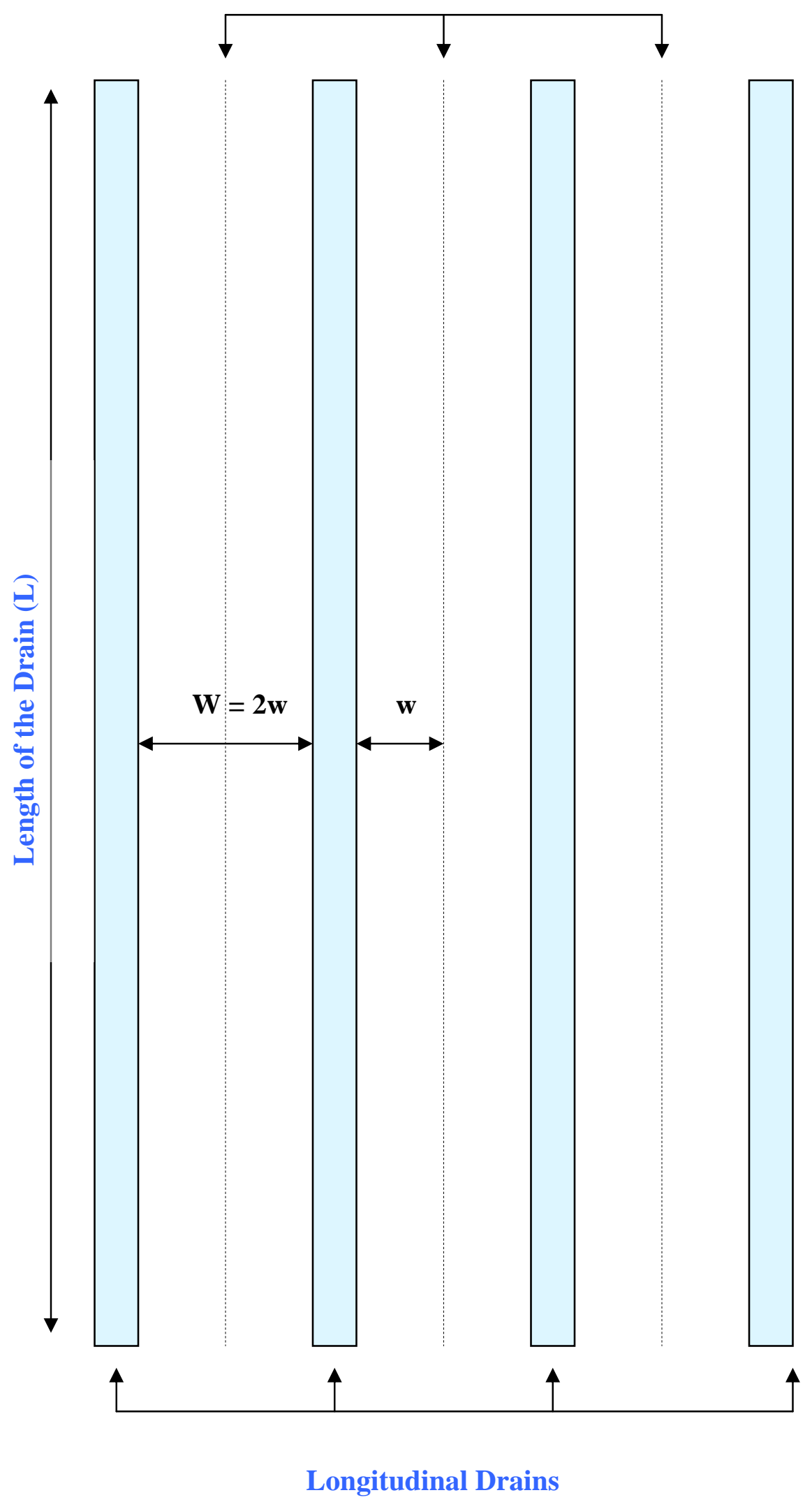

Figure 3.2: Lines of symmetry for longitudinal drains. 
The other components used in the construction of the physical model are described here:

1. Boundary condition at the line of symmetry.

2. Constant head or water level (Water supply system).

3. Longitudinal Drain.

4. End Drain.

5. Support Mechanism.

6. Piezometers.

\subsubsection{Boundary condition at the line of symmetry}

The boundary at the symmetry line was designed in a way that its width could be varied from 0 to 18 in $(45.7 \mathrm{~cm})$. The mechanism is as shown in the Figure 3.3. C clamps, $\mathrm{L}$ brackets and silicon caulk were used to immobilize the wall and to provide water tight seal at the base and sides. 


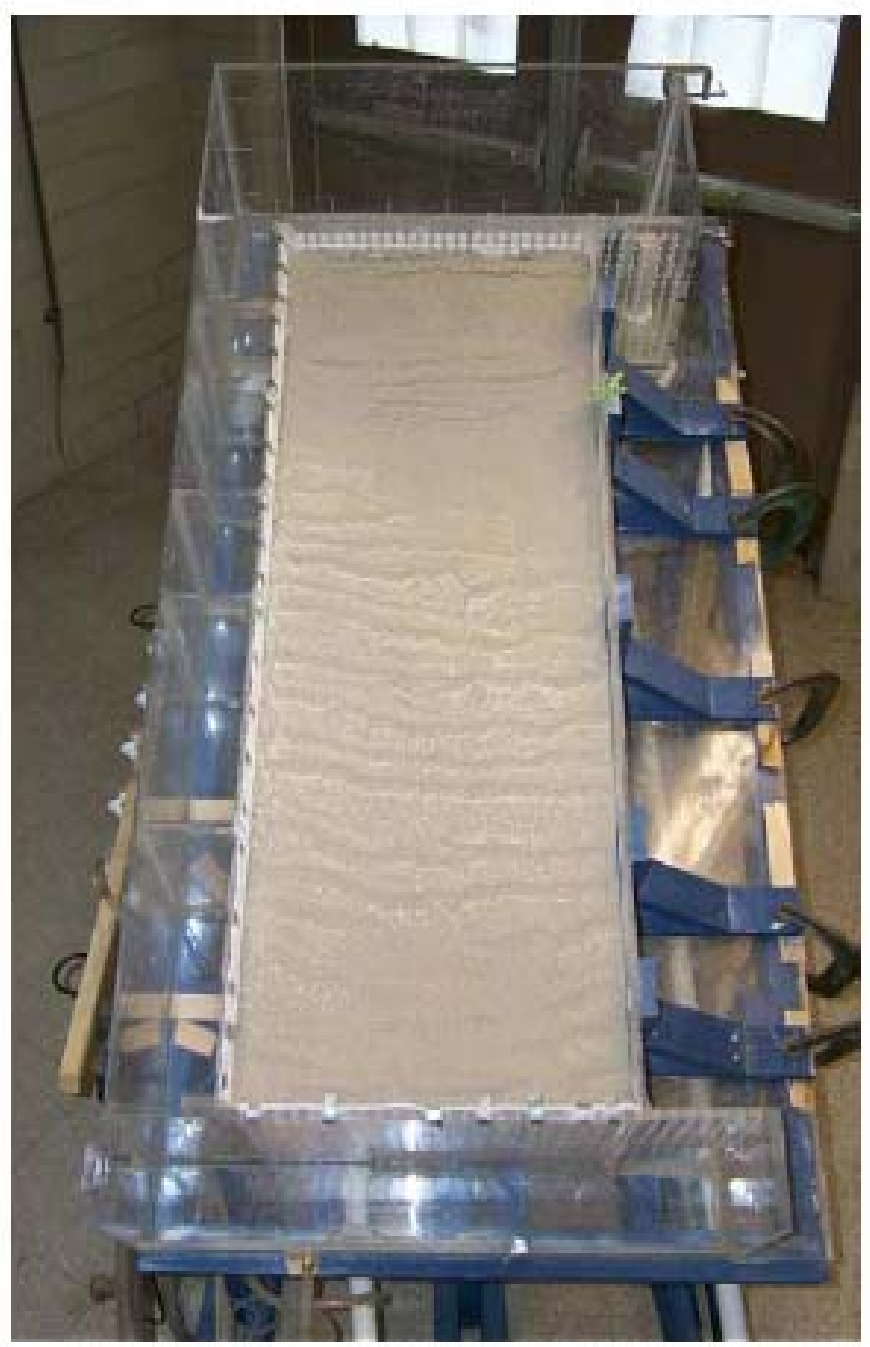

Figure 3.3: Physical apparatus simulating the slope.

\subsubsection{Constant head water level (Water supply system)}

Water was supplied to the soil mass by a matrix of holes. Half circles were drilled into the base of the plexi-glass wall separating the tank and the soil. These half circles provided free seepage at the beginning of the soil mass. During testing of widths less than 18 in $(45.7 \mathrm{~cm})$, the sections of supply tank wall that were not being used to supply water to the soil were covered with plexi-glass pieces and sealed into place. The remaining holes that were used to supply water were covered on the soil side of the tank by geotextile fabric to prevent soil from washing back into the supply tank. 


\subsubsection{Longitudinal Drains}

To determine the efficiency of the drainage system with respect to length, the longitudinal drain was divided into six separate sections. Since the first half of the longitudinal drainage system would collect a majority of the seepage, the spacing of the sections was made 6 in $(15.2 \mathrm{~cm})$ for the first half and 12 in $(30.5 \mathrm{~cm})$ for the second half. Care was taken to prevent the soil loss into the drains by using a perforated sheet of plexi-glass.

\subsubsection{End drain}

On the opposite end of the supply tank, another perforated sheet of plexi-glass similar to the supply tank is constructed. This end drain is called the terminus. It collects the remaining seepage from the soil mass.

\subsubsection{Support Mechanism}

This mechanism allows changing the slope of the apparatus to any desired angle. Adjustment of the base angle was achieved with a hydraulic jack and blocks. The elevation of the leg bolts from the floor and the distance between these bolts was used to calculate the required elevation for the upstream end bolts for a specific slope angle.

\subsubsection{Piezometers}

Piezometers help in determining the piezometric surface in the soil mass during testing. Figure 3.4 shows the layout of the piezometers. 


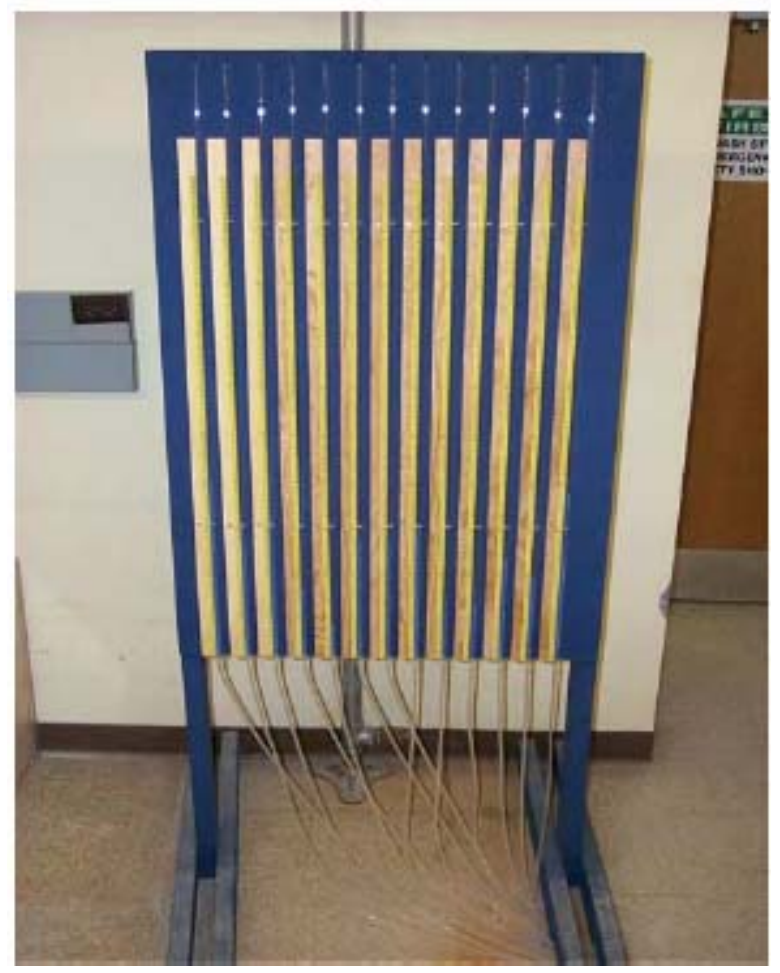

Figure 3.4: Panel of piezometers.

Before any soil was placed into the apparatus the piezometer lines were filled with water. After the soil mass had become saturated and prior to any head readings the piezometers were allowed to drain to remove any air bubbles or soil buildup in the lines.

\subsection{Simulation of Experimental apparatus}

Most of the experimental work presented in this research work was done during the previous study at West Virginia University by Stuad (2000) and Kiriakidis (2002). However, setting up an experiment takes a lot of time and effort. Repeating some of the experiments became necessary in order to verify the results. By resorting to a computer model, analyses can be done at a faster rate. Therefore, in this research work computer models were created to simulate the tests that were already done experimentally. The computer models were extended to investigate the influence of many other parameters that can influence the efficiency of the longitudinal drain in field conditions. 
Following steps describe in detail the entire procedure involved in creating a computer model:

\section{MODFLOW.}

Use of GMS Software.

Creating and getting results in a steady state model using GMS.

Steps involved in creating an inclined model.

\subsubsection{MODFLOW}

The modular finite difference groundwater flow model (MODFLOW) developed by the U.S. Geological Survey (USGS) is a computer program for simulating common features in groundwater systems (McDonald and Harbaugh, 1988; Harbaugh and McDonald, 1996). Currently, MODFLOW is the most widely used program in the world for simulating groundwater flow.

MODFLOW is designed to simulate aquifer systems in which

Saturated flow conditions exist,

Darcy's Law applies,

The density of groundwater is constant, and

$>$ The principal directions of horizontal hydraulic conductivity or transmissivities do not vary within the system.

These conditions are met for many aquifer systems for which there is an interest in analysis of groundwater flow and contaminant movement. For these systems, MODFLOW can simulate a wide variety of hydrologic features and processes. Steady state and transient flow can be simulated in unconfined aquifers, confined aquifers, and confining units. At least four different solution methods have been implemented for solving the finite difference equations that MODFLOW constructs. 
For each cell within the volume of the aquifer system, the user must specify aquifer properties. The solution consists of head (groundwater level) at every cell in the aquifer system (except for cells where head was specified as known in the input data sets) at intervals called "time steps." The head can be printed and (or) saved on a computer storage device for any time step. In addition to water levels, MODFLOW prints a water budget for the entire aquifer system. The budget lists "inflow to" and "outflow from" the aquifer system for all hydrologic features that add or remove water.

Accounting to all the above advantages, MODFLOW fits the requirements for the current research work.

\subsubsection{Use of GMS Software}

There are many number of software programs that use MODFLOW and are equipped with a user-friendly interface. But of all the programs, GMS (Groundwater Modeling Systems), a product of Department of Defense was found to be the most apt software program for the following reasons:

GMS provides complete support for the USGS MODFLOW 3D finite difference, MODPATH 3D particle tracking, MT3DMS 3D multi-species contaminant transport, the Department of Energy RT3D 3D bioremediation transport, the recently released SEAM3D 3D bioremediation transport, and the Army Corps SEEP2D 2D finite element, and FEMWATER 3D finite element groundwater models.

GMS is completely graphical, and can display a defined groundwater model in either plan view or 3D oblique view, and can be rotated interactively. Tools are provided for site characterization, model conceptualization, mesh and grid generation, geo-statistics, and output post-processing. Cross-sections and fence diagrams may be cut anywhere in the model. Hidden surface removal, and color and light source shading can be used to generate photo-realistic rendered images. Contours, color fringes, electronics and $3 \mathrm{D}$ iso-surfaces can be used to display the variation of input data or computed results. 


\subsubsection{Creating and getting results for a steady state model using GMS}

Following steps provide brief information about creating and analyzing a steady state model by using any software package that is based on MODFLOW:

$>$ Create a grid by defining the number of cells and length of the aquifer in each direction.

$>$ Create a new simulation of MODFLOW.

$>$ For modeling a transient state problem, define the stress periods, number of time steps for each stress period, and the length of time.

$>$ If the soil is saturated, define the starting head for all the cells.

For the cells with constant head, specify the value of the head. In GMS IBOUND array is used to define the constant head.

$>$ Define the elevations of each layer.

$>$ Define hydraulic conductivity, vertical anisotropy for each layer.

Define the layer behavior (confined, unconfined or convertible) for each layer.

$>$ Define wells and recharge, if they are present.

Save the simulation and Run MODFLOW.

$>$ Change the view accordingly and select the cells of interest and read the results. 


\subsubsection{Steps involved in creating an inclined model}

Modeling an inclined aquifer is a bit complicated in contrast with a horizontal model. Though it is easy to create a graphically inclined model, it is a gargantuan task to go to each and every cell and specifically define the elevation which depends on the inclination. However, using the scatter point module of GMS, an inclined aquifer can be modeled. The procedure is explained below.

For instance, the cross-section of an aquifer which has three layers and is inclined at $30^{\circ}$ is shown in Figure 3.5.

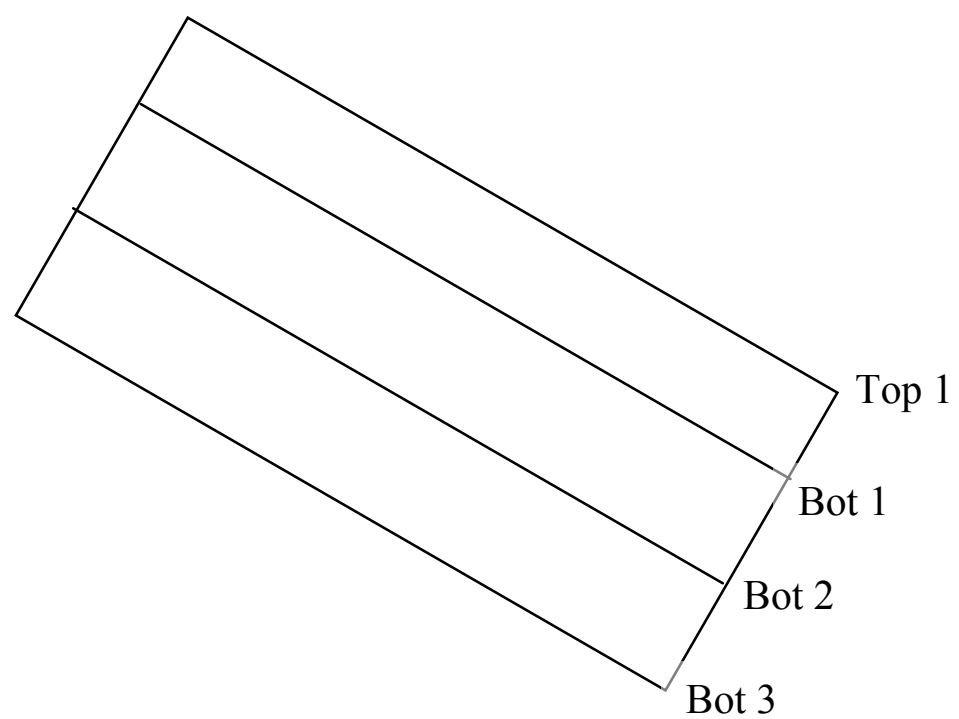

NOTE: top1, bot1, bot2, bot3 represent the elevations of the top of the first layer, bottom of the first layer, bottom of the second layer and bottom of the third layer respectively.

Figure 3.5: A three layered medium. 


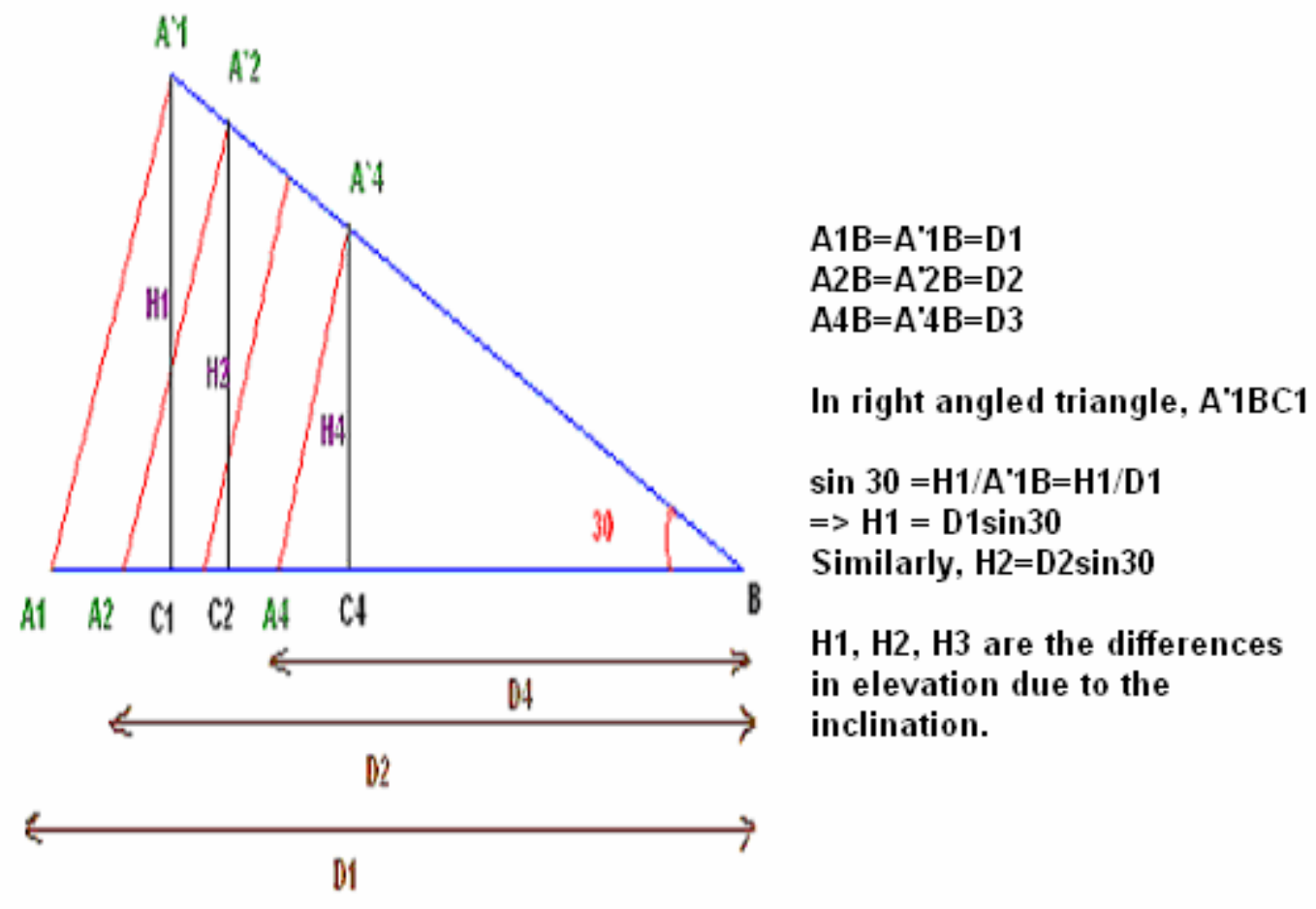

Figure 3.6: Change of co-ordinates in the inclined system.

Consider the line $A_{1} B$ to be the bottom layer of the aquifer. The original line $A_{1} B$ transforms to $A_{1}^{\prime} B$ after inclination. $A_{2}$ is a point on the line $A_{1} B$. Its transformed coordinate is $\mathrm{A}_{2}$. The change in the head due to the inclination is $\mathrm{H}_{2}$.

From the right angled triangle, $\mathrm{A}_{2} \mathrm{~B} \mathrm{C}_{2}, \quad \operatorname{Sin} 30^{\circ}=\mathrm{H} 2 / \mathrm{D} 2$.

Therefore, $\quad \mathrm{H}_{2}=0.5 \times \mathrm{D}_{2}$.

Similarly, there can be 20 other points on the line $A_{1} B$ like, $A_{3}, A_{4}$, and $A_{5}$ etc.

Their corresponding change in heads will be $\mathrm{H}_{3}, \mathrm{H}_{4}$, and $\mathrm{H}_{5}$ etc.

Final head = Initial head (before inclination) + Change in head

By using the appropriate formulae, a spread sheet can be prepared which has the 2-D geometrical information of a point and its new elevation in the fields of the spread sheet. A spread sheet for $30^{\circ}$ of a 48 in $(121.9 \mathrm{~cm})$ line would look like Table 3.1 . 
Table 3.1: A Spread sheet for $30^{\circ}$ inclination of the slope in inches.

\begin{tabular}{|c|c|c|}
\hline $\mathrm{x}$ co-ordinate & $\begin{array}{c}\text { y co-ordinate } \\
\text { (initial) }\end{array}$ & $\begin{array}{c}\text { y co-ordinate } \\
\text { (new) }\end{array}$ \\
\hline 0 & 0 & 24 \\
\hline 3 & 0 & 22.5 \\
\hline 6 & 0 & 21 \\
\hline 9 & 0 & 19.5 \\
\hline 12 & 0 & 18 \\
\hline 15 & 0 & 16.5 \\
\hline 18 & 0 & 15 \\
\hline 21 & 0 & 13.5 \\
\hline 24 & 0 & 12 \\
\hline 27 & 0 & 10.5 \\
\hline 30 & 0 & 9 \\
\hline 33 & 0 & 7.5 \\
\hline 36 & 0 & 6 \\
\hline 39 & 0 & 4.5 \\
\hline 42 & 0 & 3 \\
\hline 45 & 0 & 1.5 \\
\hline 48 & 0 & 0 \\
\hline
\end{tabular}


First a 3D horizontal grid is created. The MODFLOW solution is initiated and using the $2 \mathrm{D}$ Scatter point module, the above spread sheet is imported into GMS. The software automatically recognizes this spreadsheet as a database of $2 \mathrm{D}$ points and the corresponding heads. Using Interpolate to MODFLOW layers command, the grid can be interpolated to the desired angle.

\subsection{Description of the Tests performed}

As in the experimental model, it is not necessary to wait until the soil saturates, which saves a lot of time. Therefore, immediately after creating the grid, boundary conditions were applied. All the cells in the grid were assigned the same initial head, to indicate that soil was saturated. The cells in the left most columns were assigned a constant head of 8 in $(20.3 \mathrm{~cm})$ and the cells in the right most columns were assigned a constant head of zero inches. This indicates the presence of a constant head water supply system and an end drain (terminus) respectively. After defining the boundary conditions, a new simulation of the MODFLOW is started by activating the start new simulation tab in the MODFLOW menu.

In steady state condition, only the hydraulic conductivity of the soil is defined. However, while analyzing a transient condition, the number of stress periods and the number of time steps for each stress period have to be defined.

For instance, if the time period is one day and the number of time intervals is 24 , the results for every one hour are obtained. Therefore, models were created with one day as the time limit to observe the initial response. By specifying 48 time steps, it is possible to observe the response every 30 minutes. To observe the readings for over a longer period of time, another set of models were created. Though a single model can serve the purpose of getting the results for both the initial response and the response for over a considerable period of time, it is not recommended. Because, it needs a large number of time steps to be defined, which would take a lot of computer memory and will ultimately lead in crashing the program. 


\subsection{Notation}

Experimental: The following notation is used to describe the experimental apparatus used in this project:

$\mathrm{W}=$ Spacing between the longitudinal drains.

$\mathrm{W}=$ Width of the soil zone $(\mathrm{W} / 2)$.

$\mathrm{h}=$ Water level measured at the wall between soil and water.

$\theta=$ Inclination or slope angle.

$q=$ flow rate.

$\mathrm{K}=$ Hydraulic conductivity.

Because of the amount of experiments and the data collected it was necessary to come up with a labeling system. The labels used were as follows: the first number represents the width of the soil zone (half trench spacing, w), the second number represents the water level (h), the third number is the slope angle $(\theta)$ and the last number is the experimental number. For example, the test labeled 12-6-3-18 was a 12 in (30.5 $\mathrm{cm})$ width soil zone with a water level at 6 in $(15.2 \mathrm{~cm})$, at a slope of $3: 1$ and the experiment number was 18 .

Computer model: There are about 130 models altogether created and analyzed in the current project. To identify the test completely by just seeing the file name of the model, a notation has to be followed.

Every file in this project bears the file name which is in the following fashion:

$$
\text { DR_STATE_ANGLE_SPACING_SOIL TYPE }
$$

Where,

DR represents the longitudinal drains state. It takes the following parameters: 
DO indicates that the drains are open.

DC indicates that the drains are closed.

STATE represents if the test is conducted for the Steady or transient state.

TR indicates that the test is for the Transient state.

ST indicates that the test is for the Steady state.

ANGLE represents the inclination of the slope.

2BY1 represents the slope for 2:1.

3BY1 represents the slope for 3:1.

4BY1 represents the slope for $4: 1$.

HR represents the horizontal condition.

SPACING represents the width of the soil zone (W/2).

12 indicates that the width of the soil zone is 12 in $(30.5 \mathrm{~cm})$.

18 indicates that the width of the soil zone is 18 in $(45.7 \mathrm{~cm})$.

36 indicates that the width of the soil zone is 36 in $(91.4 \mathrm{~cm})$.

There are three soil models used in this research work. They are named as Soil A, Soil B, and Soil C. They are differentiated by their hydraulic conductivities.

\section{Example:}

A model with the file name $D O \_T R \_2 B Y 1 \_12 \_A$ indicates that:

$>$ Drains are activated in the model.

The model is being analyzed for the transient condition. 
The slope inclination angle of the model is $2: 1$.

$>$ The trench width is 12 in $(30.5 \mathrm{~cm})$.

$>$ The Soil type used is Soil A.

Similarly, a model with the file name DC_ST_3BY1_18_B indicates that:

$>$ Drains are deactivated in the model.

$>$ The model is being analyzed for the steady state condition.

$>$ The slope inclination angle of the model is $3: 1$.

The trench width is $18 \mathrm{in}(45.7 \mathrm{~cm})$.

$>$ The Soil type used is Soil B. 


\section{CHAPTER 4}

\section{RESULTS AND DISCUSSIONS: LAB MODEL}

\subsection{Introduction}

This study was undertaken to determine the performance of a longitudinal drain system that can be used to capture seepage water in an earth slope. A physical model of the drain system was constructed as described in Chapter 3 of this report. The procedure adopted for creating the computer models was also discussed in Chapter 3. The results obtained from the computer models are discussed in this section.

Abundant data on the performance of longitudinal drains were collected by using computer models. All raw data were then processed and interpreted. Several graphs were prepared to facilitate and provide visual understanding of what is actually happening along the slope. It is important to remember that the model is based on the assumption that the flow is symmetrical between parallel longitudinal drains.

The model was tested for different combinations of:

$>$ Slope angles $(\theta)(2: 1,3: 1,4: 1$ and zero slope angle).

$>$ Trench spacing $(12$ in $(30.5 \mathrm{~cm}), 18$ in $(45.7 \mathrm{~cm})$, and 6 in $(15.2 \mathrm{~cm}))$.

$>$ Soil types (low, medium and high hydraulic conductivities).

In all the tests, the seepage depth was kept constant at 8 in $(20.3 \mathrm{~cm})$. During the previous study on the physical model, a total of 7 drains were installed along the longitudinal cross section, but in the current research, totally 10 drains are considered. The 3 additional drains are in the first half of the drain system as it is important to consider the effect of the drains near the reservoir.

For the transient study, 48 time steps were used for the response in the first day, and then 24 time steps were used for the next 3 days. This leads to readings for every half hour during the first day, and then for every one hour for the next 3 days. Transient data 
is important, because it gives the information regarding when the drains would become completely functional.

\subsection{Cumulative Percentage Removal (CPR)}

The term "Cumulative percenage removal" can be defined as below:

If $\mathrm{V}_{1}, \mathrm{~V}_{2}, \mathrm{~V}_{3}, \mathrm{~V}_{4}, \mathrm{~V}_{5}$ and $\mathrm{V}_{6}$ are the volumes of water collected in drains $1,2,3,4,5$ and 6 respectively and $V_{7}$ is the volume of water collected in the end drain.

Then, the total drainage $\mathrm{V}_{\mathrm{t}}=\mathrm{V}_{1}+\mathrm{V}_{2}+\mathrm{V}_{3}+\mathrm{V}_{4}+\mathrm{V}_{5}+\mathrm{V}_{6}+\mathrm{V}_{7}$.

Now the Cumulative Percentage Removal (CPR) at nth drain is,

$$
\text { CPR at } \mathrm{D}_{\mathrm{n}}=\frac{\sum_{n=1}^{n} V n}{V t} \times 100 .
$$

\subsection{Permeability Test}

In order to obtain accurate results in the modeling work, it is important to verify the accuracy of the software program, and also the computational model developed. A simple permeability test was performed to check the accuracy of the program. Hydraulic conductivity of a soil sample was found using constant head permeability test apparatus. The constant head permeability test apparatus can be seen in Figure 4.1. 


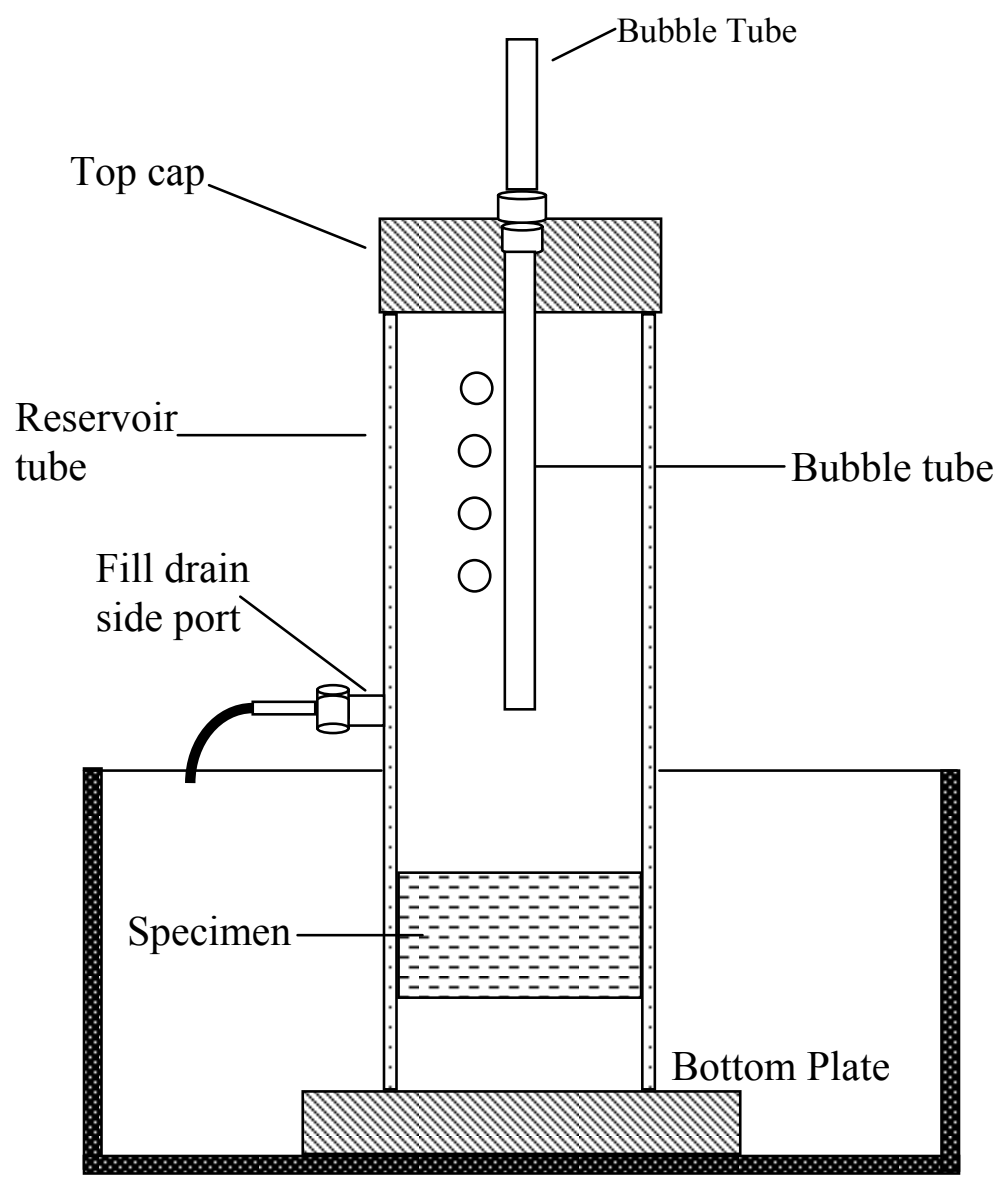

Figure 4.1: Experimental apparatus for constant head test (Cedergren, 1977).

The purpose of this experiment was to determine the accuracy of the modeling procedure adopted using the GMS package. A constant head permeability test was performed in the laboratory and the permeability of the soil was calculated using the Darcy's law. Now, the same test was simulated using the GMS package to test the validity of the computational model.

\subsubsection{Experimental Procedure}

A step-by-step experimental procedure is given below:

a.) Loosen the lower hose clamp on the top coupling and remove the reservoir tube.

b.) Place test sample in the mold, level with a straight edge, place in the bucket.

c.) Measure the diameter of both the reservoir tube and bubble tube, length of mold, L.

d.) Measure the distance between the top of the mold and top of bucket, H1 . 
e.) Take the mold out of the bucket, place the reservoir tube back on the mold and tighten the clamps.

f.) Measure the distance from the bottom of the bubble tube to the top of the mold, H2; the water head difference will be $\mathrm{H} 2-\mathrm{H} 1$.

g.) Place permeameters in the bucket and fill slowly allowing water to saturate the sample from the bottom up.

h.) When water overflows, open the upper and lower ports to allow water in the reservoir tube, keep the water overflowing the bucket.

i.) Seal the top of the bubble tube, use vacuum, draw the water into the bubble tube so that the water level is between $20 \mathrm{~cm}$ (7.9 in) and $25 \mathrm{~cm}$ (9.8 in) high as marked on the reservoir tube. Close the ports with clamps. Note the mark at which it starts.

j.) Open the bubble tube and start the timer, end test when the water level drops to the bottom of the bubble tube, or stop after between 15 and 30 minutes.

In the experiment, the radius of the cylinder used was 1.5 in $(3.8098 \mathrm{~cm})$, and the head difference H2-H1 was 24 in $(61 \mathrm{~cm})$, and the length of the soil column was 9.75 in $(24.7 \mathrm{~cm})$. Water was collected for 15 minutes on day 1, day 2, upto day 10. The amount of water collected since 8 days was almost same from then on. Therefore, it can be safely assumed that the soil column was in steady state on 8 th day, when the amount of water collected for 15 minutes was $60 \mathrm{cc}$.

Following the Darcy's law,

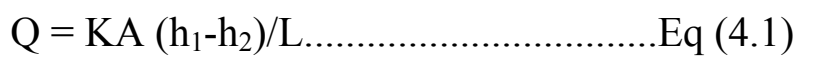

Where,

$\mathrm{Q}$ is the rate of discharge $\left(\mathrm{in}^{3} / \mathrm{min}\right)$.

$\mathrm{K}$ is the hydraulic conductivity (in/min).

$\mathrm{A}$ is the cross-sectional area $\left(\mathrm{in}^{2}\right)$. 
$\mathrm{h} 1, \mathrm{~h} 2$ represent the head at the source and sink respectively (in).

$\mathrm{L}$ is the length of the flow (in).

On substituting the values into the equation, $\mathrm{K}$ value is obtained as $0.01403 \mathrm{in} / \mathrm{min}$.

\subsubsection{Modeling Procedure}

Since creating a circular model was a daunting task using the finite difference

method, a model was created which had a rectangular cross-section. The model will still be able to produce the same result as that with circular cross-section, since the rectangular cross-section had the same area. In Darcy's equation, the geometry of the soil column did not have any effect of the value of K, but only the cross-sectional area. Therefore, it is safe to create a model with rectangular cross-section and still obtain the desired results. Figure 4.2 illustrates the MODFLOW generated grid. 


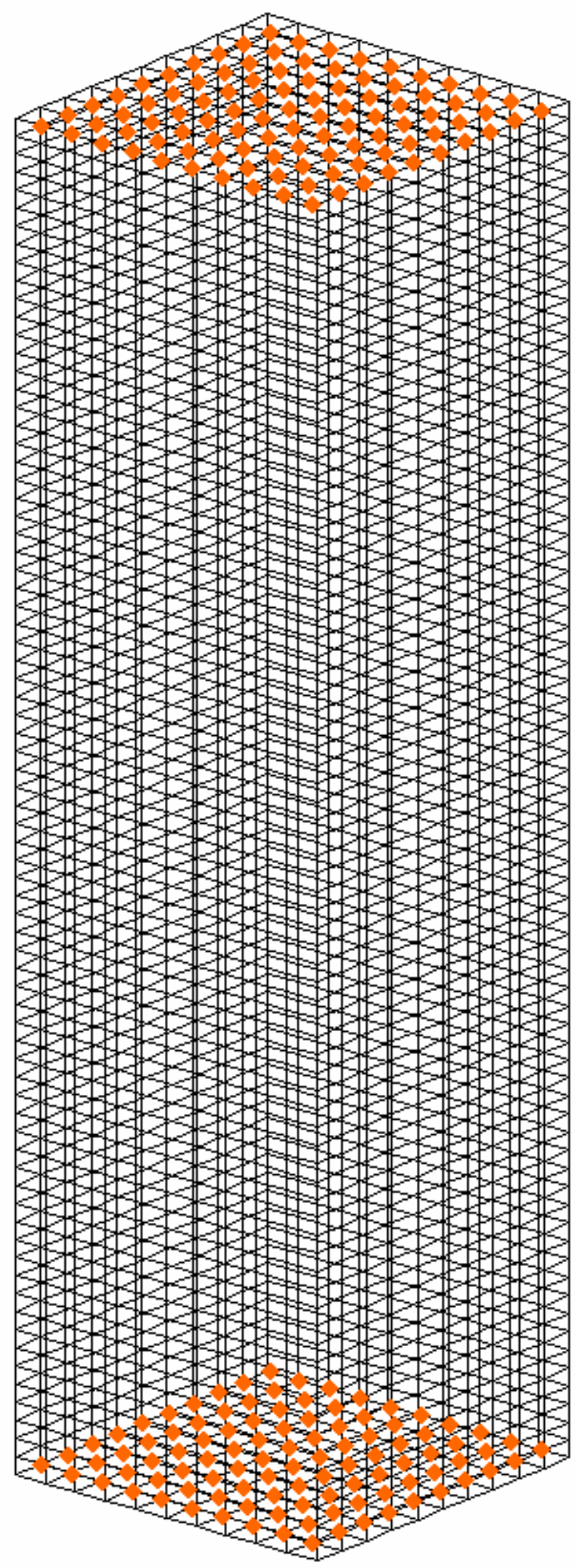

Figure 4.2: Grid used for the permeability test. 
Given below is the comparison between the experimental result and the result obtained from the computer model.

$$
\begin{array}{ll}
\text { Experimental model } & 60.0000 \text { cc per } 15 \text { mins } \\
\text { Numerical Model } & 59.2638 \text { cc per } 15 \text { mins }
\end{array}
$$

Better results can be obtained by increasing the grid resolution. More information on the influence of grid resolution can be found elsewhere (Leake et al., 2001; Nair \& Wilsnack, 1998; Jones et al., 2002). Since the results from the experimental and numerical model almost gave the same results, it proves the efficiency of the model developed.

\subsection{Comparison of Pressure Head}

To verify the accuracy of the some of the modules of the software few more tests have been performed. This included the comparison of the pressure head drop across the 48 in $(121.9 \mathrm{~cm}) \times 12$ in $(30.5 \mathrm{~cm})$ cross-section (Cross-section A) and 12 in $(30.5 \mathrm{~cm}) \mathrm{x}$ 10 in $(25.4 \mathrm{~cm})$ cross-section (Cross-section B). The experimental results were compared with the results from the computer models.

\subsubsection{Analysis by SEEP 2D}

SEEP2D is a two-dimensional finite element groundwater model. SEEP2D is designed to be used on profile models (XZ models) such as cross-sections of earth dams or levees. The problem defined above is first solved using SEEP 2D and then with MODFLOW which follows the finite difference method.

\section{Experiment 1: Flow across Cross-section A (Refer Section 4.4)}

The rectangular grid for this cross-section can be seen in Figure 4.5. The pressure head on the left edge of the rectangle is defined as 8 in $(20.3 \mathrm{~cm})$, while along the right edge is zero. 
Table 4.1 provides the comparison of the values of the pressure head at various distances along the length of the cross-section. A graph (Figure 4.3) which is plotted using the values from this table is also included.

Table 4.1: Comparison between experimental and numerical values of head across the cross-sectional area A.

\begin{tabular}{|c|c|c|}
\hline$L$ (in inches) & $\begin{array}{c}\text { Values from Computer model } \\
\text { (in inches) }\end{array}$ & $\begin{array}{c}\text { Experimental Values } \\
\text { (in inches) }\end{array}$ \\
\hline 0 & 203.2 & 161.65 \\
\hline 6 & 189.89 & 131.65 \\
\hline 12 & 175.26 & 126.65 \\
\hline 18 & 160.3248 & 121.65 \\
\hline 24 & 141.732 & 81.65 \\
\hline 36 & 101.4984 & \\
\hline 42 & 71.3232 & \\
\hline 46 & 36.2712 & \\
\hline 48 & 0 & \\
\hline
\end{tabular}




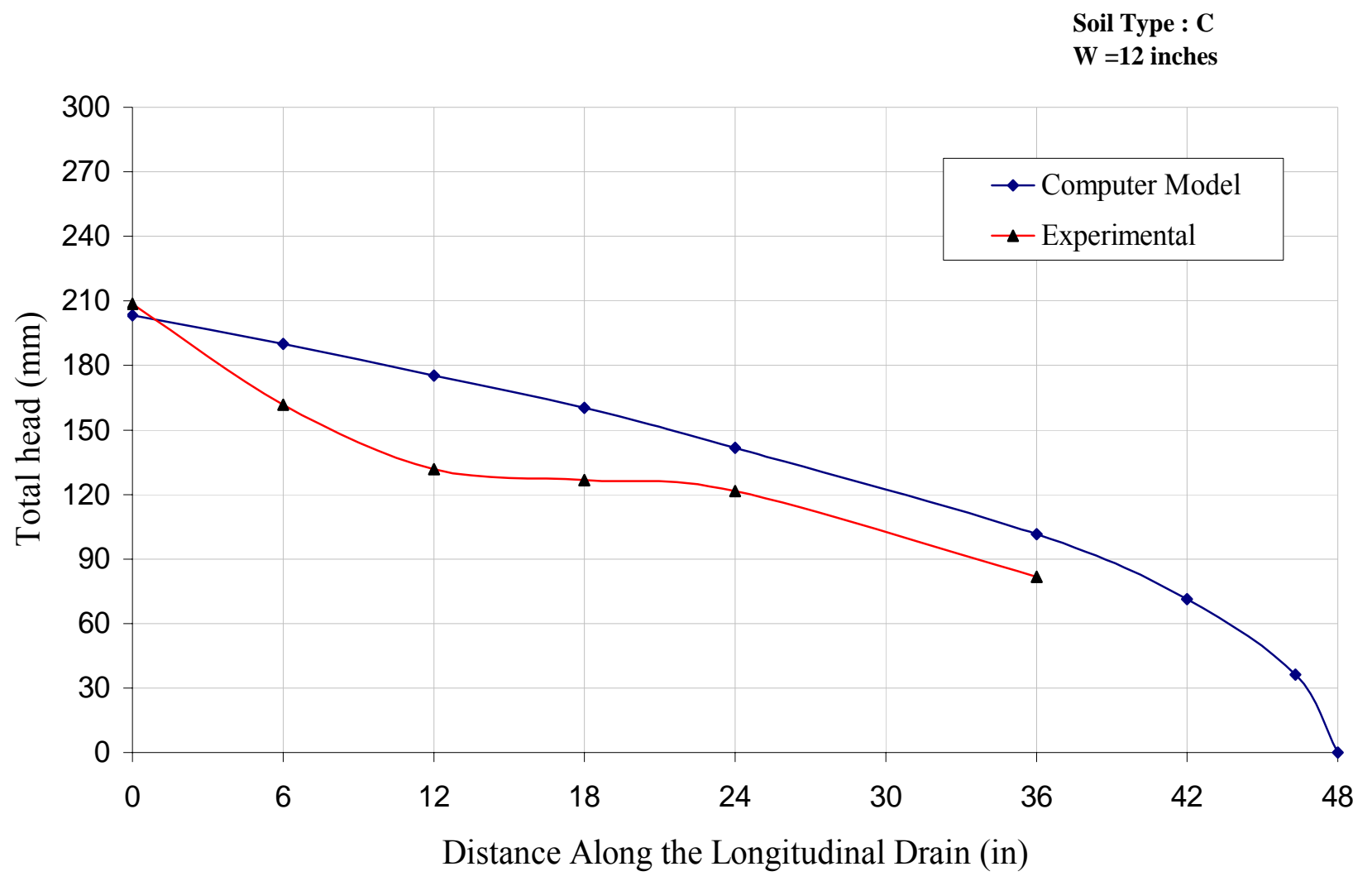

Figure 4.3: Variation of Pressure head along the cross-section A. 


\section{Experiment 2: Flow across Cross-section B (Refer Section 4.4)}

The rectangular grid modeled for this cross-section can be seen in Figure 4.6. The pressure head on the left edge of the rectangle is defined as 8 in $(20.3 \mathrm{~cm})$, while along the right edge it is zero (Figure 4.6).

Table 4.2 provides the comparison of the values of the pressure head at various distances along the length $(12$ in $(30.5 \mathrm{~cm}))$ of the cross-section. The graph (Figure 4.4) which is plotted using the values from this table is also included.

Table 4.2: Comparison between experimental and numerical values of pressure head along the cross-section B.

\begin{tabular}{|c|c|c|}
\hline L (in inches) & $\begin{array}{c}\text { Theoretical Values } \\
\text { (inches) }\end{array}$ & $\begin{array}{l}\text { Experimental } \\
\text { Values(inches) }\end{array}$ \\
\hline 0 & 203.301 & 166.65 \\
\hline 6 & 138.988 & 123.65 \\
\hline 9 & 94.183 & 53.65 \\
\hline
\end{tabular}




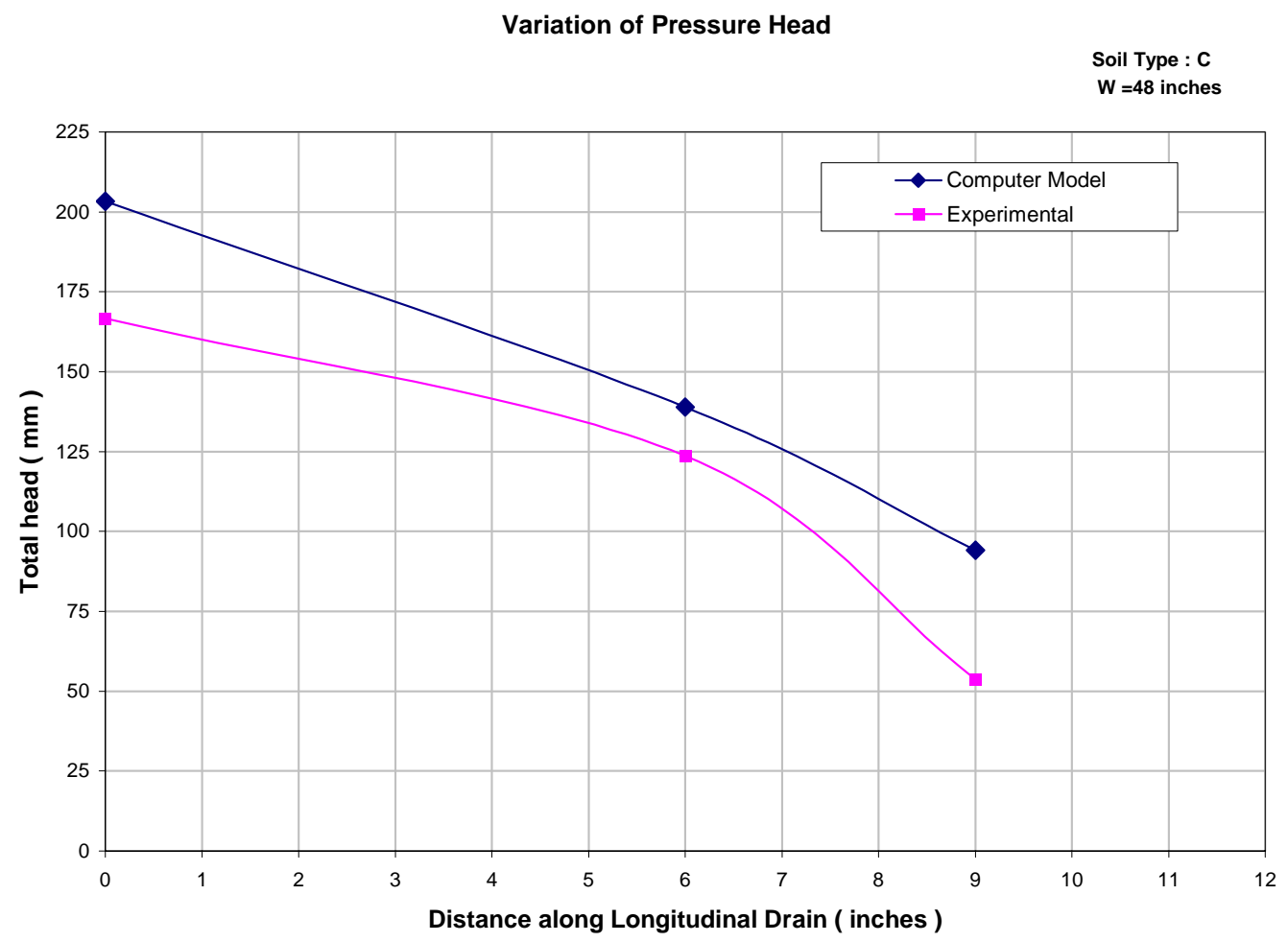

Figure 4.4: Variation of Pressure head along Cross-section B.

\section{ILLUSTRATION OF}

SEEP2D

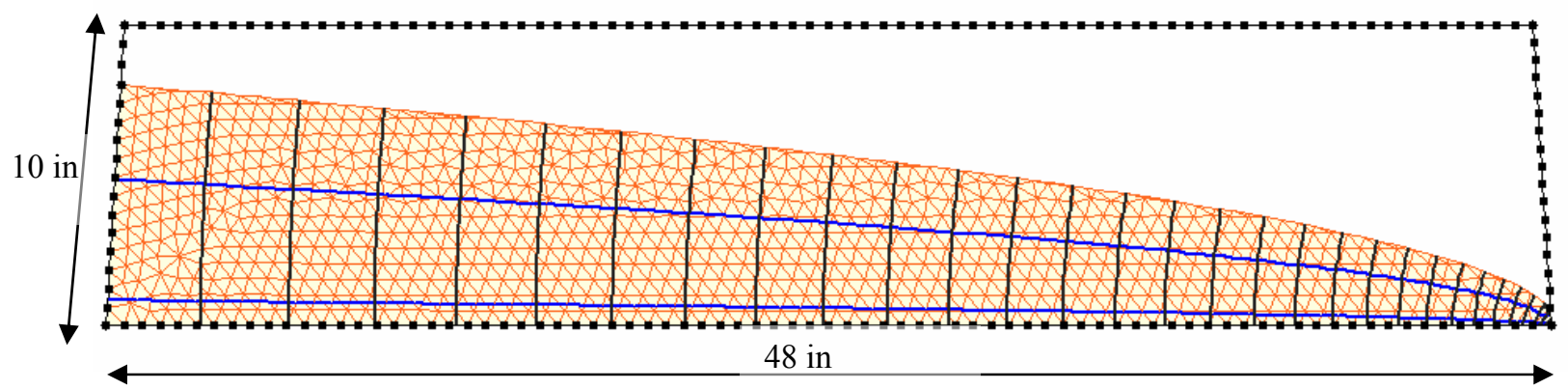

Figure 4.5: Flow net for the Cross-section A. 


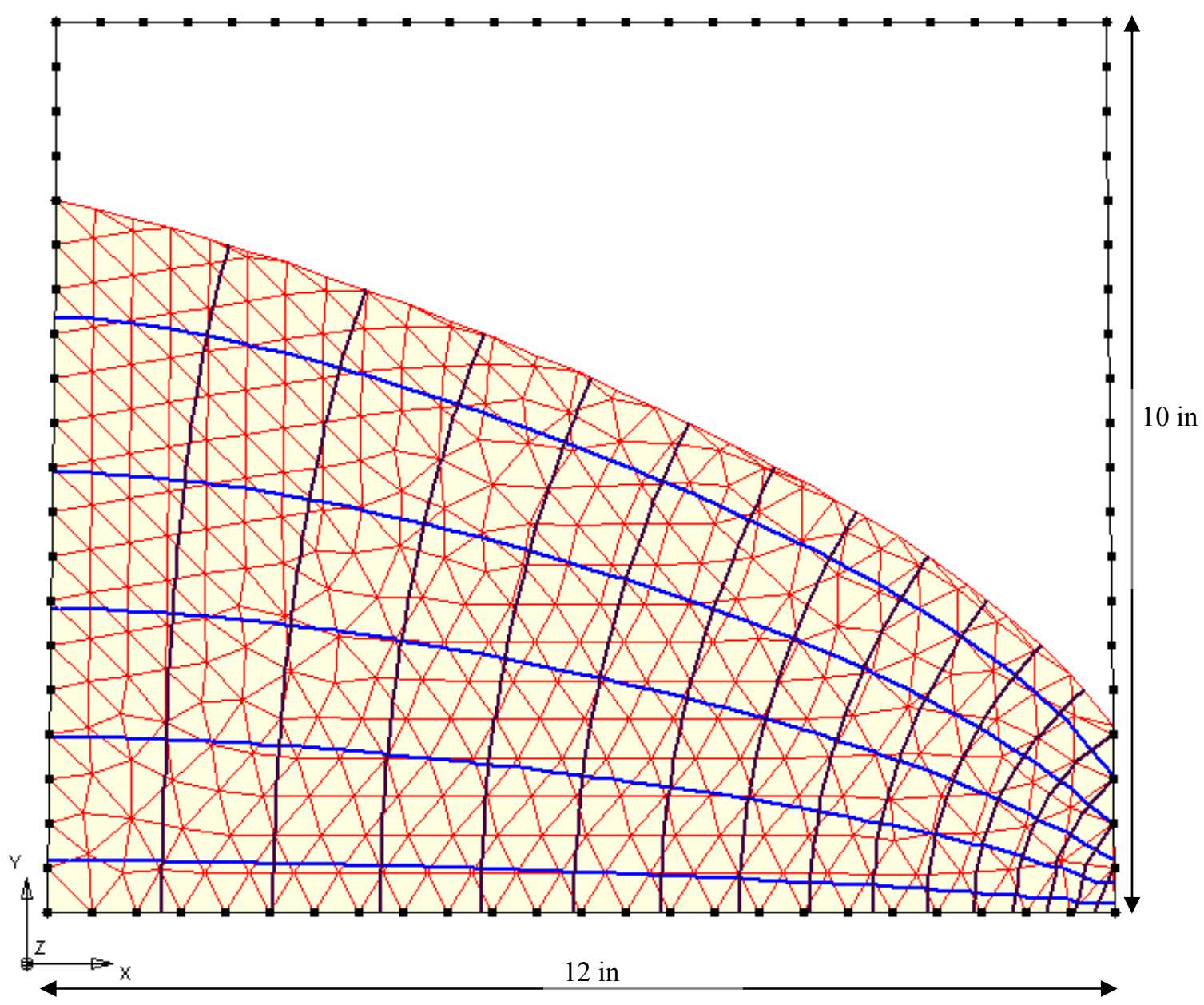

Figure 4.6: Flow net for the Cross-section B.

\subsection{Influence of location of the drains}

After completing all of the tests, it was observed that the first drain which is equal to 2 in $(5.1 \mathrm{~cm})$ in length provided the biggest water removal. This is true for different combinations of water depth (h), inclination angle $(\theta)$, half trench spacing (w), and soil type. As seen in the Figure 4.7, the first 2 drains collected more than half of the total volume seeping through the soil. Figure 4.7 shows a typical representation in seepage removal as a function of longitudinal distance for different soil types. It can be easily seen that the amount of seepage water removed from the soil decreases as the drains move further downstream. The last six drains collected less than $5 \%$ of the overall 
seepage. For the conditions in Figure 4.7, the longitudinal drain is removing almost all the water flowing through the soil.

Appendix A shows results corresponding to steady state condition for different combinations of water depths, inclination angles and trench spacing. All these results show similar trends.

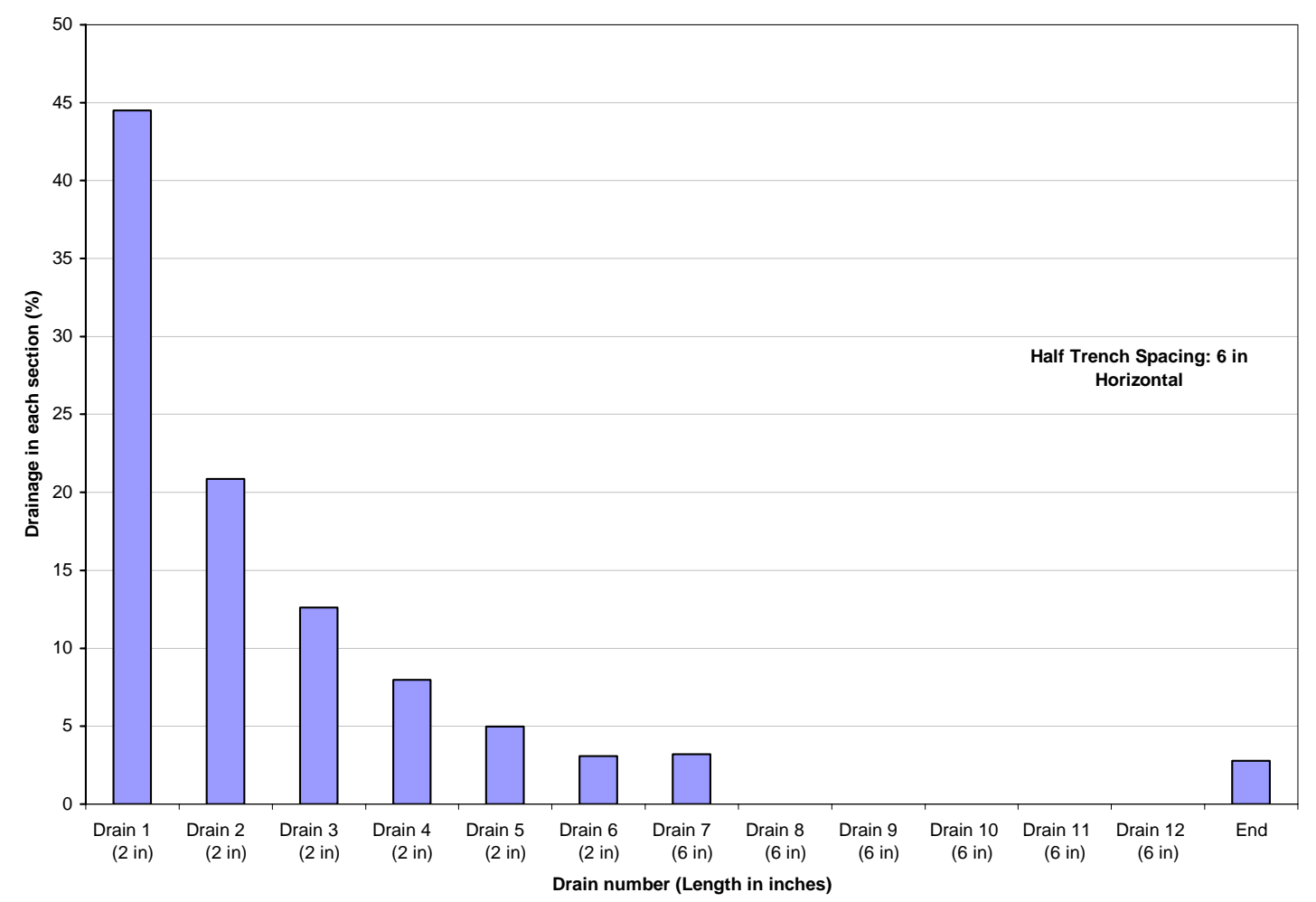

Figure 4.7: Influence of Location of drains.

\subsection{Influence of slope inclination angle}

Slope inclination angle affects the efficiency of the longitudinal drains significantly. Figure 4.8 shows the influence of slope inclination angle for a model with half trench spacing of 18 in $(45.7 \mathrm{~cm})$ and soil B.

Figure 4.8 shows that the efficiency of the drains decreases dramatically with the increase in the slope inclination. The model with zero slope drains almost $90 \%$ of water, whereas for the model with a slope of $4: 1$, the total drainage is only $75 \%$. There is a reduction of $15 \%$ in the overall efficiency between the two models, which is quite high. 
The reduction in the efficiency is only $5 \%$ between the models with $4: 1$ slope and 3:1 slope. Though this difference is not as big as $15 \%$, it is a consequence of higher slope.

Although, the slope inclination angle reduces the overall efficiency of the drains, it is still effective. Even for the worst case (2:1 slope inclination), the overall removal rate is $65 \%$.

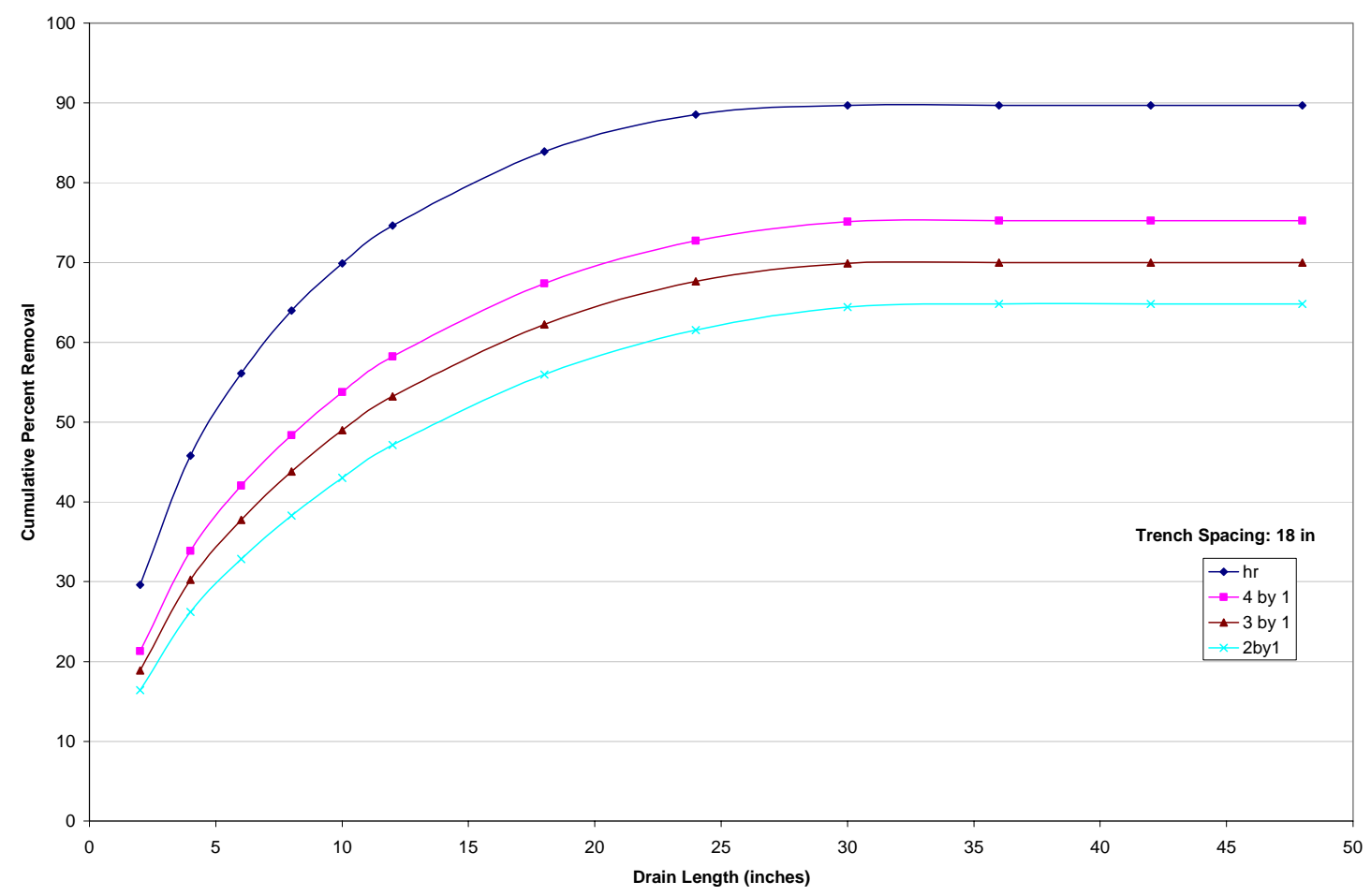

Figure 4.8: Influence of slope inclination angle.

\subsection{Influence of trench spacing}

Figure 4.9 shows the Cumulative Percentage Removal (CPR, see section 4.2) of seepage water collected throughout the drains for three values of half trench spacing (6 in $(15.2 \mathrm{~cm}), 12$ in $(30.5 \mathrm{~cm})$, and 18 in $(45.7 \mathrm{~cm}))$ for Soil type B. For all three cases shown in the Figure 4.7, CPR increases as the trench spacing decreases. As expected the smaller the longitudinal drain spacing, the more effective they become. It is easier for the seepage water flow to be diverted, if the trench spacing is small. 
The shorter the spacing between the longitudinal drains the more effective they become. However, it may not be feasible to do so in every case. Depending on economic factors, timetables and many other factors, it may not be possible to reduce the spacing between drains beyond a certain limit. Once the effectiveness of the drain is determined, the engineer must evaluate all these factors and make the best decision.

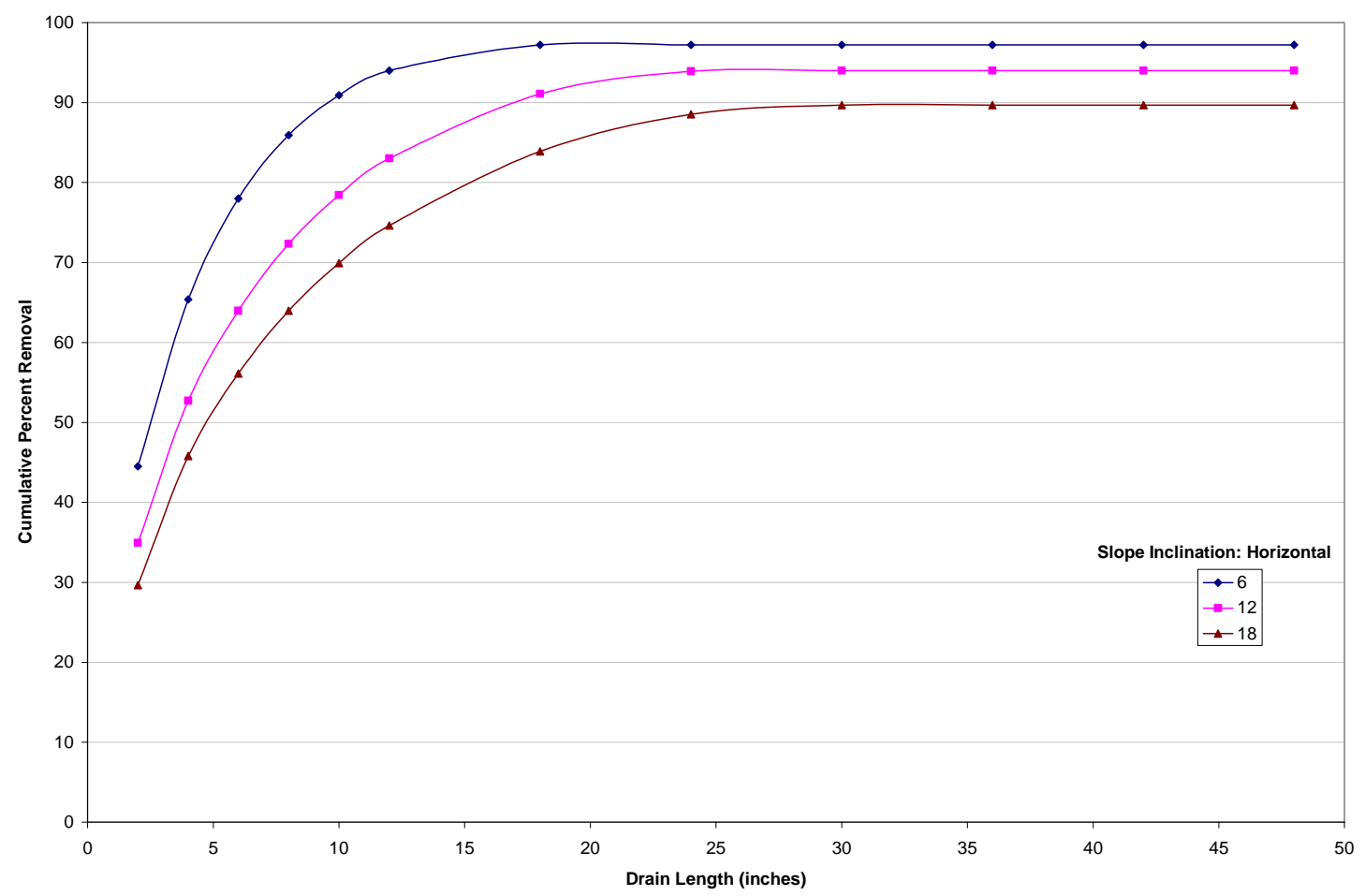

Figure 4.9: Influence of trench spacing. 


\section{CHAPTER 5}

\section{RESULTS AND DISCUSSIONS: FIELD CONDITIONS}

\subsection{Introduction}

After performing the analyses on computer models for laboratory conditions, numerical analysis was performed to simulate field conditions. The laboratory model had the dimensions in the order of inches, but to predict the behavior of the drains under field conditions, tests were conducted for the models with corresponding dimensions. A total of 24 models have been chosen with different values of longitudinal length, trench spacing and saturated water column depth. Numerical analysis was performed for each model with three different soil samples.

After running a series of tests, numerical data was collected. This data was then analyzed to determine the relations between various parameters that influence the efficiency of the drains. Description about the models considered and the influence of each parameter on drain efficiency is discussed in the following section.

\subsection{Models Considered}

The geometry of the 24 models which were considered for this part of the research work can be seen in the Table 5.1. All the models have the dimensions in order of feet. 
Table 5.1 Dimensions of the models used for field conditions.

\begin{tabular}{|c|c|c|c|c|}
\hline MODEL NO. & LENGTH $(\mathrm{ft})$ & HALF TRENCH ( ft ) & WATER LEVEL $(\mathrm{ft})$ & SLOPE INCLINATION \\
\hline 1 & 48 & 48 & 12 & $3: 1$ \\
\hline 2 & 48 & 48 & 12 & $2: 1$ \\
\hline 3 & 48 & 48 & 24 & $3: 1$ \\
\hline 4 & 48 & 48 & 24 & $2: 1$ \\
\hline 5 & 48 & 24 & 12 & $3: 1$ \\
\hline 6 & 48 & 24 & 12 & $2: 1$ \\
\hline 7 & 48 & 24 & 24 & $3: 1$ \\
\hline 8 & 48 & 24 & 24 & $2: 1$ \\
\hline 9 & 48 & 12 & 12 & $3: 1$ \\
\hline 10 & 48 & 12 & 12 & $2: 1$ \\
\hline 11 & 48 & 12 & 24 & $3: 1$ \\
\hline 12 & 48 & 12 & 24 & $2: 1$ \\
\hline 13 & 96 & 48 & 24 & $3: 1$ \\
\hline 14 & 96 & 48 & 24 & $2: 1$ \\
\hline 15 & 96 & 48 & 36 & $3: 1$ \\
\hline 16 & 96 & 48 & 36 & $2: 1$ \\
\hline 17 & 96 & 24 & 24 & $3: 1$ \\
\hline 18 & 96 & 24 & 24 & $2: 1$ \\
\hline 19 & 96 & 24 & 36 & $3: 1$ \\
\hline 20 & 96 & 24 & 36 & $2: 1$ \\
\hline 21 & 96 & 12 & 24 & $3: 1$ \\
\hline 22 & 96 & 12 & 24 & $2: 1$ \\
\hline 23 & 96 & 12 & 36 & $3: 1$ \\
\hline 24 & 96 & 12 & 36 & $2: 1$ \\
\hline
\end{tabular}

\subsection{Location and geometry of the drains}

In the laboratory model, a total of 6 drains of lengths 6 in $(15.2 \mathrm{~cm}), 6$ in, 6 in, 6 in, 12 in $(30.5 \mathrm{~cm})$ and 12 in were constructed along the length of the slope (Figure 3.1). In the numerical model there are no drains with fixed lengths. However, fixed lengths of drains were considered to be present in order to study the influence of various parameters on the total drain efficiency.

Figure 5.1 and Figure 5.2 show the location and dimensions of the drains that were considered in the numerical model. Figure 5.2 corresponds to the slope with $48 \mathrm{ft}$ $(14.6 \mathrm{~m})$ length of slope and Figure 5.1 corresponds to the slope with $96 \mathrm{ft}(29.3 \mathrm{~m})$ length. The drains that are close to the water reservoir are shorter in length when compared to the drains near the bottom of the slope because the drains near the water reservoir were found to have more influence on the drain efficiency than the others. 
Note: $1 \mathrm{ft}=0.3048 \mathrm{~m}$

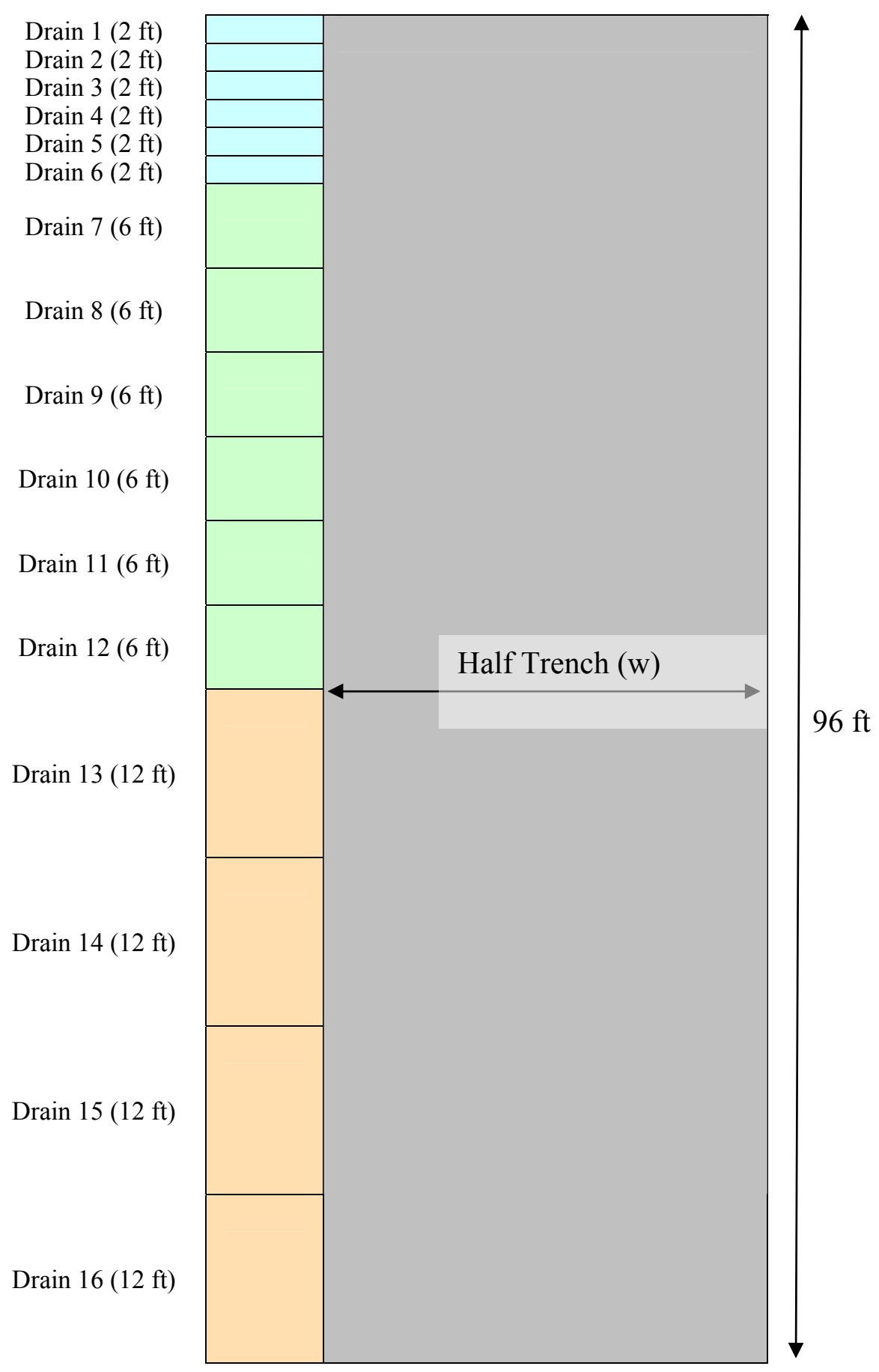

Figure 5.1: Layout of the Computer model for the slope with a length of $96 \mathrm{ft}$. 
Note: $1 \mathrm{ft}=0.3048 \mathrm{~m}$

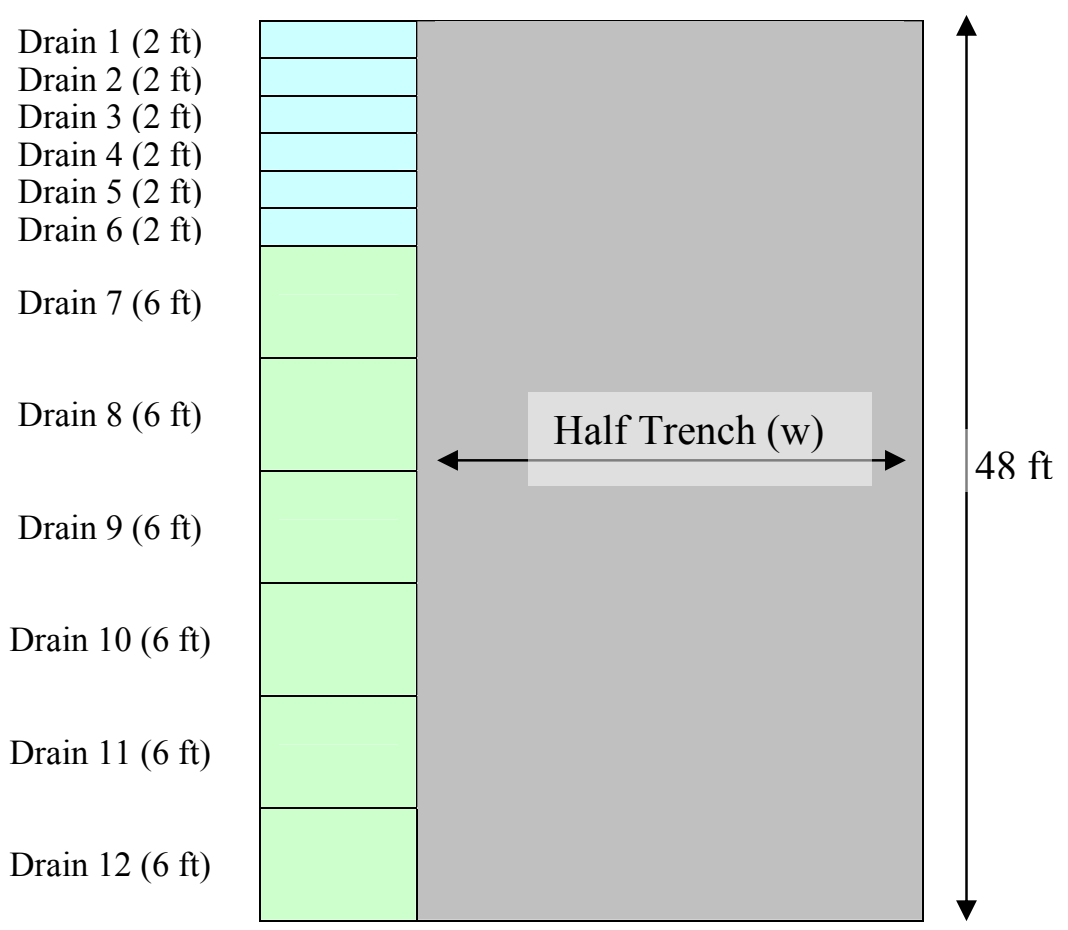

Figure 5.2: Layout of the Computer model for the slope with a length of $48 \mathrm{ft}$. 


\subsection{Influence of location of the drains}

Figure 5.3 shows the percent drainage for each drain for the numerical model with half trench spacing of $48 \mathrm{ft}(14.6 \mathrm{~m})$, water level of $12 \mathrm{ft}(3.7 \mathrm{~m})$ and inclination angle of 3:1. It is clear from Figure 5.3 that the first drain contributed to the biggest water removal and the drainage decreased with the distance along the slope. The last two drains though were longest of all the drains contributed less than $5 \%$ to the total drainage achieved. However, the cost involved in constructing these drains will be much higher than the cost of construction of the first few drains, as the length of these drains is very high. Percentage drainage for the $6^{\text {th }}$ drain is higher than that of the $5^{\text {th }}$ drain, because the length of this drain is higher than that of the previous drain (refer Figure 5.2 for the sizes of drains). Nearly $50 \%$ of water was not drained in this case. However, when the trench spacing was decreased, the percentage of drainage increased considerably. Appendix E shows similar plots for all of the remaining models used in this research work.

The following observations can be made from this section:

1. First drain provided the biggest water removal. This was true for all the models that were analyzed in this research.

2. The amount of seepage water removed from the soil decreases as the drains move further downstream.

3. To decide the length of the drains that has to be constructed, a compromise should be made between the desired efficiency and the cost. 


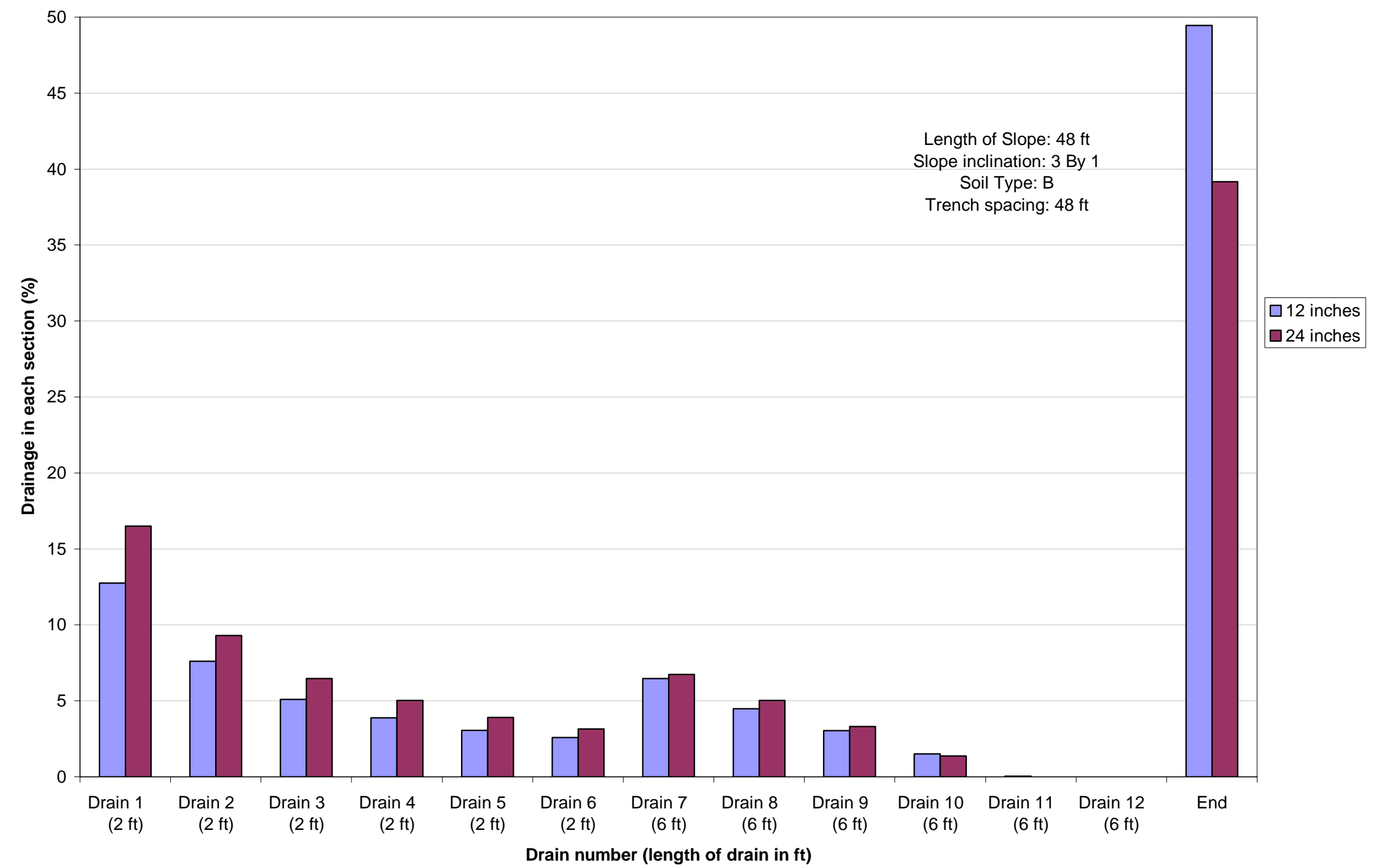

Figure 5.3: Influence of location of drains on seepage. 


\subsection{Influence of length of the slope}

This section investigates the influence of length of the slope on drain efficiency for a slope with given value of trench spacing, inclination angle and water level. In Figure 5.4 the results for the two models with different lengths (96 ft $(29.3 \mathrm{~m})$ and $48 \mathrm{ft}$ $(14.6 \mathrm{~m}))$ are compared. Both the models have same trench spacing, slope inclination and water level. As expected, the slope which has longer length contributed to the biggest water removal. 


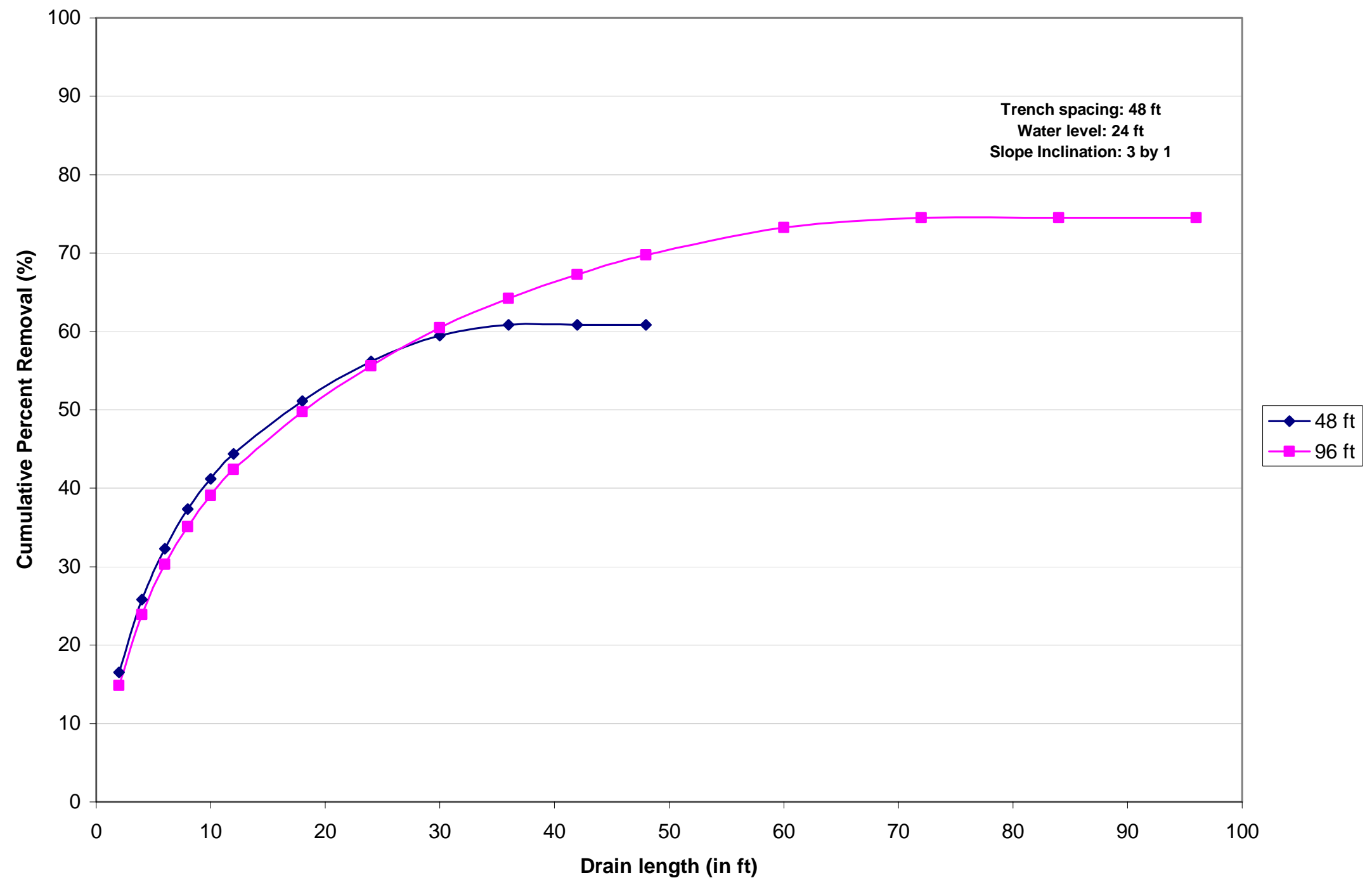

Figure 5.4: Influence of Length of slope on seepage. 


\subsection{Influence of inclination angle}

Figure 5.5 shows the variation of Cumulative Percentage Removal (CPR-see section 4.2) along the length of the slope for the models 1 and 2 (see Table 5.1). Both the models have the same slope length, trench width and saturation depth. Figure 5.5 shows that $50 \%$ of total drainage was obtained for model with slope inclination angle of 3:1, but only $45 \%$ for the model with inclination angle of 2:1. There is a $6 \%$ difference in the total drainage and $3 \%$ difference for the first 3 drains (up to $6 \mathrm{ft}(1.8 \mathrm{~m}$ ) in length).

Clearly as the inclination angle increases, the overall efficiency of the drains decreases. However, the decrease in efficiency is relatively small for the first few drains. Appendix $\mathrm{G}$ shows the results on the influence of inclination angle for the other models. It is evident from Appendix $G$ that:

1. Inclination angle of the slope decreases the overall efficiency of the longitudinal drains.

2. Decrease in the efficiency of the drains is relatively less for the first few drains.

3. The influence of the inclination angle on the drain efficiency becomes more prominent as the trench spacing increases. In the Appendix G, the Figures G.7 and G.11 correspond to the models with trench spacing of $48 \mathrm{ft}(14.6 \mathrm{~m})$ and $12 \mathrm{ft}(3.7$ $\mathrm{m})$, respectively. In Figure G. 8 the difference in Cumulative Percentage Removal (CPR) is 1.568, whereas in Figure G.7 it is 3.484 .

4. The influence of the inclination angle on the drain efficiency becomes less prominent as the saturation depth increases. In the Appendix G, the Figures G.7 and G.8, correspond to the models with saturation depth of $36 \mathrm{ft}(11 \mathrm{~m})$ and $24 \mathrm{ft}$ (7.3 m), respectively. In Figure G.7 the difference in Cumulative Percentage Removal (CPR) is 3.484, whereas in Figure G.8 it is 4.701. 


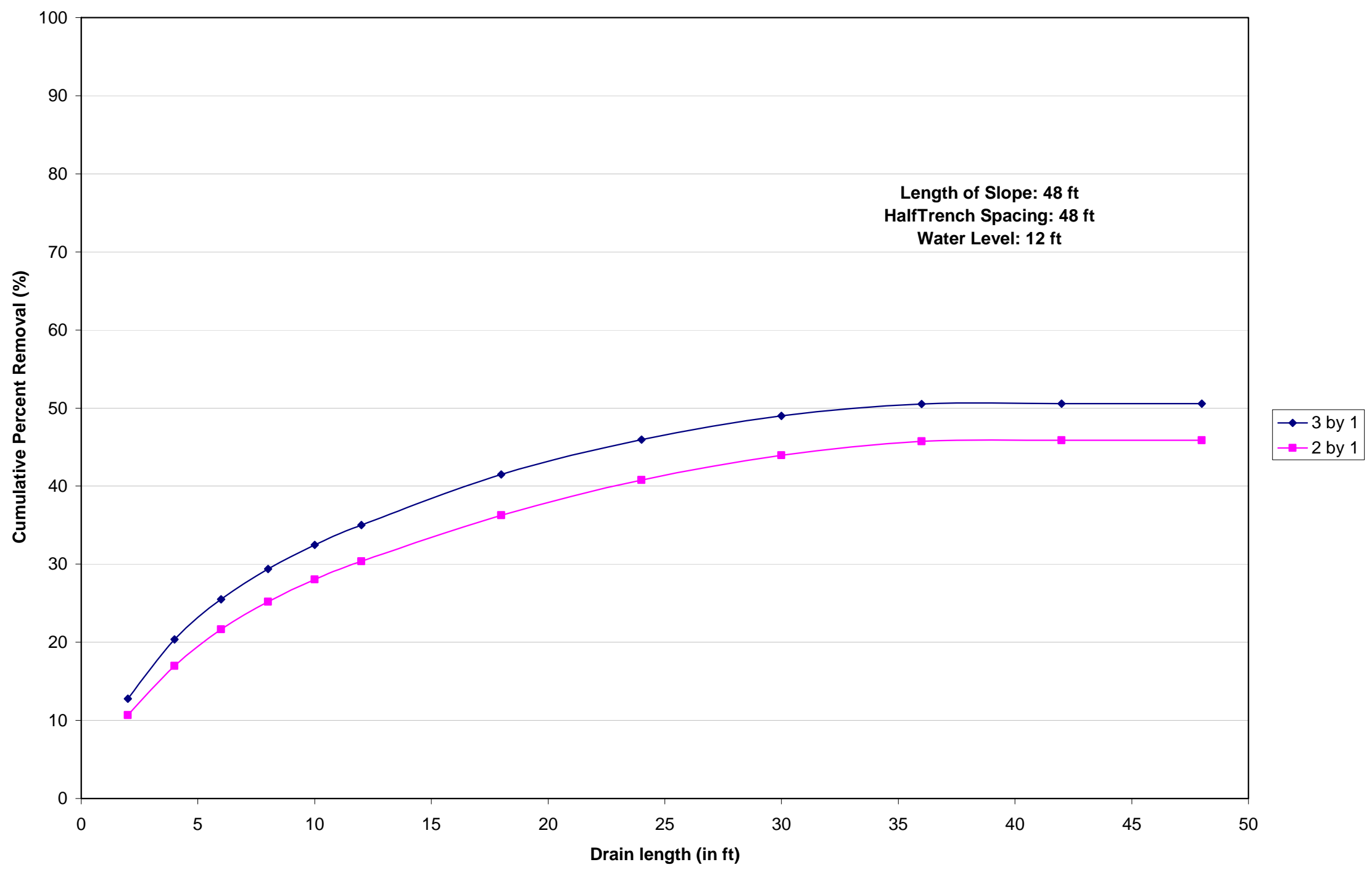

Figure 5.5: Influence of inclination angle on seepage. 


\subsection{Influence of trench spacing}

Figures 5.6 and 5.7 illustrate the variation of Cumulative Percentage Removal (CPR-see section 4.2) along the length of the slope for three different values of trench spacing. Figure 5.6 shows the results for the slope angle 3:1 and Figure 5.7 for the slope angle 2:1. Both models have the same dimensions and saturated water column depth. For both cases shown here and all the cases shown in the Appendix $\mathrm{H}$, the overall efficiency of the drains increases as the trench width decreases, because it is easier for the seepage water flow to be diverted when the trench width is small.

In Figure 5.6, it can be seen that when the trench spacing is reduced from $48 \mathrm{ft}$ $(14.6 \mathrm{~m})$ to $24 \mathrm{ft}(7.3 \mathrm{~m})$, there is an overall increase of $11.5 \%$ in the total seepage (from $39.3 \%$ to $50.8 \%)$. When the trench spacing is reduced from $24 \mathrm{ft}(7.3 \mathrm{~m})$ to $12 \mathrm{ft}(3.7 \mathrm{~m})$, the overall increase in CPR is $3.5 \%$ (from $50.8 \%$ to $54.3 \%$ ). Figure 5.7 corresponds to the slope with the same dimensions but with a slope angle of $2: 1$. When the trench spacing is reduced from $48 \mathrm{ft}(14.6 \mathrm{~m})$ to $24 \mathrm{ft}(7.3 \mathrm{~m})$, the overall increase in CPR is 15 $\%$ (from $36.9 \%$ to $49.6 \%$ ). When the trench spacing is reduced from $24 \mathrm{ft}(7.3 \mathrm{~m})$ to $12 \mathrm{ft}$ (3.7 m), the overall increase in CPR is nearly $4.3 \%$ (from $49.6 \%$ to $53.9 \%$ ).

Following observations are made from the results obtained:

1. Trench width has a significant influence on the overall efficiency of the drains.

2. The influence of trench width on the drain efficiency becomes more prominent as the inclination angle of the slope increases.

Even though the drain efficiency can be increased by decreasing the space between the drains, it may not be possible to do so in every case. Taking the cost issues, labor, construction time and other factors into consideration, the optimum value for the trench width must be evaluated. Appendix $\mathrm{H}$ shows the influence of the trench width for the other models. 


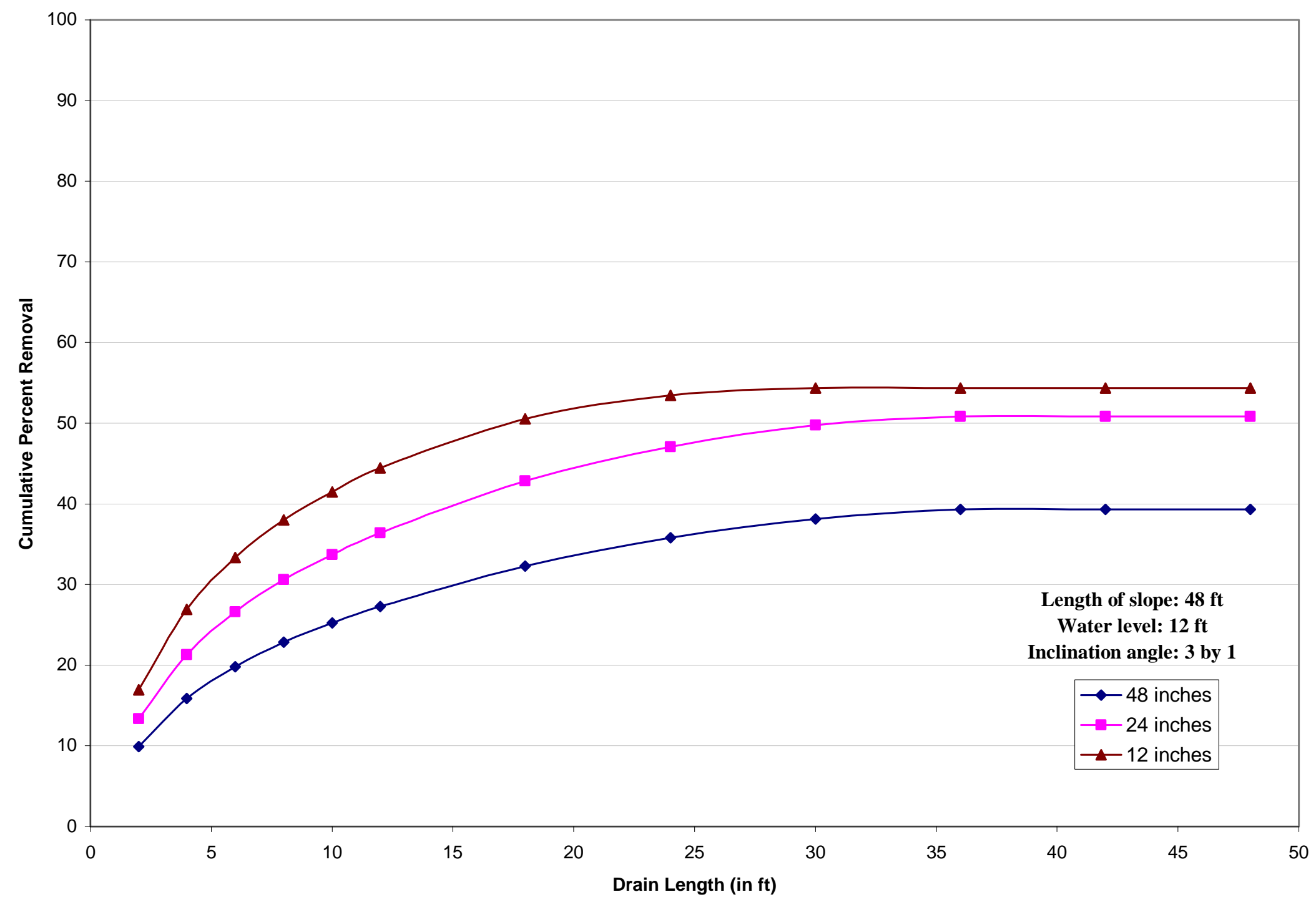

Figure 5.6: Influence of trench spacing on seepage when slope inclination is 3:1. 


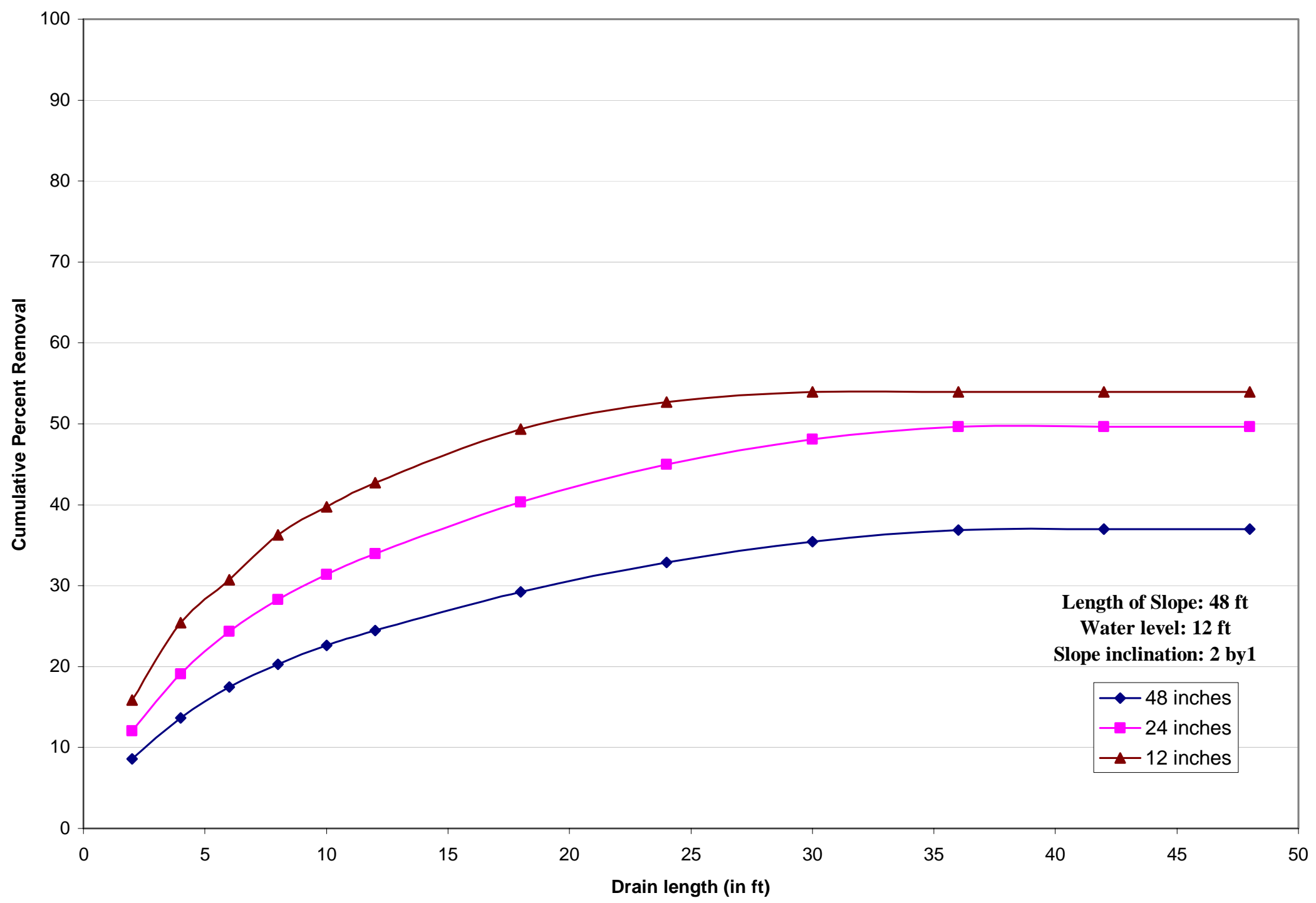

Figure 5.7: Influence of trench spacing on seepage when slope inclination is 2:1. 


\subsection{Influence of soil type}

Figure 5.8 shows the influence of soil type on the Cumulative Percentage Removal (CPR-see section 4.2) along the longitudinal direction of the slope. Figure 5.8 shows that, CPR along the length of the slope is independent on the hydraulic conductivity of the soil. Even though the CPR did not change with the soil type, the volumes of drainage were influenced by the soil type. Figure 5.9 shows the relationship between the flow rate of the drainage and the hydraulic conductivity of the soil.

Following observations can be made from Figure 5.9:

1. Hydraulic conductivity has little or no influence on CPR along the length of the slope.

2. Hydraulic conductivity is directly proportional to the volume of the drainage.

In the above experiments, the soil was assumed to be homogenous (i.e., the vertical and horizontal conductivities are equal). 


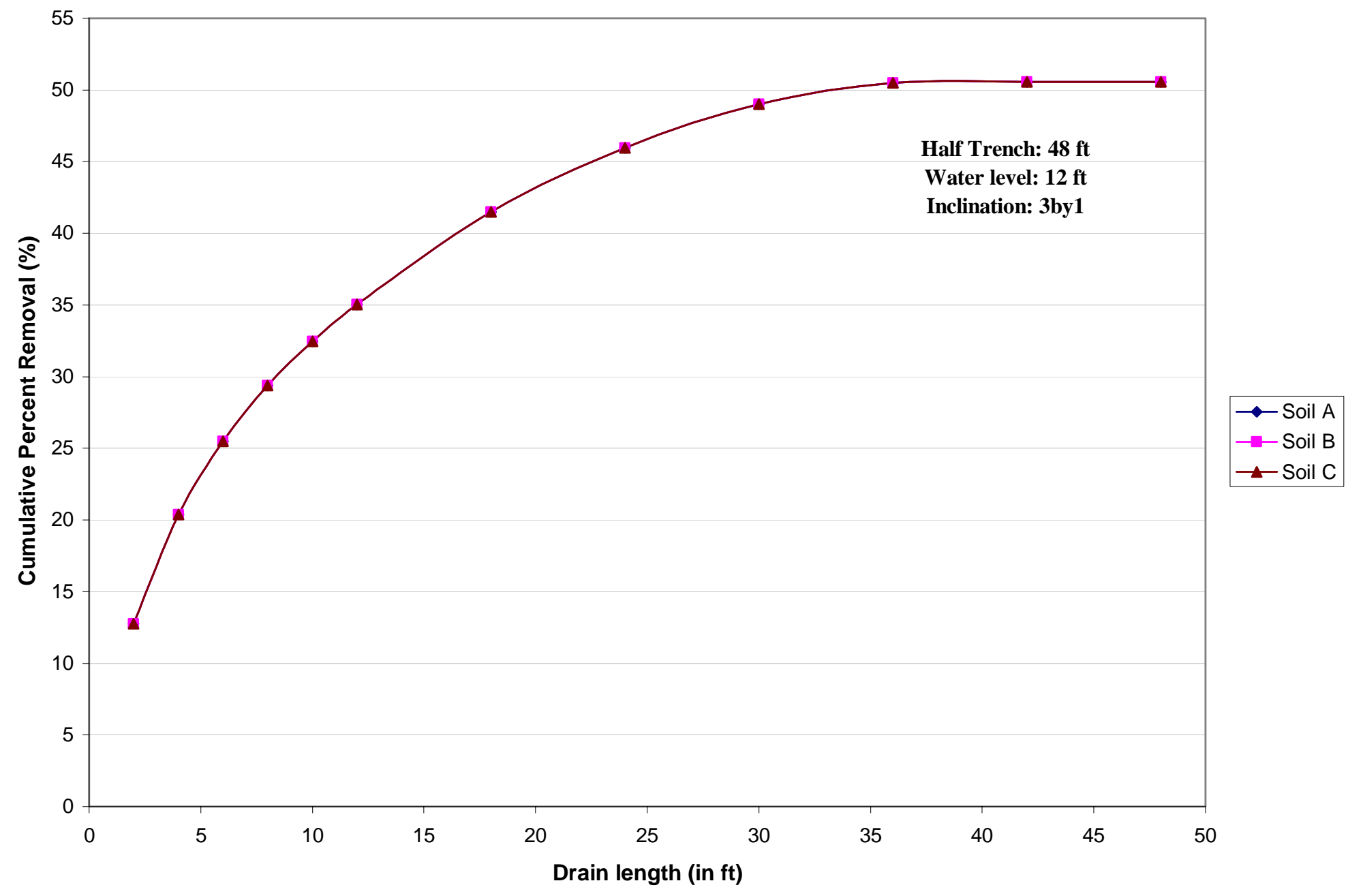

Figure 5.8: Influence of hydraulic conductivity on seepage 


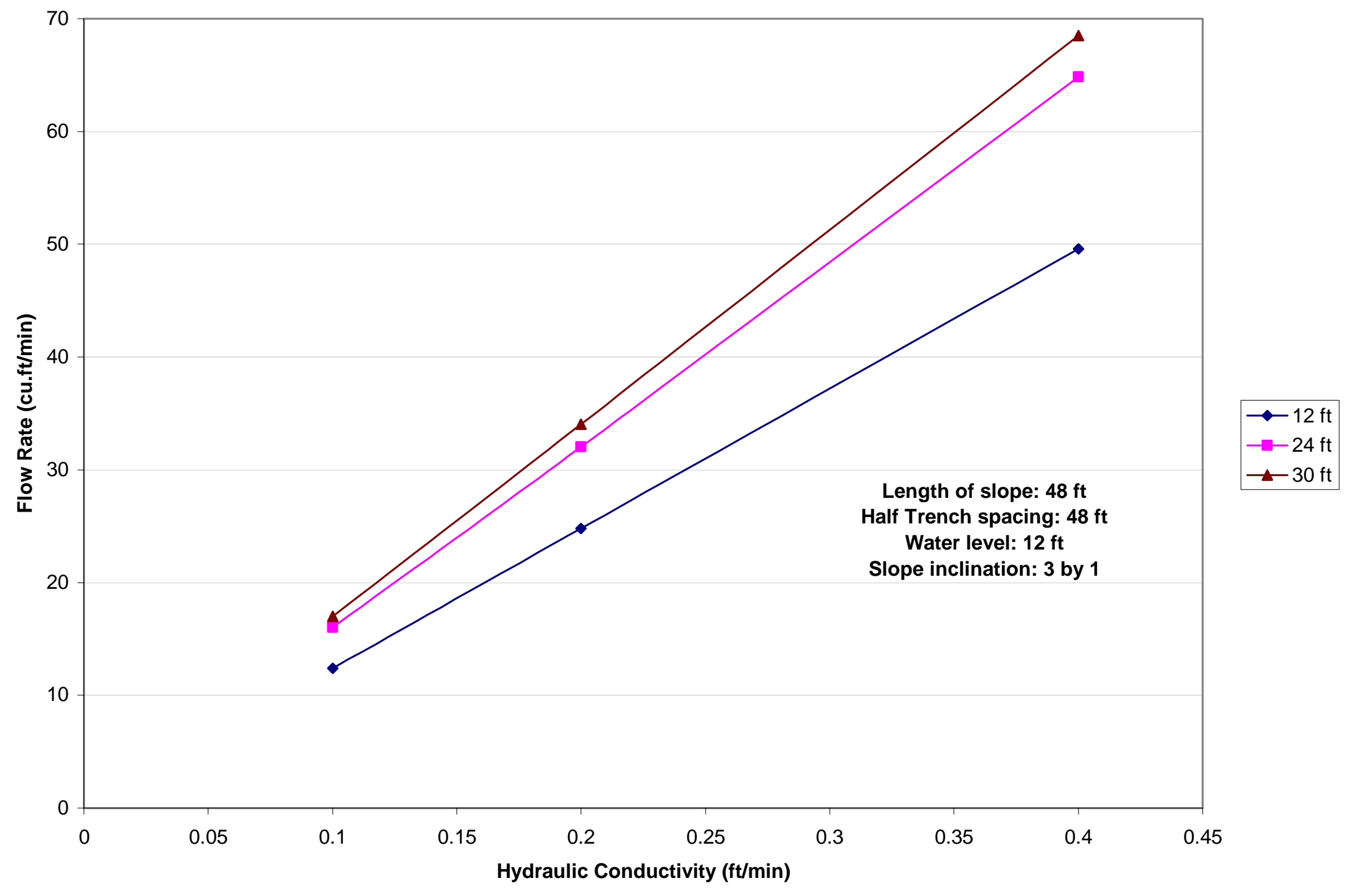

Figure 5.9: Influence of hydraulic conductivity on Volumetric Flow. 


\subsection{Transient State Analysis}

After activating the drains, water starts to flow into them. Initially, the flow rate of the water into these drains changes with time. The rate of change in flow rate decreases gradually and finally becomes zero. This point of time indicates the end of the transient state and the initiation of the steady state. It is important to know the duration of the transient state, as it indicates the time needed for the drains to become completely functional. Therefore, the transient behavior for various angles of inclination, trench spacing and soil types was investigated in this research.

It is difficult to find the exact point of time at which the system reaches the steady state, since a negligible difference in flow rate may always exist between any two points of time. Therefore, a criterion to ascertain the duration of the transient state was developed. According to this criterion, the system reaches the steady state when the flow rate at any point of time reaches a value which is $99.5 \%$ or more than the flow rate during the previous hour. The influence of various parameters on the duration of the transient state is discussed in the following section.

\subsubsection{Influence of soil type}

Figure 5.10 illustrates the influence of soil type on the duration of transient state. The number of hours passed after the drains are activated is plotted on the $\mathrm{X}$-axis and the ratio between the flow rate at the current hour to the flow rate at the previous hour is plotted on the Y-axis. Theoretically, when this ratio attains a value of ' 1 ', steady state is reached. However, the numerical solution came very close to ' 1 ', but never reached the precise value. Figure 5.10 shows the transient time for three soil types. All the three models had same length, water level, trench spacing and inclination angle. 
It can be seen that, for the soil with the highest value of hydraulic conductivity (Soil A), the drainage system reaches the steady state at a higher rate. The system with the highest value of ' $\mathrm{K}$ ' reaches the steady state in 46 hours. The system with soil sample $\mathrm{B}$ reaches the steady state in 55 hours, and the system with least value of ' $\mathrm{K}$ ' (Soil C) takes 64 hours to reach the steady state condition. 


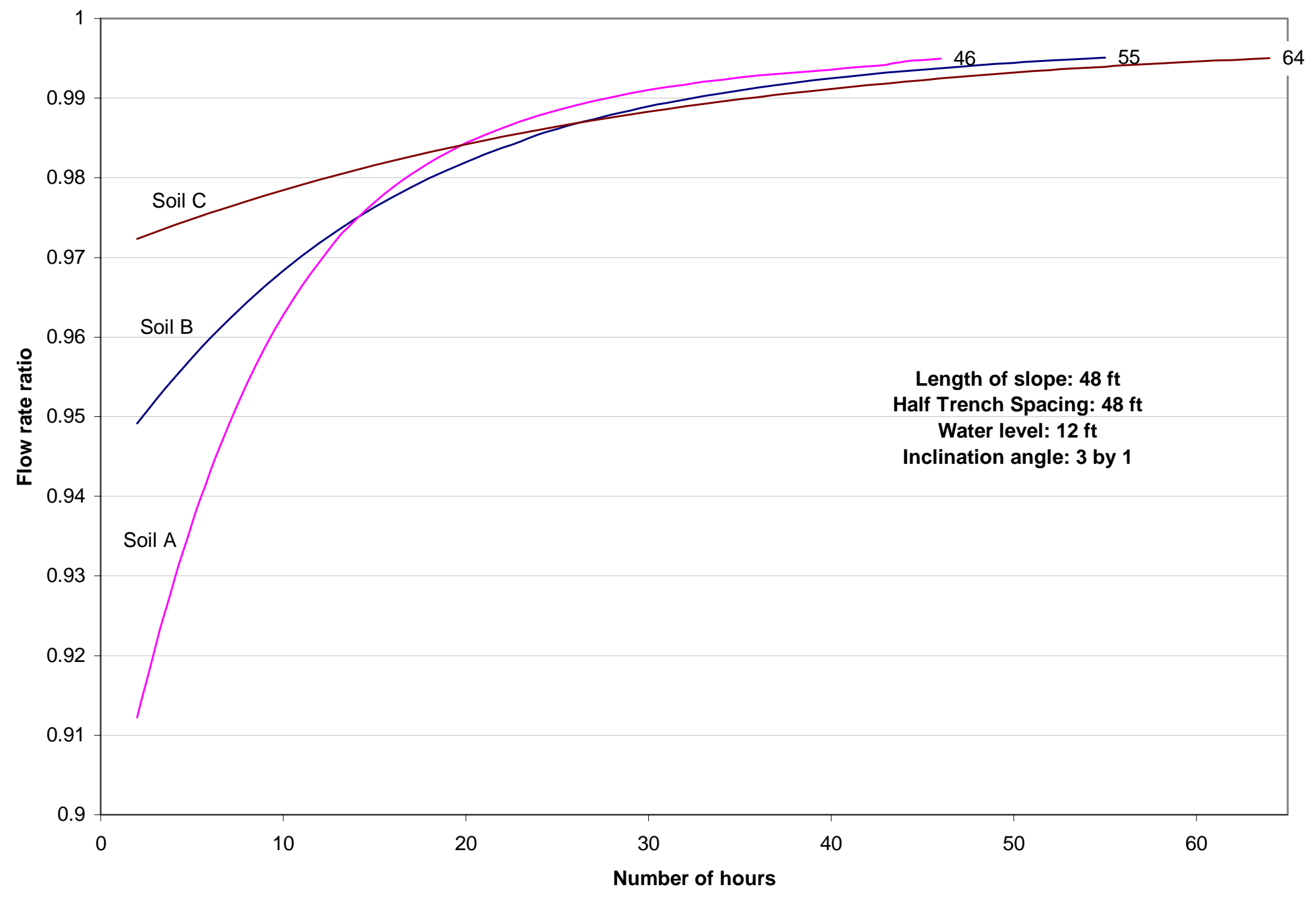

Figure 5.10: Influence of hydraulic conductivity on duration of transient state. 


\subsubsection{Influence of Trench Spacing}

Figure 5.11 shows the influence of trench spacing on the transient behavior of the slope. Figure 5.11 shows the transient time for three models with trench spacings of $48 \mathrm{ft}$ $(14.6 \mathrm{~m}), 24 \mathrm{ft}(7.3 \mathrm{~m})$ and $12 \mathrm{ft}(3.7 \mathrm{~m})$. All the models used in this section have the same length, inclination angle, water level and soil type. It can be seen from the Figure 5.11 that the trench spacing has little or no influence on the flow behavior in transient state condition. Regardless of the trench spacing, the flow behavior remains unchanged.

The influence of trench spacing on the transient behavior should not be confused with the influence of trench spacing on the effectiveness of longitudinal drains. Trench spacing has a significant influence on the effectiveness of the drains. This section focuses on the changes in flow pattern before the steady state is reached. 


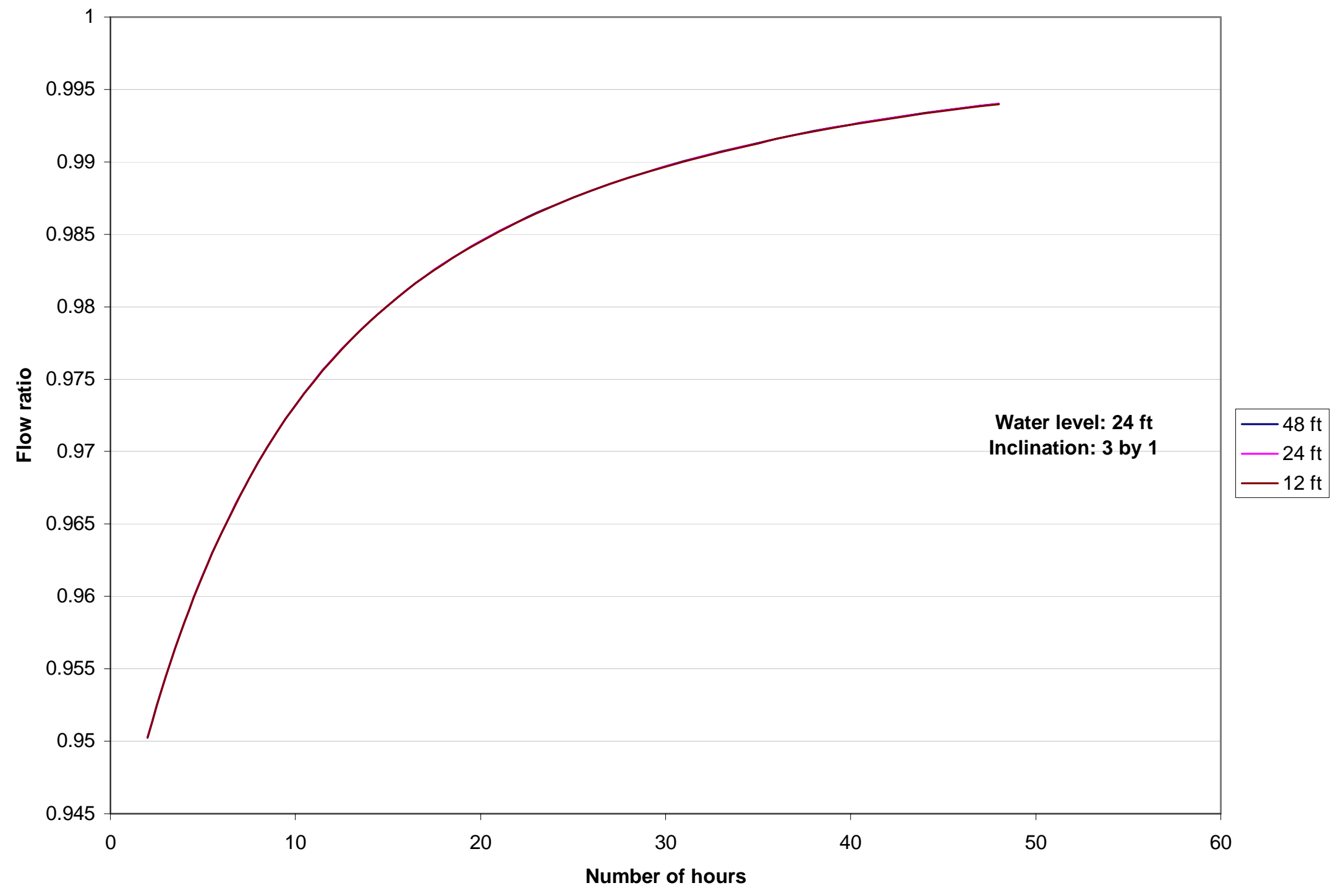

Figure 5.11: Influence of trench width on duration of transient state. 


\subsubsection{Influence of saturated water column depth}

Water level has a significant influence on the flow pattern in the transient state. Figure 5.12 shows the transient time for the models with water levels of $24 \mathrm{ft}(7.3 \mathrm{~m})$ and $12 \mathrm{ft}(3.7 \mathrm{~m})$. Both the models have same length, trench spacing, inclination angle and soil type. The model with the lower value of water level reaches the steady state earlier. 


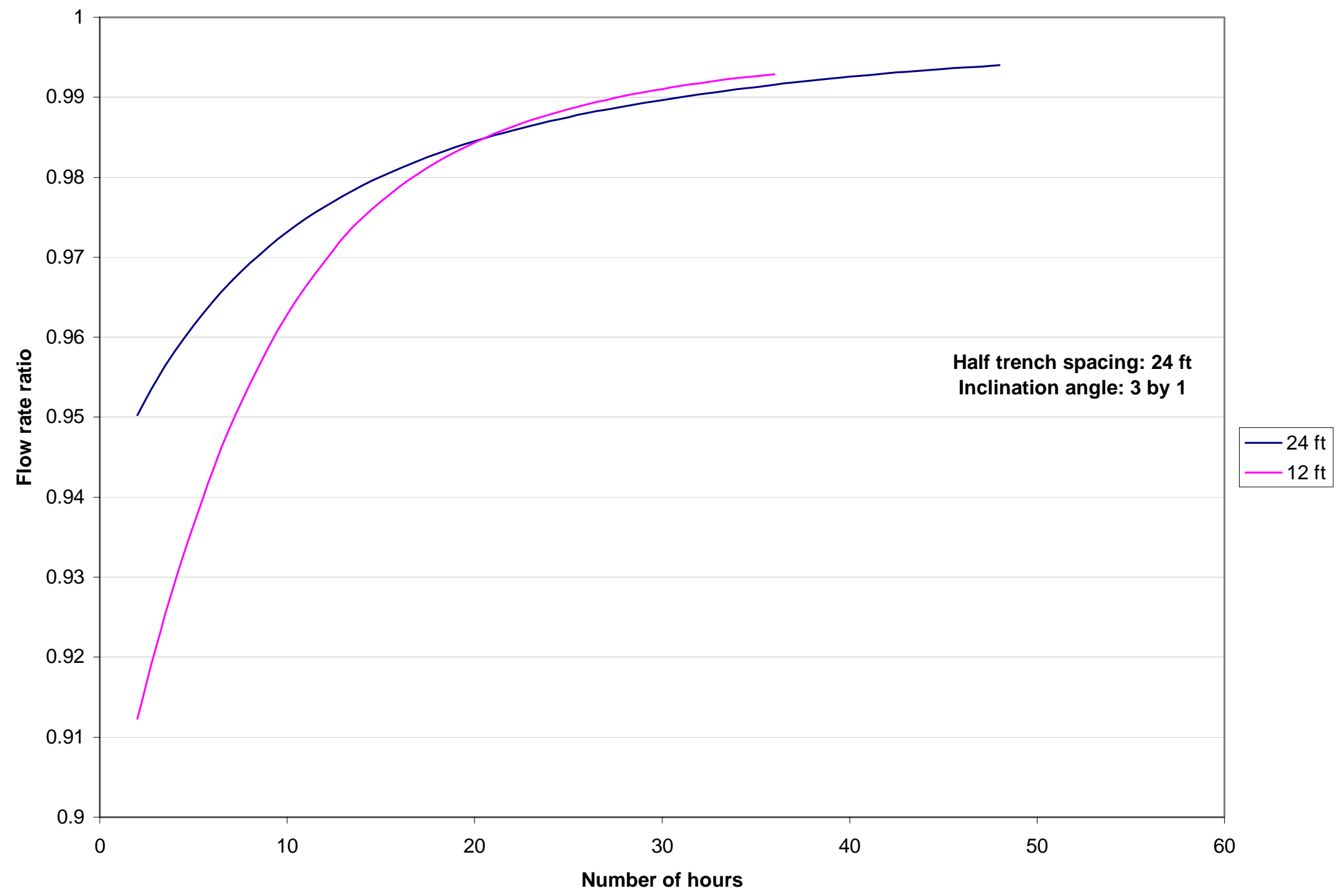

Figure 5.12: Influence of water level on duration of transient state. 


\subsubsection{Influence of inclination angle}

Figure 5.13 shows the transient time for two different angles of inclination (3:1 and 2:1). As seen in the Figure 5.13, inclination angle has no influence on the duration of transient time. Although the slope angle increases the amount of water flow, it has no influence on the duration of the transient time. 


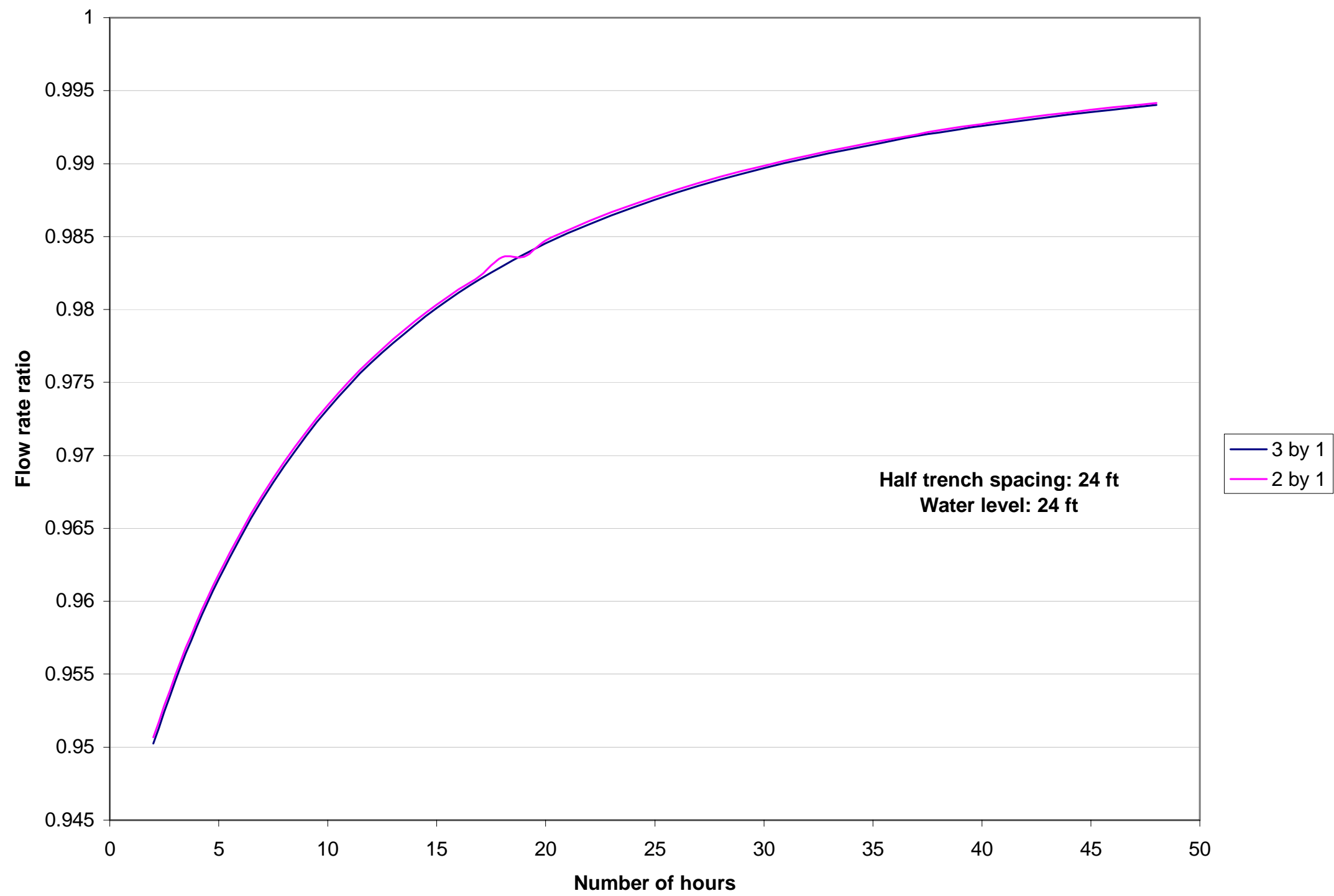

Figure 5.13: Influence of inclination angle of slope on duration of transient state. 


\subsection{Influence of deactivating the first few drains}

The influence of deactivating the first few drains near the upstream water reservoir is investigated in this section. By deactivating the first few drains, the amount of flow in the active drains adjacent to the deactivated drains has increased considerably. But the overall efficiency of the longitudinal drains has reduced slightly. Below are the results obtained from models with and without deactivated drains.

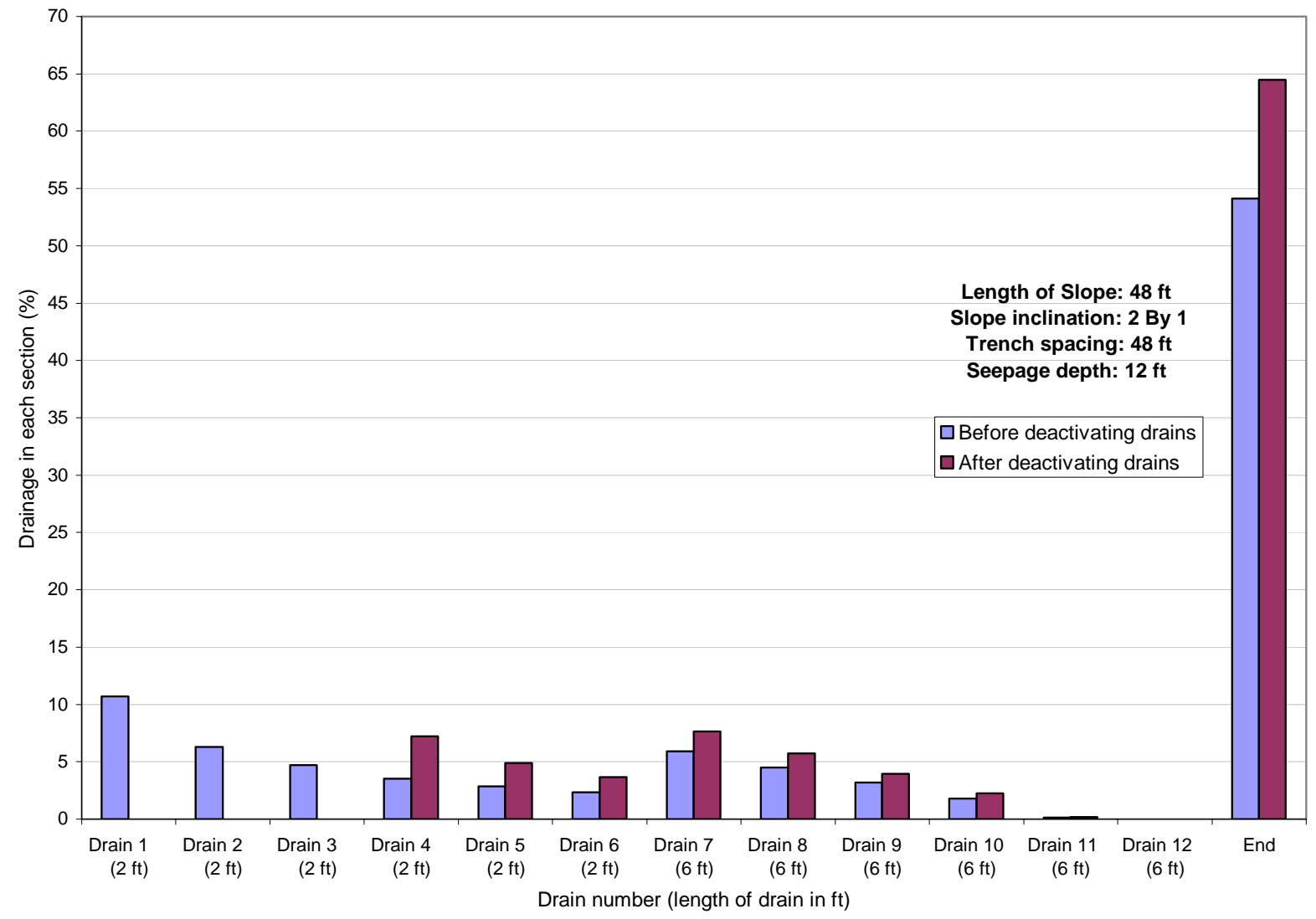

Figure 5.14: Influence of deactivating the first few drains in the steady state. 


\section{CHAPTER 6}

\section{CONCLUSIONS AND RECOMMENDATIONS}

\subsection{General Conclusions}

After analyzing more than 130 computer models, following conclusions can be drawn:

Longitudinal drains are very effective in reducing the seepage in slopes.

The first half of the drains is more effective in reducing the seepage than the second half. The first and second drains in most cases collect more than $50 \%$ of the total drainage.

\subsection{Influence of Slope Angle}

\section{Steady State:}

$>$ The slope inclination angle reduces the overall effectiveness of the longitudinal drain.

Decrease in the efficiency of the drains is relatively small (less than $10 \%$ ) in most of the cases.

\section{Transient State:}

Inclination angle of the slope has little or no influence on the duration of transient state.

\subsection{Influence of Trench Spacing}

\section{Steady State:}

The effectiveness of longitudinal drains is inversely proportional to the spacing between trenches. 
The influence of trench width on the drain efficiency becomes more prominent as the inclination of slope increases.

\section{Transient State:}

Trench width does not influence the duration of transient time.

\subsection{Influence of Seepage Depth}

\section{Steady State:}

The effectiveness of longitudinal drains is proportional to the water depth.

\section{Transient State:}

The duration of transient time increases with increase in seepage depth.

\subsection{Influence of Soil type}

Steady State:

> The hydraulic conductivity of the soil has little or no effect on the effectiveness of the longitudinal drains (i.e. Cumulative Percentage Removal (CPR-see section 4.2)).

\section{Transient State:}

The soil with higher value of hydraulic conductivity reaches the steady state faster.

\subsection{Recommendations}

The effect of anisotropy of soil on the performance of the drains should be investigated.

The effect of non-homogenous soil medium on the performance of the drains should be determined.

$>$ Wide range of geometric parameters should be considered to cover field conditions. 


\section{REFERENCES}

Cedergren, H.R. (1977) Seepage, Drainage, and Flow Nets. Wiley, New York.

Cruden, D.M. (1991) A Simple Definition of a Landslide. Bulletin of the International Association of Engineering Geology, Vol 43, p 27-29.

Dai, F.C., Lee C.F. and Ngai Y.Y. (2001) Landslide risk assessment and management: an overview. Engineering Geology, Vol 64, p 65-87.

Das, B.M. (1999) Principles of Foundation Engineering. PWS Publishing Company, fourth edition, Boston.

Das, B.M. (1998) Principles of Geotechnical Engineering. PWS Publishing Company, fourth edition, Boston.

GMS (2002) Groundwater Modeling Systems, Reference Manual for version 4.0, Environmental Modeling Systems, Inc., Utah.

Haitjema, H.M., Kelson, V. and Lange, W.D. (2001) Selecting MODFLOW Cell Sizes for Accurate Flow Fields. Groundwater, Vol. 39, Issue 6, p 931.

Harbaugh, A.W., Banta, E.R., Hill, M.C. and McDonald, M.G. (2000) MODFLOW-2000, The U.S. Geological Survey modular groundwater model: User guide to modularization concepts and the Groundwater Flow Process. U.S. Geological Survey Open-File Report 00-92, p121.

Jones, N.L., Budge, J., Lemon, A.M. and Zundel, A.M. (2002) Generating MODFLOW grids from boundary representation solid models. Groundwater, Vol. 40, p194.

Leake, S.A., Lawson, P.W., Lilly, M.R. and Claar, D.V. (2001) Assignment of boundary conditions in embedded groundwater. Groundwater, Vol. 36, Issue 4, p 621. 
Nair, S.K. and Wilsnack, M.M. (1998) A Comparison of Two Approaches to Simulating Lake-Groundwater Interactions with MODFLOW. Proceedings of MODFLOW 98, Golden, Colorado, p 871 - 878.

Ricardo, C.K.L. Seepage in earth slopes with longitudinal drainage trenches. M.S.Thesis, Department of Civil and Environmental Engineering, West Virginia University.

Stanic, B. (1984) Influence of Drainage Trenches on Slope Stability. Journal of Geotechnical Engineering, ASCE, Vol 110(11), p 1624-1636.

Stuad, B.T. (2000) Seepage through longitudinal drainage trenches. M.S. Thesis, Department of Civil and Environmental Engineering, West Virginia University.

Wang, H.F. and Anderson, M.P. (1982) Introduction to Groundwater Modeling. W.H. Freeman and Company, San Francisco. 


\section{APPENDIX A}

Seepage removal under Laboratory conditions for

\section{Soil B}

(For different values of trench spacing, slope inclination angle and saturation depth.) 


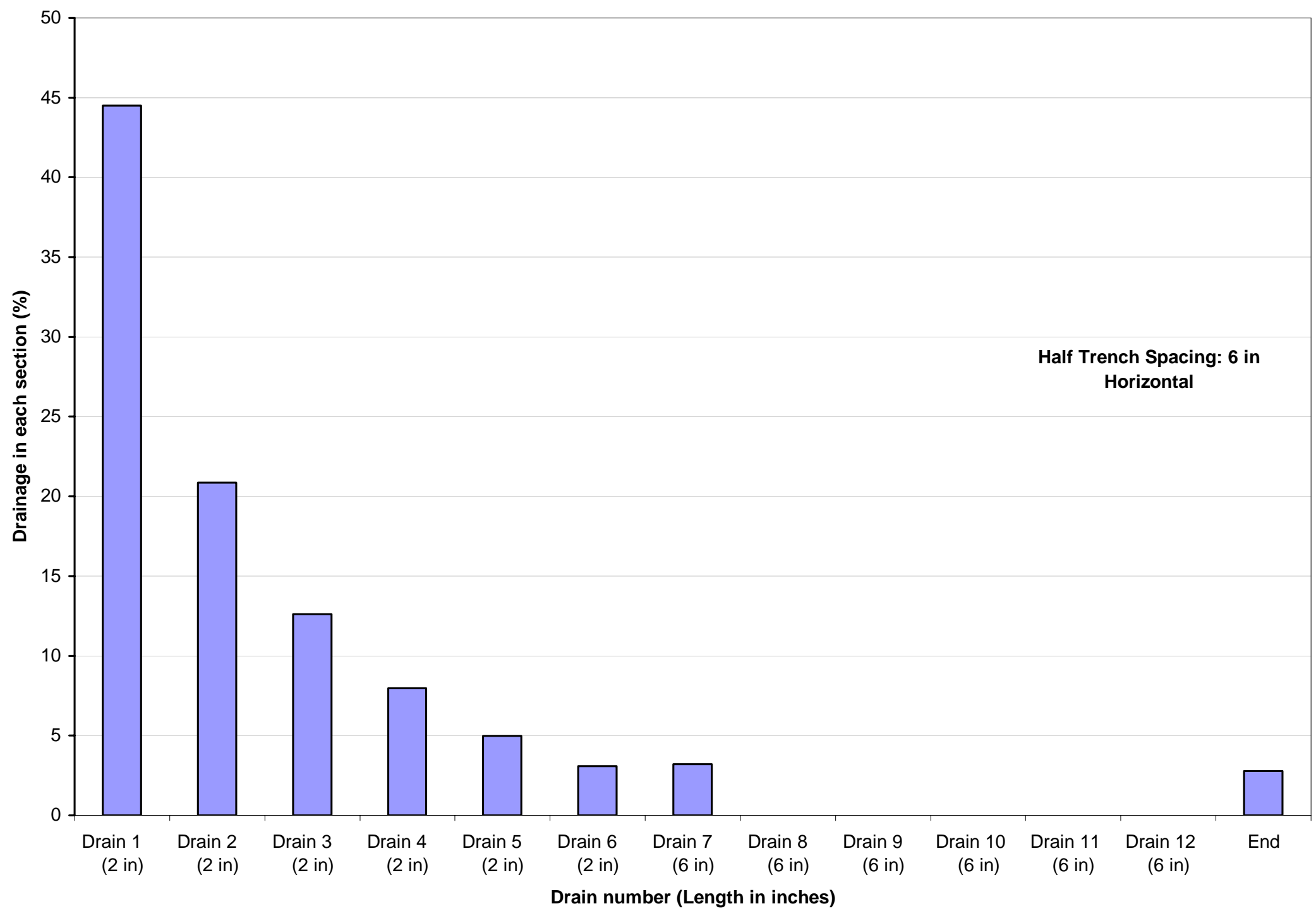

Figure A.1: Percent Seepage for Soil B ( $\mathrm{w}=6$ in, and slope is horizontal). 


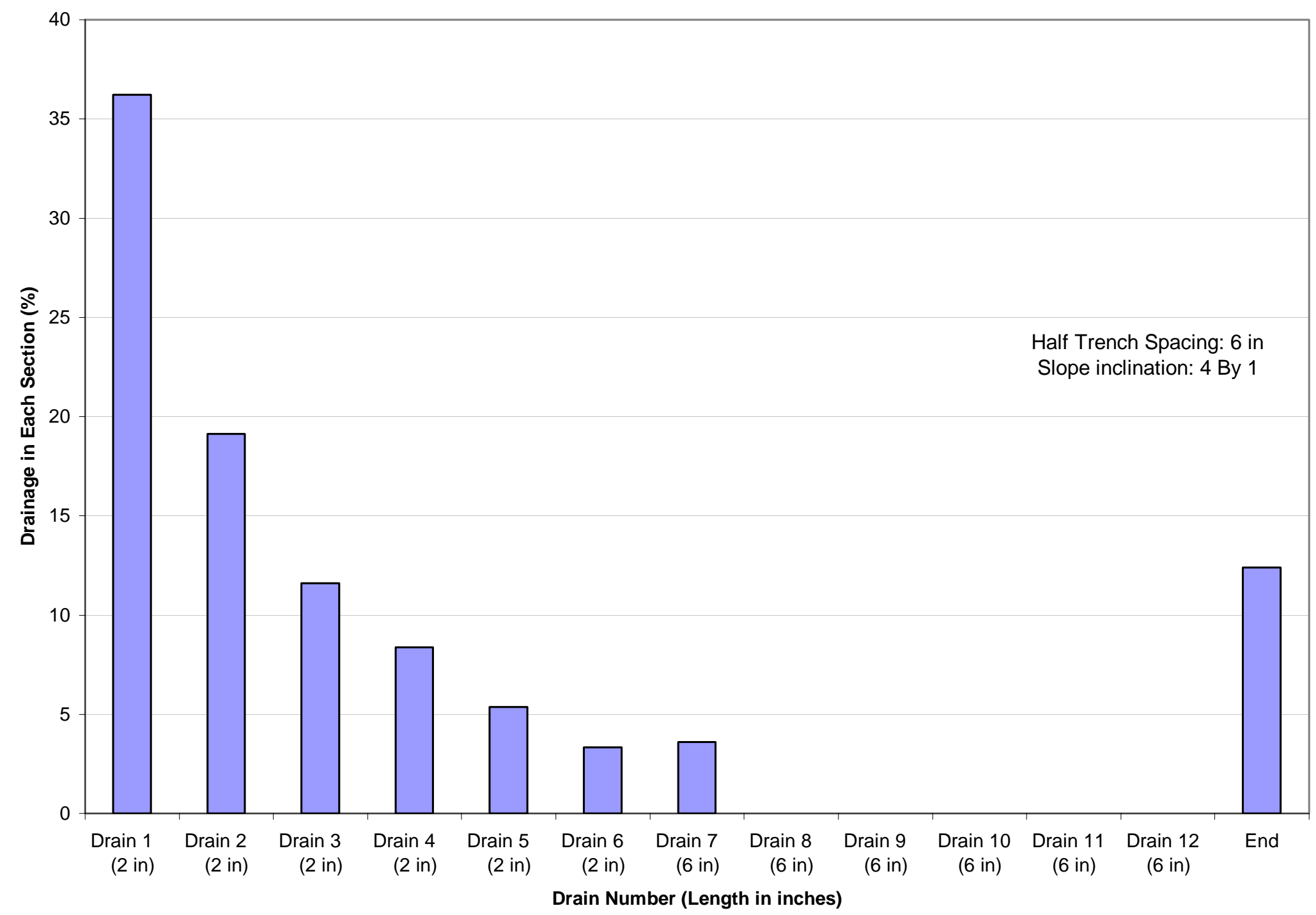

Figure A.2: Percent Seepage for Soil B ( $\mathrm{w}=6$ in, and 4:1 angle slope). 


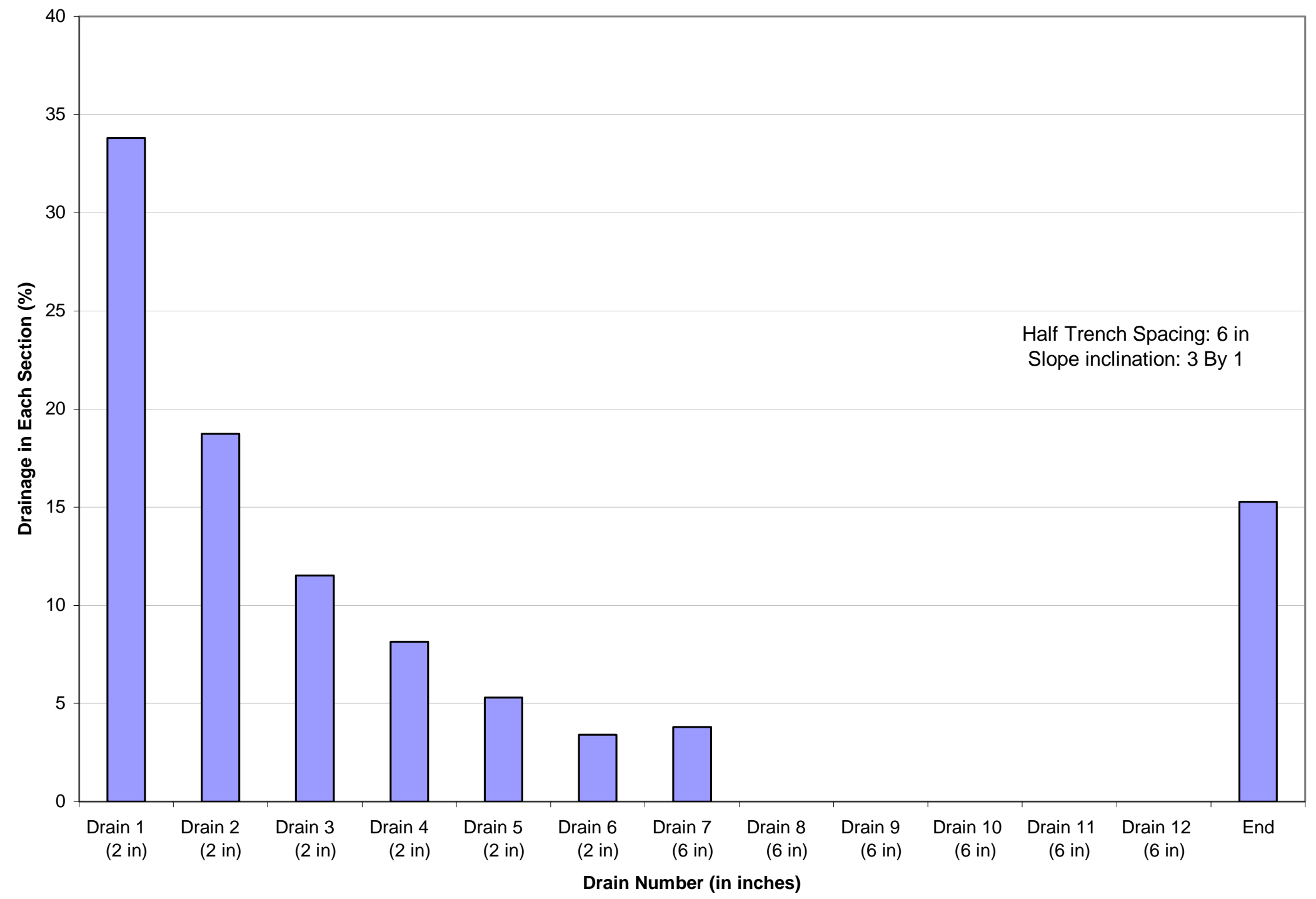

Figure A.3: Percent Seepage for Soil B ( $w=6$ in, 3:1 angle slope). 


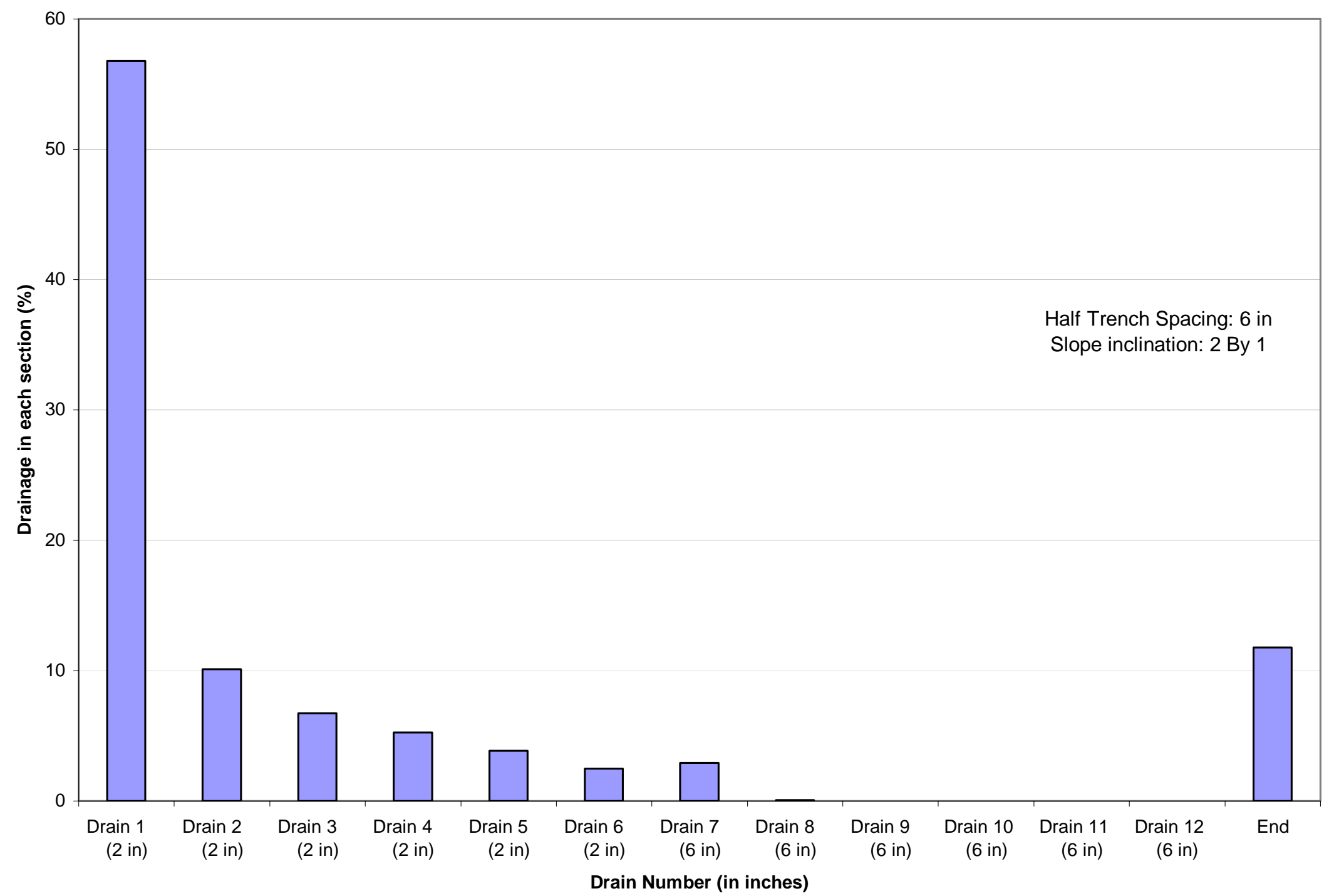

Figure A.4: Percent Seepage for Soil B ( $w=6$ in, 2:1 angle slope). 


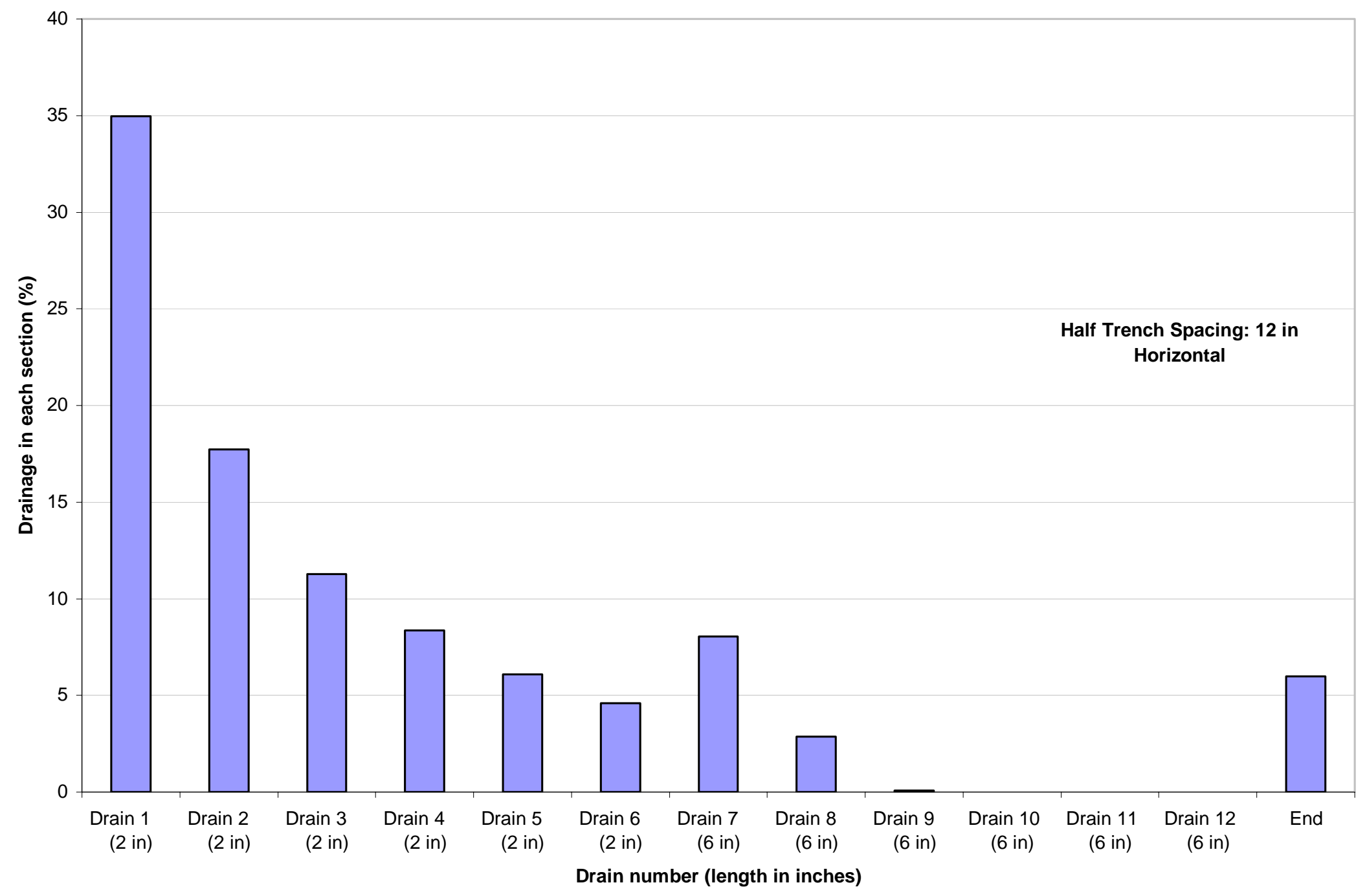

Figure A.5: Percent Seepage for Soil B ( $w=12$ in, horizontal slope). 


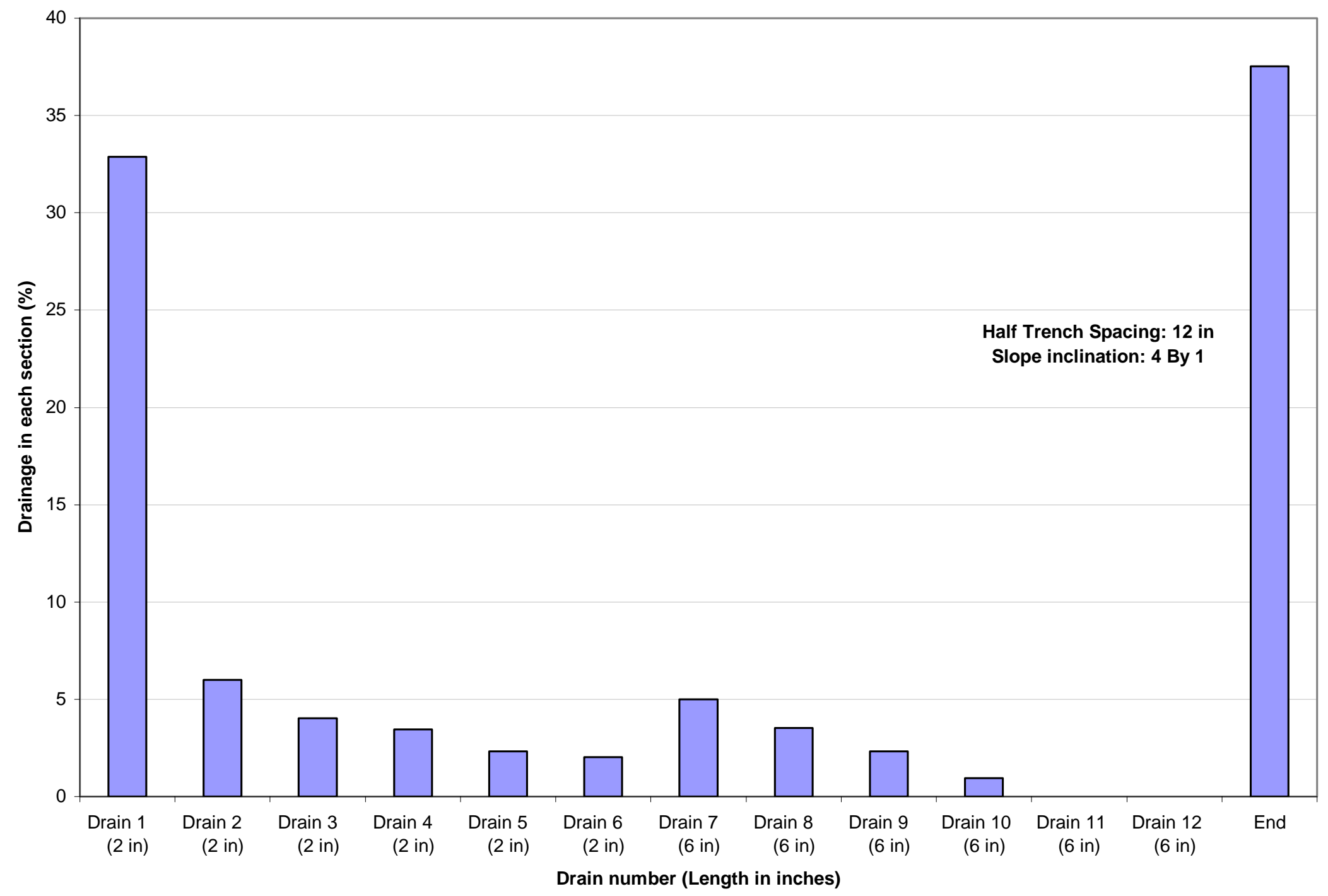

Figure A.6: Percent Seepage for Soil B ( $w=12$ in, 4:1 angle slope). 


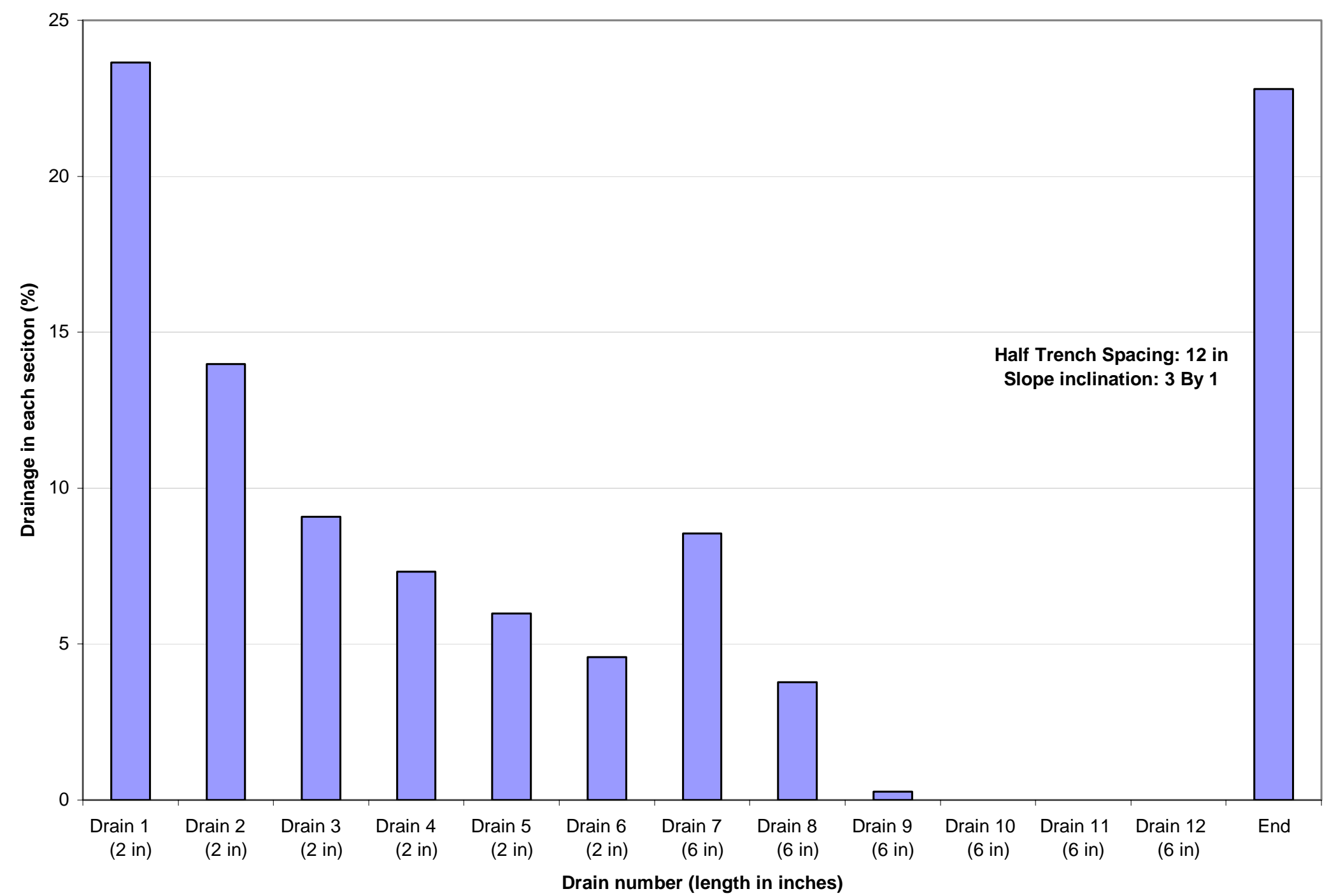

Figure A.7: Percent Seepage for Soil B ( $w=12$ in, 3:1 angle slope). 


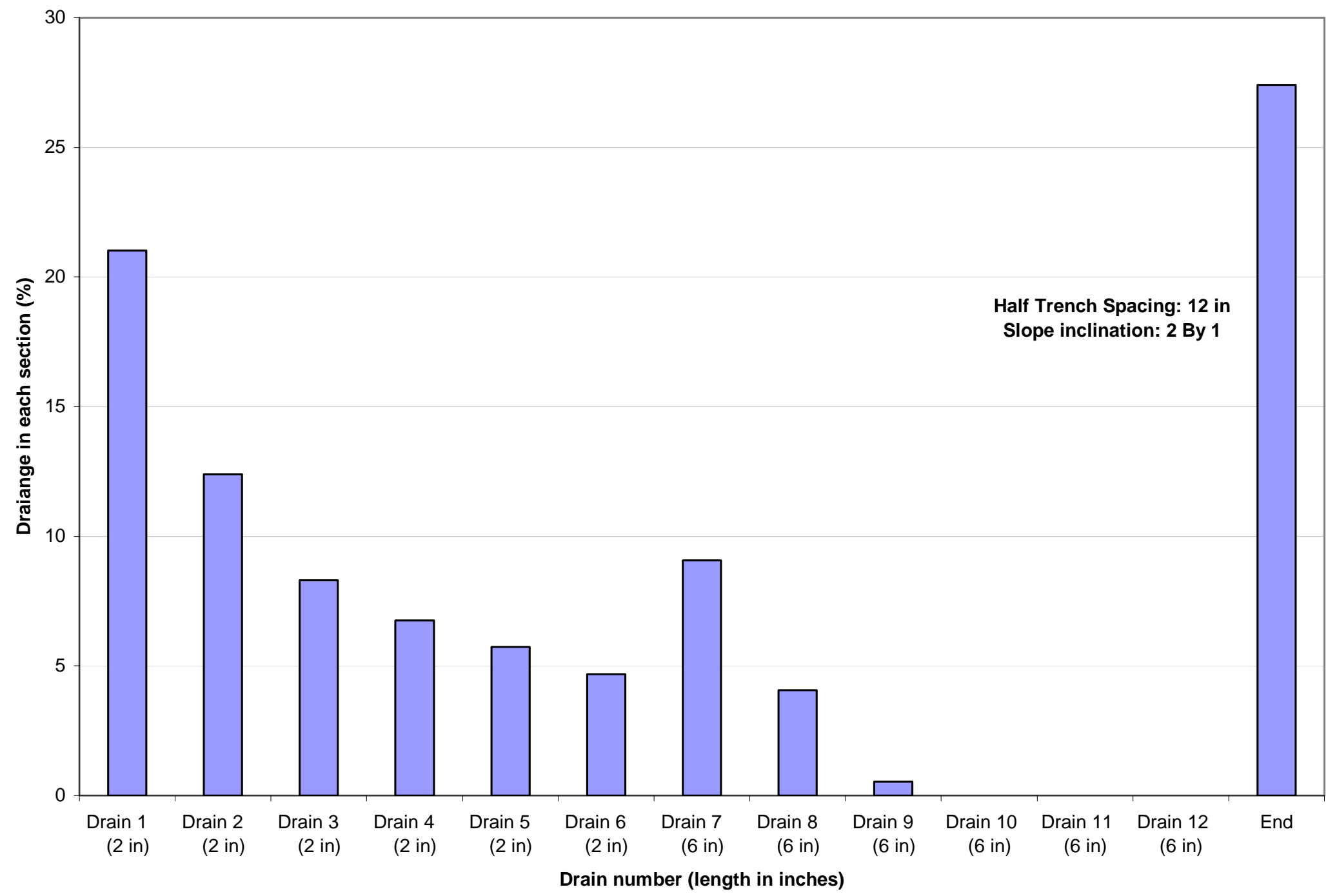

Figure A.8: Percent Seepage for Soil B ( $\mathrm{w}=12$ in, and 2:1 angle slope). 


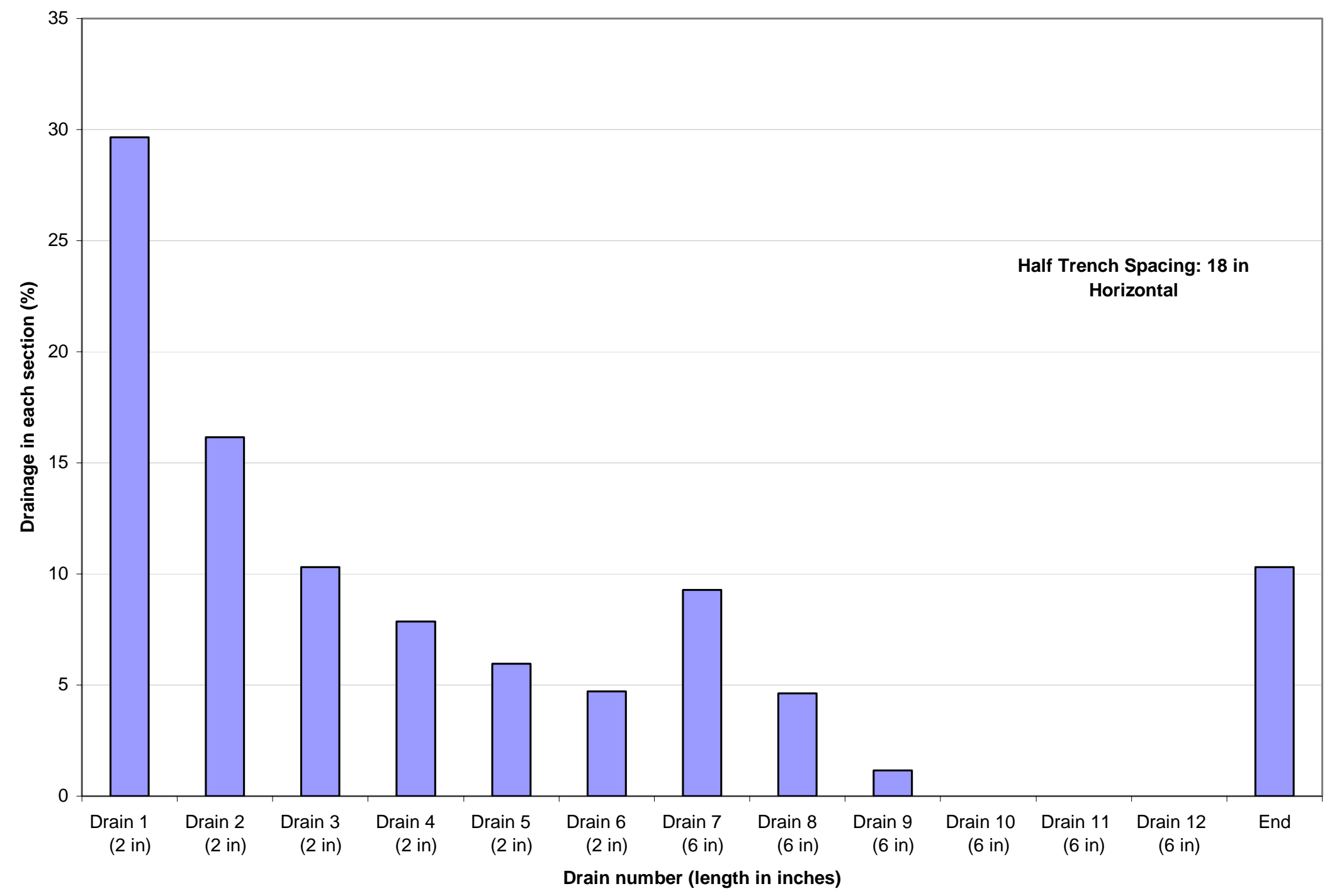

Figure A.9: Percent Seepage for Soil B ( $w=18$ in, horizontal slope). 


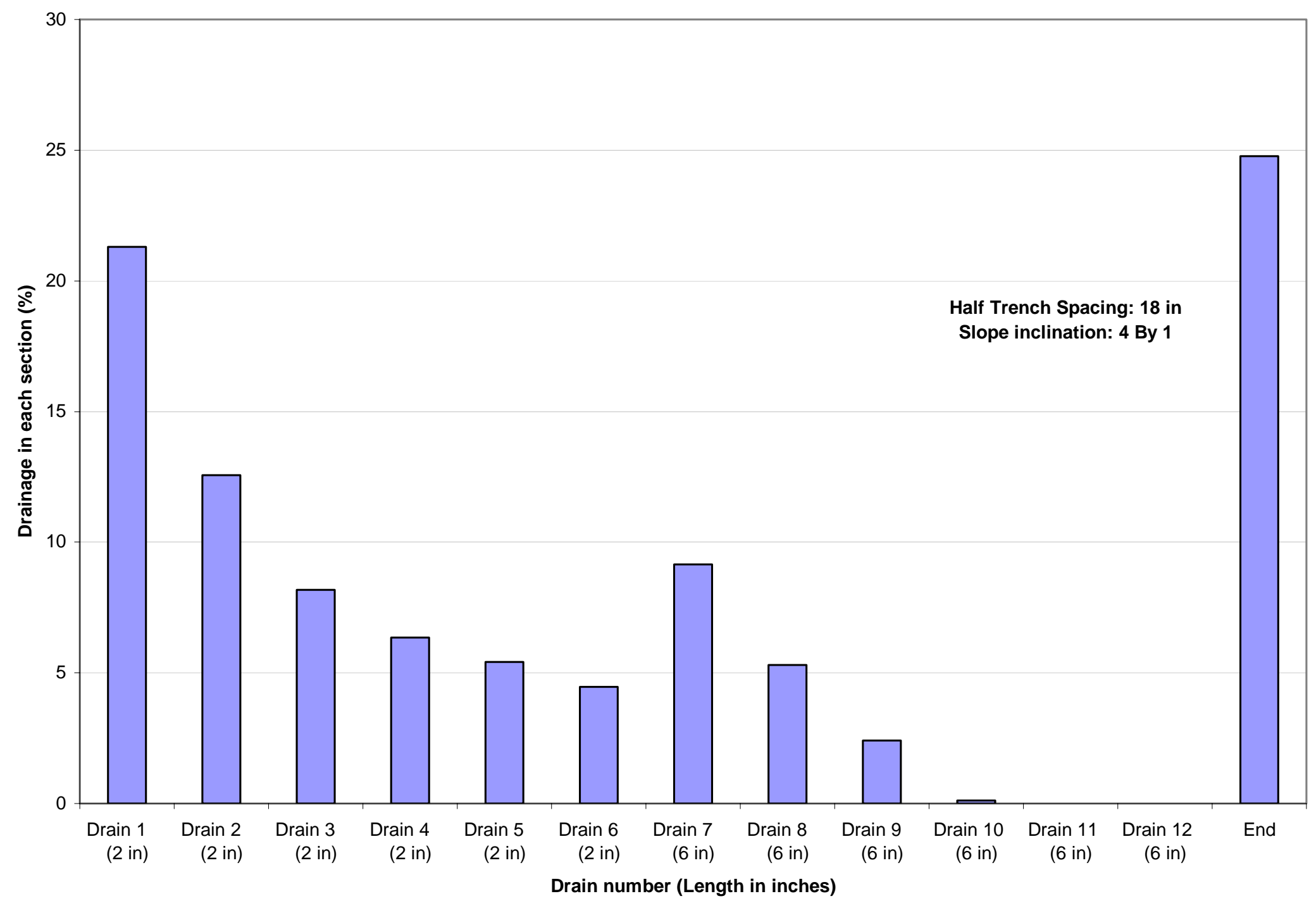

Figure A.10: Percent Seepage for Soil B ( $w=18$ in, 4:1 angle slope). 


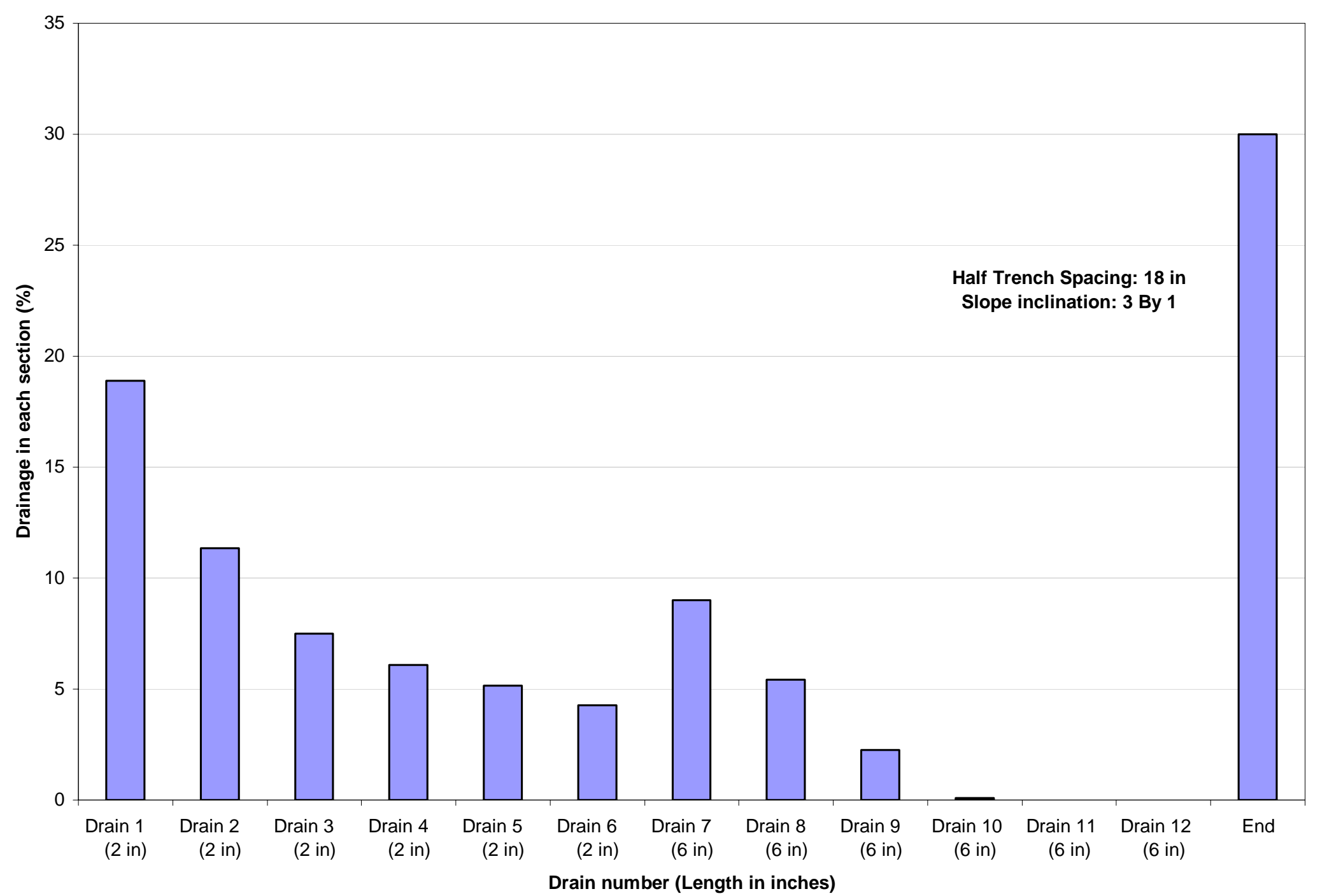

Figure A.11: Percent Seepage for Soil B ( $w=18$ in, 3:1 angle slope). 


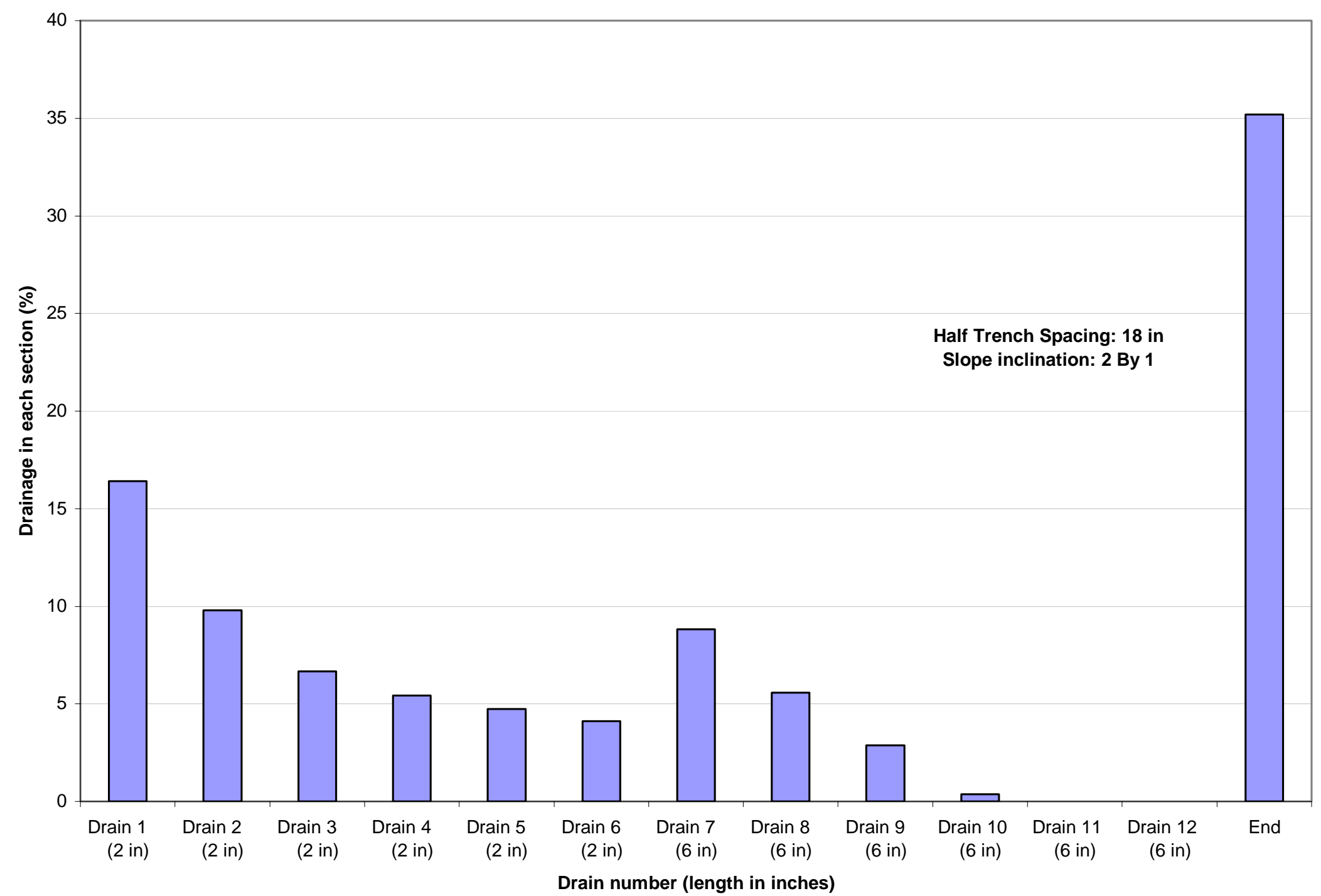

Figure A.12: Percent Seepage for Soil B ( $\mathrm{w}=18$ in, and 2:1 angle slope). 


\section{APPENDIX B}

Cumulative Percentage Removal (CPR- see section 4.2) under

Laboratory conditions for Soil B

(For different values of trench spacing

and slope inclination angle at Lab Conditions.) 


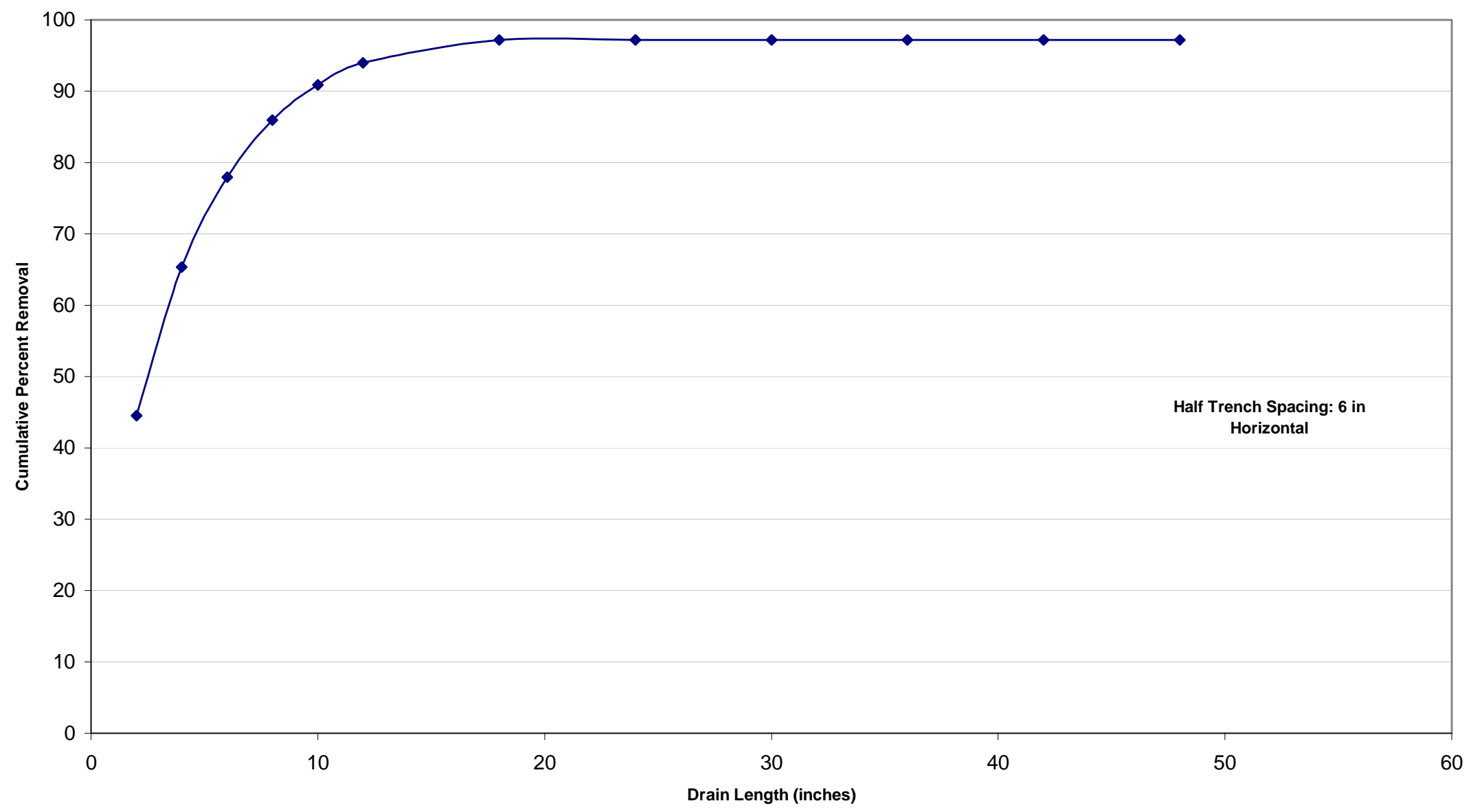

Figure B.1: Cumulative Percentage Removal for Soil type B ( $w=6$ in, slope is horizontal). 


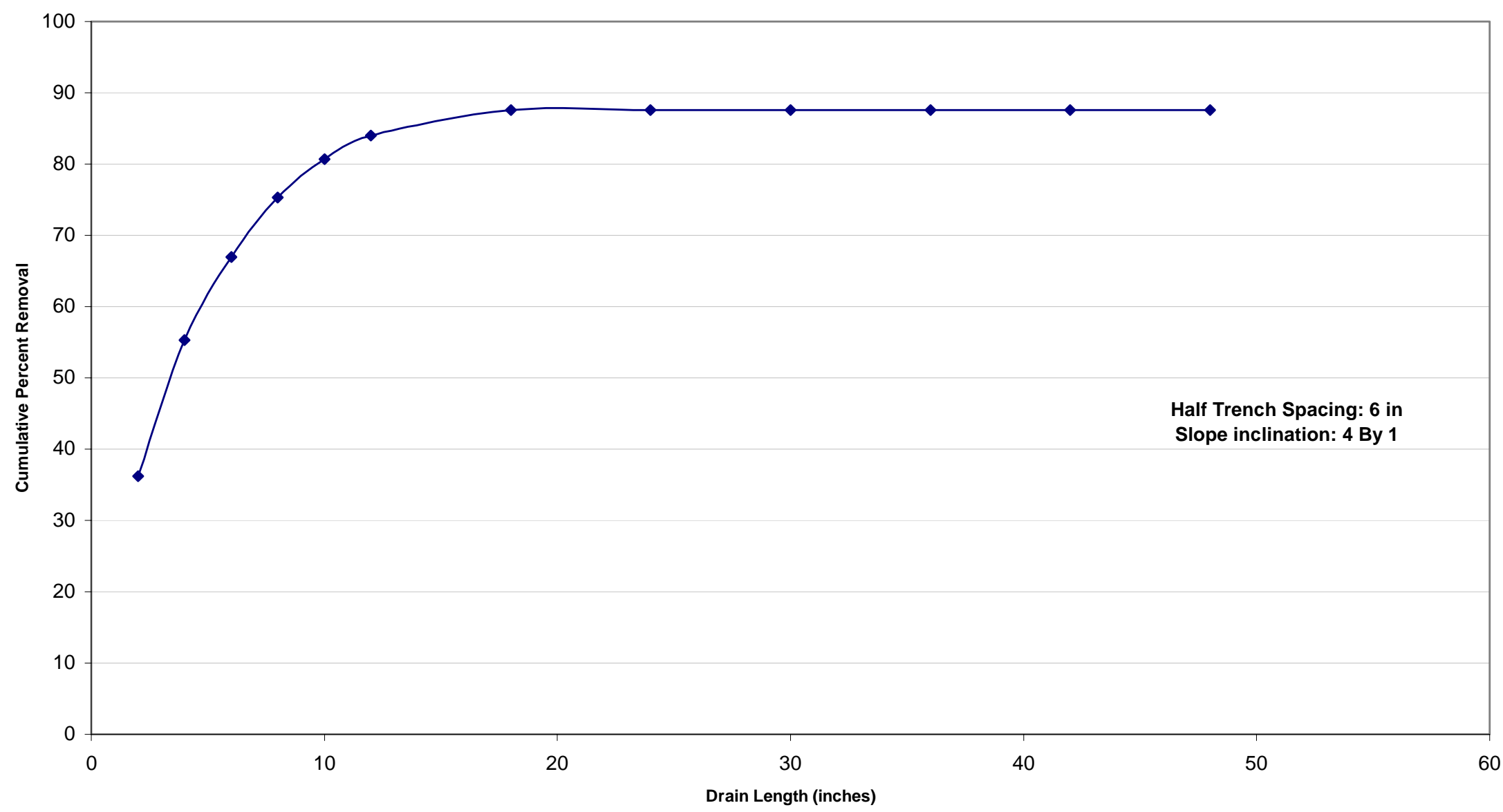

Figure B.2: Cumulative Percentage Removal for Soil type B ( $w=6$ in, 4:1 slope angle). 


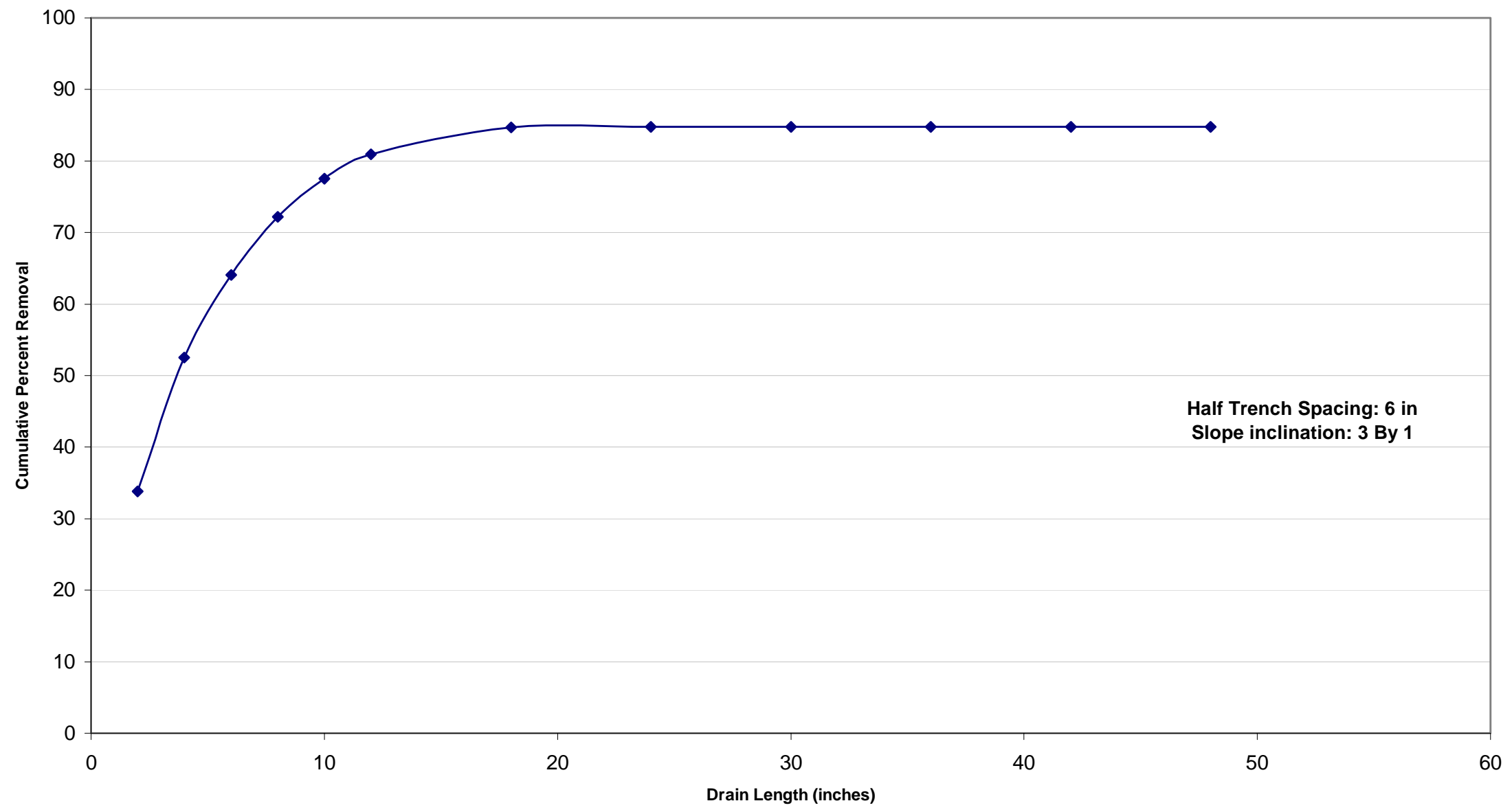

Figure B.3: Cumulative Percentage Removal for Soil type B ( $w=6$ in, 3:1 slope angle). 


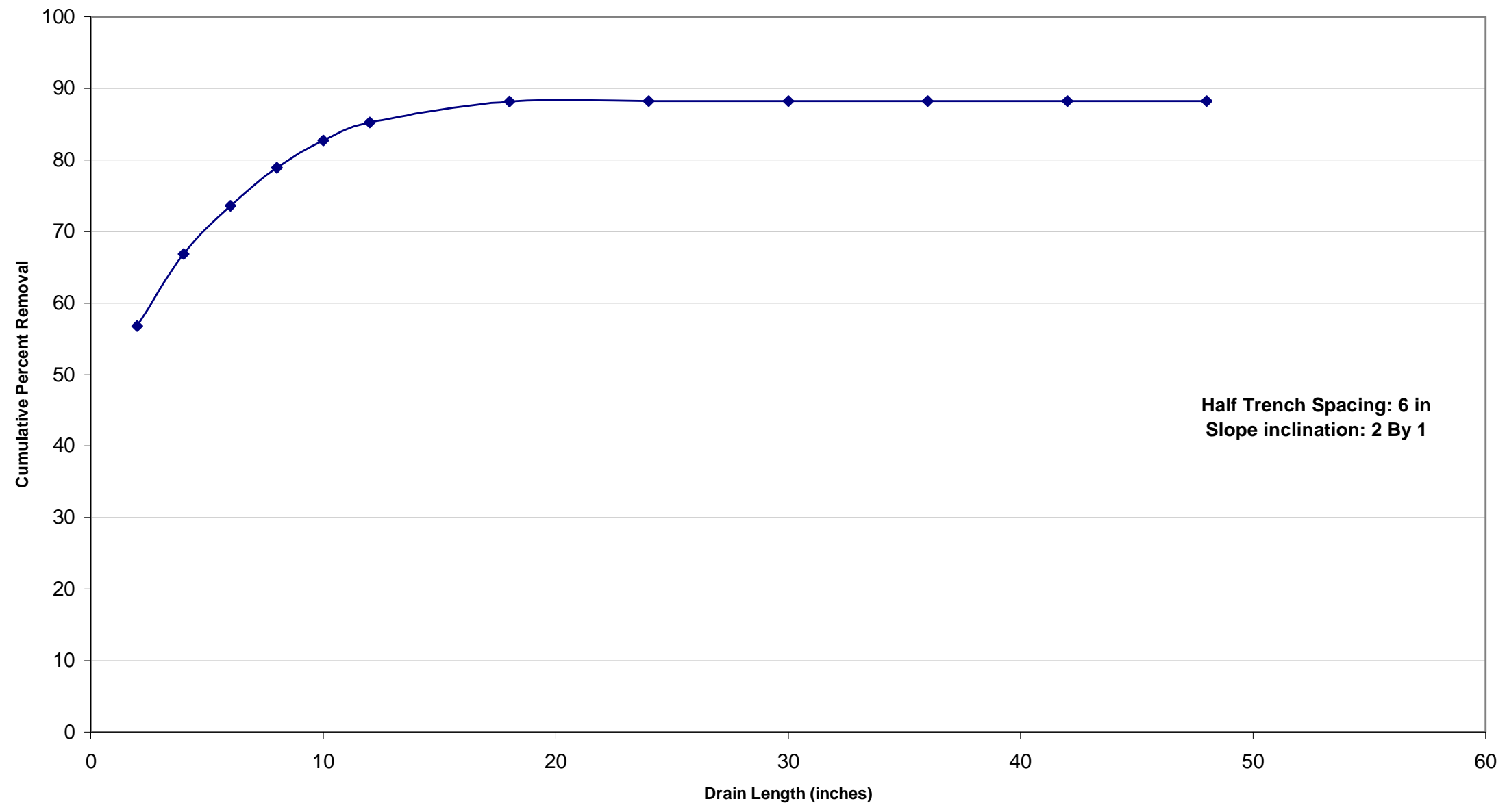

Figure B.4: Cumulative Percentage Removal for Soil type B ( $w=6$ in, 2:1 slope angle). 


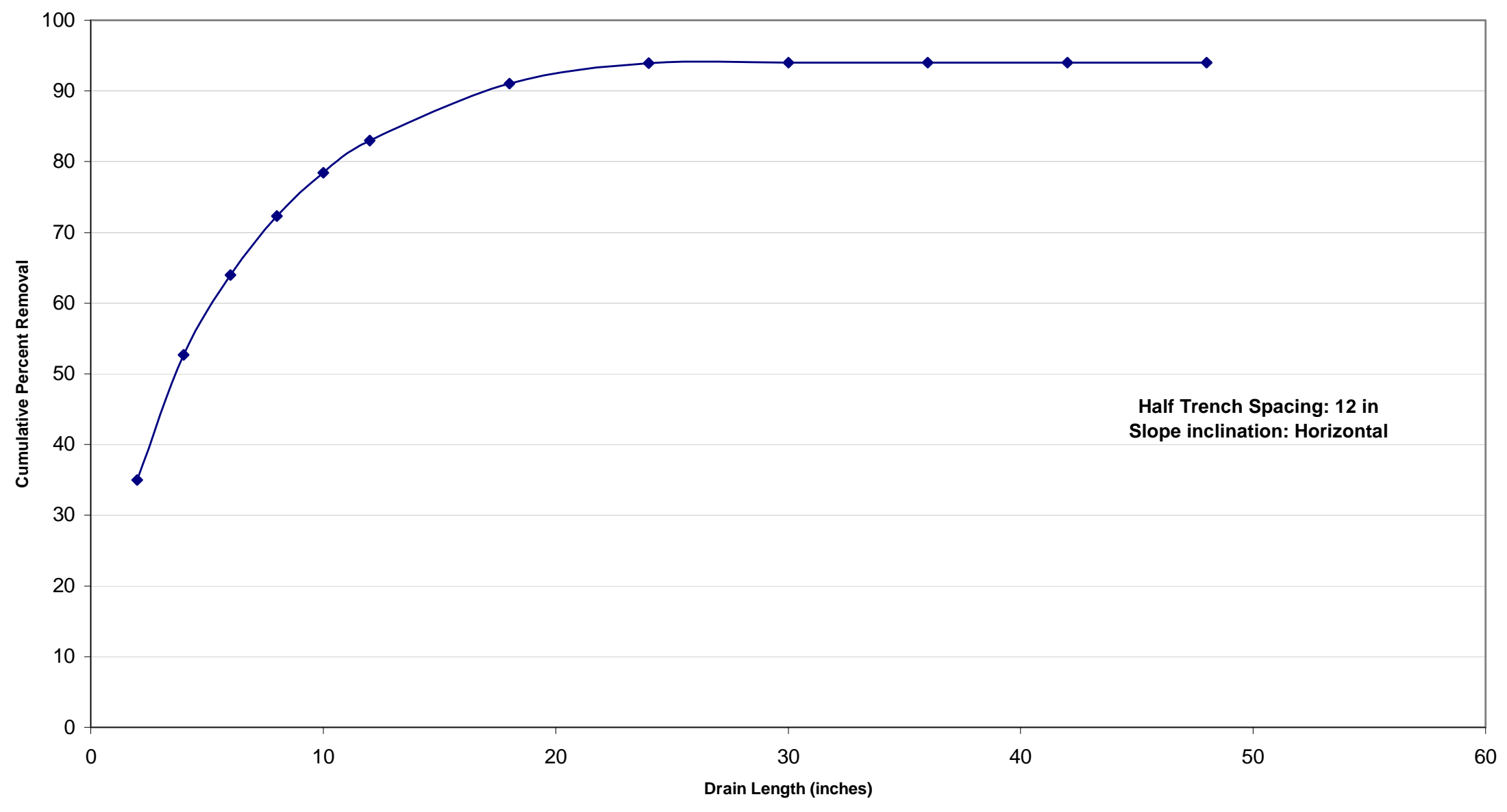

Figure B.5: Cumulative Percentage Removal for Soil type B ( $w=12$ in, slope is horizontal). 


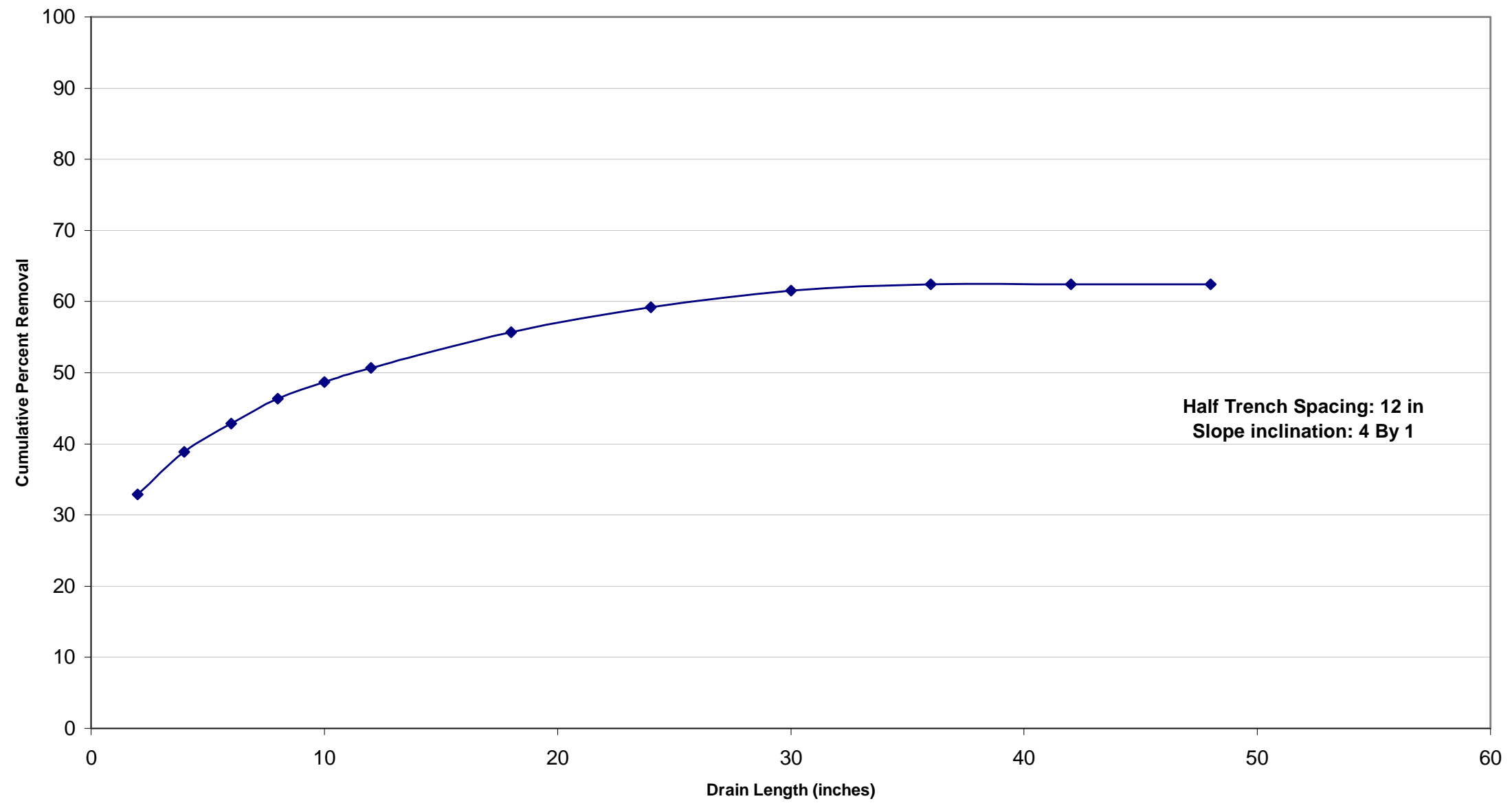

Figure B.6: Cumulative Percentage Removal for Soil type B ( $w=12$ in, 4:1 slope angle). 


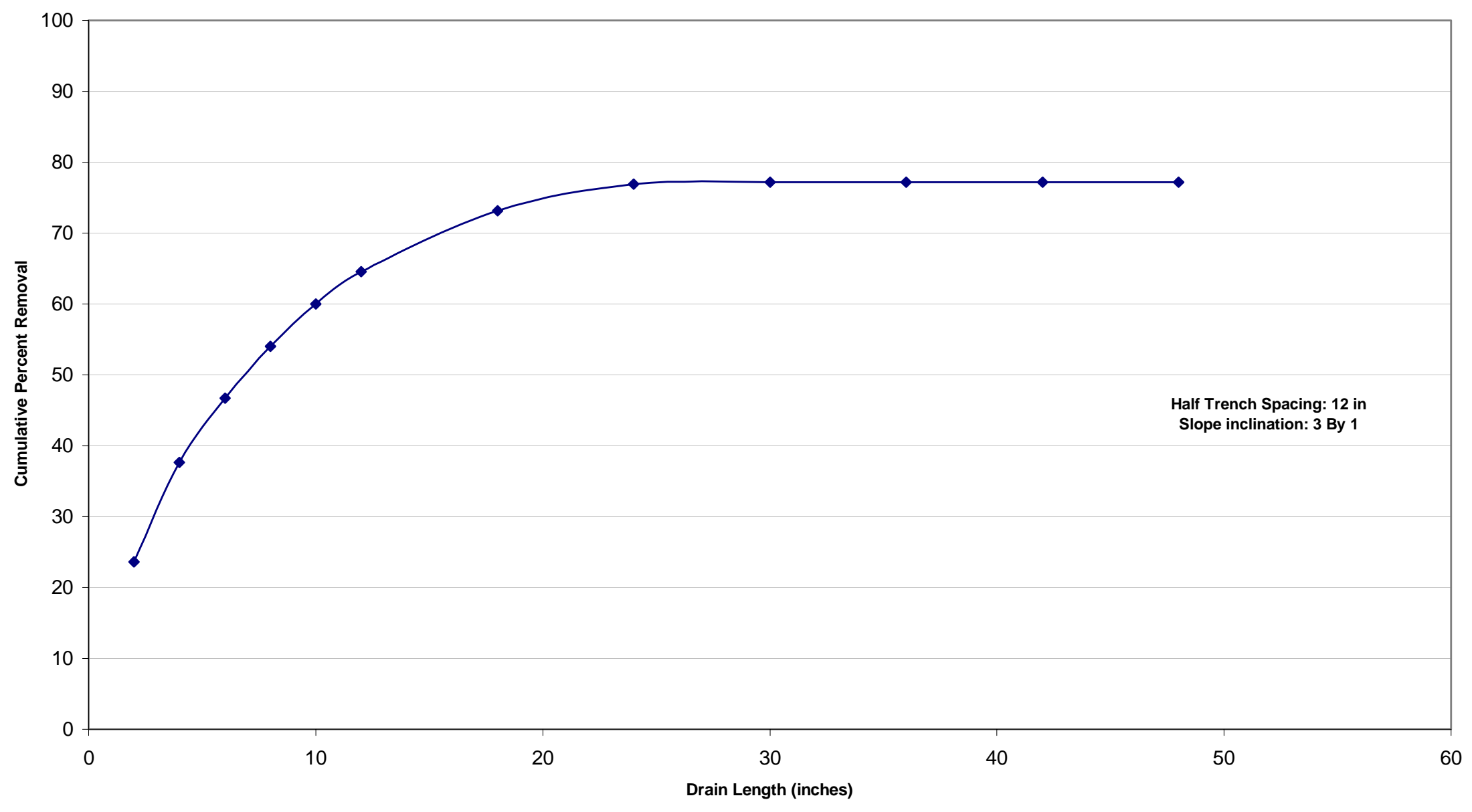

Figure B.7: Cumulative Percentage Removal for Soil type B ( $w=12$ in, 3:1 slope angle). 


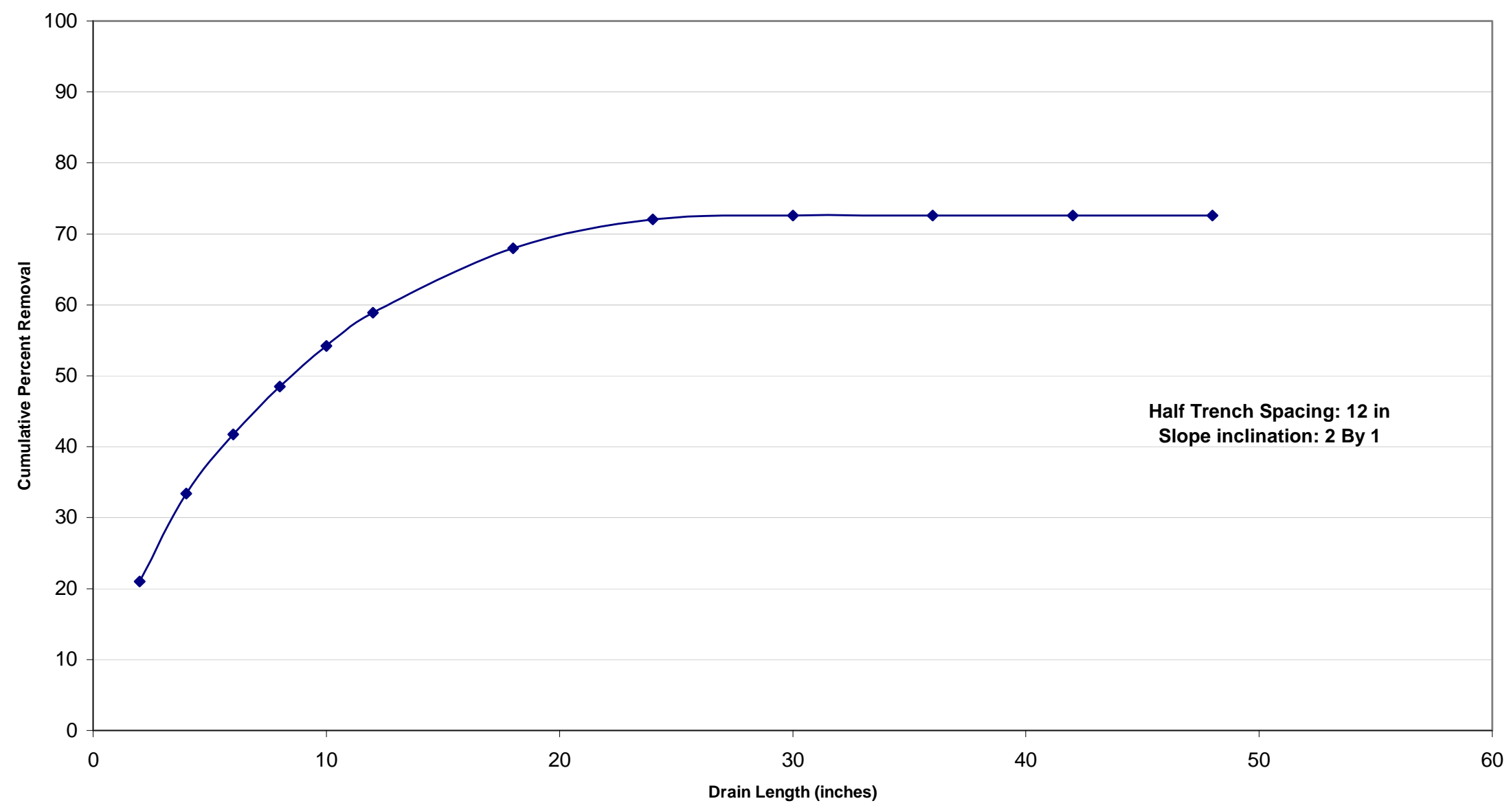

Figure B.8: Cumulative Percentage Removal for Soil type B ( $w=12$ in, 2:1 slope angle). 


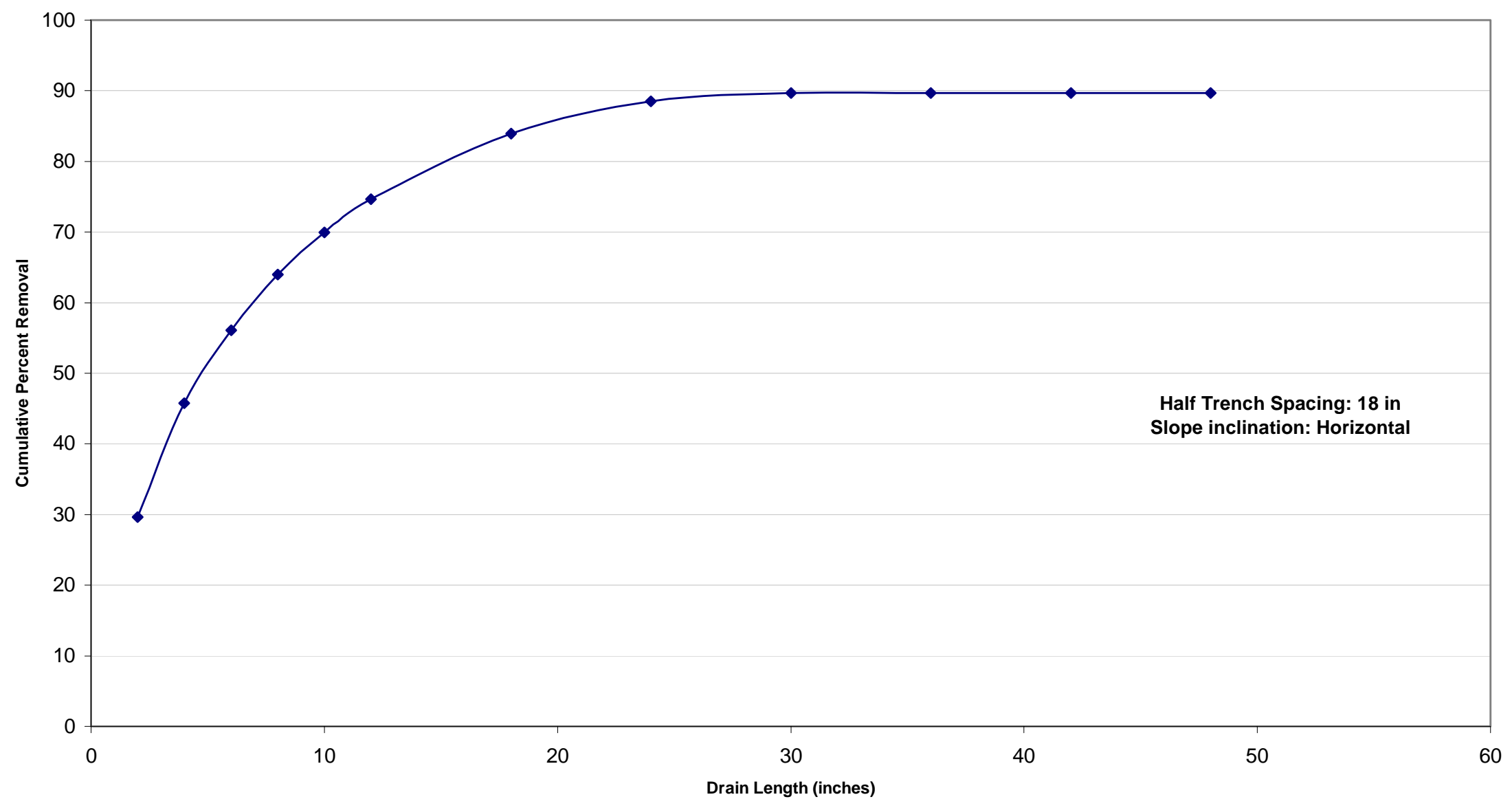

Figure B.9: Cumulative Percentage Removal for Soil type B ( $\mathrm{w}=18$ in, slope is horizontal). 


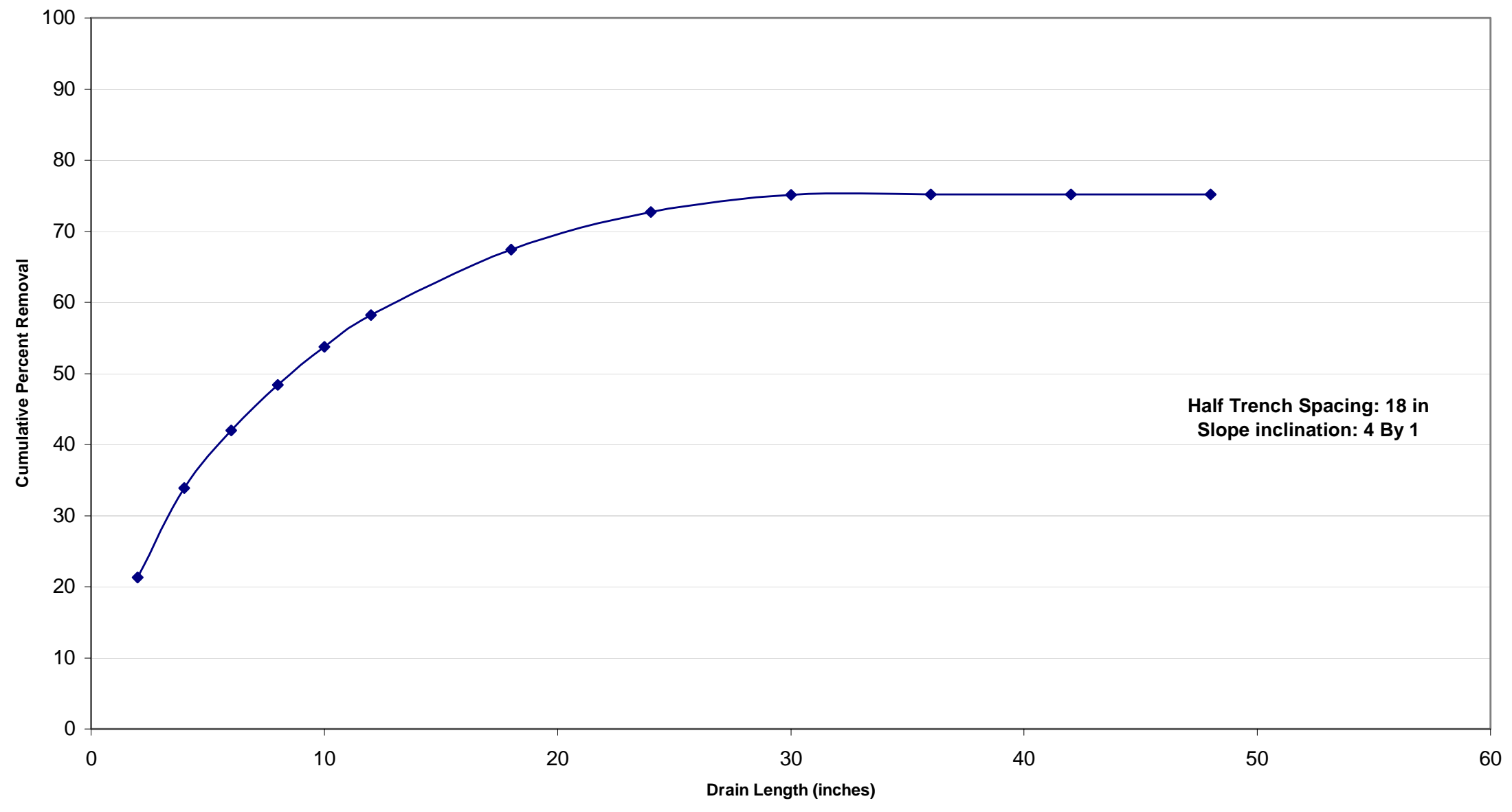

Figure B.10: Cumulative Percentage Removal for Soil type B ( $w=18$ in, 4:1 slope angle). 


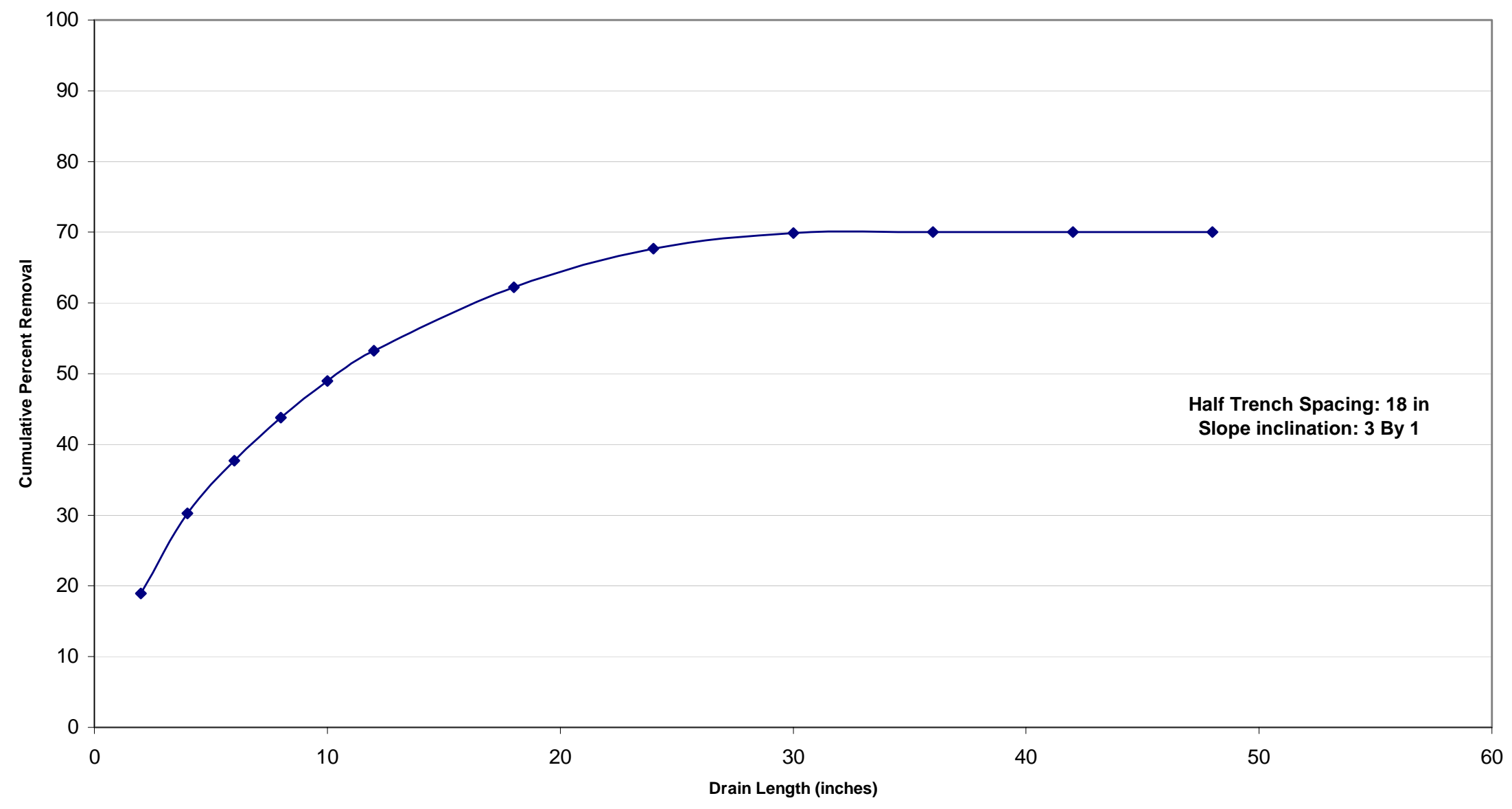

Figure B.11: Cumulative Percentage Removal for Soil type B ( $w=18$ in, 3:1 slope angle). 


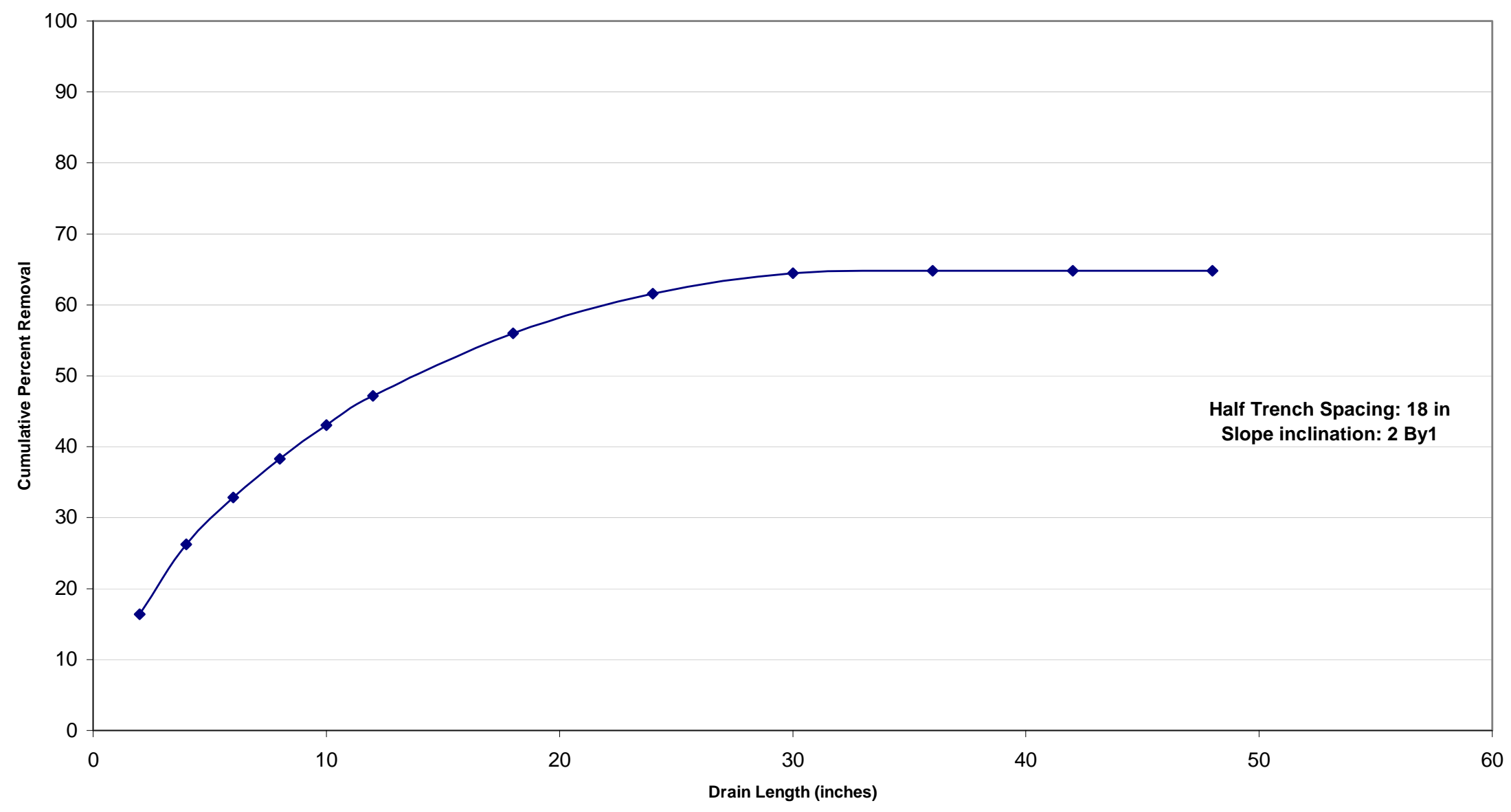

Figure B.12: Cumulative Percentage Removal for Soil type B ( $w=18$ in, 2:1 slope angle). 


\section{APPENDIX C}

Influence of Trench Spacing on Seepage under Laboratory conditions for Soil B

(For different values of slope inclination angles.) 


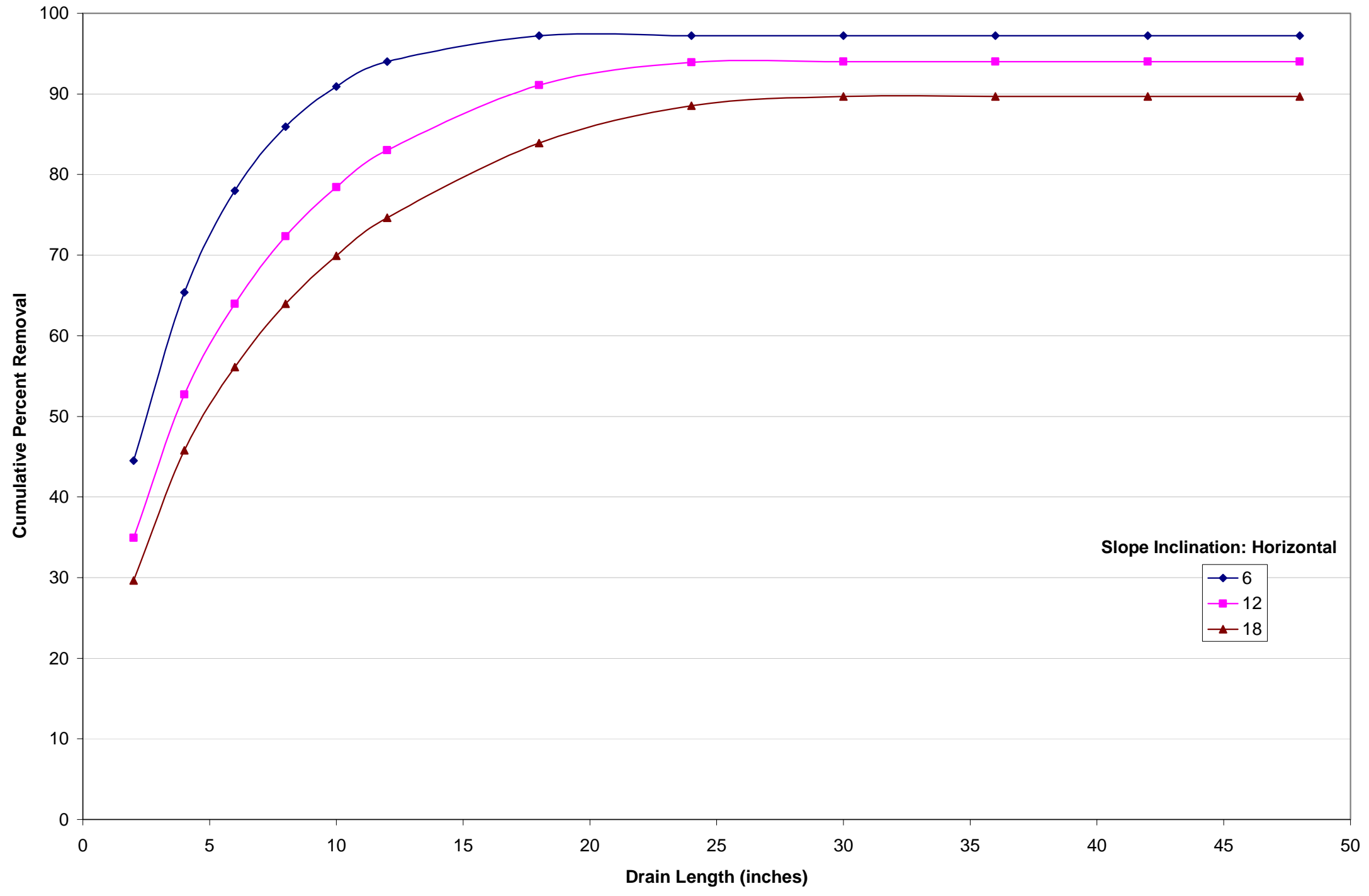

Figure C.1: Influence of Trench Spacing for Soil B (Slope is horizontal). 


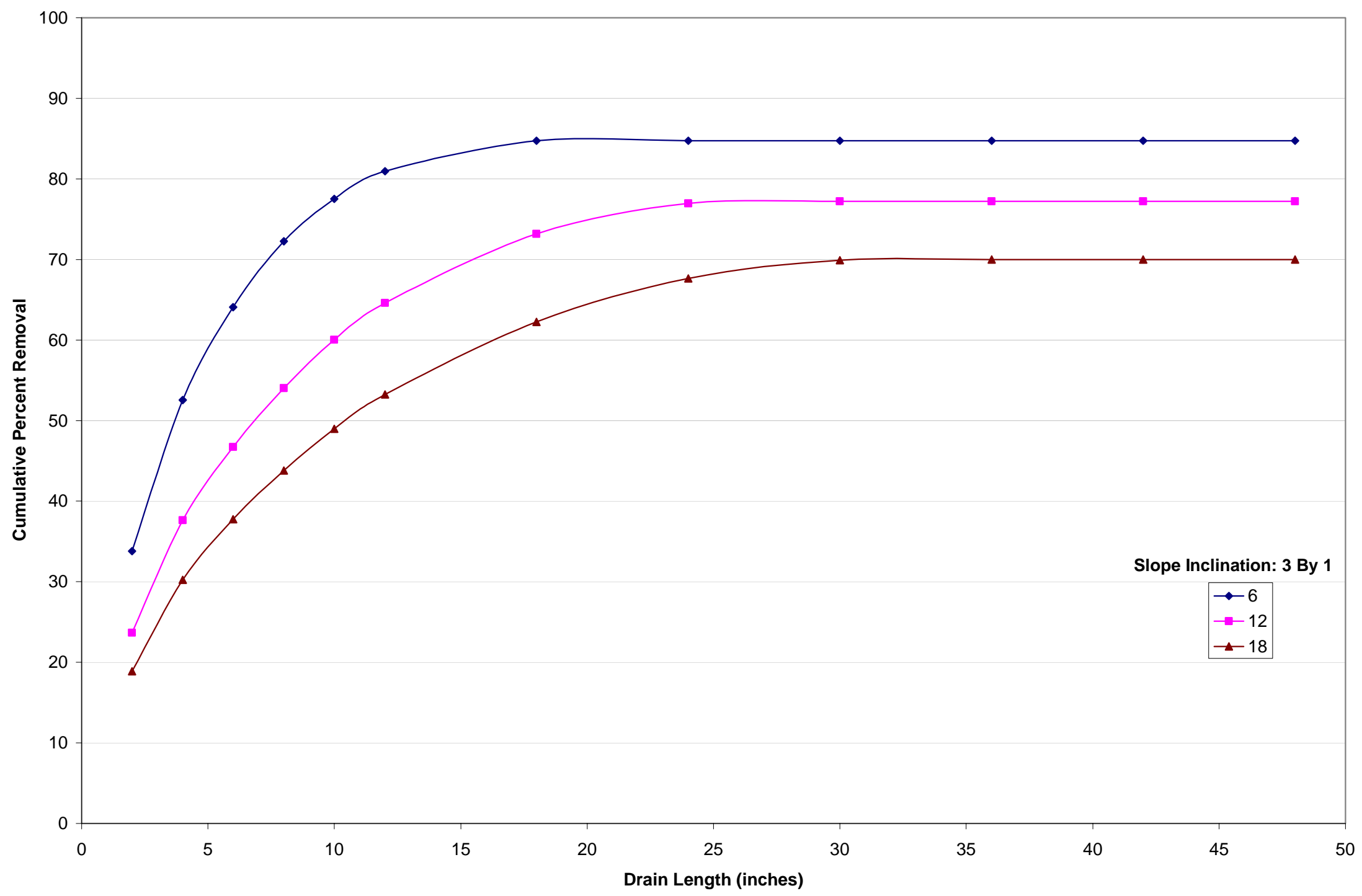

Figure C.2: Influence of Trench Spacing for Soil B (3:1 Slope angle). 


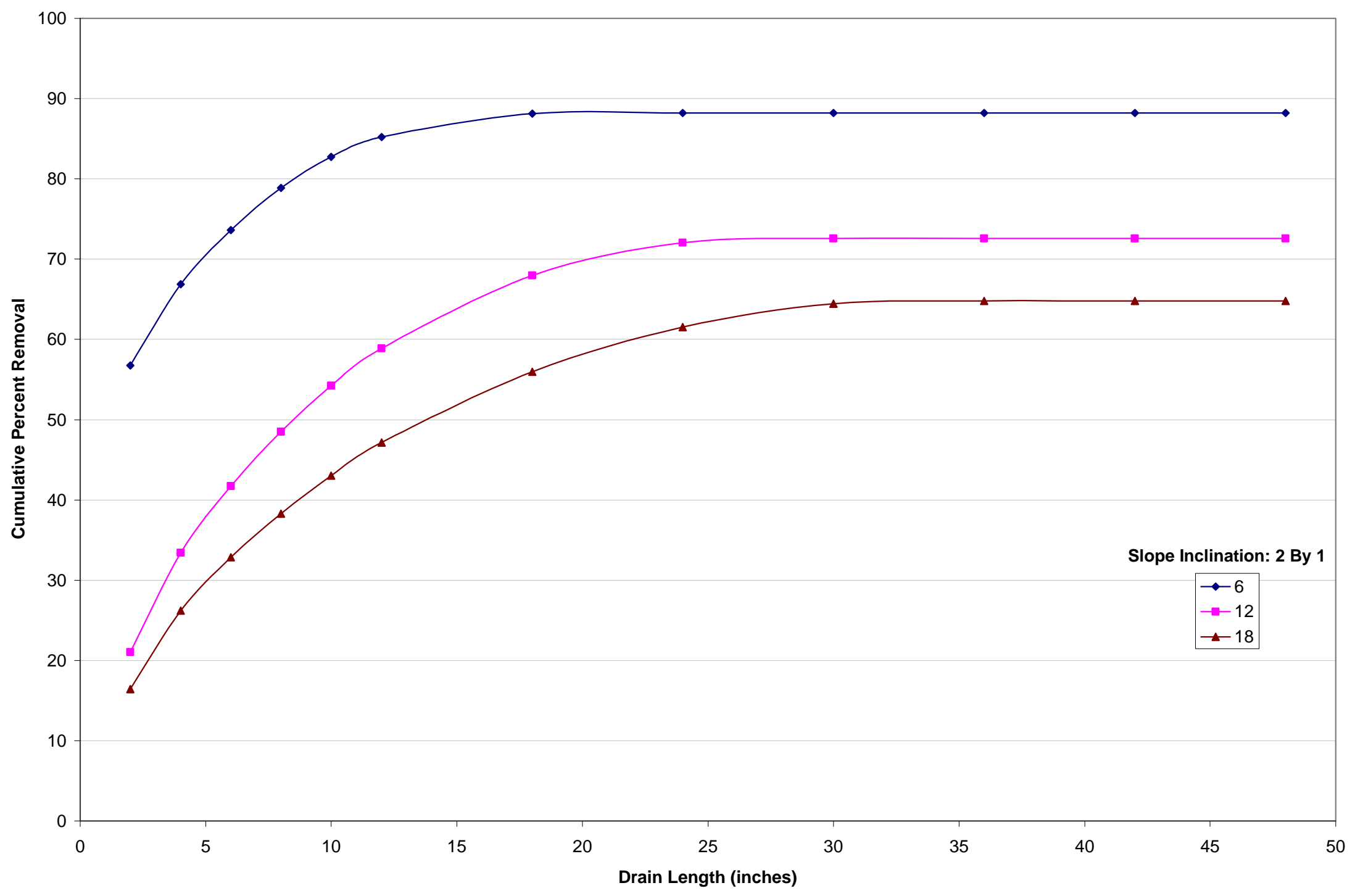

Figure C.3: Influence of Trench Spacing for Soil B (2:1 Slope angle). 


\section{APPENDIX D}

Influence of Slope inclination angle on Seepage under Laboratory conditions for Soil B

(For different values of Trench spacing at Lab conditions.) 


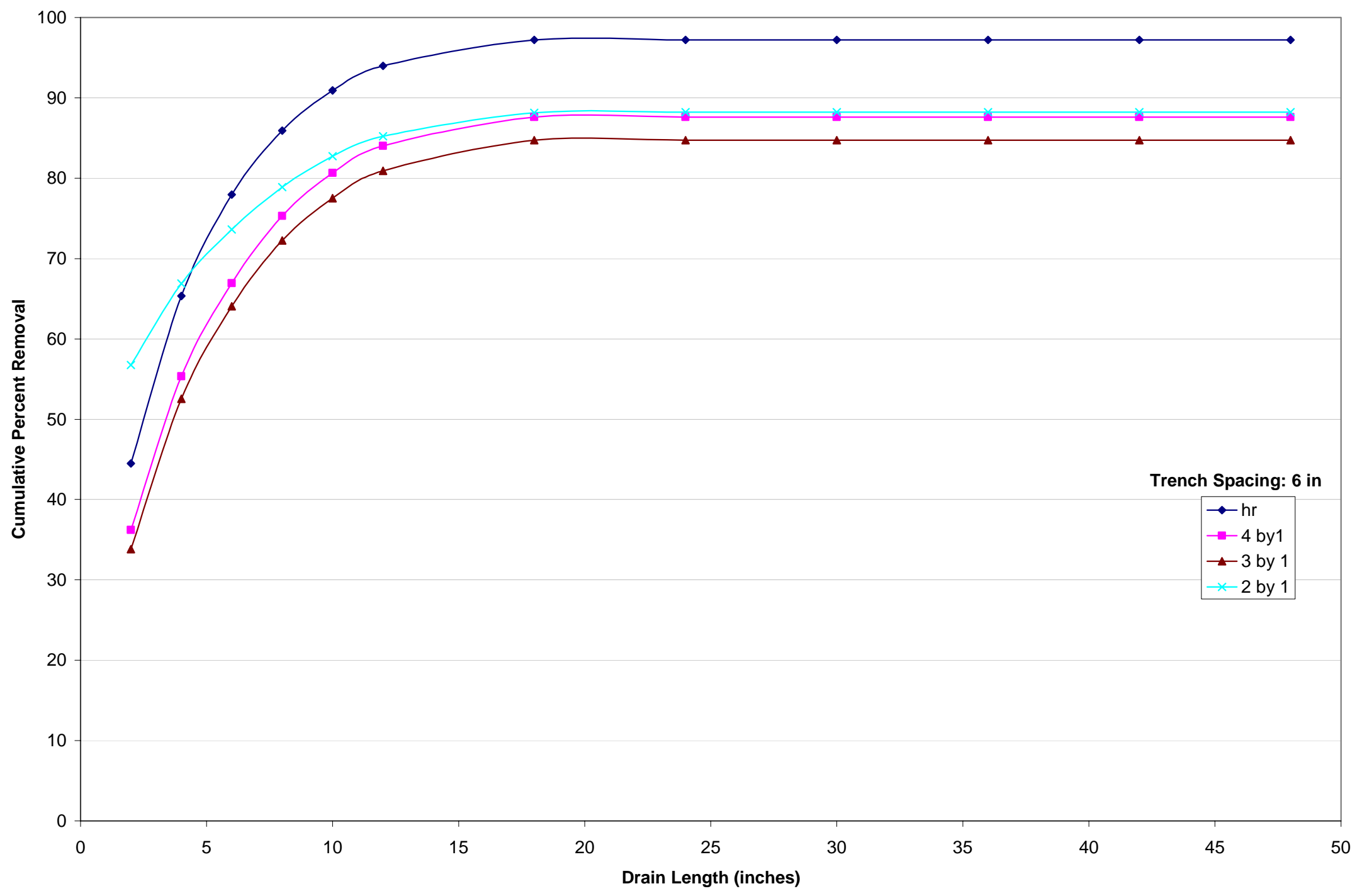

Figure D.1: Influence of Slope inclination angle for Soil B ( $w=6$ inches) 


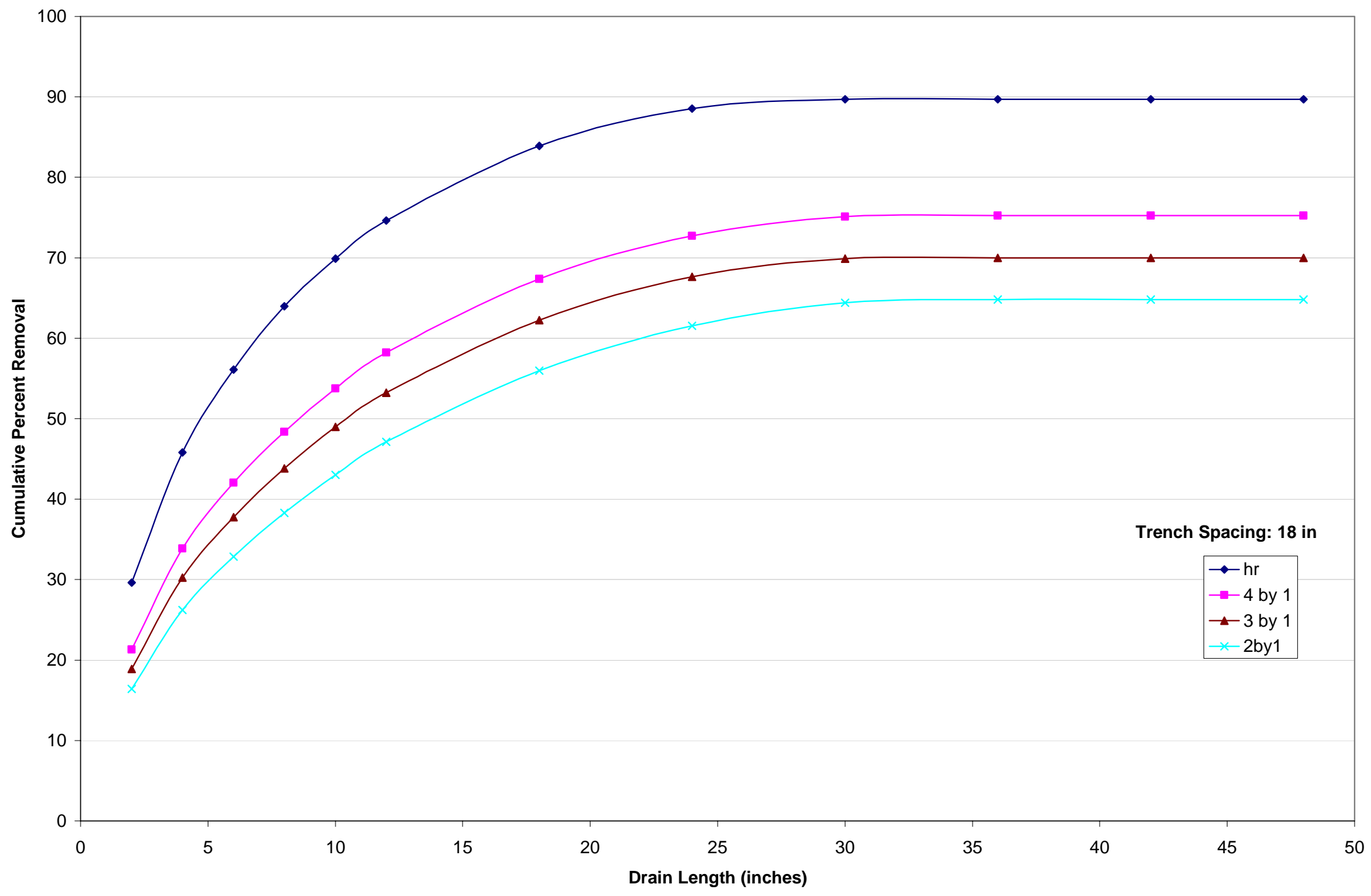

Figure D.2: Influence of Slope inclination angle for Soil B ( $w=18$ inches). 


\section{APPENDIX E}

Seepage Removal under Field conditions for

Soil B

(For different values of trench spacing, slope inclination angle and saturation depth.) 


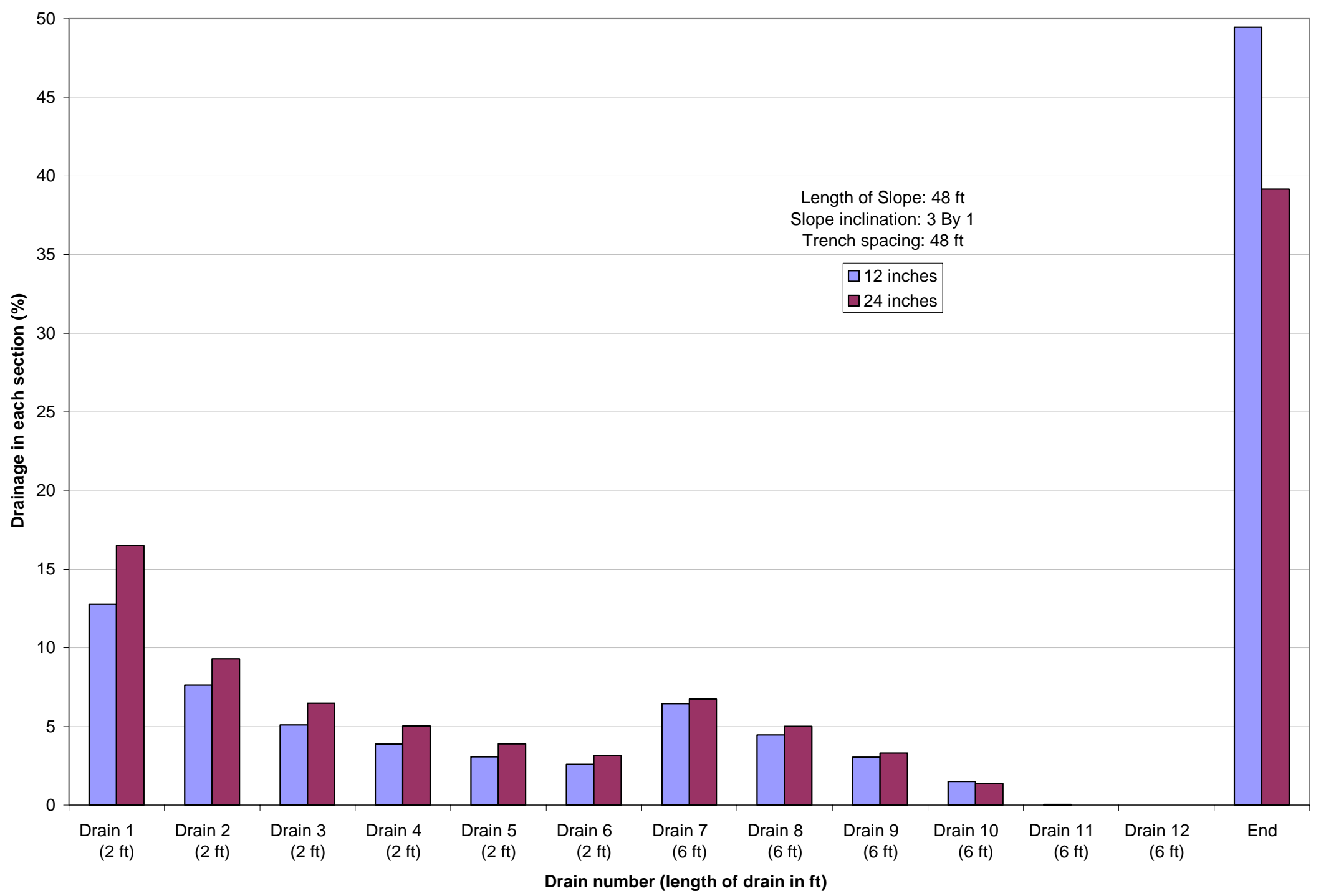

Figure E.1: Percentage of drainage in each section for Soil B for different water levels $(\mathrm{L}=48 \mathrm{ft}, 3: 1$ Slope inclination, $\mathrm{w}=48 \mathrm{ft}$ ). 


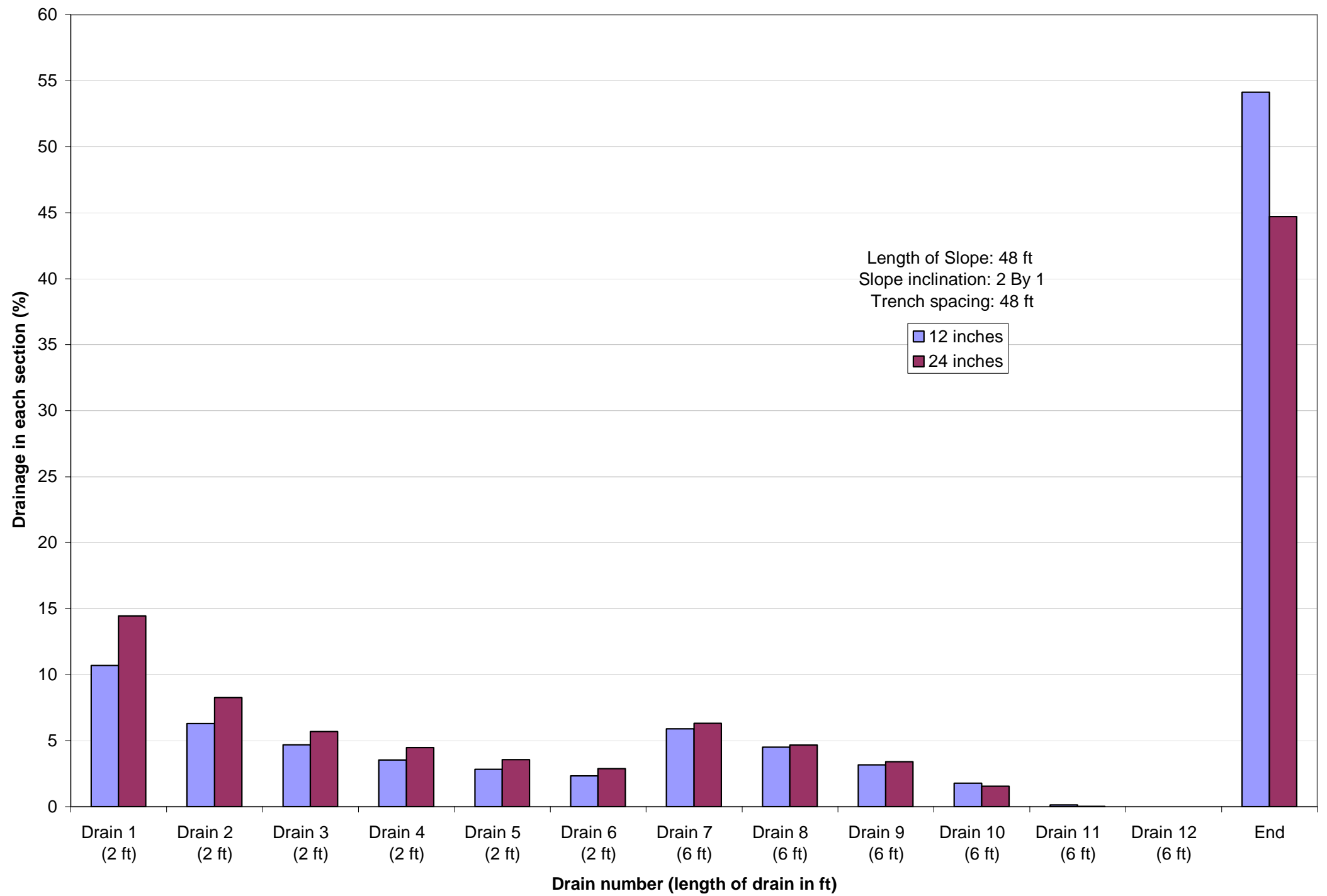

Figure E.2: Percentage of drainage in each section for Soil B for different water levels $(\mathrm{L}=48 \mathrm{ft}, 2: 1$ Slope inclination, $\mathrm{w}=48 \mathrm{ft}$ ). 


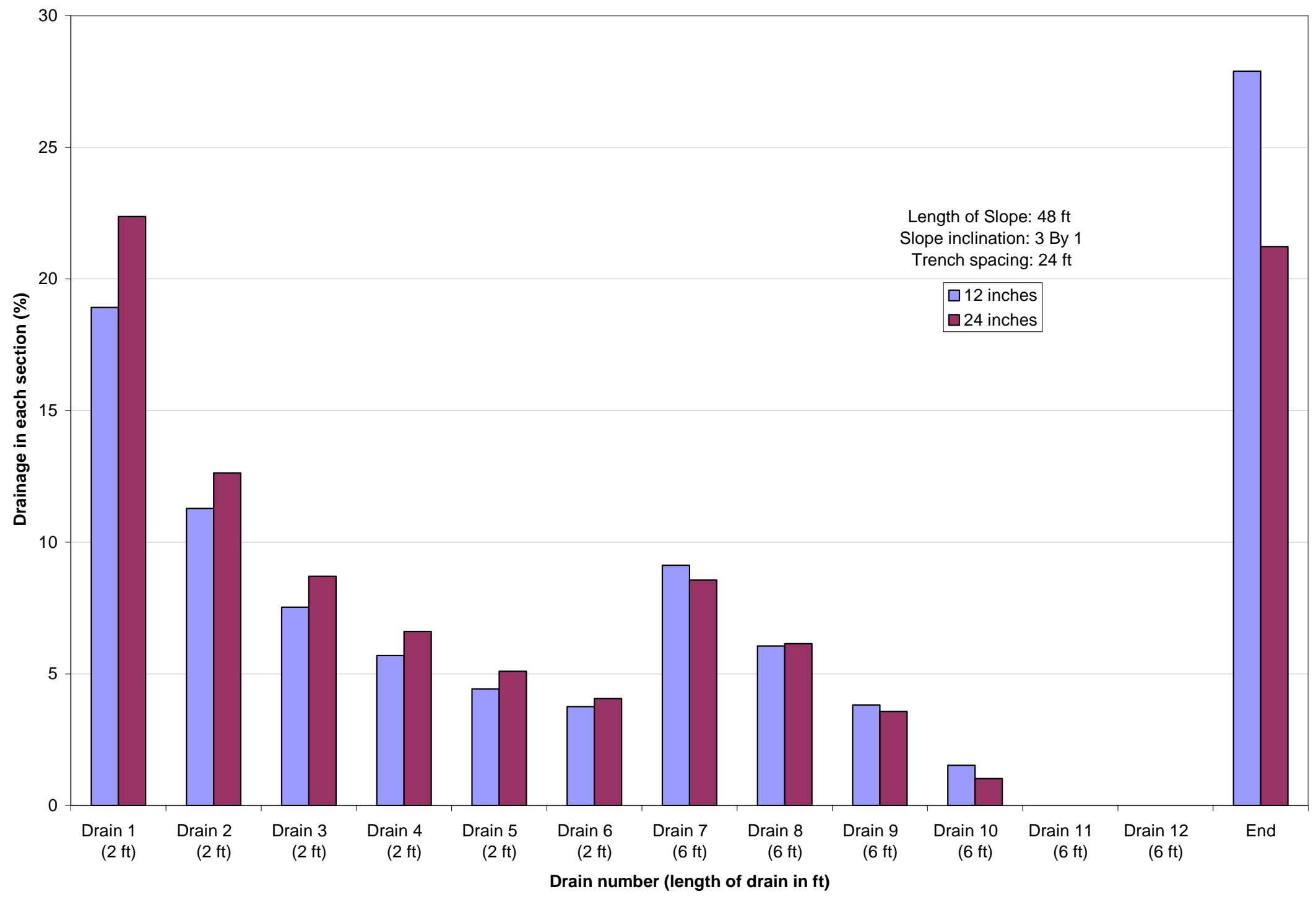

Figure E.3: Percentage of drainage in each section for Soil B for different water levels $(\mathrm{L}=48 \mathrm{ft}, 3: 1$ Slope inclination, $\mathrm{w}=24 \mathrm{ft}$ ). 


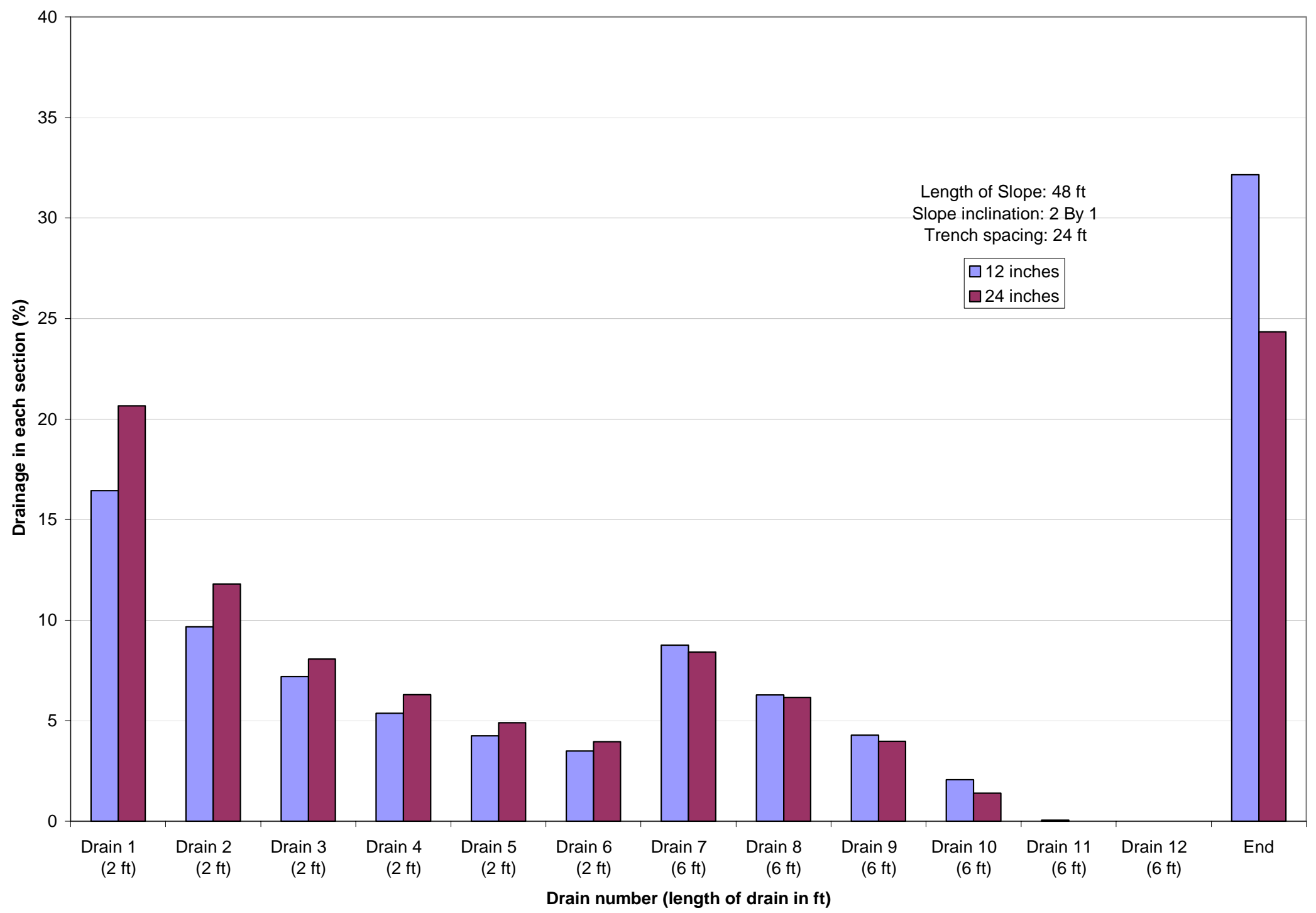

Figure E.4: Percentage of drainage in each section for Soil B for different water levels $(\mathrm{L}=48 \mathrm{ft}, 2: 1$ Slope inclination, $\mathrm{w}=24 \mathrm{ft})$. 


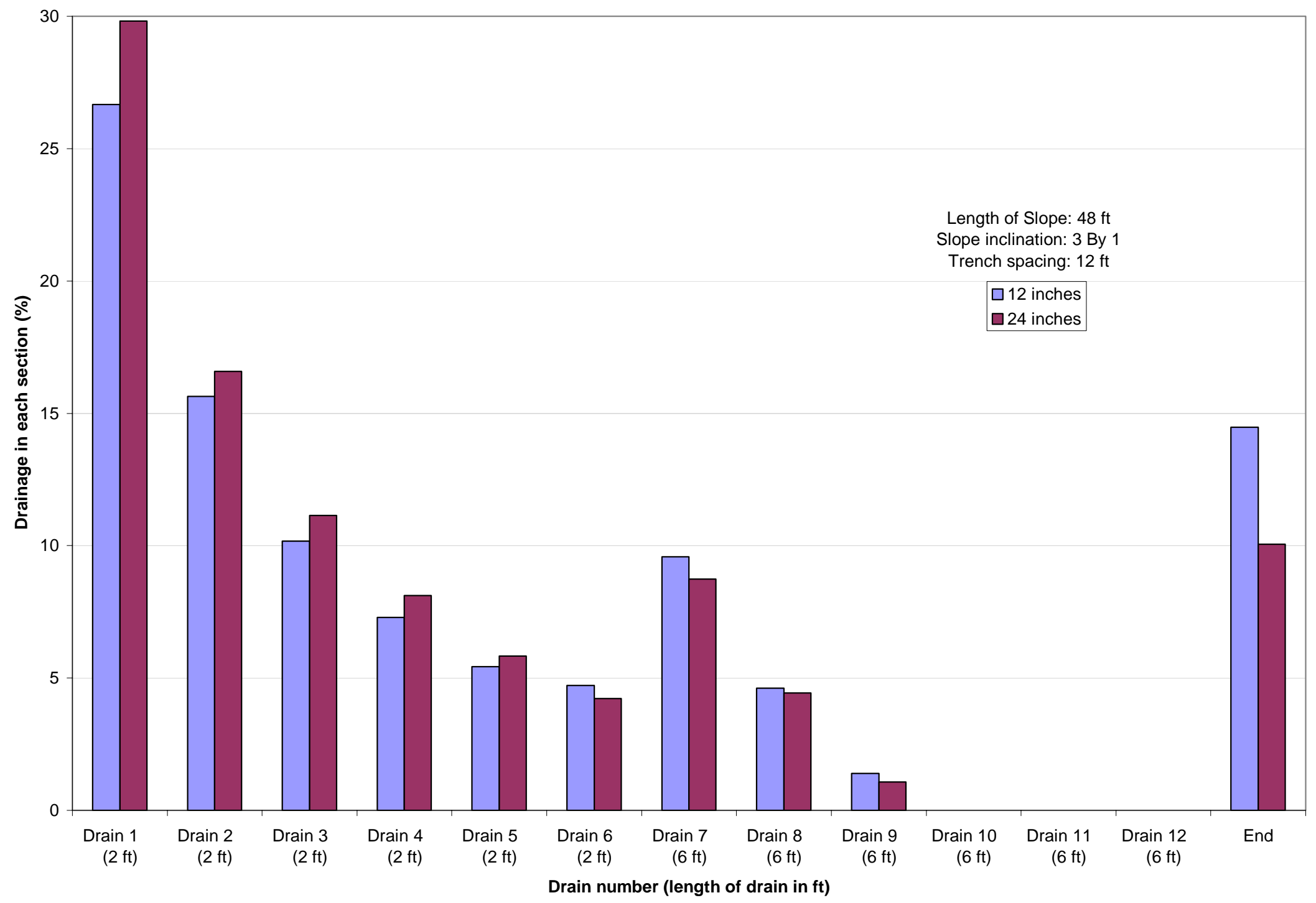

Figure E.5: Percentage of drainage in each section for Soil B for different water levels $(\mathrm{L}=48 \mathrm{ft}, 3: 1$ Slope inclination, $\mathrm{w}=12 \mathrm{ft})$. 


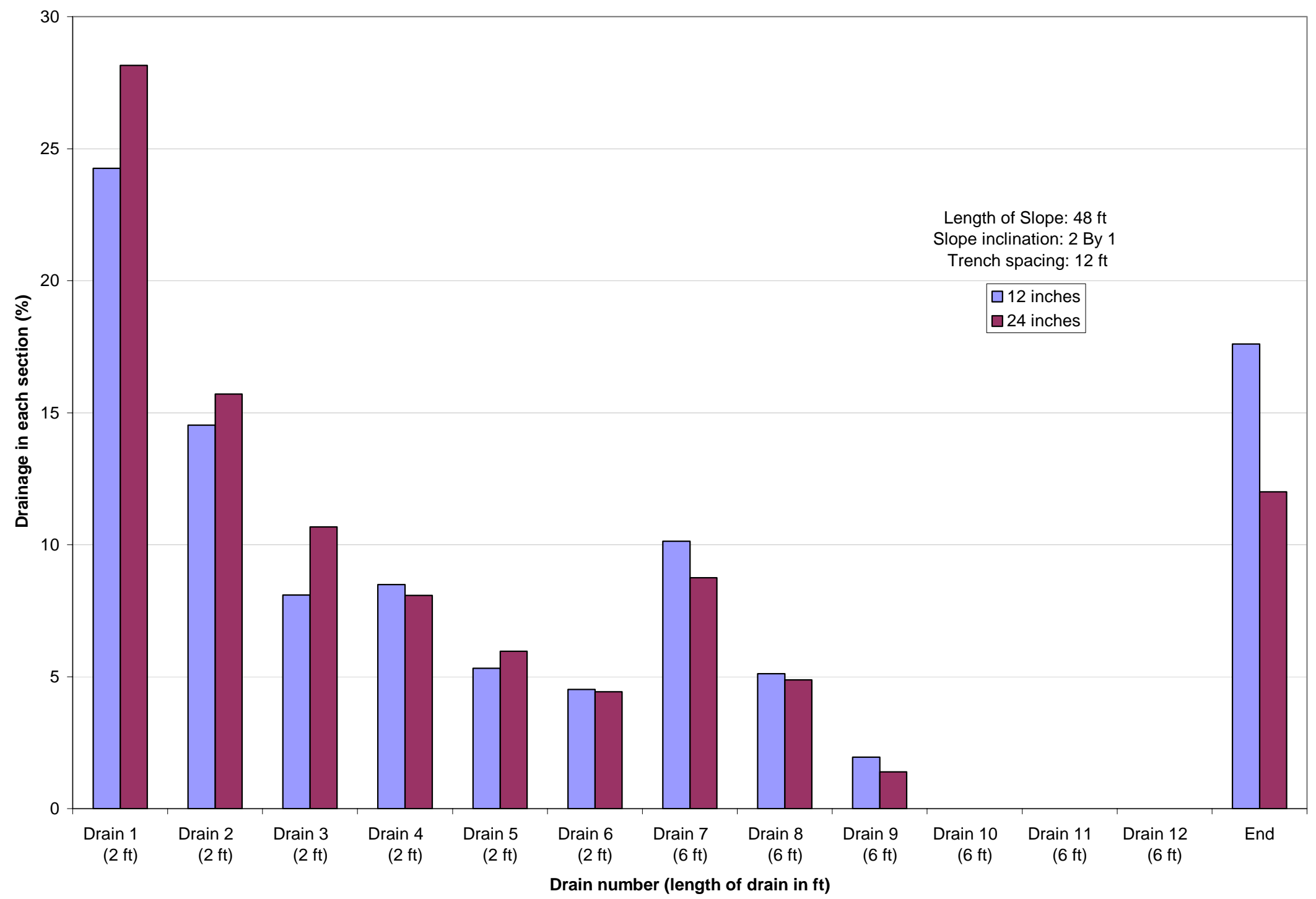

Figure E.6: Percentage of drainage in each section for Soil B for different water levels $(\mathrm{L}=48 \mathrm{ft}, 2: 1$ Slope inclination, $\mathrm{w}=12 \mathrm{ft}$ ). 


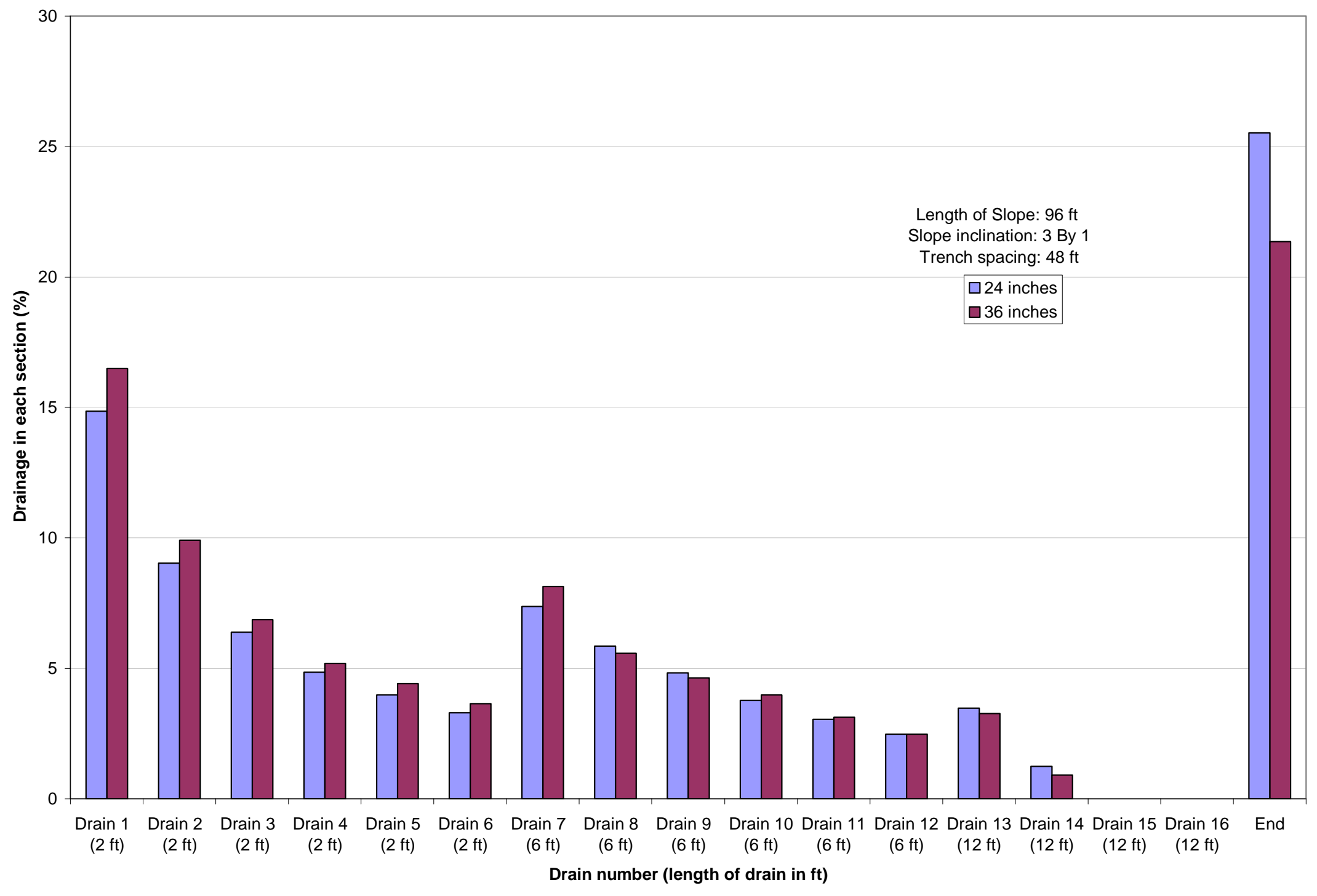

Figure E.7: Percentage of drainage in each section for Soil B for different water levels $(\mathrm{L}=96 \mathrm{ft}, 3: 1$ Slope inclination, $\mathrm{w}=48 \mathrm{ft})$. 


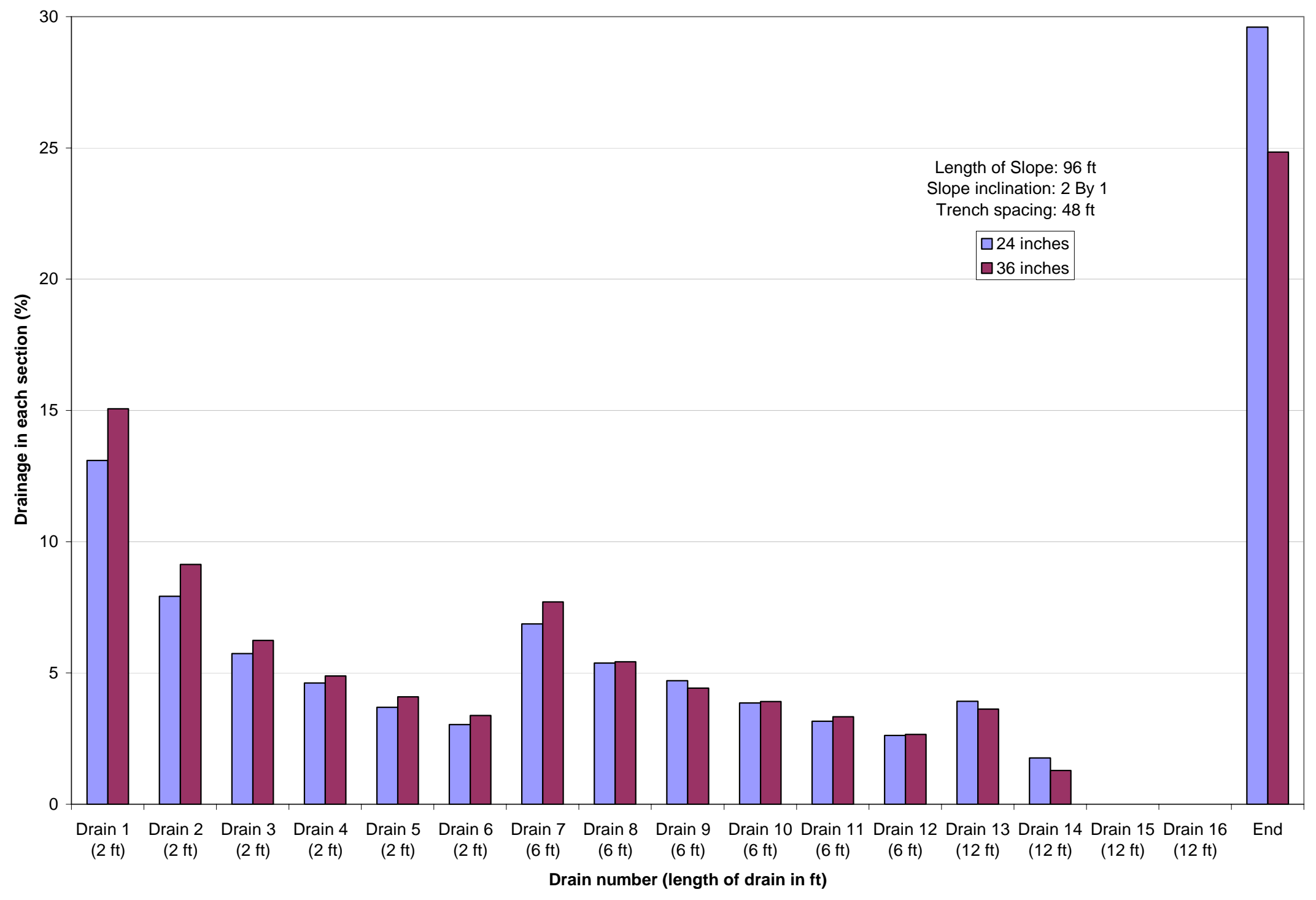

Figure E.8: Percentage of drainage in each section for Soil B for different water levels $(\mathrm{L}=96 \mathrm{ft}, 2: 1$ Slope inclination, $\mathrm{w}=48 \mathrm{ft}$ ). 


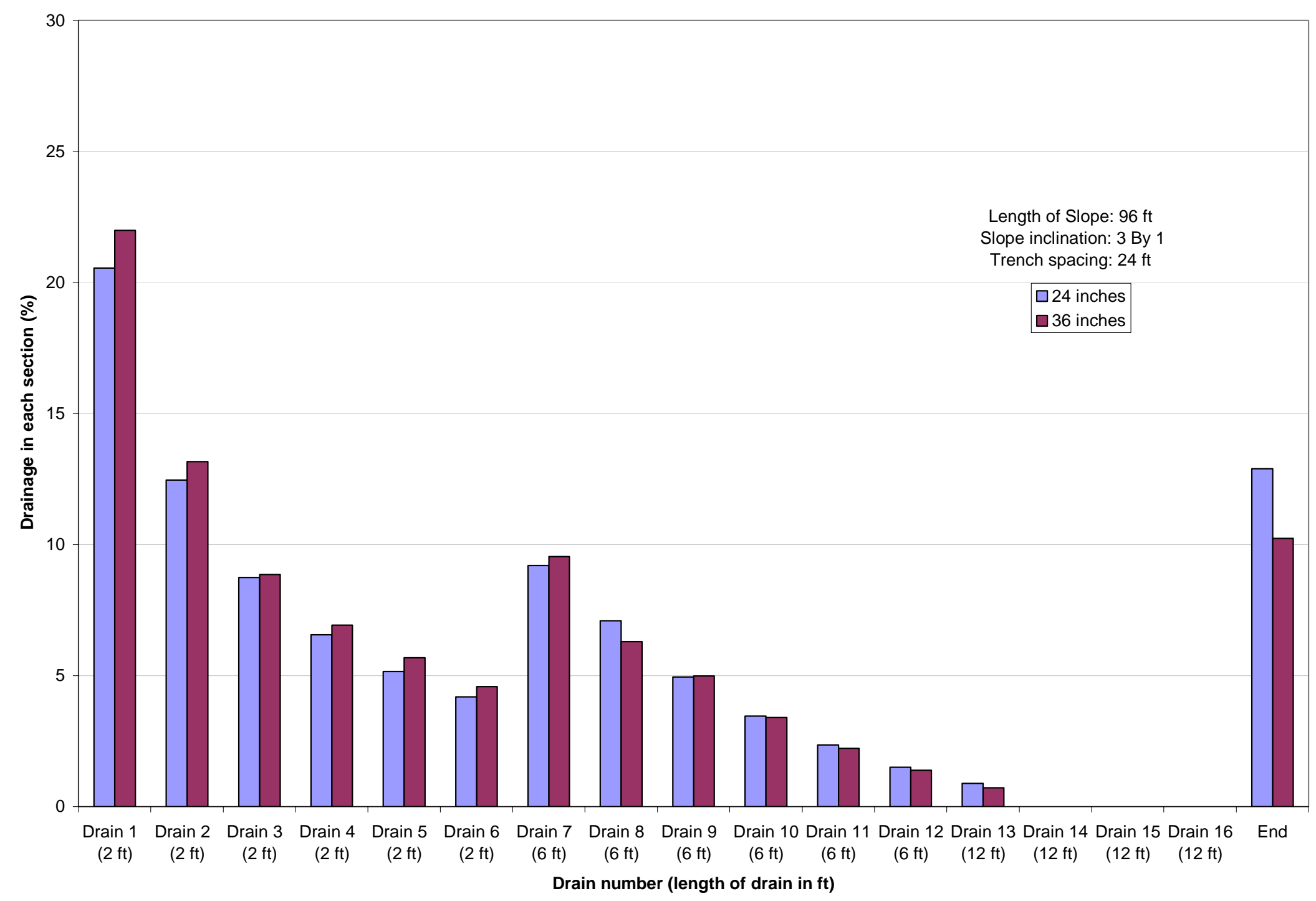

Figure E.9: Percentage of drainage in each section for Soil B for different water levels $(\mathrm{L}=96 \mathrm{ft}, 3: 1$ Slope inclination, $\mathrm{w}=24 \mathrm{ft})$. 


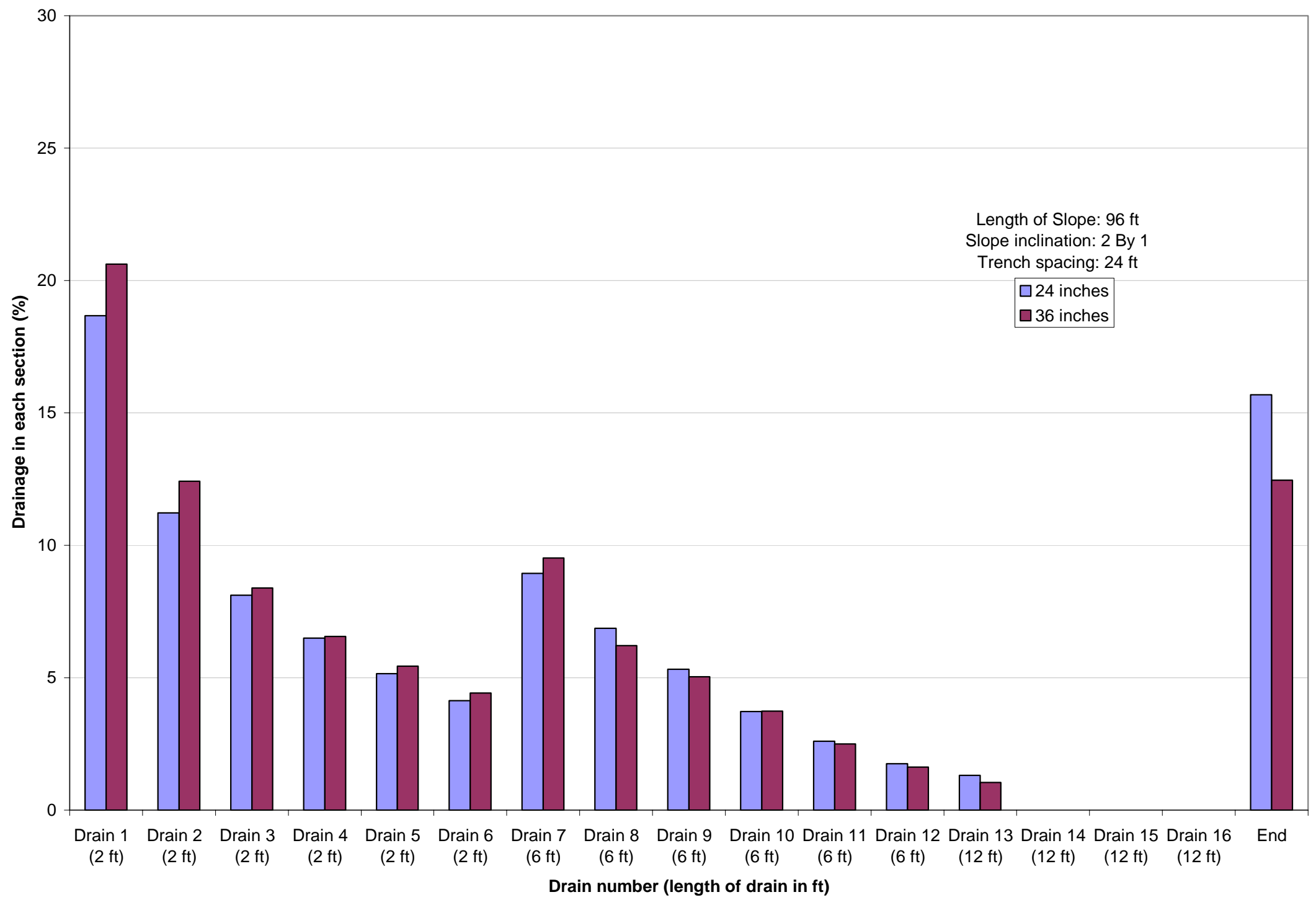

Figure E.10: Percentage of drainage in each section for Soil B for different water levels $(\mathrm{L}=96 \mathrm{ft}, 2: 1$ Slope inclination, $\mathrm{w}=24 \mathrm{ft}$ ). 


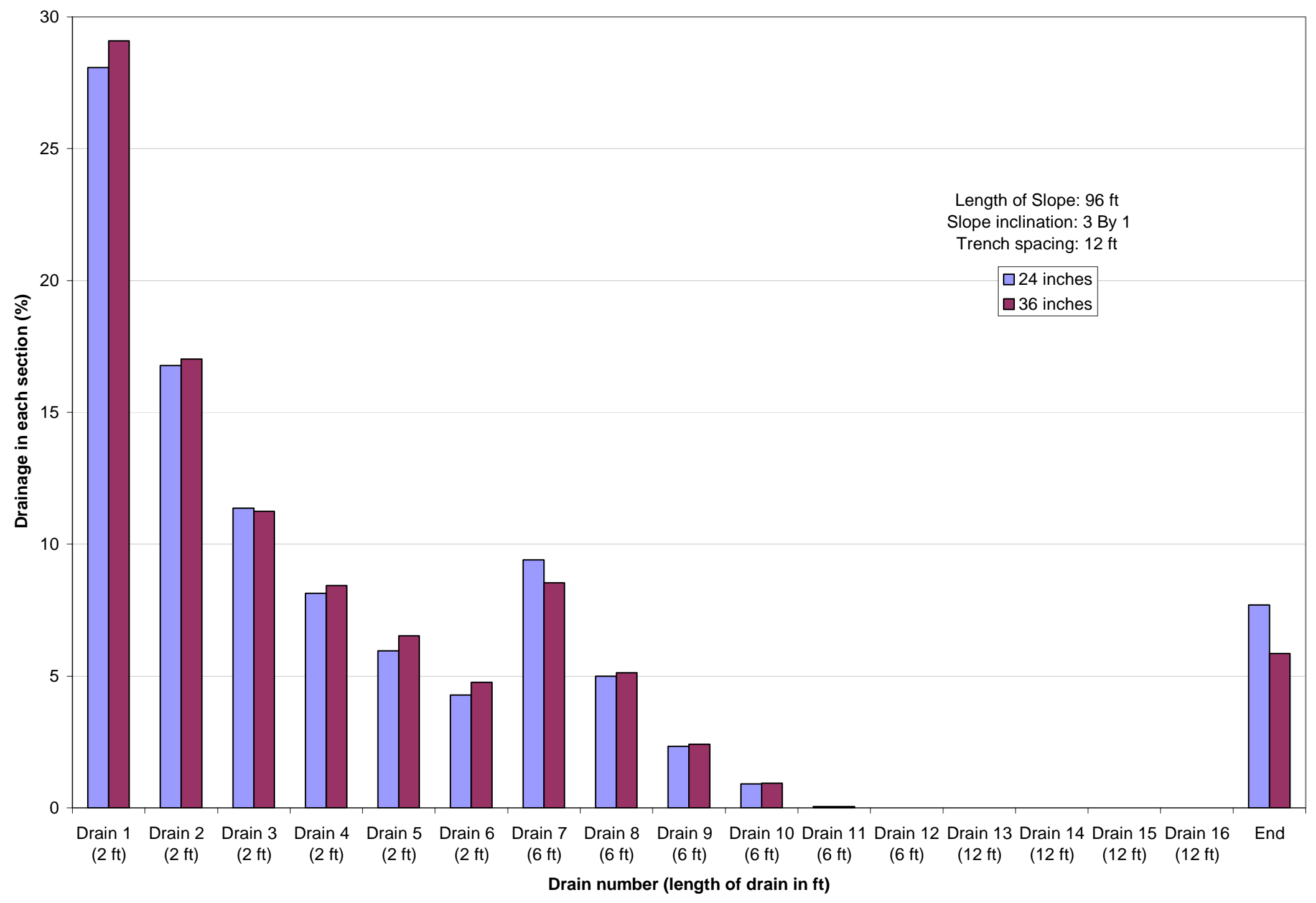

Figure E.11: Percentage of drainage in each section for Soil B for different water levels $(\mathrm{L}=96 \mathrm{ft}, 3: 1$ Slope inclination, $\mathrm{w}=12 \mathrm{ft})$. 


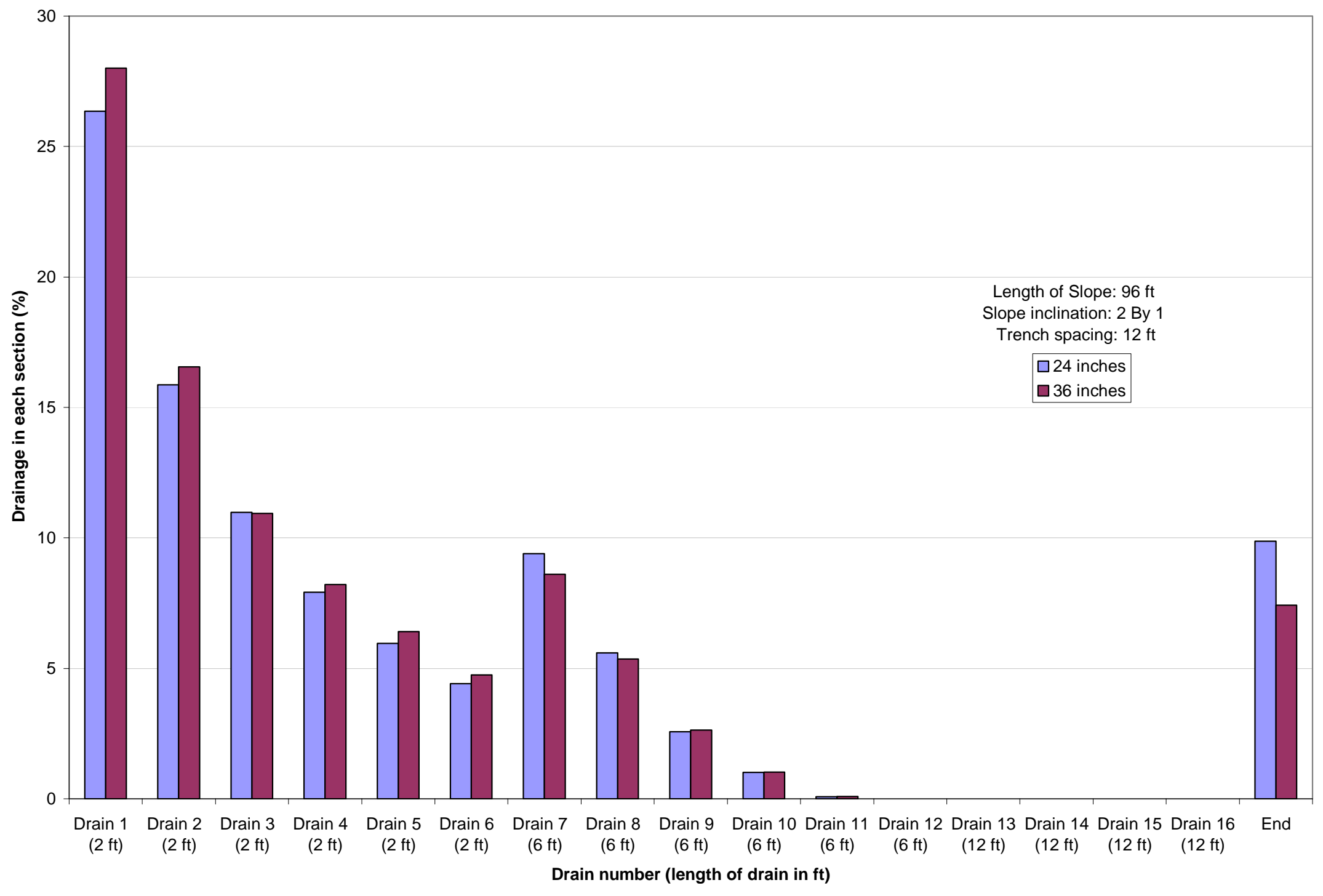

Figure E.12: Percentage of drainage in each section for Soil B for different water levels $(\mathrm{L}=96 \mathrm{ft}, 2: 1$ Slope inclination, $\mathrm{w}=12 \mathrm{ft})$. 


\section{APPENDIX F}

Influence of Length of the Slope on Seepage under Field conditions for Soil B

(For different values of trench spacing, slope inclination angle and saturation depth.) 


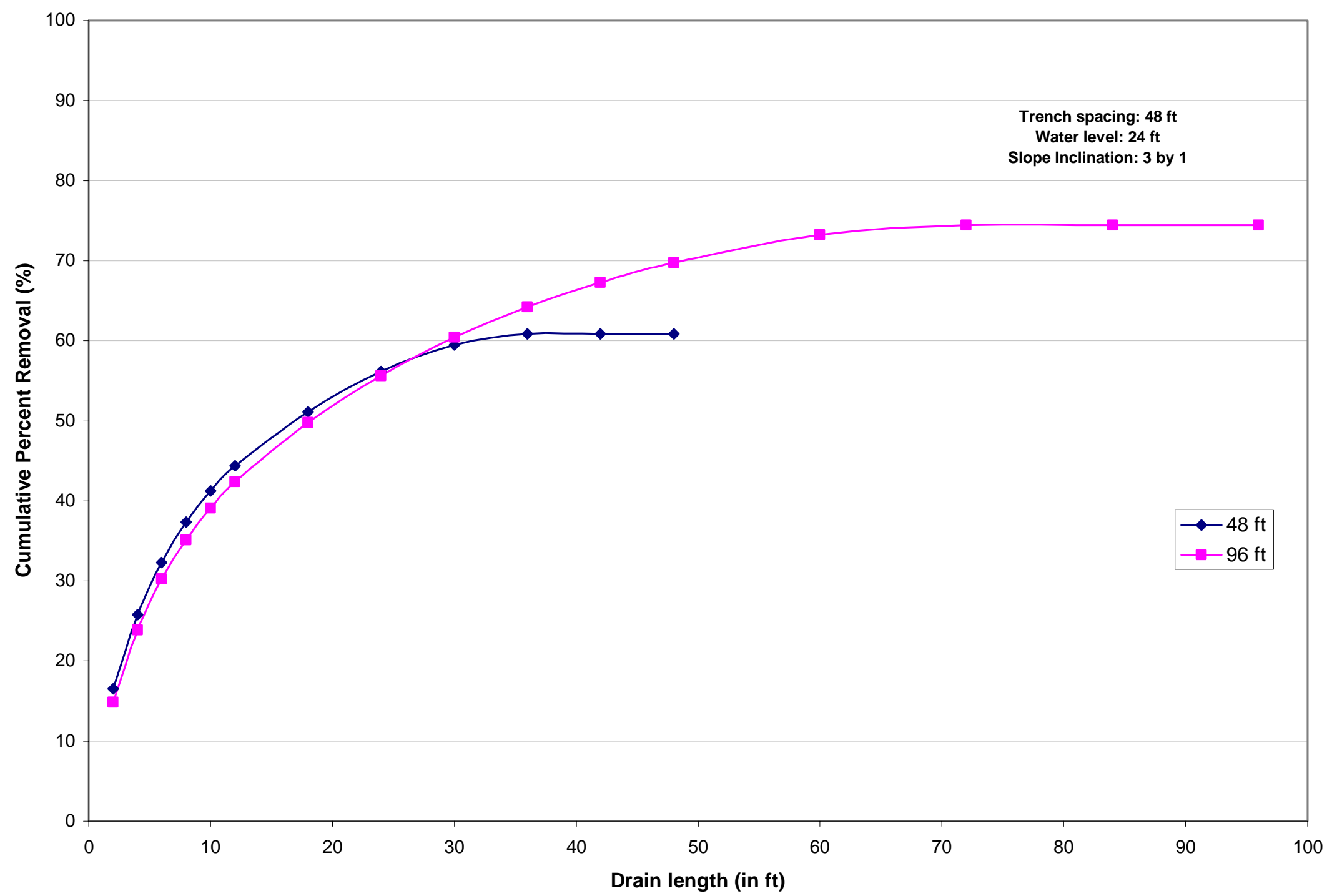

Figure F.1: Influence of Length of the slope on CPR $(\mathrm{w}=48 \mathrm{ft}, 3: 1$ Slope inclination, Water level $=24 \mathrm{ft})$. 


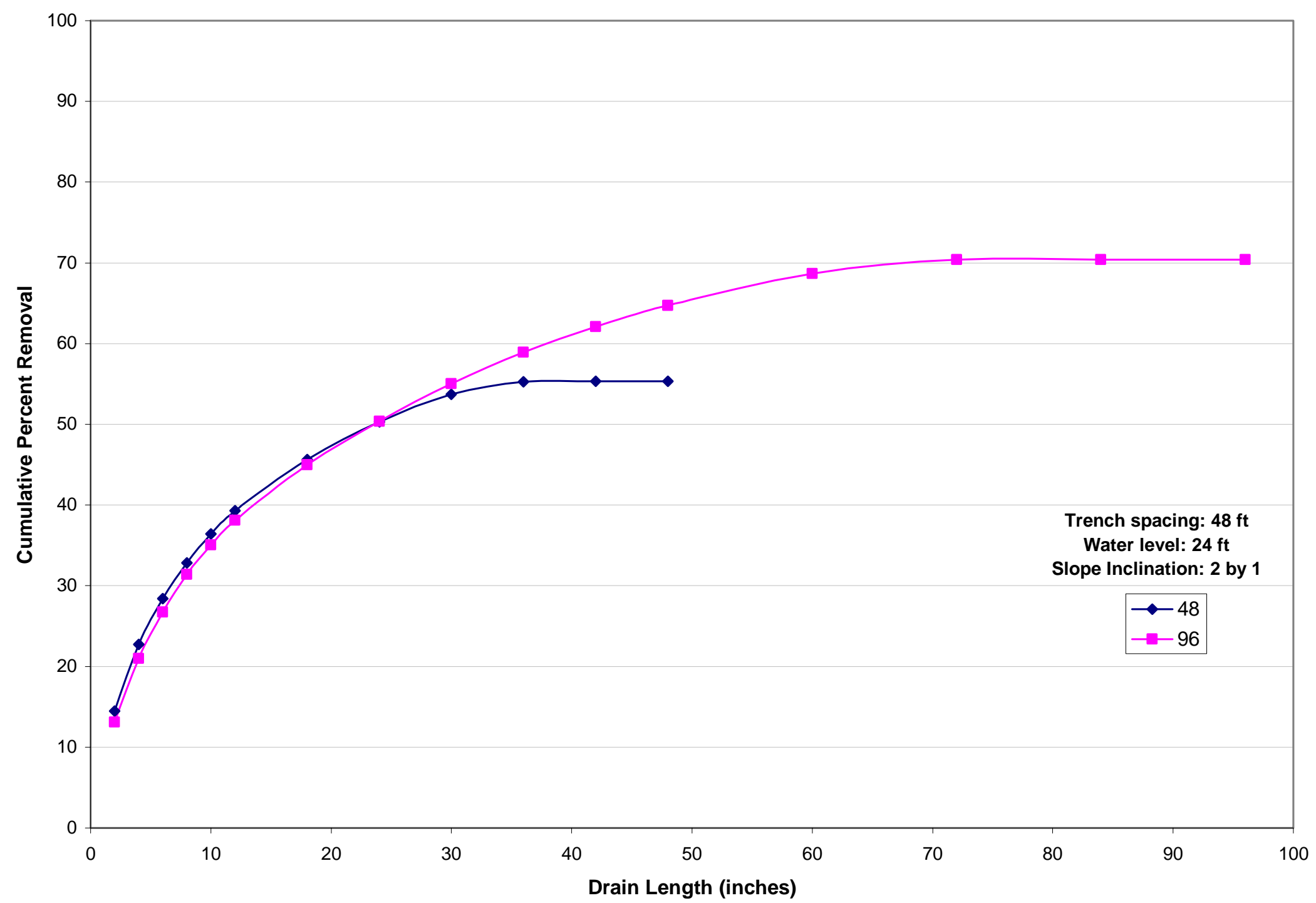

Figure F.2: Influence of Length of the slope on CPR $(w=48 \mathrm{ft}, 2: 1$ Slope inclination, Water level $=24 \mathrm{ft})$. 


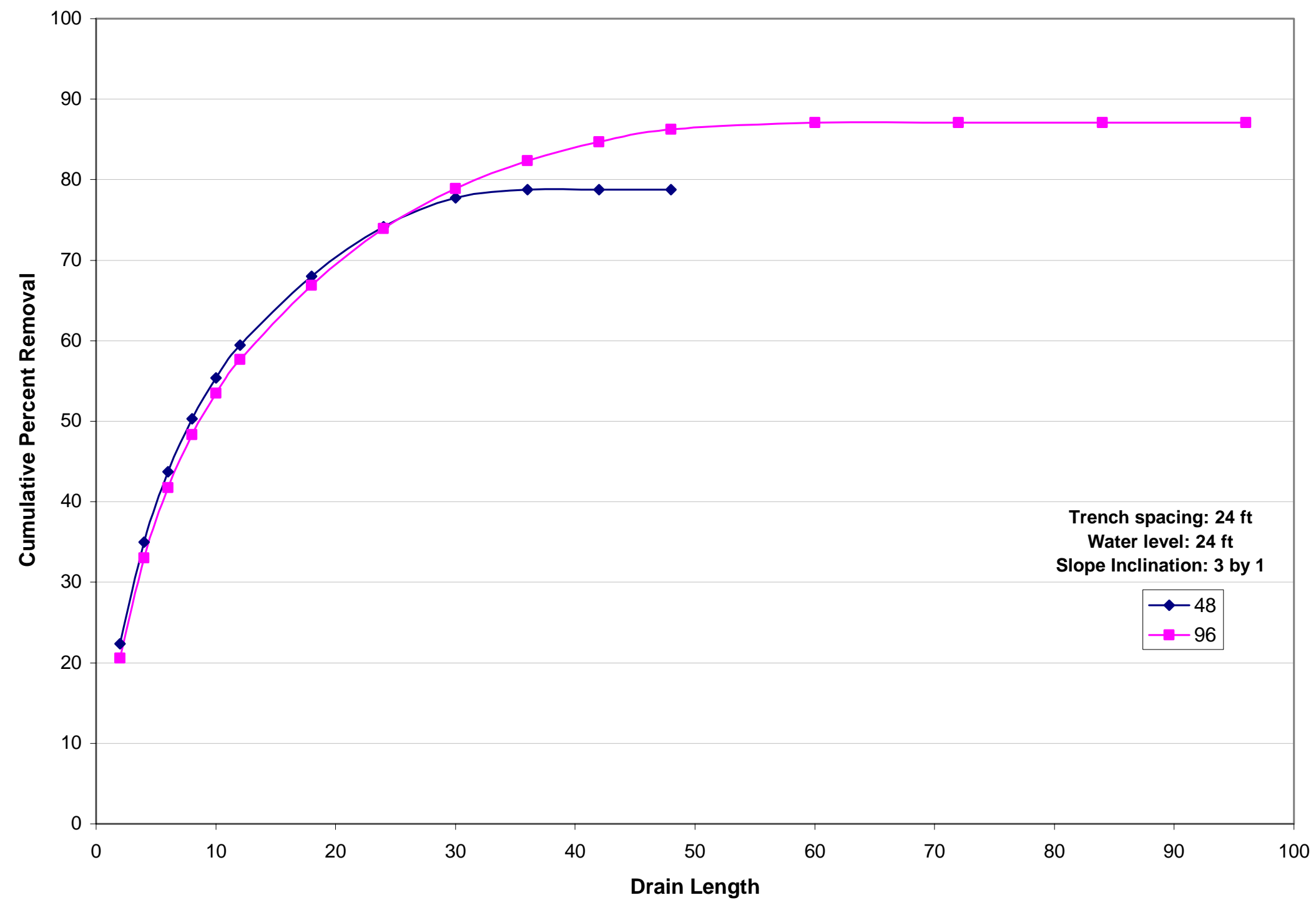

Figure F.3: Influence of Length of the slope on CPR $(\mathrm{w}=24 \mathrm{ft}, 3: 1$ Slope inclination, Water level $=24 \mathrm{ft})$. 


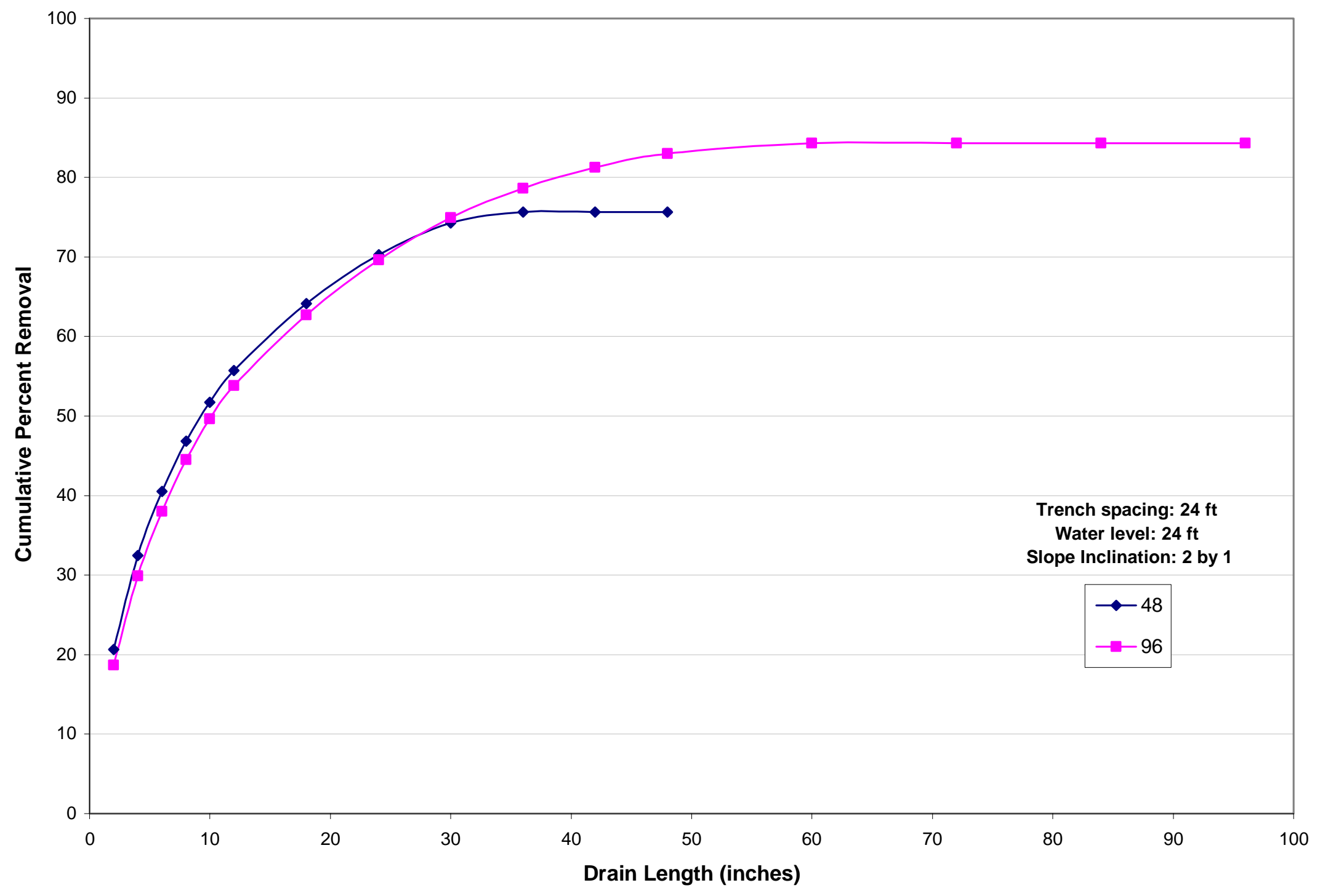

Figure F.4: Influence of Length of the slope on CPR $(w=24 \mathrm{ft}, 2: 1$ Slope inclination, Water level $=24 \mathrm{ft})$. 


\section{APPENDIX G}

Influence of Slope angle on Seepage under Field conditions for

Soil B

(For different values of trench spacing and water level.) 


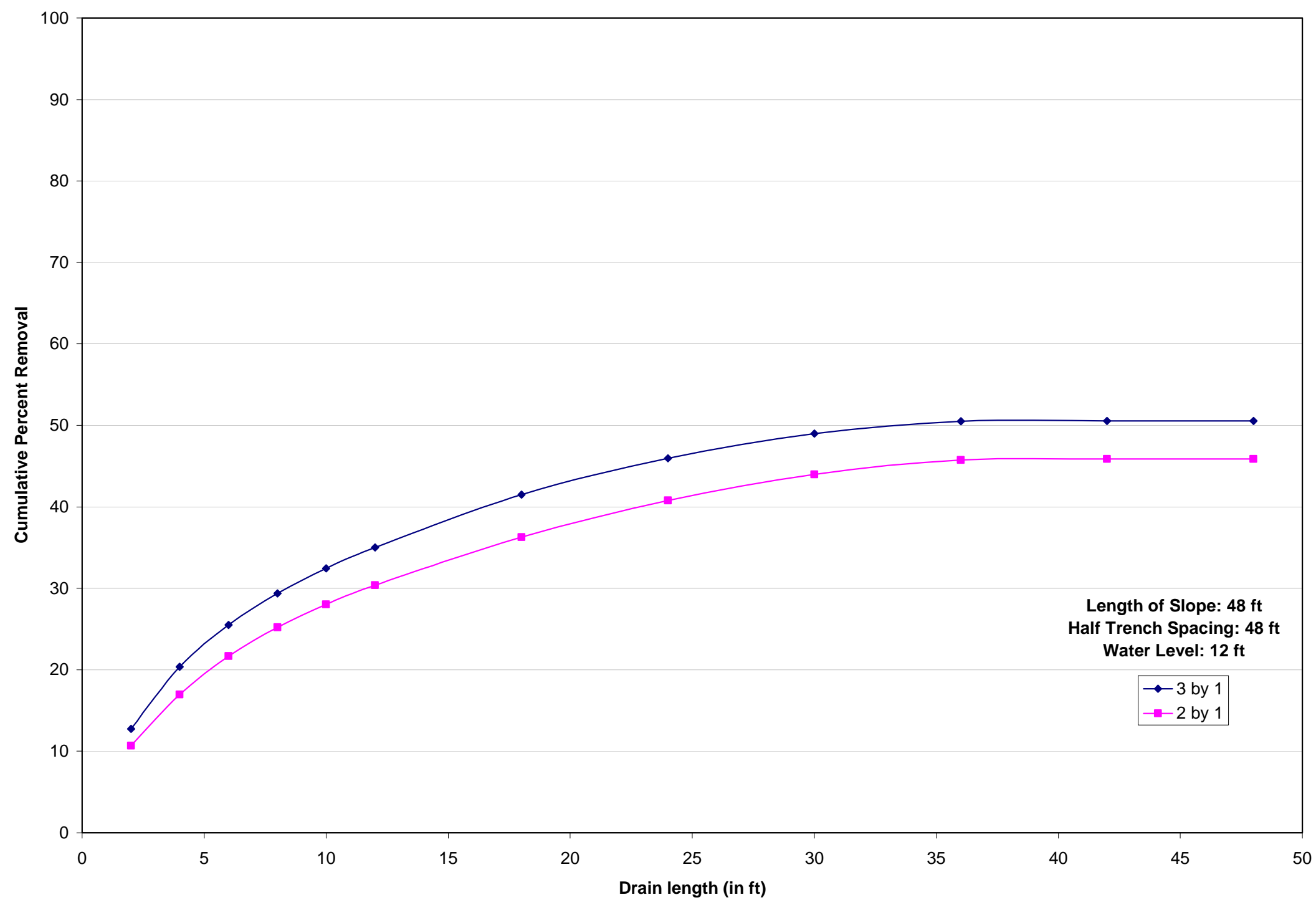

Figure G.1: Influence of Slope inclination angle for Soil B $(\mathrm{L}=48 \mathrm{ft}, \mathrm{w}=48 \mathrm{ft}$, water level $=12 \mathrm{ft})$. 


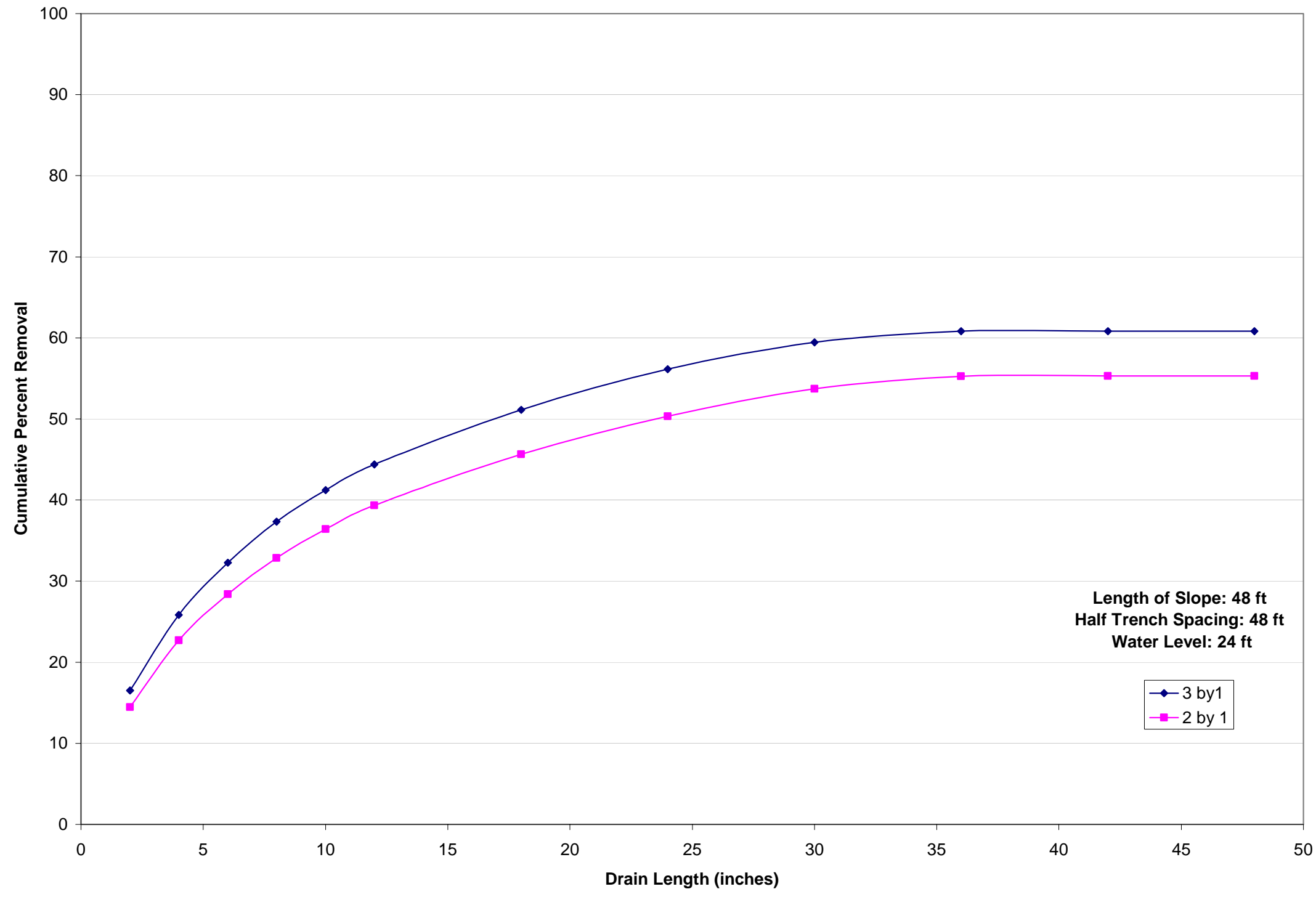

Figure G.2: Influence of Slope inclination angle for Soil B $(\mathrm{L}=48 \mathrm{ft}, \mathrm{w}=48 \mathrm{ft}$, water level $=24 \mathrm{ft})$. 


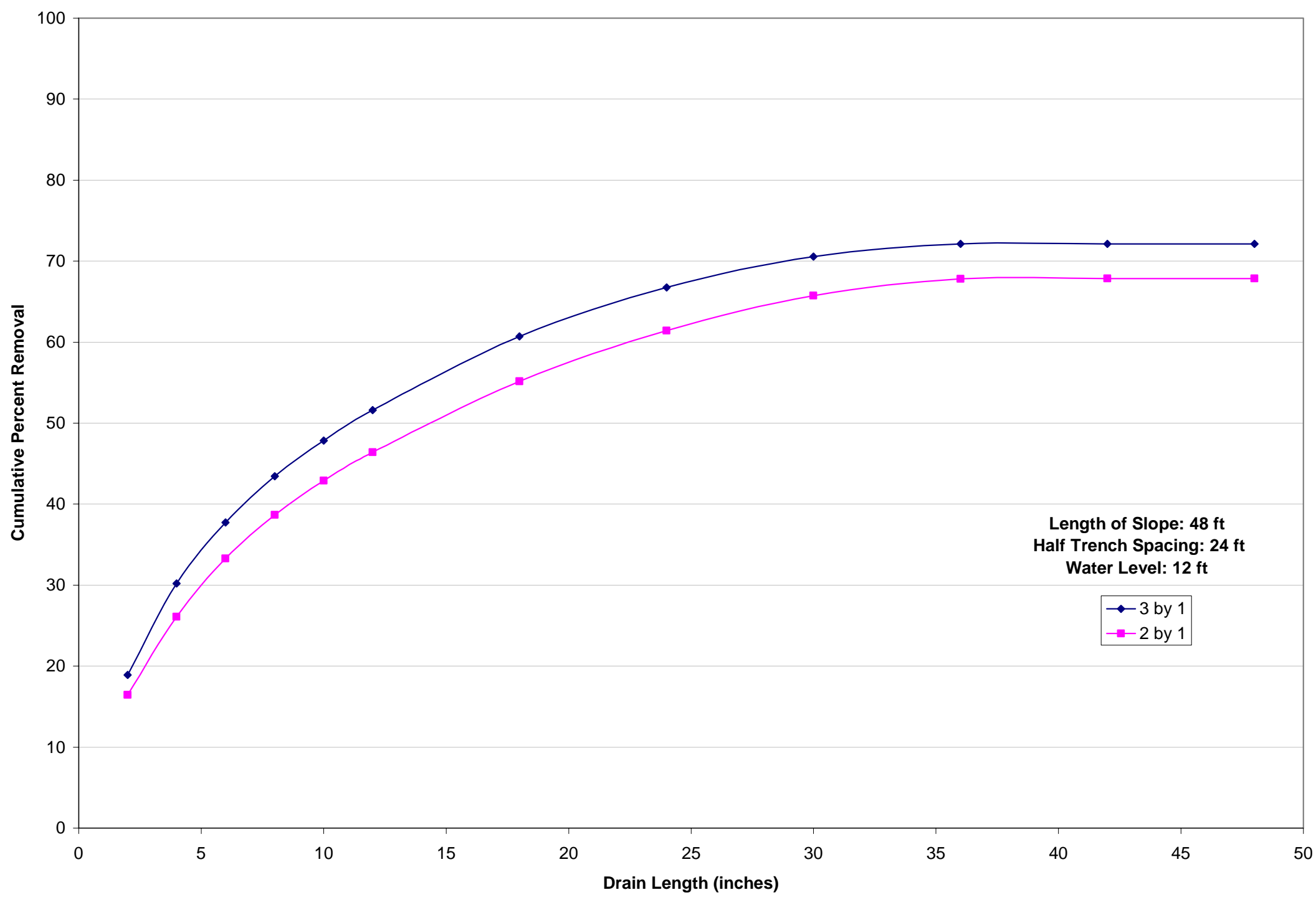

Figure G.3: Influence of Slope inclination angle for Soil B $(\mathrm{L}=48 \mathrm{ft}, \mathrm{w}=24 \mathrm{ft}$, water level $=12 \mathrm{ft})$. 


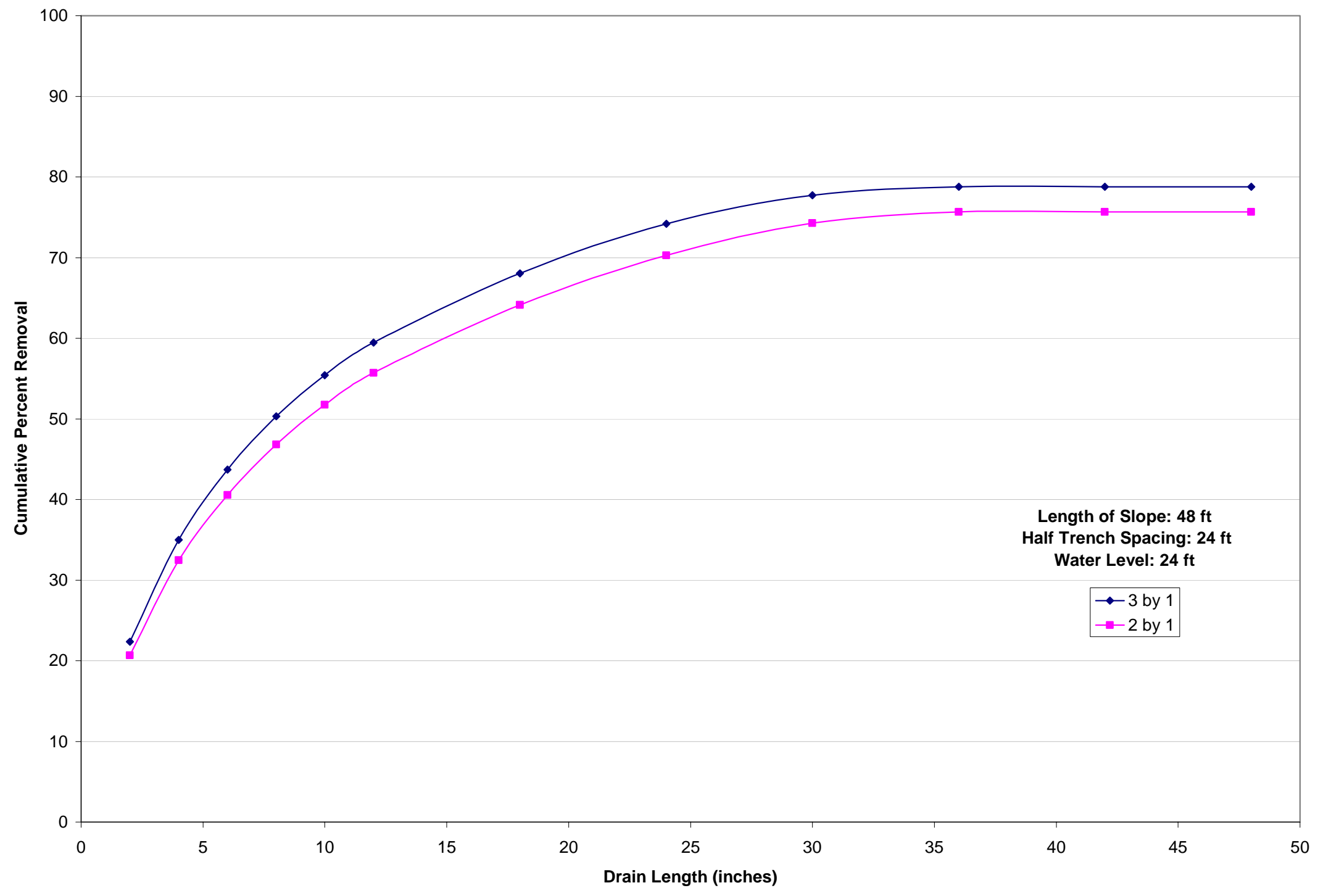

Figure G.4: Influence of Slope inclination angle for Soil B $(\mathrm{L}=48 \mathrm{ft}, \mathrm{w}=24 \mathrm{ft}$, water level $=24 \mathrm{ft})$. 


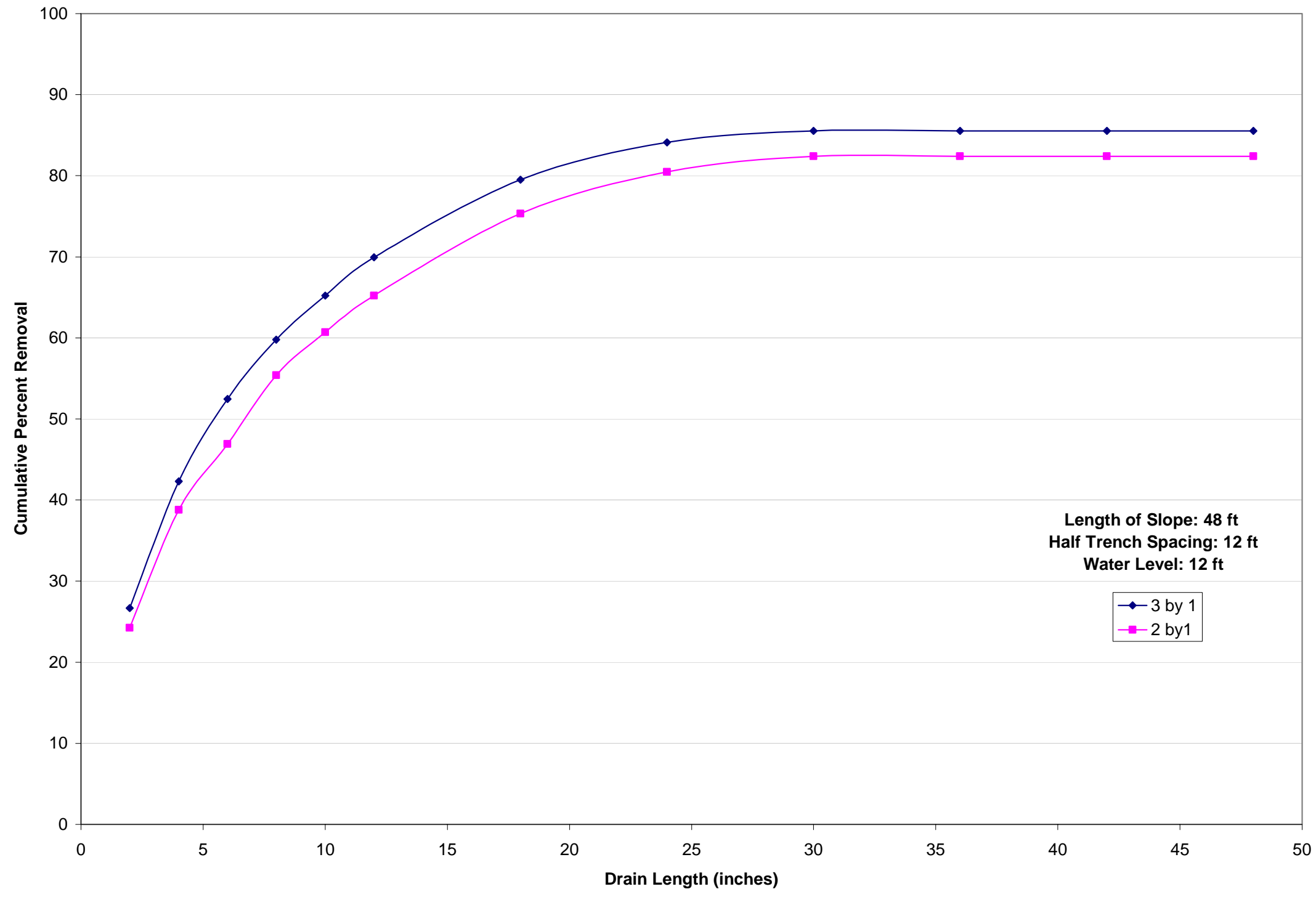

Figure G.5: Influence of Slope inclination angle for Soil B $(\mathrm{L}=48 \mathrm{ft}, \mathrm{w}=12 \mathrm{ft}$, water level $=12 \mathrm{ft})$. 


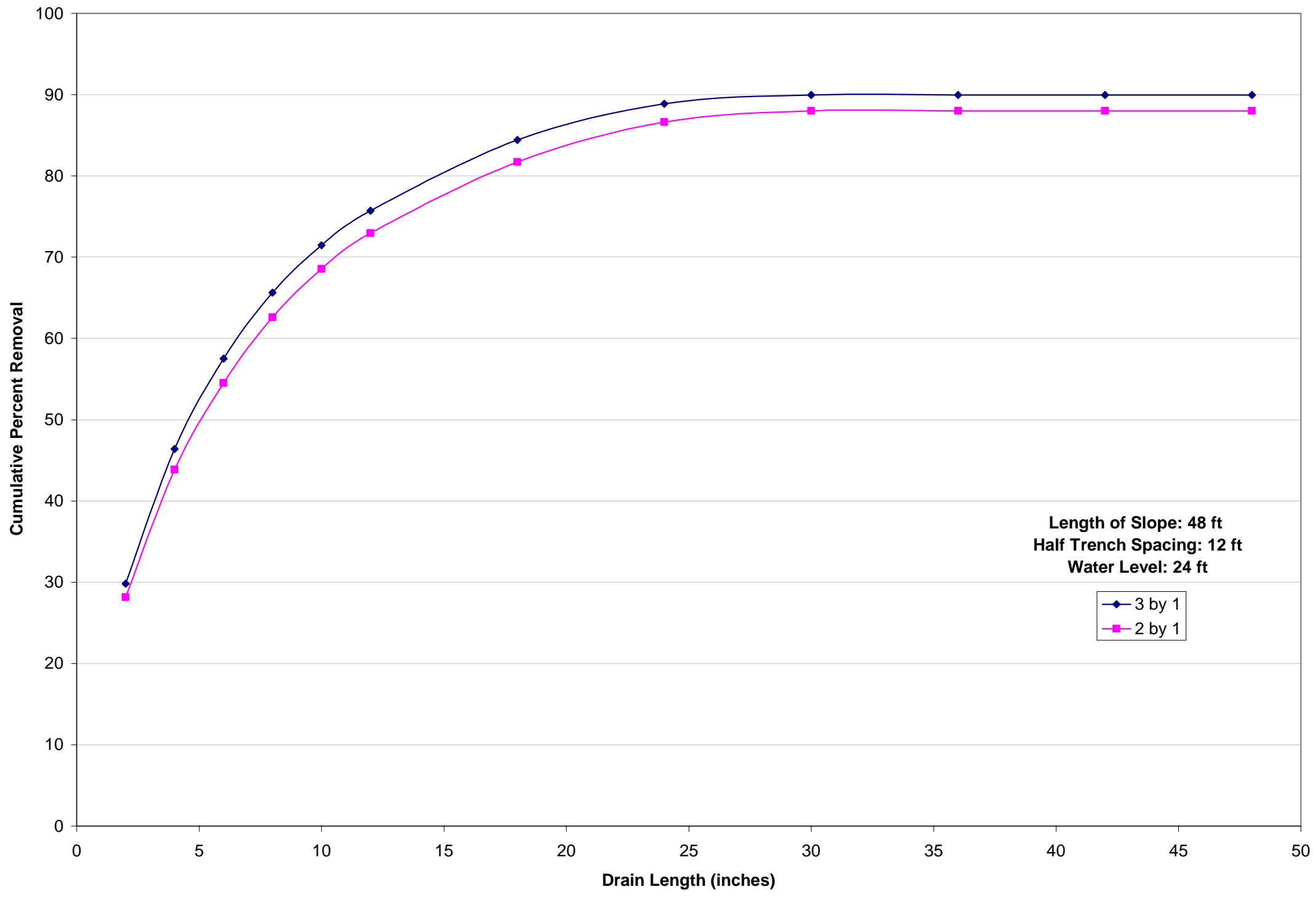

Figure G.6: Influence of Slope inclination angle for Soil B $(\mathrm{L}=48 \mathrm{ft}, \mathrm{w}=12 \mathrm{ft}$, water level $=24 \mathrm{ft})$. 


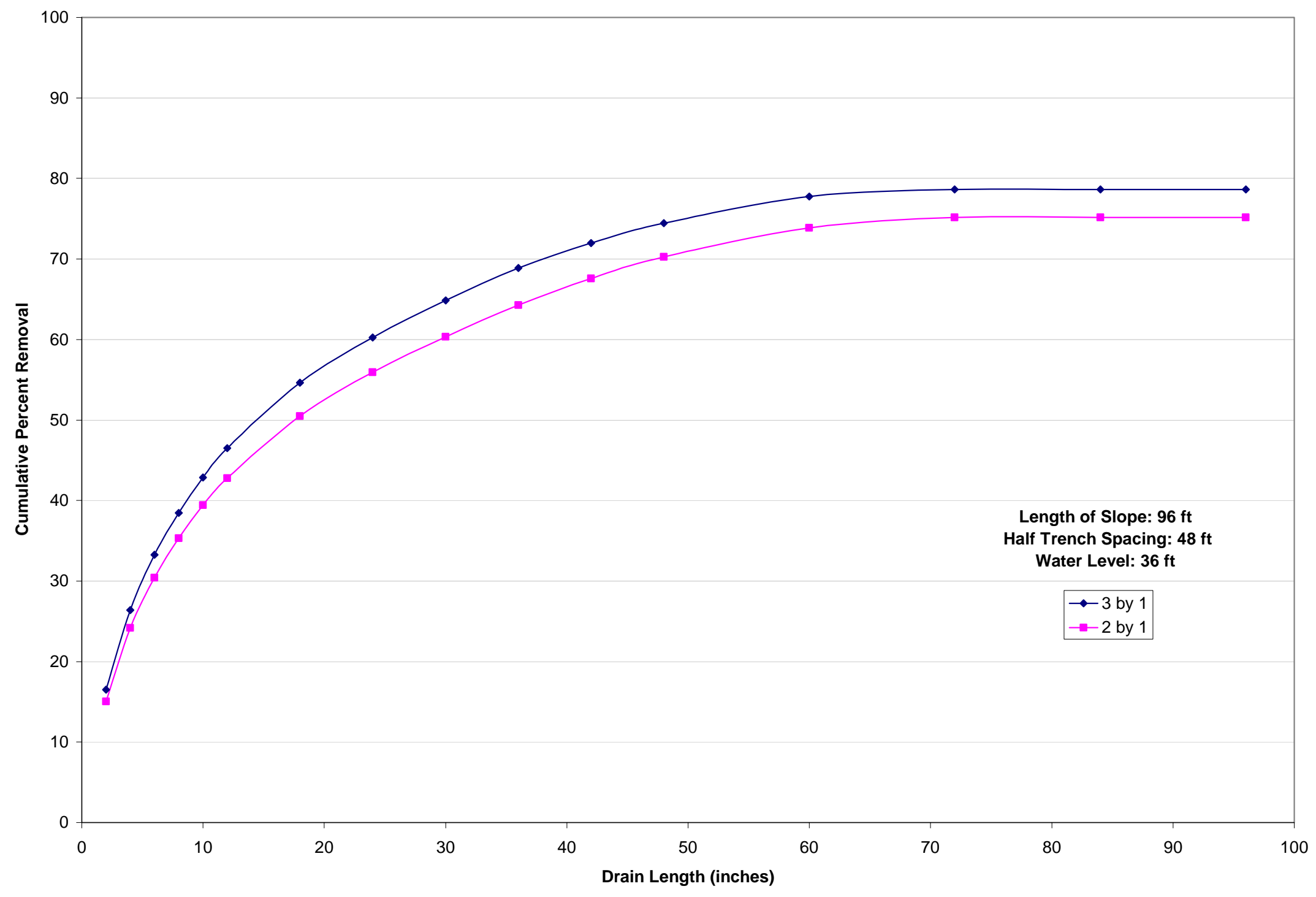

Figure G.7: Influence of Slope inclination angle for Soil B $(\mathrm{L}=96 \mathrm{ft}, \mathrm{w}=48 \mathrm{ft}$, water level $=36 \mathrm{ft})$. 


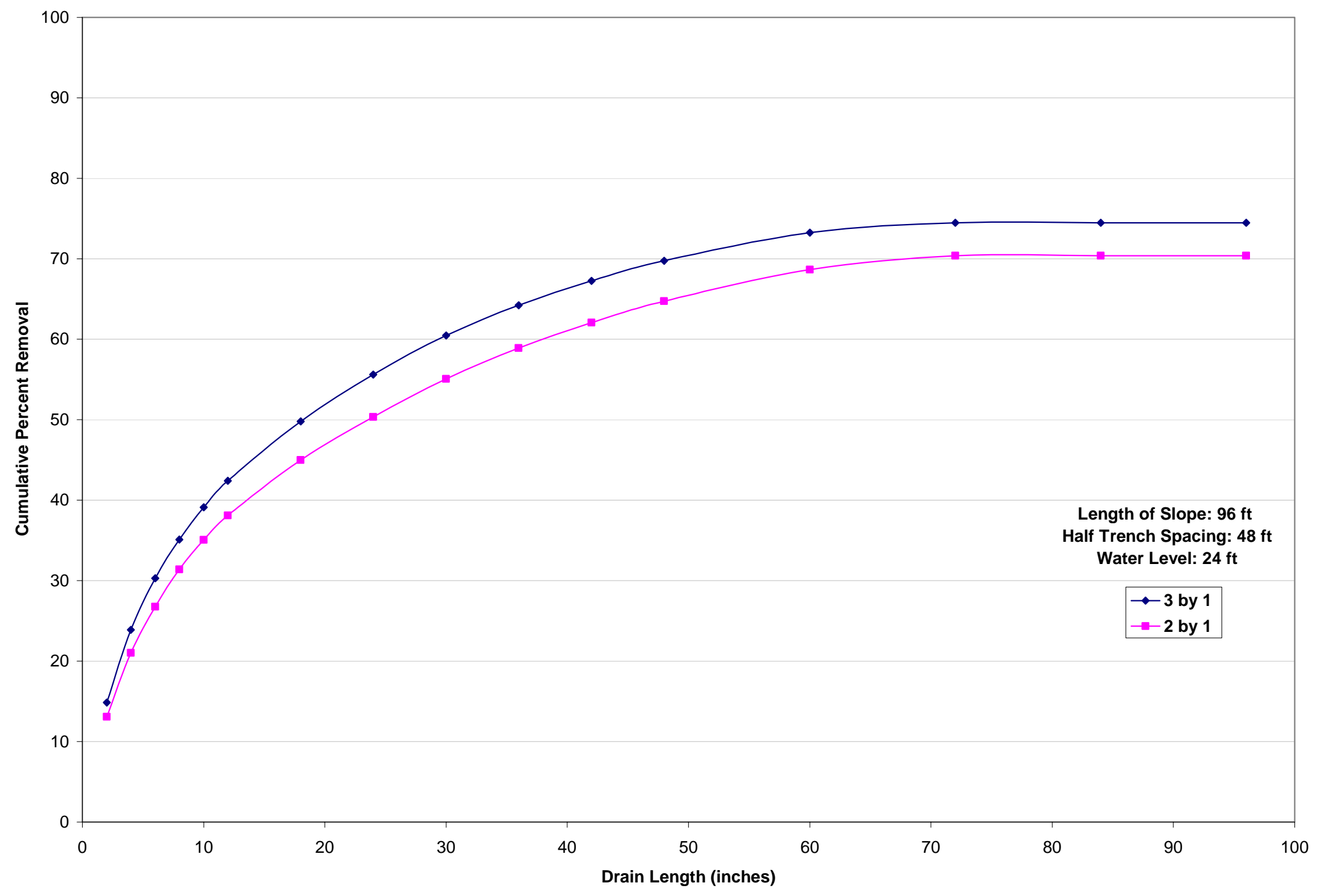

Figure G.8: Influence of Slope inclination angle for Soil B $(\mathrm{L}=96 \mathrm{ft}, \mathrm{w}=48 \mathrm{ft}$, water level $=24 \mathrm{ft})$. 


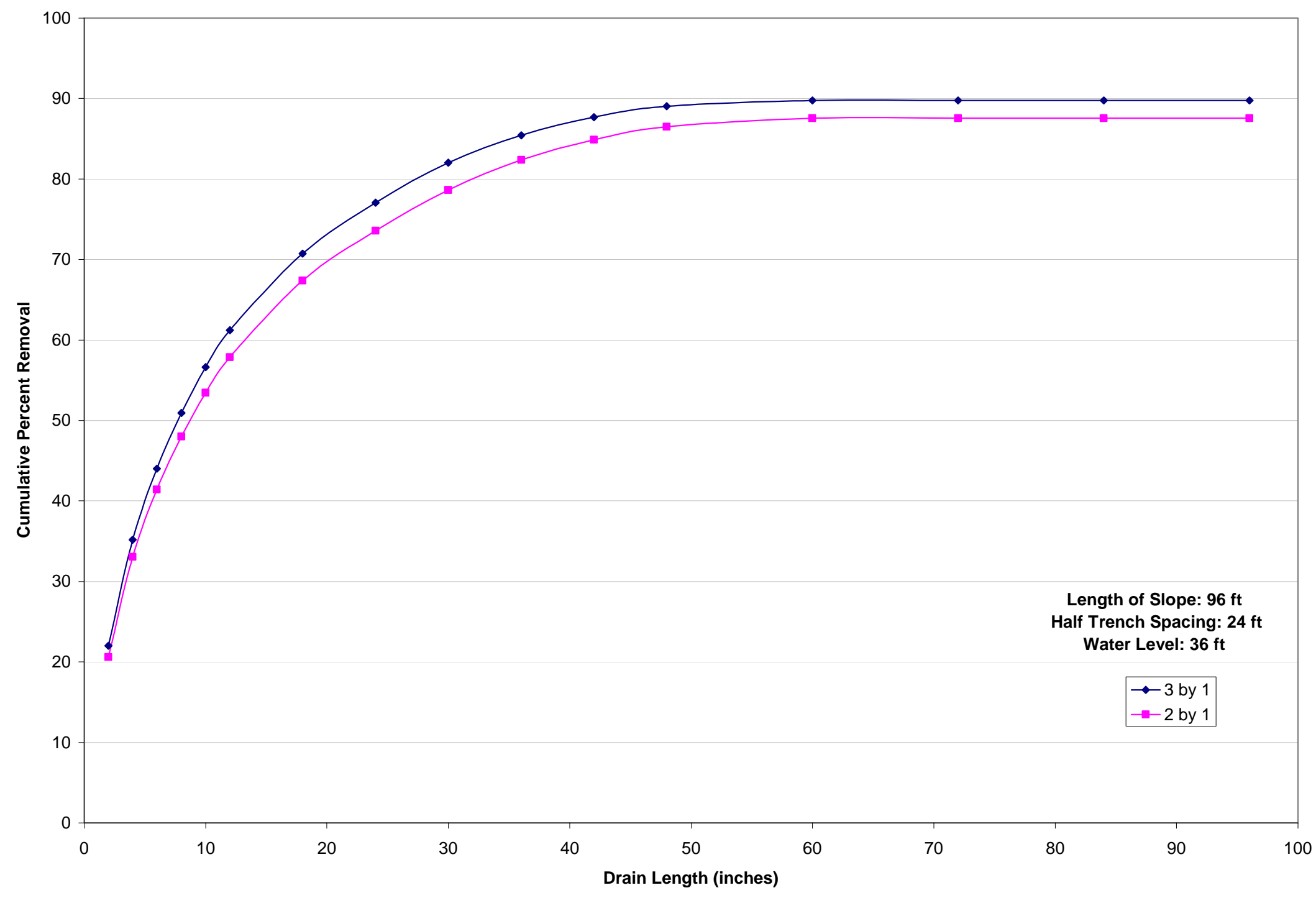

Figure G.9: Influence of Slope inclination angle for Soil B ( $\mathrm{L}=96 \mathrm{ft}, \mathrm{w}=24 \mathrm{ft}$, water level $=36 \mathrm{ft})$. 


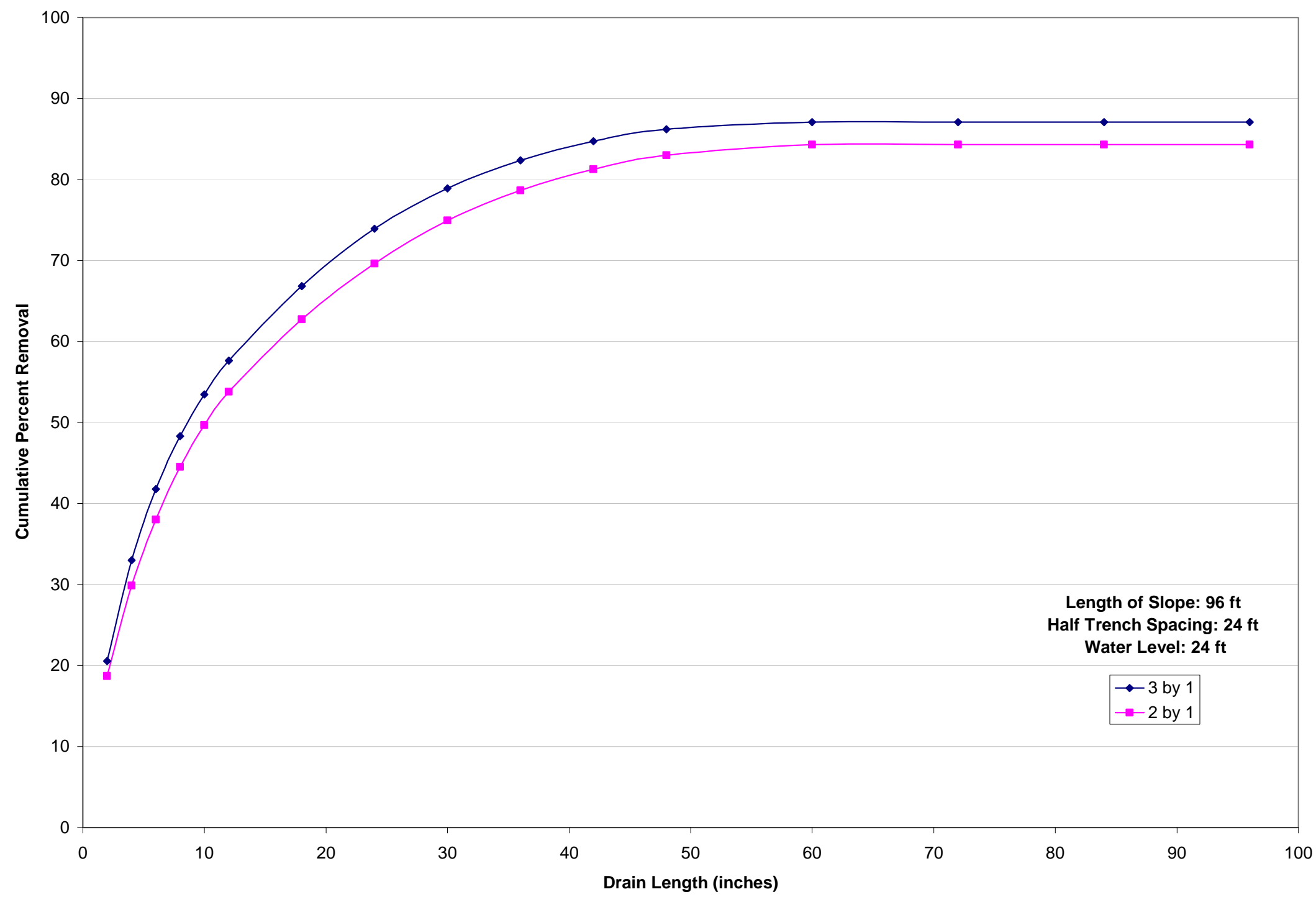

Figure G.10: Influence of Slope inclination angle for Soil B $(\mathrm{L}=96 \mathrm{ft}, \mathrm{w}=24 \mathrm{ft}$, water level $=24 \mathrm{ft})$. 


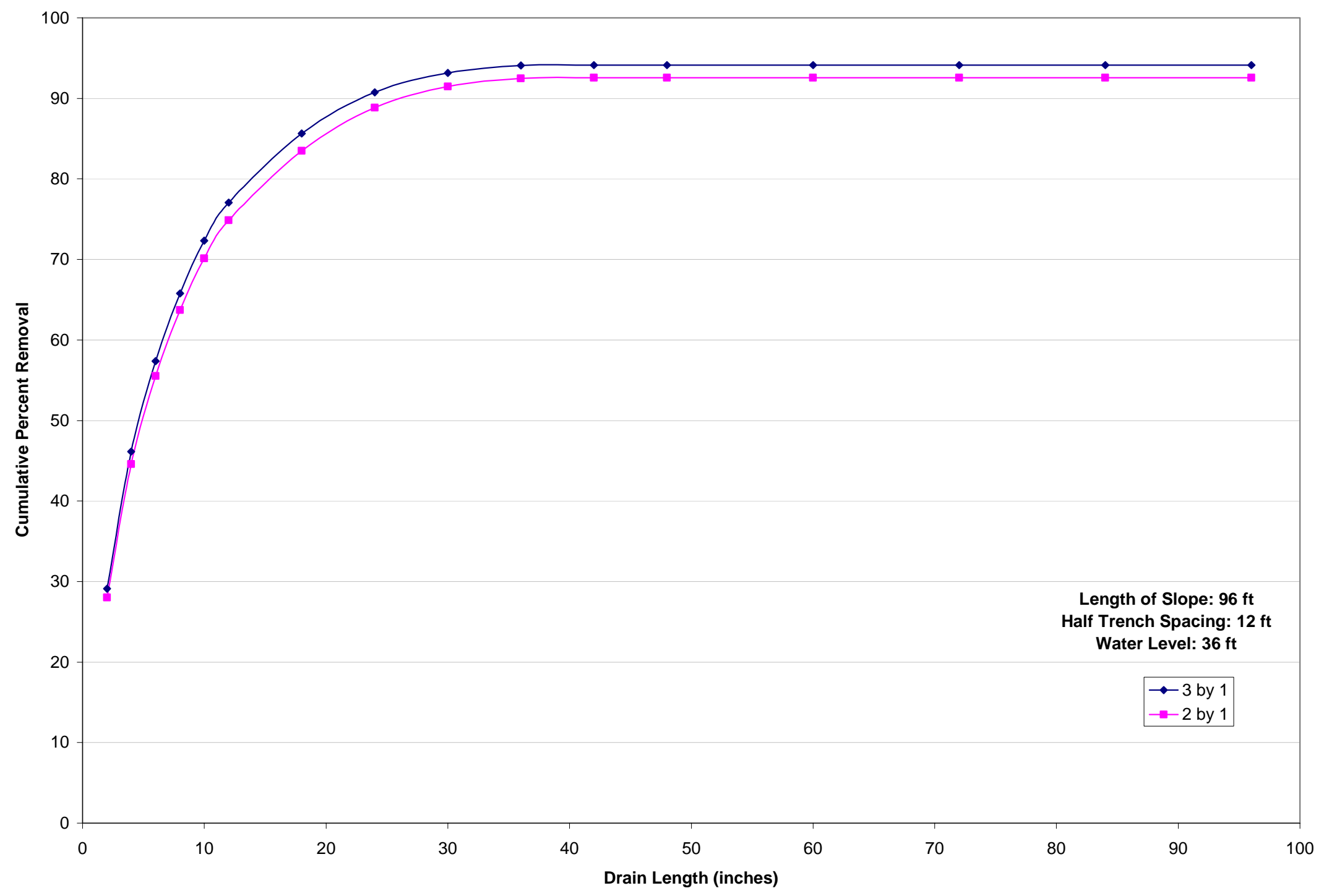

Figure G.11: Influence of Slope inclination angle for Soil B ( $\mathrm{L}=96 \mathrm{ft}, \mathrm{w}=12 \mathrm{ft}$, water level $=36 \mathrm{ft})$. 


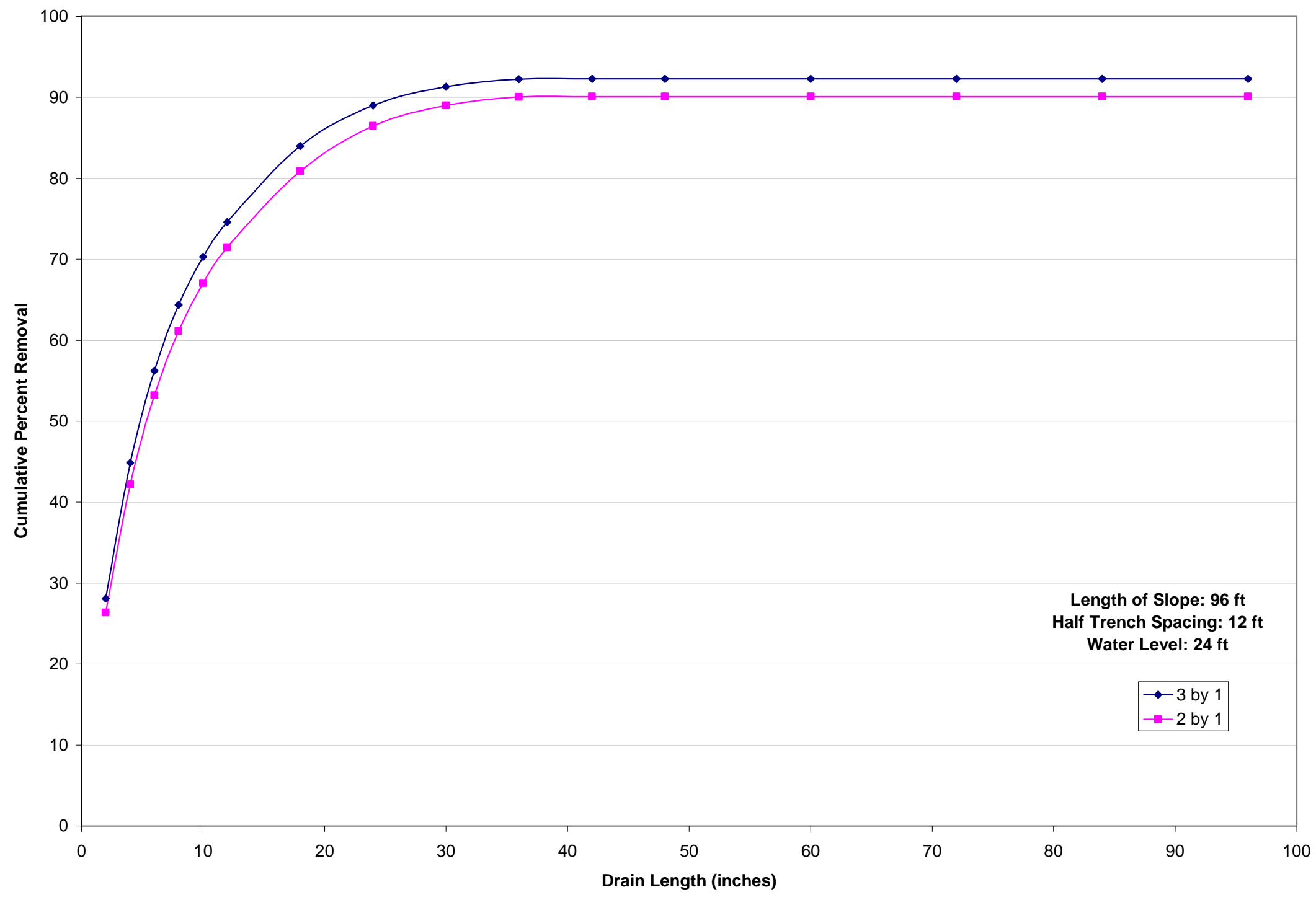

Figure G.12: Influence of Slope inclination angle for Soil B $(\mathrm{L}=96 \mathrm{ft}, \mathrm{w}=12 \mathrm{ft}$, water level $=24 \mathrm{ft})$. 


\section{APPENDIX H}

Influence of Trench Spacing on Seepage under Field conditions for

Soil B

(For different values of Slope inclination and water levels.) 


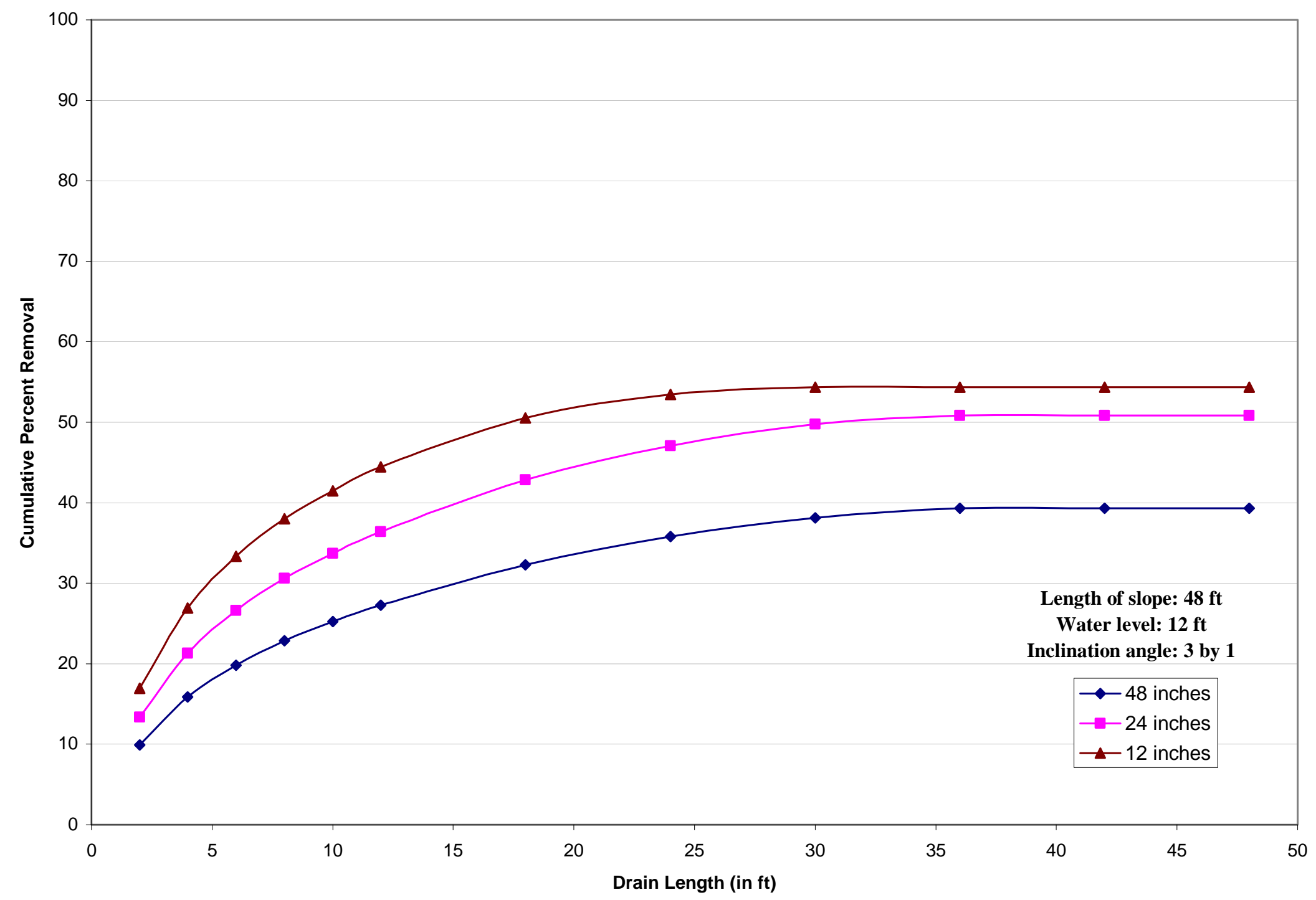

Figure H.1: Influence of Trench Spacing for Soil B ( $L=48 \mathrm{ft}$, water level = $12 \mathrm{ft}, 3: 1$ Slope angle). 


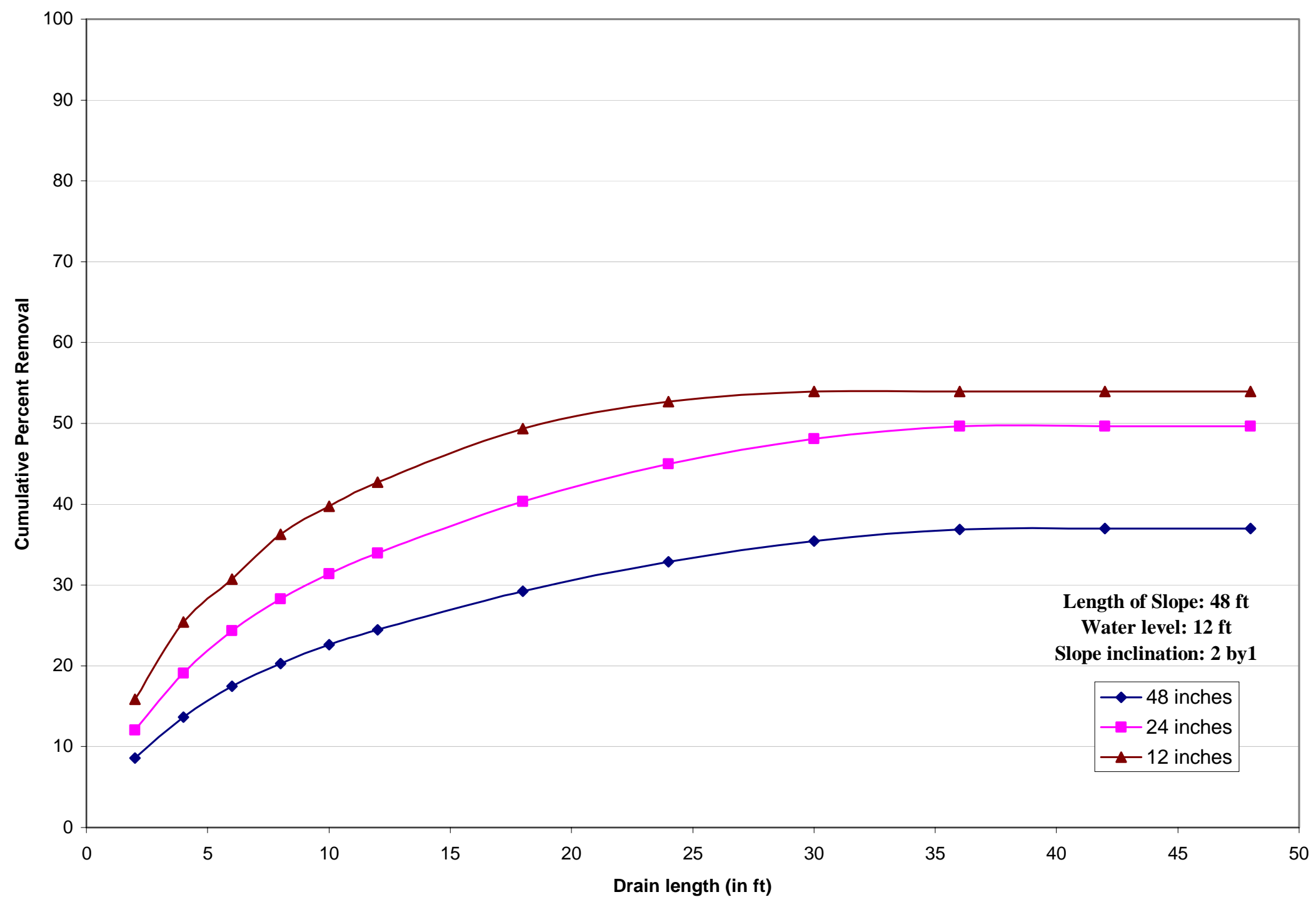

Figure H.2: Influence of Trench Spacing for Soil B ( $L=48 \mathrm{ft}$, water level = $12 \mathrm{ft}, 2: 1$ Slope angle). 


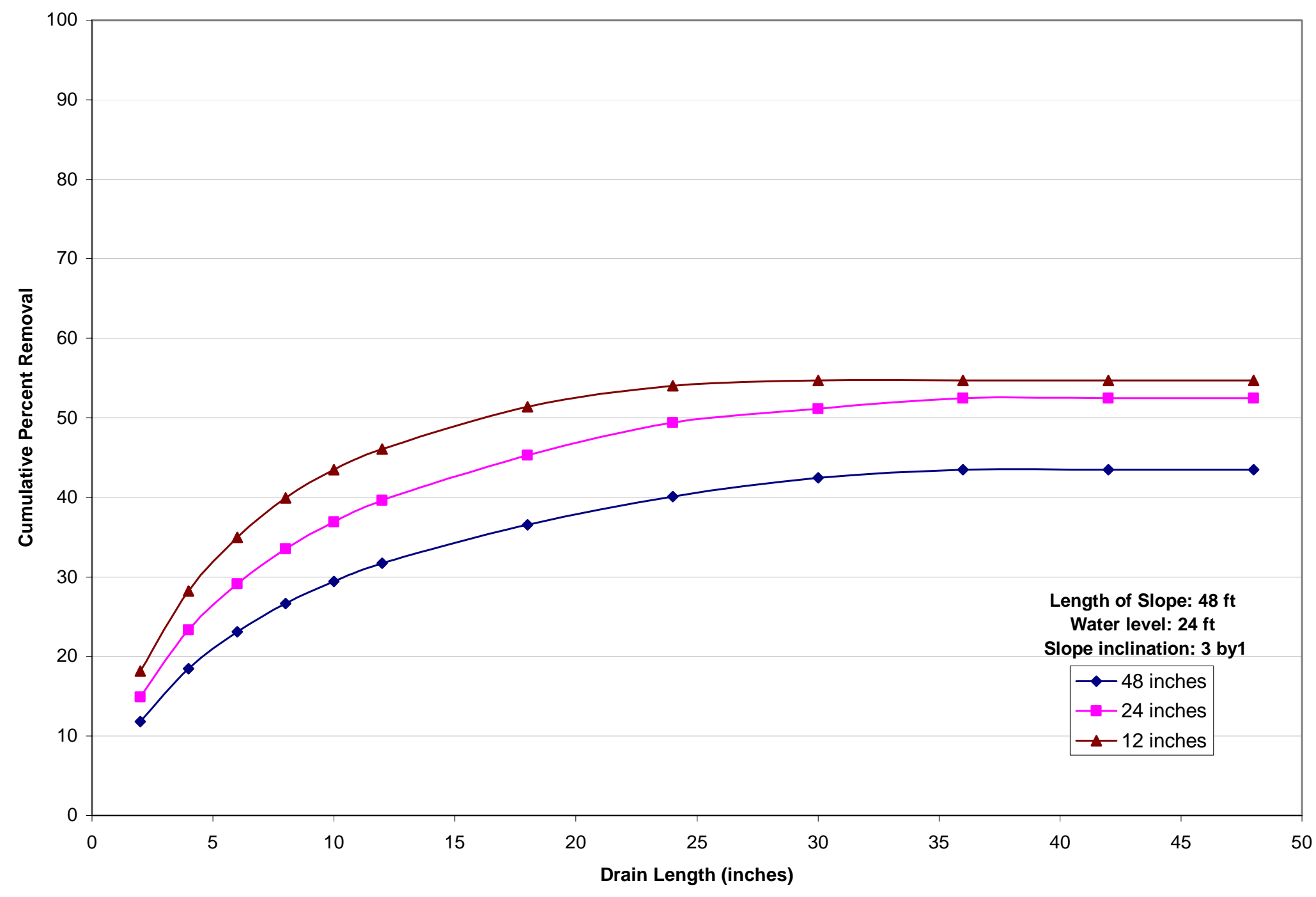

Figure H.3: Influence of Trench Spacing for Soil B ( $L=48 \mathrm{ft}$, water level $=24 \mathrm{ft}, 3: 1$ Slope angle). 


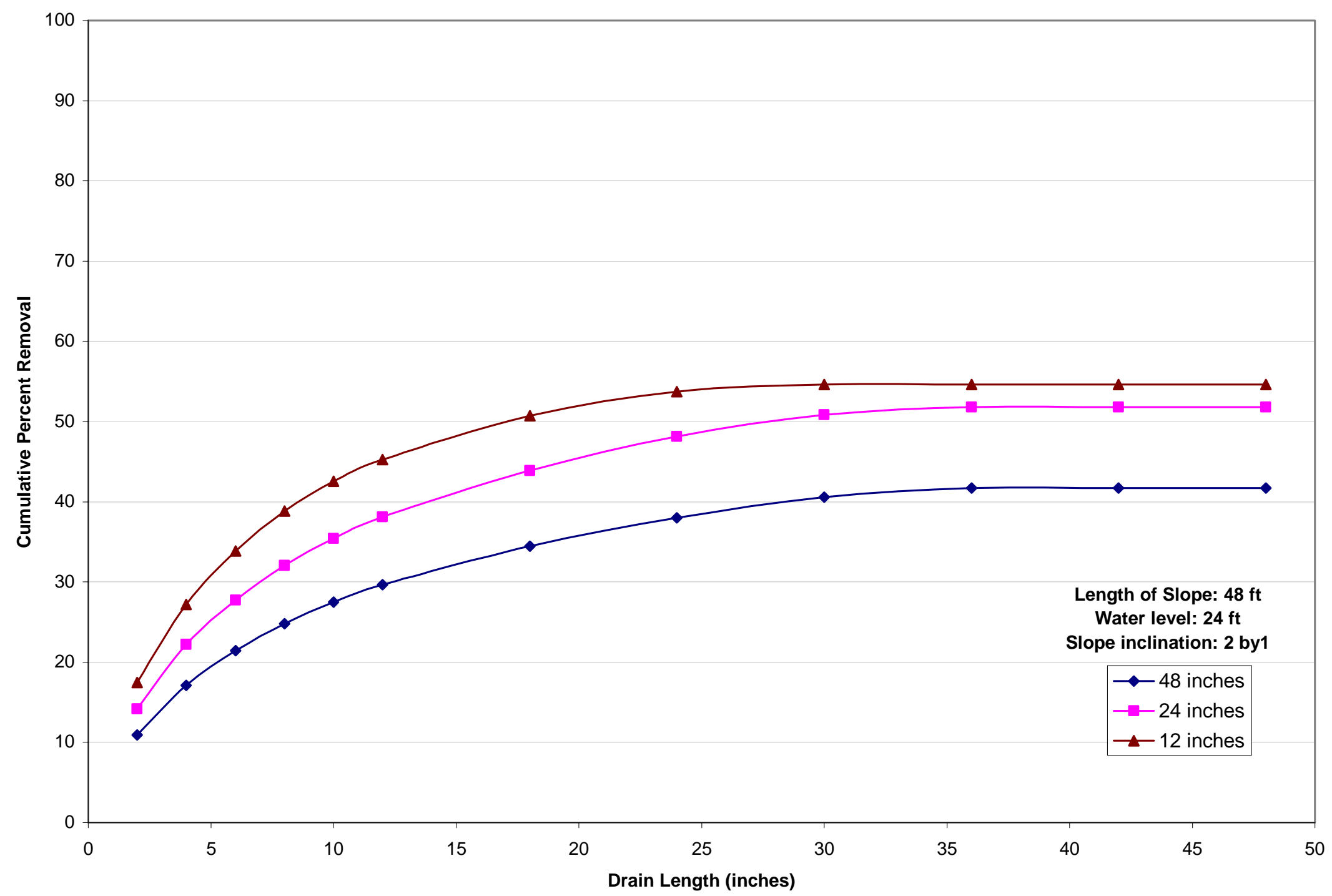

Figure H.4: Influence of Trench Spacing for Soil B ( $L=48 \mathrm{ft}$, water level = $24 \mathrm{ft}, 2: 1$ Slope angle). 


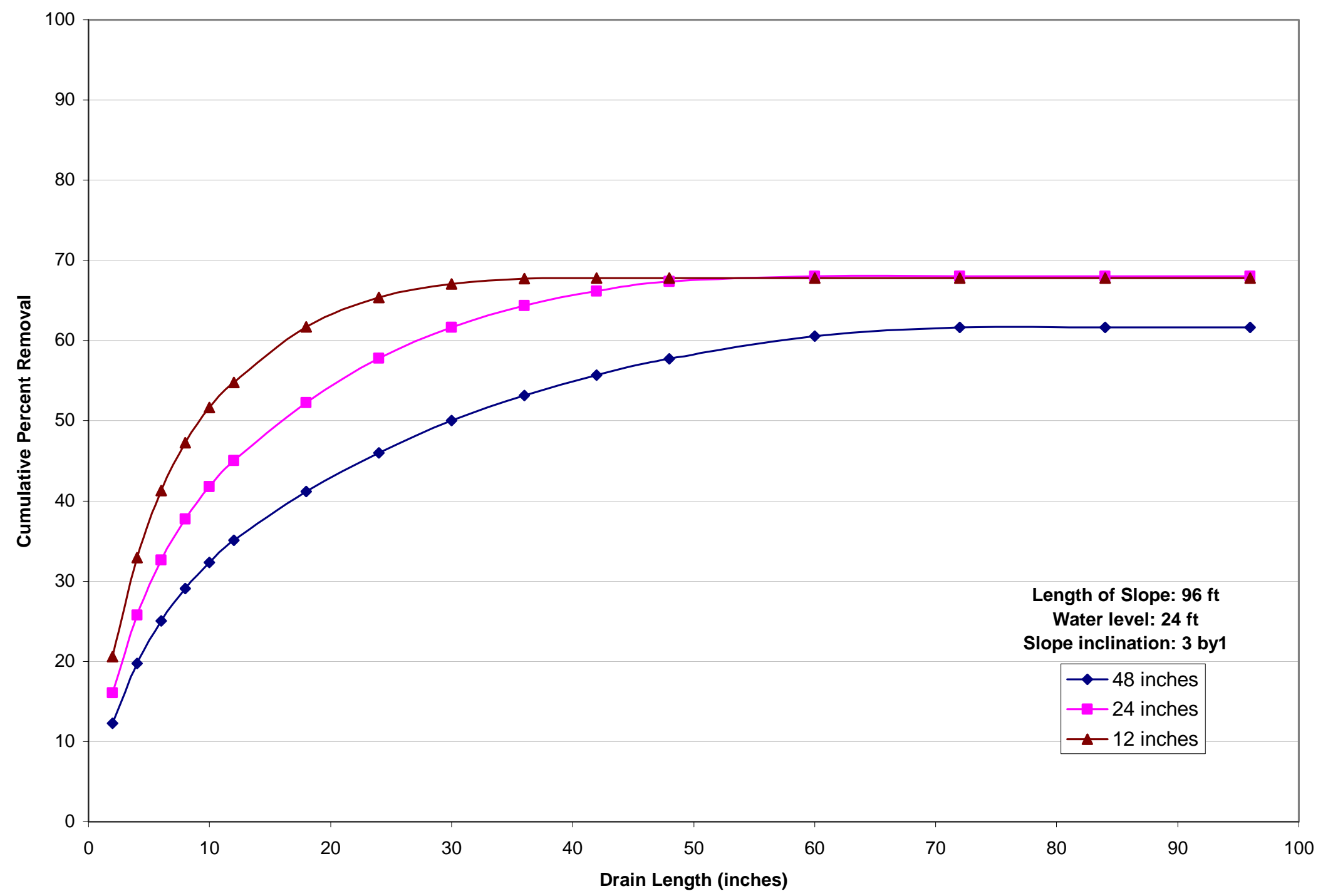

Figure H.5: Influence of Trench Spacing for Soil B ( $L=96 \mathrm{ft}$, water level = $24 \mathrm{ft}, 3: 1$ Slope angle). 


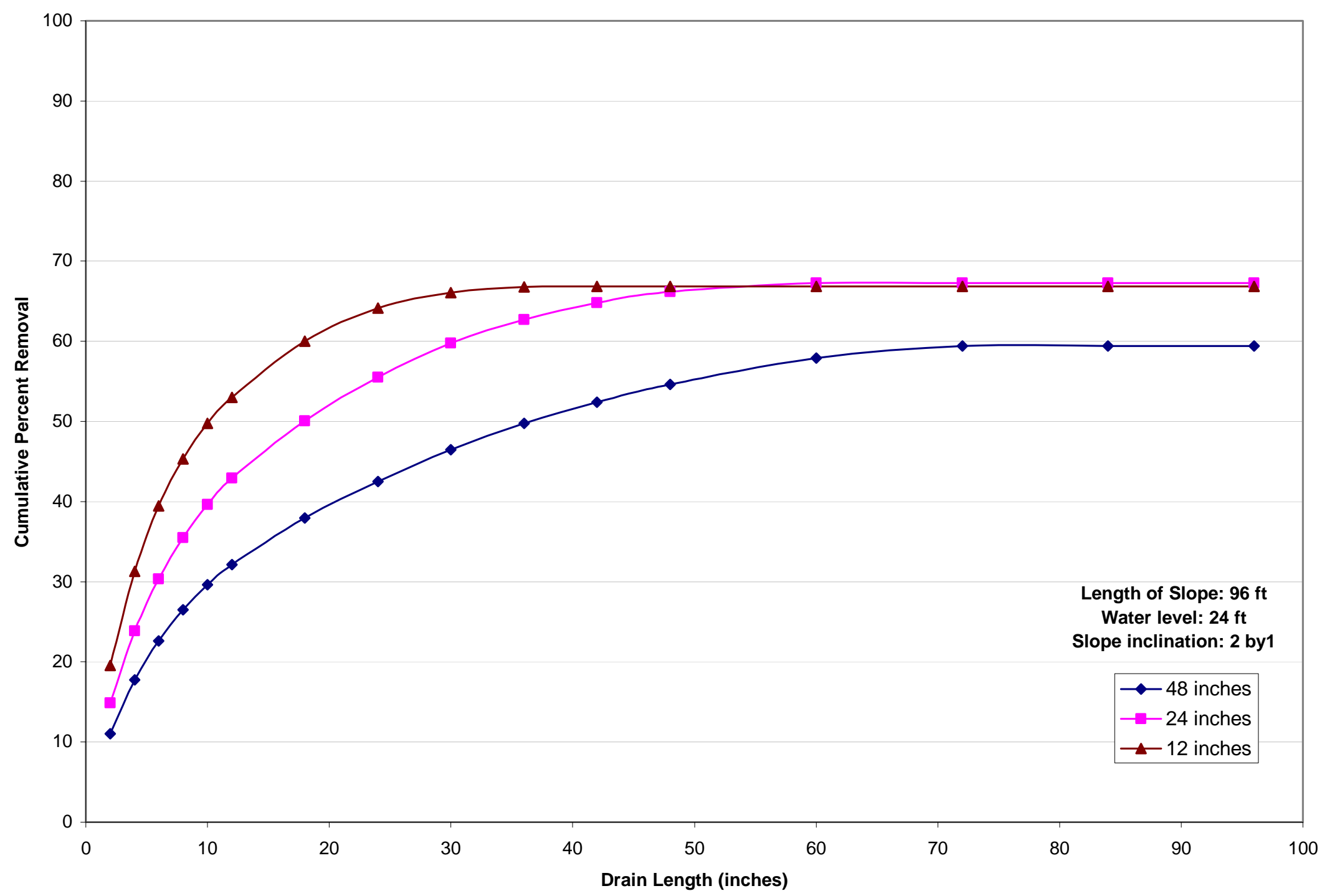

FigureH.6: Influence of Trench Spacing for Soil B ( $L=96 \mathrm{ft}$, water level $=24 \mathrm{ft}, 2: 1$ Slope angle). 


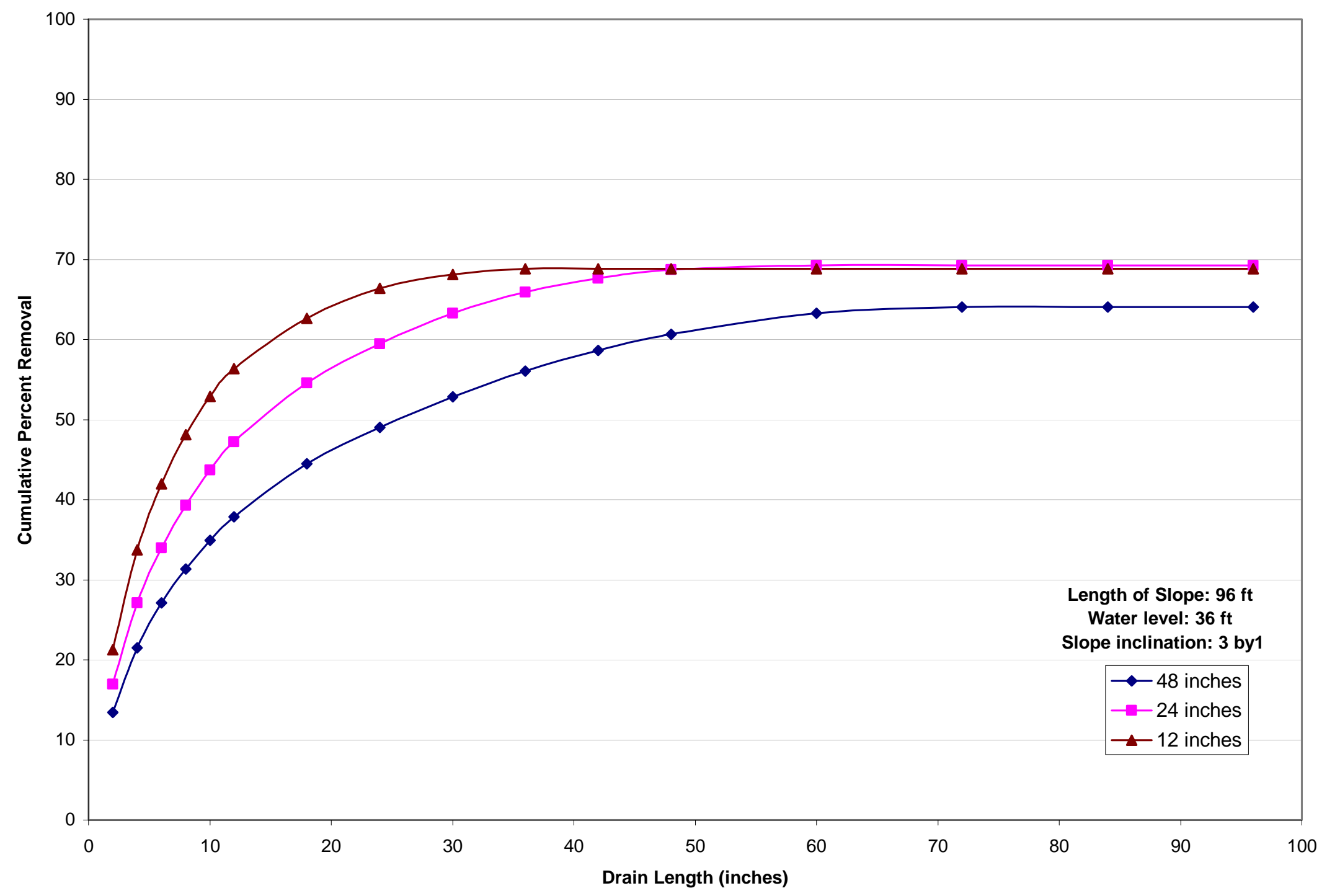

Figure H.7: Influence of Trench Spacing for Soil B ( $\mathrm{L}=96 \mathrm{ft}$, water level $=36 \mathrm{ft}, 3: 1$ Slope angle). 


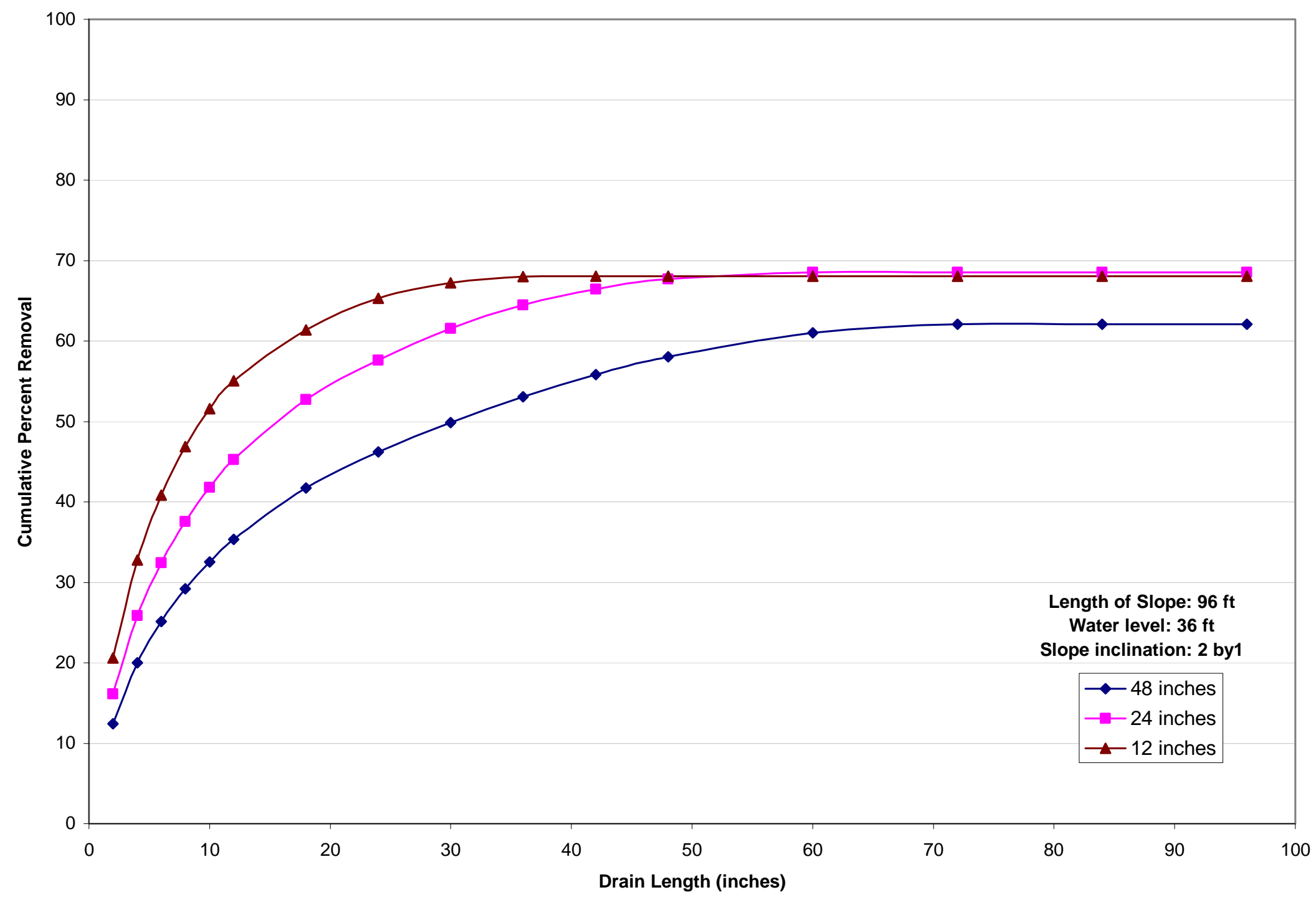

Figure H.8: Influence of Trench Spacing for Soil B ( $\mathrm{L}=96 \mathrm{ft}$, water level $=36 \mathrm{ft}, 2: 1$ Slope angle). 


\section{APPENDIX I}

\section{Derivation of Governing Equation}

(Equation 2.3) 


\section{DERIVATION OF EQUATION 2.3}

Consider the flow into and out of an elemental cube whose sides are of length $\Delta x, \Delta y$, and $\Delta \mathrm{z}$. The volume of the cube is $\Delta \mathrm{V}=\Delta \mathrm{x} . \Delta \mathrm{y} . \Delta \mathrm{z}$.

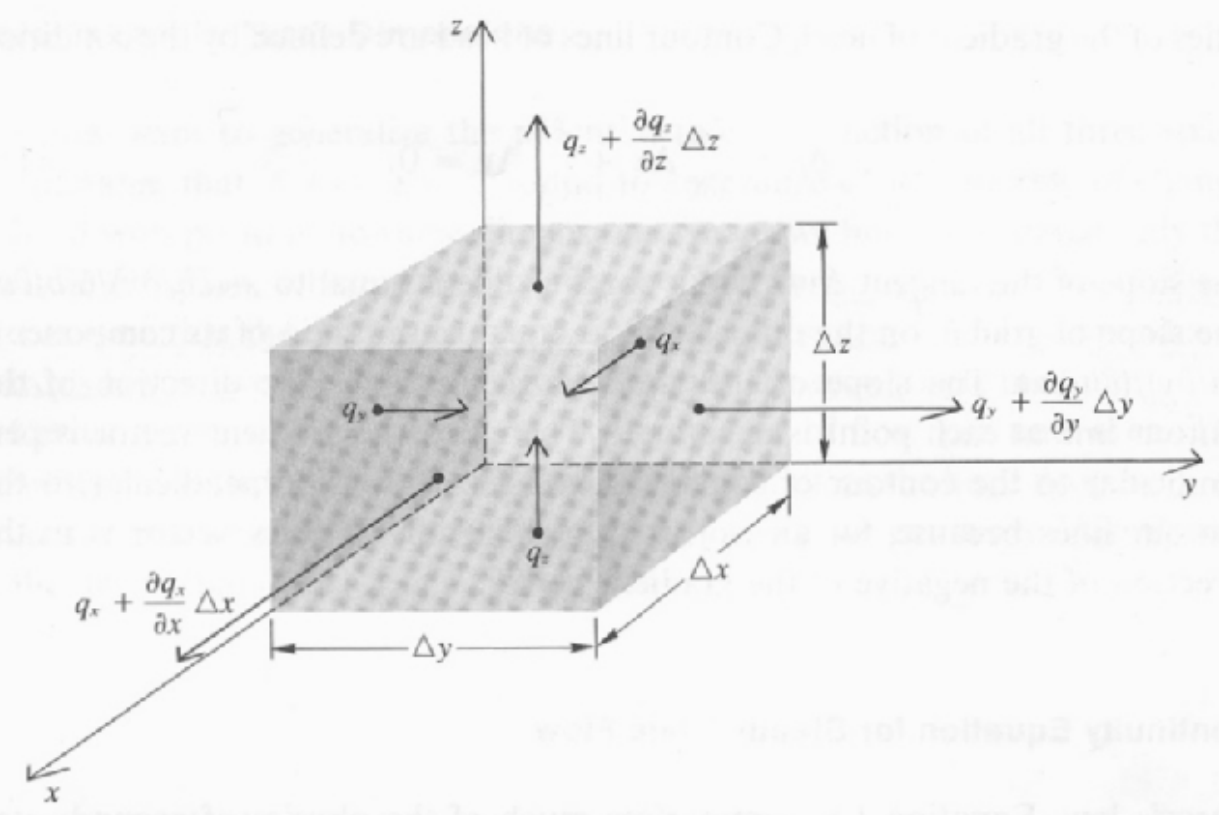

Figure I.1: Analysis of net volume flow per unit time through an infinitesimal cube (Wang \& Anderson, 1982).

$\mathrm{q}_{\mathrm{x}}, \mathrm{q}_{\mathrm{y}}, \mathrm{q}_{\mathrm{z}}$ represent the volume rate of flow per unit area through the rear, left and bottom faces of the cube respectively, and

$$
\begin{aligned}
& \left(\mathrm{q}_{\mathrm{x}}+\left(\frac{\partial q_{x}}{\partial x}\right) \Delta x\right), \\
& \left(\mathrm{q}_{\mathrm{y}}+\left(\frac{\partial q_{y}}{\partial y}\right) \Delta y\right), \text { and }
\end{aligned}
$$


$\left(\mathrm{q}_{\mathrm{z}}+\left(\frac{\partial q_{z}}{\partial \mathrm{z}}\right) \Delta \mathrm{z}\right)$

represent the volume rate of flow per unit area through the front, right and top faces of the cube respectively.

The discharge is the product of the flow rate per unit area times the area of the face through which the flow occurs.

From the above considerations, the net change in the discharge rate in the $\mathrm{x}$ direction is

$\left[\left(\frac{\partial q_{x}}{\partial x}\right) \Delta x\right] \Delta \mathrm{y} . \Delta \mathrm{z}$, which can rewritten as $\left(\frac{\partial q_{x}}{\partial x}\right) \Delta V$

Similarly, the net change in the discharge rate in the $\mathrm{y}$ and $\mathrm{z}$ directions are $\left(\frac{\partial q_{y}}{\partial y}\right) \Delta V$ and $\left(\frac{\partial q_{z}}{\partial z}\right) \Delta V$ respectively.

Assuming that the water is incompressible, and the elemental volume contains no sources or sinks, it is apparent that the volume of water flowing in is equal to that flowing out.

Hence,

$$
\left(\frac{\partial q_{x}}{\partial x}\right) \Delta V+\left(\frac{\partial q_{y}}{\partial y}\right) \Delta V+\left(\frac{\partial q_{z}}{\partial z}\right) \Delta V=0 \ldots . . . \mathrm{Eq} \mathrm{I.1}
$$

Dividing the equation by $\Delta V$,

$$
\left(\frac{\partial q_{x}}{\partial x}\right)+\left(\frac{\partial q_{y}}{\partial y}\right)+\left(\frac{\partial q_{z}}{\partial z}\right)=0 \ldots \ldots . . \text { Eq. I.2 }
$$

The above equation is called the continuity equation for the steady state flow.

Following Darcy's law,

$$
\mathrm{q}_{\mathrm{x}}=-\mathrm{K}_{\mathrm{x}} \frac{\partial h}{\partial x}, \ldots . . \text { Eq. I.3 }
$$




$$
\begin{gathered}
\mathrm{q}_{\mathrm{y}}=-\mathrm{K}_{\mathrm{y}} \frac{\partial h}{\partial y} \ldots . \text { Eq. I.4 } \\
\text { and } \mathrm{q}_{\mathrm{z}}=-\mathrm{K}_{\mathrm{z}} \frac{\partial h}{\partial z} \ldots . \text { Eq. I.5 }
\end{gathered}
$$

By substituting the Darcy's law into the continuity equation, the following equation is obtained:

$$
\frac{\partial}{\partial x}\left(K_{x x} \frac{\partial h}{\partial x}\right)+\frac{\partial}{\partial y}\left(K_{y y} \frac{\partial h}{\partial y}\right)+\frac{\partial}{\partial z}\left(K_{z z} \frac{\partial h}{\partial z}\right)=0 \ldots . \text { Eq. I.6 }
$$

Considering the presence of any sources or sinks, and assuming $\mathrm{W}$ to be volumetric flux per unit volume due to presence of these sources or sinks, the above equation will become:

$$
\frac{\partial}{\partial x}\left(K_{x x} \frac{\partial h}{\partial x}\right)+\frac{\partial}{\partial y}\left(K_{y y} \frac{\partial h}{\partial y}\right)+\frac{\partial}{\partial z}\left(K_{z z} \frac{\partial h}{\partial z}\right)-W=0 \ldots . \text { Eq. I.7 }
$$

If $S_{s}$ is the specific storage of the medium, the elemental volume retains a portion of flow in itself which is equal to $S_{s} \frac{\partial h}{\partial t}$. The above equation thus becomes,

$$
\frac{\partial}{\partial x}\left(K_{x x} \frac{\partial h}{\partial x}\right)+\frac{\partial}{\partial y}\left(K_{y y} \frac{\partial h}{\partial y}\right)+\frac{\partial}{\partial z}\left(K_{z z} \frac{\partial h}{\partial z}\right)-W=S_{s} \frac{\partial h}{\partial t} \ldots . \text { Eq. I.8 }
$$

